\title{
Molecular phylogeny and morphological reconstructions of Plagiochilaceae (Jungermanniopsida) with hypotheses on biogeography and divergence times
}

\author{
Dissertation \\ Zur Erlangung des Doktorgrades \\ Der Mathematisch-Naturwissenschaftlichen Fakultäten \\ Der Georg-August-Universität zu Göttingen
}

Vorgelegt von

Dipl.-Biol. Henk Groth

aus Elmshorn

Göttingen 2005 
D 7

Referent: $\quad$ Prof. Dr. S. R. Gradstein

Korreferent: PD Dr. M. Hauck

Tag der mündlichen Prüfung: 03.11.2005 
1 Acknowledgements .......................................................................................... 1

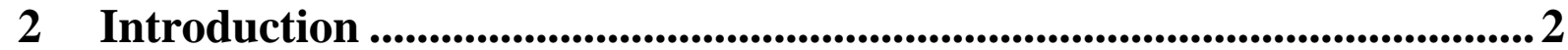

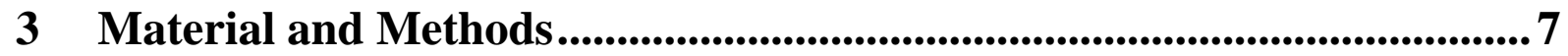

3.1 Taxon sampling ...................................................................................................... 7

3.2 Genetic Methods...................................................................................................... 7

3.2.1 Markers selected for this study ..............................................................

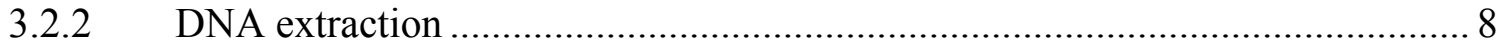

3.2.3 Polymerase chain reaction (PCR) …………………………………..... 9

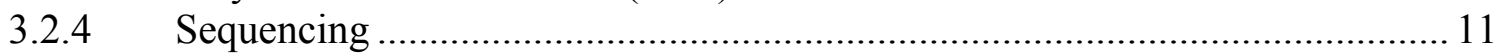

3.3 Preparation of the molecular data........................................................... 11

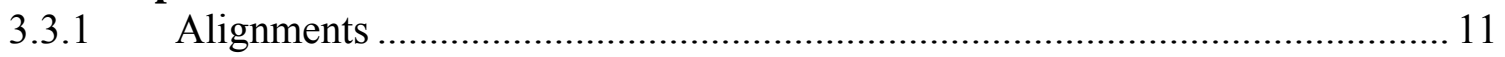

3.3.2 Building of the NEXUS file ....................................................................... 12

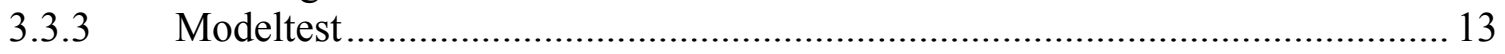

3.4 Analyses of the data............................................................................................................ 15

3.4.1 Secondary structures ……………………………………………….... 15

3.4.2 Distance plots ...................................................................................... 15

3.4.3 Testing for congruent signals in the molecular data ........................................ 15

3.4.4 Phylogenetic analyses ........................................................................... 16

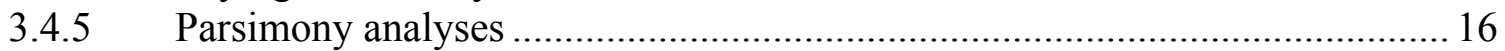

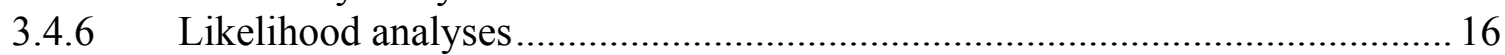

3.5 Analyses of the trees......................................................................................... 17

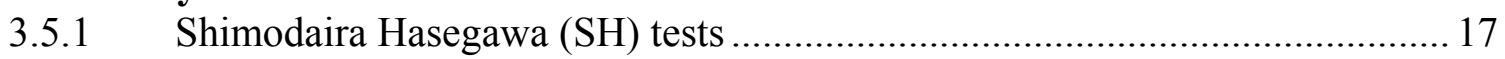

3.5.2 Mapping of morphology on the resulting tree................................................ 17

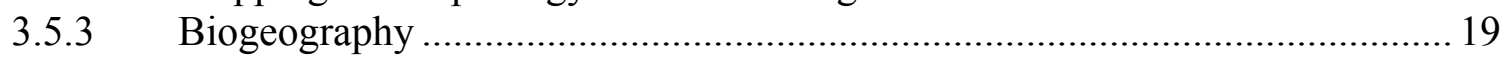

3.5.4 Molecular clock................................................................................... 22

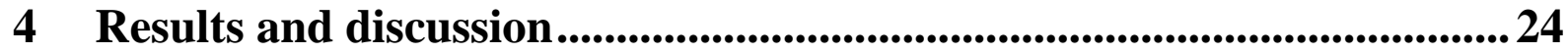

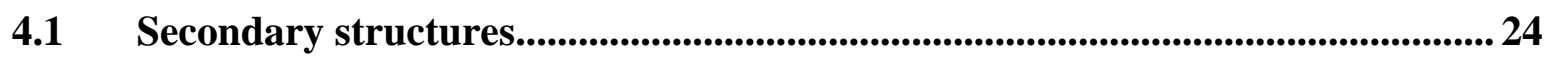

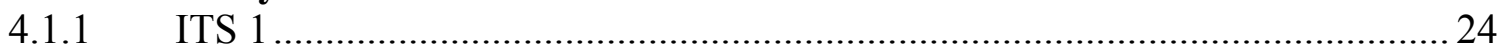

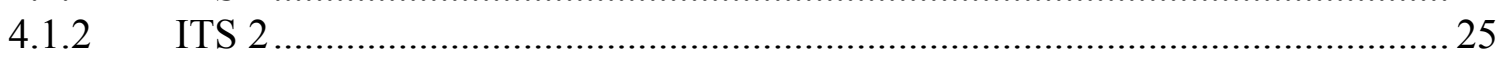

4.2 Distance plots................................................................................................................... 26

4.3 Molecular circumscription of Plagiochilaceae........................................................... 28

4.4 Phylogenetic analyses............................................................................................. 31

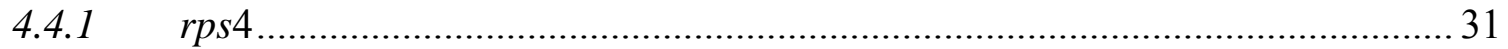

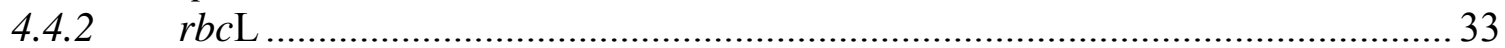

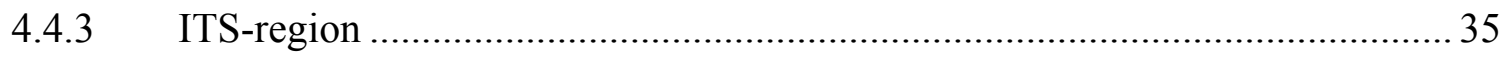

4.4.4 Combined dataset ........................................................................................ 36

4.4.5 Placement of Plagiochila andina Steph............................................................ 39

4.4.6 Placement of Plagiochila radiculosa Mitt. …………………………………..... 39

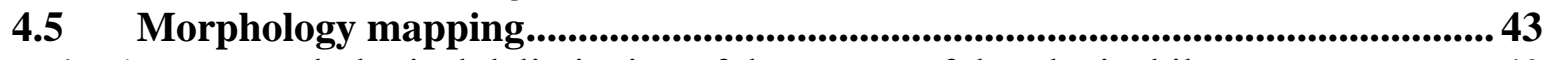

4.5.1 Morphological delimitation of the genera of the Plagiochilaceae..................... 43

4.5.2 Morphological delimitation of the sections of Plagiochila................................ 45

4.5.3 Distribution of homoplastic, synapomorphic, and autapomorphic morphological characters in Plagiochila / Plagiochilaceae................................5 55

4.5.4 Usefulness of different morphological markers at different taxonomical levels in Plagiochilaceae (and other groups)............................................................5 57

4.6 Biogeography ....................................................................................................58

4.6.1 Current and historical distribution of the sections of Plagiochila ....................58

4.6.2 Current and historical distribution of the genera of Plagiochilaceae ................ 77

4.6.3 Origin and dispersion of Plagiochilaceae........................................................... 81 
4.6.4 Dispersal patterns in Plagiochilaceae.

4.6.5 Comparison between the distribution patterns of Plagiochilaceae and other groups

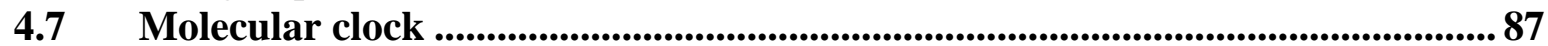

5 Discussion and Conclusions.....................................................................92

6 Literature ..........................................................................................97

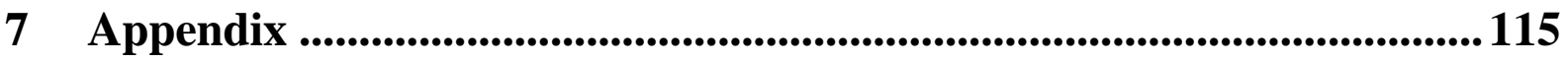

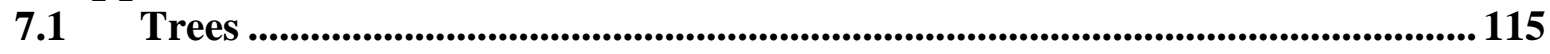

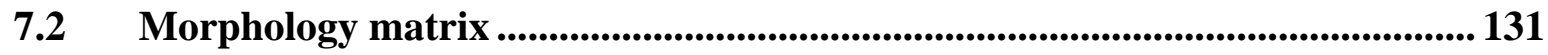

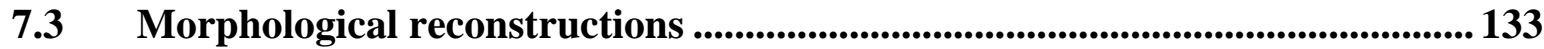

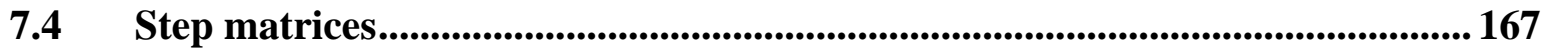

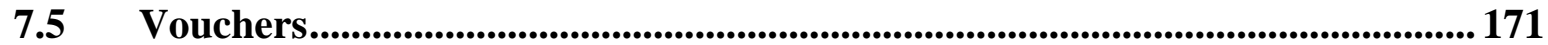




\section{Abstract}

Plagiochilaceae are one of the largest families of leafy liverworts, with an estimated species number of about 500, the magnitude of them placed in the genus Plagiochila. Members of the family occur worldwide from the high north to the far south. Despite the broad geographical amplitude of the family, most of the species occur in the humid tropics.

In this work three independent genetic markers from two different genome types (chloroplast rps4 and rbcL, nuclear ITS region) of 120 Plagiochila species as well as 8 species of other genera currently accepted in the same family were sequenced. Complex phylogenetic analyses including up to 7 different evolution models lead to a highly supported 3-marker-topology. The molecular delimitation of the original concept of the Plagiochilaceae has been evaluated based on further plastid rps 4 and $r b c \mathrm{~L}$ sequences from international databases. The aspect of structural conservation and folding patterns of the nuclear ITS region, as known from organisms like yeast, green algae or flowering plants, was adapted and used for modelling of stable secondary structures of the nuclear markers ITS1 and ITS2, therefore providing the first structure model for liverworts of this region.

These genetic data were compared to 34 morphological characters, which have been evaluated from literature and were plotted on the 3-marker-topology. Morphological delimitations of 18 sections of Plagiochila and 7 genera of Plagiochilaceae were analysed, including three sections that appear for the first time in molecular studies. The distribution of homoplastic, synapomorphic, and autapomorphic characters was analysed with respect to taxonomic selection of the analysed species, revealing most morphological characters as homoplastic.

Biogeographical models have been developed, describing hypothetical origin and dispersal events of the sections of Plagiochila. In an attempt to obtain further insights into the prehistorical world-wide development and distribution of the family, it was tried to calibrate a molecular clock, based on one fossil and two geographical events. Divergence times fit to the results of the biogeographical analyses, but will have to be checked when more fossils are available. Nevertheless, this is the first trial for the molecular dating of a liverwort family. In this study, Australasia is identified as the putative origin of the family, whose development over the last 140 million years leads to the worldwide distribution we can see today. 


\section{Acknowledgements}

I wish to thank Prof. Dr. Rob Gradstein for the possibility to work in the department, as well as helpful comments and corrections of the manuscript. Additionally, he has collected many interesting Plagiochila species during several field trips to Indonesia and South America. I am indebted to Dr. Jochen Heinrichs for supervision of my work and many helpful comments and suggestions regarding my $\mathrm{PhD}$ thesis. With his extensive knowledge on Plagiochilaceae, he undertook the tedious work of determination and confirmation of the species identity of the DNA vouchers.

I am thankful to PD Dr. Markus Hauck, as he has kindly agreed to be the co-referee of this work. Dr. Harald Schneider has provided suggestions on phylogenetic analyses and programs. Dr. Carsten Renker (Leipzig) has been very helpful in early stages of the lab work, and has done the ITS sequencing of Plagiochila corrugata. Dipl.-Biol. Melanie Lindner has sequenced most of the African material during her diploma thesis.

I wish to thank my fellow PhD and Diploma students Dipl.-Biol. Kathrin Feldberg, Florian A. Hartmann, M. Sc Anna Luiza Ilkiu-Borges, Dipl.-Biol. Jorge Jacome, Dipl.-Biol. Marcus Lehnert, Dipl.-Biol. Melanie Lindner, Dr. Alexander Schmidt-Lebuhn, Dr. Michaela Schmull, and B. Sc Rosemary Wilson as well as all other colleagues of the department for the maintenance of a good working atmosphere and many fruitful discussions.

I am thankful to Dipl.-Biol. Tae-Won Kang for many a fruitful discussion and the opinion of a "non-botanist". My wife Milena has supported me in many difficult situations and was always willing to discuss my results and theories. I am also very thankful to Elke Zufall-Roth and Ruth Pilot from the department of Experimental Phycology and Collection of Algae Göttingen (EPSAG) for assistance with sequencing and help in the lab. I am indebted to Prof. Dr. W. Engel of the Institute for Human Genetics (Göttingen), for allowing the sequencing of parts of my samples in his facility and Petra Schupp for processing of my material.

I also wish to thank the custodians of the Herbaria that were willing to send plant material for DNA analyses, as well as the numerous collectors of liverwort species, especially John Engel, Matt von Konrat (Chicago), and David Long (Edinburgh).

Finally I wish to thank my family for continuous support and understanding.

This work was supported by the Deutsche Forschungsgemeinschaft, grant no. He 3584/1. 


\section{Introduction}

Plagiochilaceae are one of the largest families of leafy liverworts, with an estimated species number of about 500 (Inoue, 1984; So and Grolle, 2000a). Members of the family occur worldwide from the high north to the far south. Despite the broad geographical amplitude of the family, most of the species occur in the humid tropics.

The name "Plagiochilaceae" was first used by Buch (1936), who applied it to the genus Plagiochila (Dumort.) Dumort. Previously, the genus was included in the "Epigonanthaceae" (Verdoorn, 1932) or the Jungermanniaceae (Jørgensen, 1934). Although the name "Plagiochilaceae" was invalid, as it was published without a description, it was soon accepted by other authors (Buch et al., 1938; Evans, 1939), who included Plagiochila, Chiastocaulon Carl, Syzygiella Spruce, Plagiochilidium Herzog, Wettsteinia Schiffn., and Tylimanthus Mitt. in the family, based on characters of the perianth, leaf shape and insertion, as well as the form of the oil bodies.

Müller (1951) validated the name Plagiochilaceae and added the two genera Mylia Gray and Pedinophyllum (Lindenb.) Lindenb.

In 1959 Schuster included Xenochila R.M.Schust., Anomylia R.M.Schust., and Leptoscyphus Mitt in the family. He used a wide variety of characters (e.g. branching type, leaf shape, cell structure, form of the oil bodies, mode of asexual reproduction, position and morphology of the sexual organs) to delimit the Plagiochilaceae. However, he stressed the difficulties in finding characters exclusive to the family, as distinct from those eliminating most of the other leafy liverworts (Schuster, 1959).

In 1980 Schuster published an improved concept of the Plagiochilaceae, now including ten genera in two subfamilies. Pedinophyllum, Plagiochila, Rhodoplagiochila R.M.Schust., Xenochila, Chiastocaulon, Acrochila R.M.Schust., Plagiochilion S.Hatt., and Plagiochilidium in the subfamily Plagiochiloideae and Syzygiella and Protosyzygiella (Inoue) R.M.Schust. in the Syzygielloideae. In this work the family Plagiochilaceae was defined by perianth shape, the unspecialised position of the sexual organs, the pluristratose capsule walls, and the massive seta. This definition was generally accepted by later authors.

Grolle (1983) moved Syzygiella and Protosyzygiella into the Jungermanniaceae subfamily Jamesonielloideae, based on the morphology of the perianth. 
Removal of Syzygiella from Plagiochilaceae was confirmed by Groth and Heinrichs (2005), using $r b c \mathrm{~L}$ sequences, who showed that Syzygiella is not a member of the Plagiochilaceae and should tentatively be placed in the Lophoziaceae.

Heinrichs et al (20xx) raised Plagiochila sect. Fruticellae to genus level, forming the morphological well delimitated genus Proskauera.

The last work on the complete family of the Plagiochilaceae was published by Inoue (1984), who accepted six genera in three subfamilies, Plagiochilidium (Plagiochilidoideae), Xenochila (Xenochiloideae), and Pedinophyllum, Plagiochilion, Acrochila, and Plagiochila (Plagiochiloideae).

The family Plagiochilaceae is currently placed in the order Jungermanniales (class Jungermanniopsida, subclass Jungermanniidae) sister to Geocalycaceae (Heinrichs et al., 2005b).

Over $90 \%$ of the known species of the Plagiochilaceae belong to Plagiochila. Morphologically this genus is defined by dioicous condition, a laterally compressed perianth with a dorsal keel which is usually slightly longer than the ventral one, alternating, rarely subopposite foliation, and usually lateral branching. The other genera are comparatively small and contain only about 20 species altogether (Hässel de Menéndez, 1983; Heinrichs et al., 2006; Inoue, 1964; Inoue, 1966a; Inoue, 1966b; Inoue and Schuster, 1971; Schuster, 1980).

Members of the Plagiochilaceae are some of the most important bryophytes in the tropics (Gradstein, 1995; Heinrichs, 2002; So and Grolle, 2000a) and have therefore often been collected and their systematics have received much interest. Because of the overwhelming number of species, most work was concentrated on Plagiochila. The first attempts to classify the members of this large genus [up to 400 - 450 species worldwide (Inoue, 1984; So and Grolle, 2000a)] reach as far back as the first half of the $19^{\text {th }}$ century (Lindenberg, 1839). He subdivided Plagiochila into six sections, based on perianth shape, leaf shape, and branching pattern. Later authors accepted this classification (e.g. Gottsche et al., 1844) or proposed different systems.

Spruce (1884-1885) and others (Inoue and Schuster, 1971; Jones, 1962; Schiffner, 1900a; Schiffner, 1900b) proposed the division of the genus into two major, rank-free groups, Ramiflorae and Cauliflorae (with a further subdivision into a varying number of sections) based on branching types and position of the perianth. Jones (1962) in his treatment of 
Plagiochila in Africa, however, doubted that this grouping reflected natural relationships. This agrees with Heinrichs et al. (2002b) and Heinrichs (2002), who showed that Ramiflorae and Cauliflorae do not form monophyletic lineages.

Of the other authors (Carl, 1931a; Dugas, 1929; Stephani, 1901), Stephani and Dugas choose rather simple approaches: Stephani split the genus into the Ampliatae and Patulae (based on the shape of the ventral leaf base). These rank-free groups were further subdivided corresponding to the origin of the species. Dugas erected three (also rank-free) groups, the Ligulatae, Rotundifoliae, and Trigonifoliae. Species were distributed solely based on their leaf shape.

The most comprehensive work was by Carl (1931a), who treated the genus worldwide (with the exception of Africa). Carl used morphological characters (leaf cell pattern, leaf position, density of foliation, position of androecia, modes of asexual reproduction) in combination with geographic origin of taxa to group the species into fifty sections in three subgenera.

The usage of modern systematic methods (e.g. the analysis of secondary metabolites, Scanning Electron Microscopy [SEM], sequence analysis) in combination with morphological investigations provided new insights in the phylogenetic structure and natural relationships of Plagiochila and has already led to several rearrangements in the genus (e.g. Groth and Heinrichs, 2005; Groth et al., 2002; Groth et al., 2003; Heinrichs et al., 2006; Heinrichs et al., 2002a; Heinrichs et al., 2000b; Heinrichs et al., 2000a; Heinrichs, 2002; Heinrichs et al., 2005b; Renker et al., 2002; Rycroft et al., 2002).

Also, the systematics of other genera of the Plagiochilaceae was recently affected by these new approaches, especially by molecular data. Thus, Chiastocaulon, erected by Carl (1931b) owing to a unique branching type and lowered to subgeneric rank by Inoue (1984), was reinstated (Groth and Heinrichs, 2003) based on nr ITS and cp rps4 data. On the other hand, Rhodoplagiochila (Schuster, 1980), described because of its reddish colour, had to be included in the synonomy of Plagiochila bifaria (Sw.) Lindenb. (Heinrichs et al., 2004d), as the outcome of nr ITS studies and morphology. Equally, Steereochila ecuadorica Inoue, the sole member of the genus Steereochila Inoue (Inoue, 1987), was placed in Plagiochila, as $P$. dimorpha Lindenb. \& Gottsche var. ecuadorica Inoue (Heinrichs, 2002). Furthermore Szweykowskia cucullifolia (J.B.Jack \& Steph.) Gradst. \& M.Reiner, originally excluded from Plagiochila (Gradstein and Reiner-Drehwald, 1995), was reincluded in the genus as $P$. cucullifolia (Heinrichs, 2002) based on $\mathrm{nr}$ ITS data and phylogenetic analyses of 
morphological and chemical characters. Finally, Proskauera, originally in Plagiochila as sect. Fruticellae (P. fruticella, P. pleurata) was recognized as an own genus by Heinrichs et al (2006), based on its unique morphology and on rps4 and ITS sequences.

As to the other genera currently placed in the Plagiochilaceae, the phylogenetic position of Plagiochilion has been confirmed by molecular studies (Groth and Heinrichs, 2005; Groth and Heinrichs, 2003; Heinrichs et al., 2005b) while Pedinophyllum is resolved as a member of the Plagiochilaceae [Pedinophyllum interruptum, (Groth and Heinrichs, 2003)] or the Jungermanniaceae [Pedinophyllum truncatum, (He-Nygrén et al., 2004). Acrochila, Plagiochilidium, and Xenochila have not been studied lately.

With the inclusion of Pedinophyllopsis R.M.Schust. \& Inoue (He-Nygrén and Piippo, 2003) eight genera are currently accepted in the family Plagiochilaceae: Acrochila, Chiastocaulon, Pedinophyllopsis, Pedinophyllum, Plagiochila, Plagiochilidium, Plagiochilion, Proskauera, and Xenochila.

Morphologically the family is defined by dioicous condition (except Pedinophyllum) and the campanulate to (long-) cylindrical, laterally compressed perianth with a wide mouth. The capsule is ovoid, the valves are elliptical and usually consist of $4-10$ layers of cells. Branching is mostly lateral intercalar or terminal (rarely ventral intercalar [Chiastocaulon, Plagiochilion]). Asexual reproduction is variable, occurring by means of caducous leaves or leaf fragments, or with propagules (or multicellular gemmae [e.g. Pedinophyllopsis, Xenochila]). The ventral merophyte is about $1-3$ cells wide (in some groups 5 - 10). Leaves are usually alternating or opposite (e.g. Plagiochilion), mostly entire, rarely deep bilobed (e.g. Plagiochila steyermarkii H.Rob.). The leaf margin is entire or variously dentated. Underleaves finally, are usually small, sometimes missing, or reduced to stalked slime papillae (Inoue, 1984; Schuster, 1959).

This study analyses sequences of 128 species of Plagiochilaceae, from three independent molecular markers (cp rps4, cp rbcL, and nr ITS) of major parts of its range, to investigate phylogenetic relationships in the Plagiochilaceae. It is attempted to answer the following questions:

- What are the phylogenetic relationships among the genera of the Plagiochilaceae?

- What are the phylogenetic structures inside Plagiochila? 
- Is it possible to morphologically characterise the groups defined by molecular markers?

- Is the division of Plagiochilaceae in one very big and several small genera justified?

- What is the distribution of homoplastic and synapomorphic characters in the family?

- Is it possible to calibrate a molecular clock?

- Is it possible to reconstruct the dispersal routes and mechanisms of the family?

- What is the geographical origin of the family?

- Where is the centre of clade diversity? 


\section{Material and Methods}

\subsection{Taxon sampling}

Because of the notorious morphological plasticity of the genus (e.g. Carl, 1931a; Heinrichs, 2002; Inoue, 1984; Inoue and Schuster, 1971) it is difficult to determine the number of extant species of Plagiochilaceae. So and Grolle (2000a) estimated the number at about 500 species, making it one of the largest families of Hepaticae worldwide. Nevertheless, the number of published binominals is at least four times higher (Inoue, 1984). To build a representative dataset for the genus, 120 Plagiochila species were sampled (Tab. 14) (based on the works of Carl, 1931a; Heinrichs, 2002; Inoue, 1984; Inoue and Schuster, 1971; Jones, 1962; So, 2001). In addition to one outgroup taxa (Herbertus sendtneri (Nees) A.Evans (Herbertaceae) and Chiloscyphus profundus (Nees) J.J.Engel \& R.M.Schust. (Geocalycaceae) eight representatives of the other genera of Plagiochilaceae were included [Acrochila biserialis (Lehm. \& Lindenb.) Grolle, Chiastocaulon dendroides (Nees) Carl, Pedinophyllum interruptum (Nees) Lindenb., Plagiochilion mayebarae S.Hatt., Plagiochilion oppositum (Hook.) R.M.Schust., Pedinophyllopsis abdita R.M.Schust. \& Inoue, Proskauera fruticella, Proskauera pleurata]. The complete dataset thus represents about one fourth of the accepted species in the family and includes species from all major parts of its range (So and Grolle, 2000a).

\subsection{Genetic Methods}

\subsubsection{Markers selected for this study}

ITS region (=Internal Transcribed Spacer).

The nuclear ITS regions separate 18S rDNA and 5.8S rDNA (ITS 1), and 5.8S rDNA and 26S rDNA (ITS 2) (Álvarez and Wendel, 2003). The length of ITS 1 ranges from $307 \mathrm{bp}$ (Plagiochila fruticella (Hook. \& Taylor) Gottsche, Lindenb. \& Nees) to $396 \mathrm{bp}$ (P. teysmannii Sande Lac.). After exclusion of unalignable positions (app. $15 \%$ ), the variation at base level is $25 \%$ for the whole dataset ( $24 \%$ for Plagiochila only). The size of ITS 2 ranges from $241 \mathrm{bp}$ (P. heterophylla Lindenb.) to 304 bp (P. corrugata (Nees) Nees \& Mont.), with a variation at base level of $31 \%$ for the whole dataset (28\% for Plagiochila only). The length variation of the 5.8S lies between $157 \mathrm{bp}$ (P. effusa Steph.) and $163 \mathrm{bp}$ (P. tabinensis Steph.). After exclusion of unalignable positions (app. $50 \%$ ), the variation at base level is $32 \%$ for 
the whole dataset (30\% for Plagiochila only). The nrITS-region was found to be able to group Plagiochila species into well supported sectional clades (e.g. Heinrichs, 2002) and to separate related genera from Plagiochila (Groth and Heinrichs, 2003).

$\underline{\text { rps4 }}$ (=ribosomal protein s4).

The chloroplast rps4 gene codes for a protein attached to the small subunit of the chloroplast ribosome (Ohyama et al., 1986). The complete sequence is 609 bp in size (in Plagiochilaceae). After exclusion of the primer regions (42 bp), the variation at base level is $12.5 \%$ for the whole dataset ( $9 \%$ for Plagiochila only). The gene was used the first time for phylogenetic analyses of the Poaceae (Nadot et al., 1994). In Plagiochila it was found to be able to shed light on the relationships between clades classified as sections (Groth and Heinrichs, 2003).

$\underline{r b c L}$ (=ribulose-1,5-bisphosphate carboxylase [Large subunit]).

The chloroplast $r b c \mathrm{~L}$ gene codes for the large subunit of the central enzyme of the Calvincycle ("RUBISCO") (Ohyama et al., 1986). It is approximately 1434 bp long (reference: Marchantia polymorpha L., GenBank accession: NC001319). For this study the first $1379 \mathrm{bp}$ have been sequenced. After exclusion of the primer regions (54 bp), the variation at base level is $10 \%$ for the whole dataset ( $6 \%$ for Plagiochila only). The phylogenetic signal of the cp $r b c \mathrm{~L}$ gene has proven to be fit for analyses at genus level of bryophytes (Lewis et al., 1997), major groups of mosses (e.g.: De Luna et al., 1999; Tsubota et al., 2002), and liverworts (Groth and Heinrichs, 2005; Heinrichs et al., 2005b; Wilson et al., 2004), and was therefore chosen to investigate the deep phylogenetic relationships in Plagiochilaceae.

\subsubsection{DNA extraction}

Total DNA was extracted from herbarium material. Specimens used for the molecular investigation were provided by U. Drehwald, J. Engel, E. Fischer, B. Goffinet, R. Gradstein the late R. Grolle, J. Heinrichs, I. Holz, D. Long, R. Ochyra, T. Pócs, M. Sauer, A. SchäferVerwimp, C. Renker, and D. Rycroft.. These specimens are housed in GOET. Furthermore specimens from HIRO were included in the molecular analyses courtesy of H. Deguchi and T. Deguchi. In most cases, label information was accepted. Some specimens were identified by J. Heinrichs or M.-L. So. 
Two to five shoots per voucher were cleaned under a light microscope and treated with the Invisorb Spin Plant Mini Kit (Invitek, Berlin), following the manufacturers instructions. Extraction results were checked on a $1 \%$ agarose gel.

\subsubsection{Polymerase chain reaction (PCR)}

Polymerase chain reaction (Saiki et al., 1988), was carried out on a PTC 200 thermocycler (MJ Research), using the following receipt:

Table 1 Formula for PCR master mix.

\begin{tabular}{|c|c|}
\hline Reagent & amount / concentration \\
\hline Taq (BioLine) & $2 \mathrm{u}$ \\
\hline $10 \mathrm{x}$ Buffer & $1 / 10$ diluted \\
\hline $\mathrm{MgCl}_{2}$ & $2 \mathrm{mM}$ \\
\hline Primer (forward) & $2 \mu \mathrm{M}$ \\
\hline Primer (reverse) & $2 \mu \mathrm{M}$ \\
\hline DMSO & $4 \%$ \\
\hline $\mathrm{H}_{2} \mathrm{O}$ & add up to $50 \mu \mathrm{l}$ \\
\hline Template & $1 \mu \mathrm{l}$ (app. $10-100 \mathrm{ng}$ DNA) \\
\hline
\end{tabular}

Primers were used as indicated in Figs. $1-3$ with the appropriate protocol for each gene (Tab. 2). Results were checked on a 1\% agarose gel. In cases where no PCR product could be detected a nested PCR was performed.

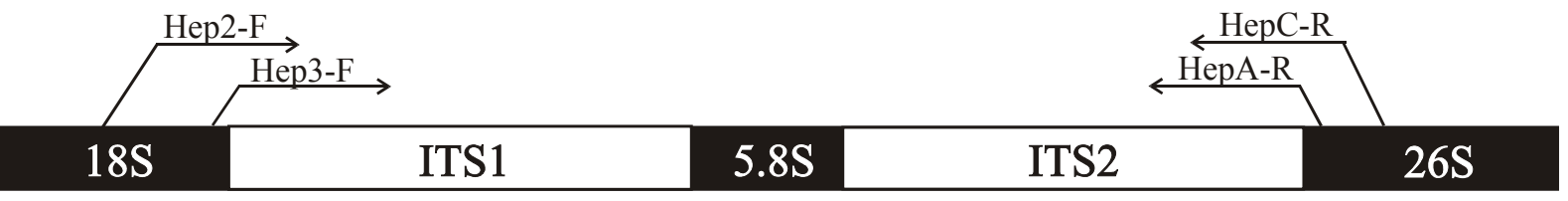

Figure 1 Graphical overview of the ITS-region. Arrows indicate PCR-primer.

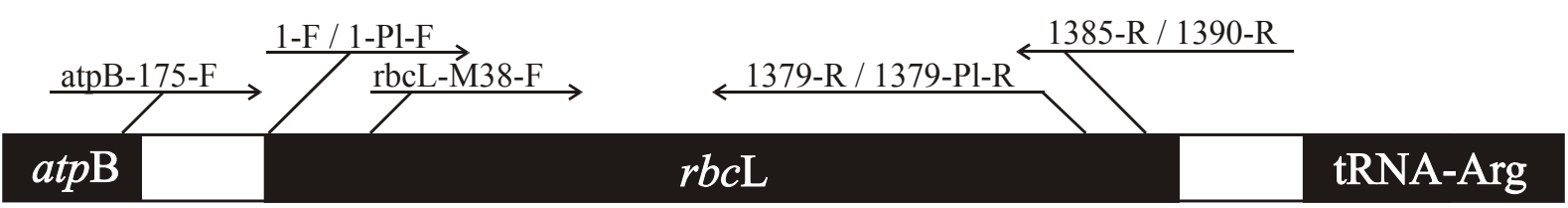

Figure 2 Graphical overview of the $r b c L$-region. Arrows indicate PCR-primer. 


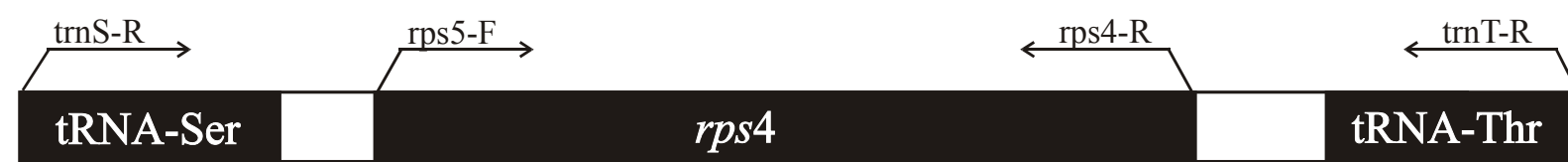

Figure 3 Graphical overview of the rps4-region. Arrows indicate PCR-primer.

Table 2 PCR protocols for the amplification of ITS, $r b c \mathrm{~L}$ and $r p s 4$

\begin{tabular}{|l|c|c|c|c|}
\hline & \multicolumn{2}{|c|}{ ITS / rbcL } & \multicolumn{2}{c|}{ rps4 } \\
\hline Initial denaturation & $92^{\circ} \mathrm{C}$ & $120 \mathrm{~s}$ & $95^{\circ} \mathrm{C}$ & $180 \mathrm{~s}$ \\
\hline Denaturation & $92^{\circ} \mathrm{C}$ & $60 \mathrm{~s}$ & $95^{\circ} \mathrm{C}$ & $60 \mathrm{~s}$ \\
\hline Annealing & $51^{\circ} \mathrm{C}$ & $50 \mathrm{~s}$ & $52^{\circ} \mathrm{C}$ & $60 \mathrm{~s}$ \\
\hline Elongation & $72^{\circ} \mathrm{C}$ & $90 \mathrm{~s}$ & $72^{\circ} \mathrm{C}$ & $180 \mathrm{~s}$ \\
\hline Cycles & 25 & - & 30 & - \\
\hline Final elongation & $72^{\circ} \mathrm{C}$ & 10 min & $72^{\circ} \mathrm{C}$ & 7 min \\
\hline Storage & $4^{\circ} \mathrm{C}$ & for ever & $4^{\circ} \mathrm{C}$ & for ever \\
\hline
\end{tabular}


Table 3 Primers used for PCR amplification and for sequencing ("s")

\begin{tabular}{|c|c|c|c|}
\hline \multicolumn{2}{|c|}{ Primer } & \multirow{2}{*}{\begin{tabular}{|l|} 
Sequence \\
GAGTCATCAGCTCGCGTTGAC
\end{tabular}} & \multirow{2}{*}{\begin{tabular}{|l|} 
Corresponding paper \\
Groth et al. (2003)
\end{tabular}} \\
\hline \multirow{4}{*}{ ITS } & Hep2-F & & \\
\hline & Hep3-F (s) & CGGTTCGCCGCCGGTGACG & Groth et al. (2003) \\
\hline & HepC-R & TCTCCAGACTACAATTCGCACA & Groth et al. (2003) \\
\hline & HepA-R (s) & CGCCGCTACTAGGGAAATCCTA & Groth et al. (2003) \\
\hline \multirow{12}{*}{ rbcL } & atpB-175-F & TGTTGAACTTCACAAGTAACA & Taberlet et al. (1991) \\
\hline & 1-F & ATGTCACCACAAACAGAAACTAAAGCAAGT & Homepage Paul G. Wolf* \\
\hline & 1-Pl-F & ATGTCACCACAAACGGAGACTAAARCAGGT & Wilson et al. (2004) \\
\hline & M38-F & GGTGTTGGATTTAAAGCTGGTG & Homepage Paul G. Wolf* \\
\hline & 1379-R & TCACAAGCAGCAGCTAGTTCAGGACTC & Homepage Paul G. Wolf* \\
\hline & 1379-PI-R & TCRCAAGCAGCRGCTAAATCRGGA & Groth and Heinrichs (2005) \\
\hline & 1385-R & AATTCAAATTTAATTTCTTTCC & Homepage Paul G. Wolf* \\
\hline & 1390-R & CTTTCCAWAYTTCRCAAGCAGCRG & Homepage Paul G. Wolf* \\
\hline & 680PI-F (s) & GCYGAAACTGGTGAAATTAAG & Wilson et al. (2004) \\
\hline & 700Pl-R (s) & GTCCTTTAATTTCACCAGTTTC & Wilson et al, (2004) \\
\hline & 170-F (s) & GAAGAAGCAGGAGCAGCRGTAGC & Groth and Heinrichs (2005) \\
\hline & 1200-R (s) & TGYCCYAAAGTTCCACCACC & Wilson et al. (2004) \\
\hline \multirow{4}{*}{ rps4 } & rps5-F (s) & ATGTCCCGTTATCGAGGACCT & Nadot et al. (1994) \\
\hline & rps4-R (s) & TTARRCTTGRCGAGAATAATATTC & Groth and Heinrichs (2003) \\
\hline & trnS-R & TACCGAGGGTTCGAATC & Taberlet et al. (1991) \\
\hline & trnT-R & TCTACCGATTTCGCCATATC & Taberlet et al. (1991) \\
\hline
\end{tabular}

* = http://bioweb.usu.edu/wolf/rbcL\%20primer\%20map.htm

\subsubsection{Sequencing}

Sequencing was carried out on capillary sequencers (ABI 3100, MegaBace 1000), using the sequencing kits recommended by the manufactures. (see Tab. 3 for a list of primers).

\subsection{Preparation of the molecular data}

\subsubsection{Alignments}

Sequences were aligned manually, using BioEdit 7.0.0 (Hall, 1999). PCR primers (rps4, $r b c \mathrm{~L}$ ) and unalignable positions (ITS) were excluded. Missing positions were coded as “?”. 


\subsubsection{Building of the NEXUS file}

To prepare the molecular data for phylogenetic analysis, a NEXUS file (Maddison et al., 1997) was created from each of the three alignments ( $r p s 4, r b c L$, ITS). The protein coding files $(r p s 4, r b c \mathrm{~L})$ included partitions for $1^{\text {st }}, 2^{\text {nd }}$ and $3^{\text {rd }}$ codon position. The ITS file was divided into partitions, representing ITS 1, 5.8S rDNA and ITS 2.

Additionally, each file was built containing only transversions (TV) by replacing C \& T with $\mathrm{Y}$, and $\mathrm{A} \& \mathrm{G}$ with $\mathrm{R}$.

For the analyses of the complete dataset, one file containing all partitions for all markers was created. PAUP* (Swofford, 2002) and MrBayes (Huelsenbeck and Ronquist, 2001; Ronquist and Huelsenbeck, 2003) settings were included in the files.

Table 4 Number of parsimony informative characters and total base count of datasets [TV (transversions) $=$ exchange of purines vs. pyrimidines ].

\begin{tabular}{|c|c|c|c|}
\hline & & \multicolumn{2}{|c|}{ characters } \\
\hline & & $\begin{array}{c}\text { parsimony } \\
\text { inf. }\end{array}$ & total number \\
\hline \multirow{4}{*}{ ITS } & complete & 268 & 606 \\
\hline & ITS 1 & 171 & 298 \\
\hline & ITS 2 & 82 & 147 \\
\hline & $5.8 \mathrm{~s}$ & 15 & 161 \\
\hline \multirow{6}{*}{ rps4 } & complete & 202 & \multirow{2}{*}{567} \\
\hline & complete, TV only & 60 & \\
\hline & $1^{\text {st }} \& 2^{\text {nd }}$ position & 95 & \multirow{2}{*}{378} \\
\hline & $1^{\text {st }} \& 2^{\text {nd }}$ position, TV only & 28 & \\
\hline & $3^{\text {rd }}$ position & 107 & \multirow{2}{*}{189} \\
\hline & $3^{\text {rd }}$ position, TV only & 32 & \\
\hline \multirow{6}{*}{$r b c \mathbf{L}$} & complete & 296 & \multirow{2}{*}{1326} \\
\hline & complete, TV only & 111 & \\
\hline & $1^{\text {st }} \& 2^{\text {nd }}$ position & 77 & \multirow{2}{*}{884} \\
\hline & $1^{\text {st }} \& 2^{\text {nd }}$ position, TV only & 40 & \\
\hline & $3^{\text {rd }}$ position & 219 & \multirow{2}{*}{442} \\
\hline & $3^{\text {rd }}$ position, TV only & 71 & \\
\hline
\end{tabular}




\subsubsection{Modeltest}

The results of a phylogenetic analysis strongly depend on the evolutionary models used (Buckley, 2002; Buckley and Cunningham, 2002; Lemmon and Moriarty, 2004). Thus it is necessary to have confidence in the models selected. The program Modeltest 3.6 (Posada and Crandall, 1998) was used to find the models of evolution that best fit the datasets of this study.

The program uses two different algorithms: "hierarchical Likelihood Ratio Tests" (hLRT) and the "Akaike Information Criterion" (AIC) (Akaike, 1974). In this study the models suggested by AIC were selected because recent work on model selection (Posada and Buckley, 2004) indicated that AIC is superior to hLRT.

When using combined datasets the question arises as to how many models should be used (Cox et al., 2004; Goffinet et al., 2004; Nylander et al., 2004). To check for differences between homogenous (one model) and heterogeneous (more than one model) approaches, the dataset was split into one, three, and seven partitions (Tab. 5) and a model of evolution was assigned to each partition. (As in the ITS dataset the most variable positions have been excluded prior to phylogenetic analyses, ITS1 and ITS2 are is not split up further, e.g. in stem and loop regions.)

Table 5 Dataset partitions.

\begin{tabular}{|c|c|c|c|c|c|c|c|}
\hline number of & \multicolumn{7}{|c|}{ data partitions: } \\
\hline 1 & \multicolumn{7}{|c|}{ complete dataset } \\
\hline 3 & \multicolumn{3}{|c|}{ ITS region } & \multicolumn{2}{|c|}{ rps4 } & \multicolumn{2}{|c|}{$r b c \mathrm{~L}$} \\
\hline 7 & ITS 1 & $5.8 \mathrm{~S}$ & ITS 2 & $\begin{array}{l}r p s 4,1^{\text {st }} \& \\
2^{\text {nd }} \text { codon } \\
\text { positions }\end{array}$ & $\begin{array}{l}\text { rps } 4,3^{\text {rd }} \\
\text { codon } \\
\text { positions }\end{array}$ & $\begin{array}{l}r b c \mathrm{~L}, 1^{\mathrm{st}} \& \\
2^{\text {nd }} \text { codon } \\
\text { positions }\end{array}$ & $\begin{array}{c}r b c \mathrm{~L}, 3^{\text {rd }} \\
\text { codon } \\
\text { positions }\end{array}$ \\
\hline
\end{tabular}


Table 6 Models selected by Modeltest 3.6 (AIC)

\begin{tabular}{|c|c|c|}
\hline data partition & model & model parameters (PAUP* format) \\
\hline $\begin{array}{l}\text { combined } \\
\text { dataset }\end{array}$ & $\mathrm{GTR}+\mathrm{I}+\mathrm{G}$ & 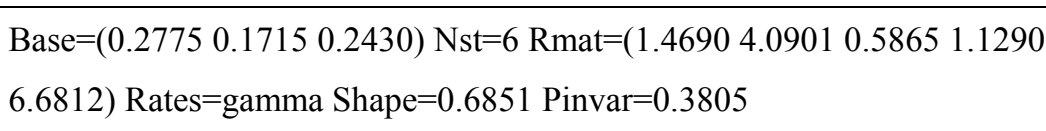 \\
\hline rps4 complete & $\mathrm{TVM}+\mathrm{I}+\mathrm{G}$ & 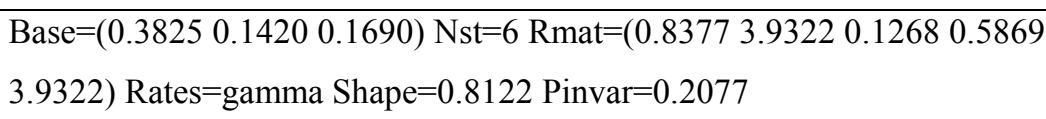 \\
\hline $\begin{array}{l}\text { rps } 41^{\text {st }} \& 2^{\text {nd }} \\
\text { positions }\end{array}$ & $\mathrm{TVM}+\mathrm{G}$ & 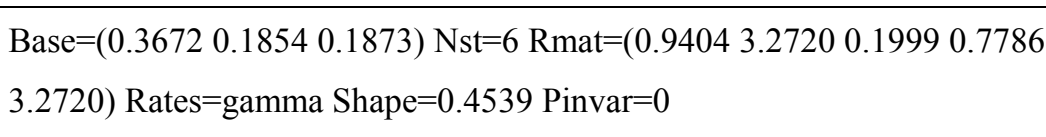 \\
\hline $\begin{array}{l}\text { rps4 } 3^{\text {rd }} \\
\text { positions }\end{array}$ & $\mathrm{GTR}+\mathrm{G}$ & 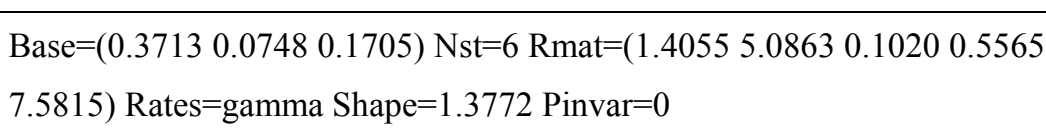 \\
\hline rbcL complete & $\mathrm{GTR}+\mathrm{I}+\mathrm{G}$ & 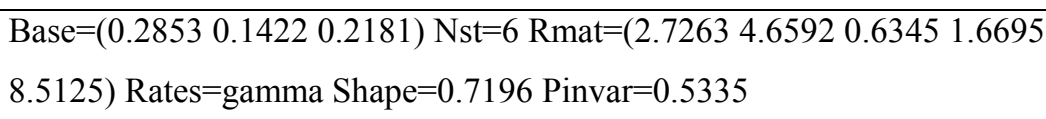 \\
\hline $\begin{array}{l}r b c \mathrm{~L} 1^{\text {st }} \& 2^{\text {nd }} \\
\text { positions }\end{array}$ & $\mathrm{GTR}+\mathrm{I}+\mathrm{G}$ & $\begin{array}{l}\text { Base }=(0.24860 .19640 .3146) \text { Nst=6 Rmat }=\left(\begin{array}{l}7.1422 \\
\text { 9.1477 }\end{array}\right) \text { Rates }=\text { gamma Shape }=0.4338 \text { Pinvar }=0.7157\end{array}$ \\
\hline $\begin{array}{l}r b c \mathrm{~L} 3^{\text {rd }} \\
\text { positions }\end{array}$ & $\mathrm{TVM}+\mathrm{I}+\mathrm{G}$ & 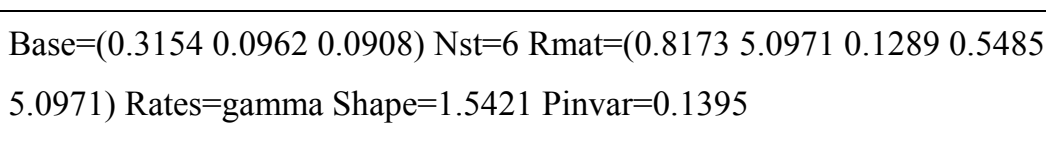 \\
\hline ITS region & $\mathrm{GTR}+\mathrm{I}+\mathrm{G}$ & 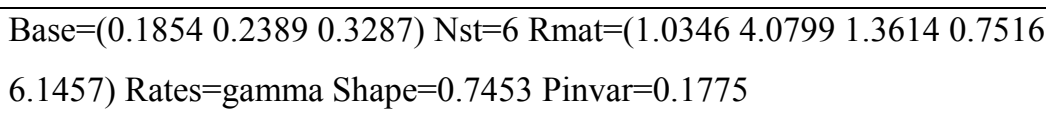 \\
\hline ITS1 & $\mathrm{GTR}+\mathrm{I}+\mathrm{G}$ & 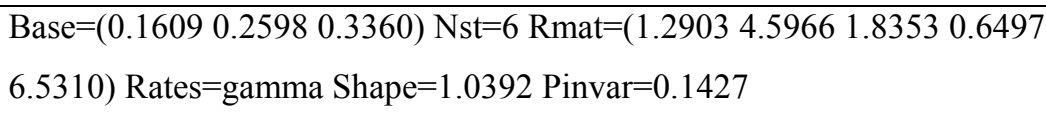 \\
\hline ITS2 & $\operatorname{TrN}+\mathrm{G}$ & 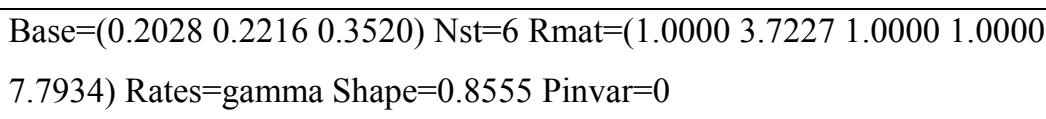 \\
\hline $5.8 \mathrm{~S}$ rDNA & $\mathrm{K} 80+\mathrm{G}$ & Base $=$ equal Nst $=2$ TRatio $=1.3737$ Rates $=$ gamma Shape $=0.6376$ Pinvar $=0$ \\
\hline
\end{tabular}




\subsection{Analyses of the data}

\subsubsection{Secondary structures}

DNA sequences of ITS 1 and ITS 2 were translated into RNA and folded on the mfold-server 3.1 (http://www.bioinfo.rpi.edu/ zukerm/, (Mathews et al., 1999; Zuker, 2003)), using the following options: RNA-sequence $=$ linear, percent suboptimal number $=5$, upper bound of computed foldings $=50$, window parameter $=$ default, maximum interior $/$ bulge loop size $=$ 30 , maximum asymmetry of an interior / bulge loop $=30$, and maximum distance between paired bases $=$ no limit. The resulting structures were visually compared. When necessary, partial sequences were cut out and folded separately.

\subsubsection{Distance plots}

Distance plots can be used to detect saturated mutations in a dataset by plotting uncorrected against corrected distances and measuring the deviation from the straight line (Cox et al., 2004). Thus, distance plots of ITS, $r b c \mathrm{~L}$ and $r p s 4$ were constructed. For the complete markers ( $r b c \mathrm{~L}, r p s 4$, and ITS), first and second codon positions ( $r p s 4$ and $r b c \mathrm{~L}$ ), as well as third codon positions ( $r p s 4$ and $r b c \mathrm{~L}$ ), uncorrected P-distances were computed and plotted against corrected F84-distances, accounting for the whole distance, respectively transitions (TI) and transversions (TV) only. (As in the ITS dataset the most variable positions have been excluded prior to phylogenetic analyses, ITS1 and ITS2 are is not split up further, e.g. in stem and loop regions.)

\subsubsection{Testing for congruent signals in the molecular data}

Several ILD-tests (Farris et al., 1994) as implemented in PAUP* 4.0b 10 (Swofford, 2002) were performed using the HomPart command. Settings were: nreps $=200$ search $=$ heuristic $/$ rearrlimit $=100 \cdot 10^{6}$. Constant characters were excluded from the dataset beforehand .

As the test statistics may be erroneous under several circumstances [e.g. different length of the partitions (rps4 with 294 variable sites, $r b c \mathrm{~L}$ with 460 variable sites, ITS with 391 variable sites)] (Barker and Lutzoni, 2002; Darlu and Lecointre, 2002), single gene phylogenies were visually inspected for incongruences. 


\subsubsection{Phylogenetic analyses}

Phylogenetic trees of the separate and the combined datasets were inferred using the maximum likelihood (ML) and maximum parsimony (MP) algorithms as implemented in PAUP* version 4.0b10 (Swofford, 2002).

\subsubsection{Parsimony analyses}

Maximum parsimony analyses were performed using the following options: heuristic search mode, tree bisection-reconnection branch swapping (TBR), MULTrees option on, and collapse zero-length branches on. All characters were treated as equally weighted and unordered.

Because the search for the most parsimonious tree(s) of the single genes reached the hardware limits of the computer (Power Mac G5, 1024 Mb RAM), calculation time was restricted to 72 hours. The combined dataset was calculated without time limitations.

MP Bootstrap support was calculated with 200 replicates and a rearrangement limit of $20 \cdot 10^{6}$ and regarded as significant when exceeding 70 (Felsenstein, 1985; Hillis and Bull, 1993).

\subsubsection{Likelihood analyses}

Maximum likelihood analyses implementing the models proposed by Modeltest 3.6 were calculated as heuristic searches (Tab. 3.3.3). Branching confidence was assessed using MrBayes (version 3.1.2, Huelsenbeck and Ronquist, 2001; Ronquist and Huelsenbeck, 2003), a program for Bayesian inference of phylogeny. Five hundred thousand generations were calculated of which every hundredth was saved, resulting in 5,000 saved trees. Trees collected before the likelihood score had stabilized were deleted. The remaining trees with a stable likelihood score were condensed to a majority rule consensus tree. Branch support of the consensus tree, referred to as posterior probabilities (PP), was regarded as significant when $\geq$ 0.95 (Larget and Simon, 1999). Bayesian inference was carried out with the best fitting model for the combined data set (homogenous approach), or one model for each marker (three models), or one model for ITS1, ITS2, and 5.8S, respectively, as well as one model for $1^{\text {st }} \&$ $2^{\text {nd }}$ positions and one for the $3^{\text {rd }}$ position of $r p s 4$ and $r b c L$ (seven models). 


\subsection{Analyses of the trees}

\subsubsection{Shimodaira Hasegawa (SH) tests}

SH-tests (Shimodaira and Hasegawa, 1999) were used to investigate whether one or more trees with a different topology than the tree resulting from the ML analyses are equally good explanations of the data. For this purpose trees with the topologies of interest were generated using TreeView vers. 1.6.6 (Page, 1996). The SH-tests, as implemented in PAUP* 4.0b 10 (Swofford, 2002), were carried out using the LScores command. Settings were: SHTest = FullOpt BootReps $=1000$.

\subsubsection{Mapping of morphology on the resulting tree}

To map the morphological features of the included taxa on the resulting ML tree Mesquite (Maddison and Maddison, 2006) was used, utilizing parsimony reconstructions. For this purpose a data matrix (NEXUS format, Maddison et al., 1997) coding for selected features was constructed (Appendix: 7.2).

The following morphological characters were evaluated from literature (Carl, 1931a; Gradstein and Reiner-Drehwald, 1995; Grolle, 1960; Grolle and Heinrichs, 1999; Groth et al., 2002; Groth et al., 2003; Groth et al., 2004b; Groth and Heinrichs, 2003; Heinrichs et al., 2004a; Heinrichs et al., 2001; Heinrichs et al., 2002a; Heinrichs et al., 1998; Heinrichs et al., 2000b; Heinrichs et al., 2000a; Heinrichs, 2002; Heinrichs et al., 2002d; Heinrichs et al., 2002c; Heinrichs et al., 2002b; Heinrichs et al., 2003; Heinrichs et al., 2004b; Heinrichs et al., 2005c; Heinrichs and Gradstein, 2000; Inoue, 1966a; Inoue, 1984; Inoue, 1987; Inoue and Schuster, 1971; Jones, 1962; Lindenberg, 1839; Müller et al., 1999; Renker et al., 2002; Rycroft et al., 2002; Rycroft et al., 2004; Schuster, 1959; So, 2000a; So, 2000b; So, 2001; So and Grolle, 2000a; So and Grolle, 2000b; Vanden Berghen, 1981): 


\section{Gametophyte}

1. (dominating) branching type: (0) lateral intercalar, (1) lateral terminal, (2) ventral intercalar

2. leaves laterally oppressed: (0) no, (1) yes

3. surface wax: (0) absent, (1) present (at least on some leaves or stem sectors)

4. (well defined) vitta: (0) absent, (1) present

5. ill defined vitta: (0) absent, (1) present

6. leaf surface: (0) smooth, (1) with small papillae, (2) with spherical papillae

7. leaf position: (0) alternating, (1) (sub-) opposite

8. underleaves: (0) completely missing, (1) vestigial, (2) well developed

9. paraphyllia: (0) absent, (1) on dorsal stem surface, (2) on ventral stem surface

10. differentiation of a (creeping) stoloniform that gives rise to (ascending) leafy shoots: (0) no, (1) yes

11. rhizoids: (0) absent, (1) present on creeping and leafy sectors of shoots, (2) present on creeping sectors of shoots only

12. position of rhizoids: (0) scattered on stem surface, (1) fasciculated at ventral leaf bases,

13. asexual reproduction by propagules: (0) no, (1) yes

14. asexual reproduction by caducous leaves: (0) no, (1) yes

15. asexual reproduction by flagelliform branches: (0) no, (1) yes

16. colour of oil bodies: (0) colourless, opaque, (1) brownish

17. structure of oil bodies: (0) homogenous, (1) coarsely segmented, (2) fine papillose

18. sexual condition: (0) monoecious, (1) dioecious

19. androecia: (0) simple, (1) fan shaped (or at least gregarious)

20. opposite male bracts in dorsal view: (0) not overlapping, (1) overlapping

21. perianth shape: (0) cylindrical, (1) campanulate, (2) subrotundate

22. perianth mouth: (0) always toothed, (1) (sometimes) entire

23. perianth with: (0) two keels, (1) three keels, (2) more than three keels

24. dorsal keel of perianth: (0) without wing, (1) with one wing, (2) with $1-2$ wings, (3) with ridge and low wing

25. ventral keel of perianth: (0) without wing, (1) with one wing, (2) with $1-2$ wings 


\section{Sporophyte}

26. seta: (0) short (less than $12 \mathrm{~mm}$ longer than perianth), (1) long (more than $12 \mathrm{~mm}$ longer than perianth)

27. capsule shape: $(0)+/$ - globose, (1) cylindrical

28. epidermal layer of capsule wall: (0) with thickenings, (1) without thickenings

29. innermost layer of capsule wall: (0) with thickenings, (1) without thickenings

30. type of thickenings in innermost layer of capsule wall: (0) ladder like / fenestrate, (1) nodulose, discrete or confluent at base or (partly) coalescent, (2) mixture of discrete and coalescent thickenings

31. spores (at time of release): (0) unicellular, (1) multicellular

32. sporoderm structure: (0) verrucate, (1) baculate, (2) echinate - baculate

33. elater surface: (0) smooth, (1) rough

34. spirals per elater: (0) $1-2,(1) 2,(2)$ more than 2

The data was plotted on the ML tree (Appendix: 7.3).

\subsubsection{Biogeography}

The actual distribution of the species analysed in this study was evaluated from literature (e.g. Heinrichs, 2002; Inoue, 1984; Inoue and Schuster, 1971; Müller et al., 1999; So, 2001) and plotted on maps as well as summarized in a table (Tab. 14).

To develop a hypothesis of the ancient distributions, it is possible to map the current distributions of the analysed species on a phylogenetic tree (in this case the ML tree of the 3marker-analyses, Fig. 25 / 26) and reconstruct the dispersal patterns on deeper nodes. The program DIVA (Ronquist, 1996) can be used to for this purpose. However, as this program was initially developed to work on parasite-host scenarios, it is not possible to define the relationships between the geographical regions. For this reason MacClade (Maddison and Maddison, 2000), a tool to map and reconstruct characters on phylogenetic trees, was used here (as e.g. Ballard and Sytsma, 2000). This program allows for step matrices with up to 26 character states (= geographical regions). The relationships between the character states can individually be defined by the user as costs for the change of one character state into another, providing the possibility to test several different hypotheses of ancient dispersal patterns.

Geographical regions were defined based on the floral regions recognized by Takhtajan (1978), combined with the regions inhabited by the analysed species (Fig. 4). Basically, costs 
are based on the distance between the areas. Thus, cost of range extension from one area to an adjacent one is 1. Cost of dispersal across seas or oceans is 2 (Fig. 4). Cost of range extensions across greater distances are calculated using the shortest possible route. Possible dispersal routes were reconstructed based on the current distribution of single species or closely related taxa. In a second step the basic matrix was altered by increasing the cost for oversea dispersal. Thirdly, east $\rightarrow$ west and west $\rightarrow$ east travel over sea was scored differently, to test for the influence of different main wind currents on the resulting dispersal patterns.

In total, five different matrices were used: I - III with costs for oversea dispersal rising from 2 to 4 , and $\mathbf{I V}$ and $\mathbf{V}$ favouring either east $\rightarrow$ west or west $\rightarrow$ east routes over sea (Appendix 7.4). Nevertheless, it should be noted that the distribution models assumed here are not very flexible. It is for example not possible to account for change in main wind directions, continental drift, or prehistoric climates. 


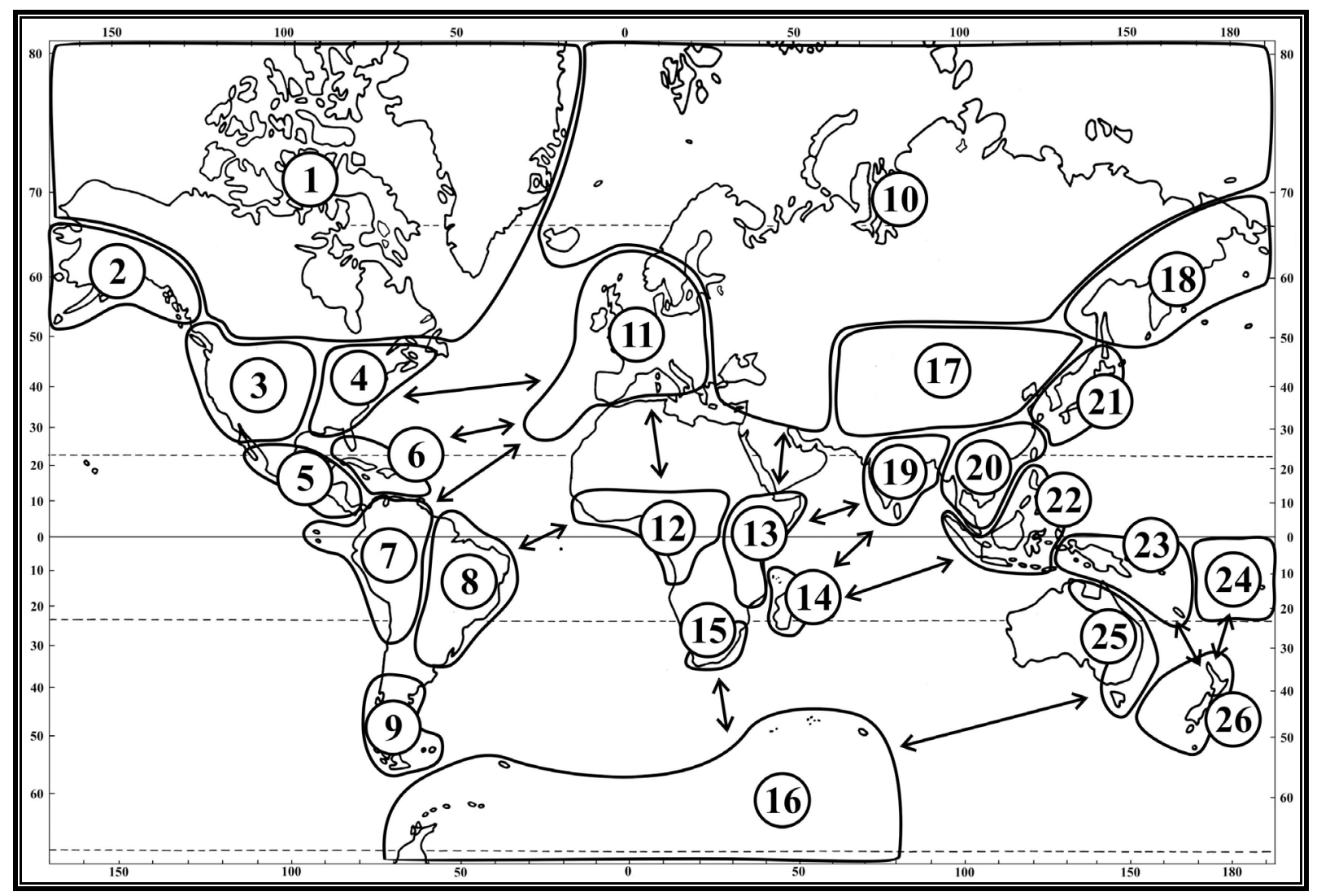

Figure 4 Geographical areas used for the coding of the species distribution. (1) West Holarctic, (2) Alaska, (3) West U.S.A., (4) East U.S.A., (5) Central America, (6) West Indies, (7) North-West South America, (8) East South America, (9) Patagonia, (10) East Holarctic, (11) Europe, (12) West Africa, (13) East Africa, (14) Madagascar, (15) Cape Region, (16) Antarctica, (17) China, (18) Kamtschatka, (19) India, (20) Indochina, (21) Japan, (22) Malesia, (23) Papuasia, (24) Polynesia, (25) Australia, (26) New Zealand. Direct range extension is allowed in neighbouring regions. Arrows indicate routes for (hypothetical) dispersal between non adjacent regions. 


\subsubsection{Molecular clock}

A molecular clock was calculated, using the algorithms implemented in r8s version 1.50 (Sanderson, 2003). As the data on the whole does not follow the molecular clock hypothesis (Langley and Fitch, 1974) (-ln L $=28488.47294$ with enforced molecular clock is significantly worse than $-\ln \mathrm{L}=28154.44115$ without molecular clock enforced [on a threshold value of 0.05]), penalized likelihood (PL, Sanderson, 2002) was used to calculate a chronogram necessary for calibrating ages (algorithm $=\mathrm{TN}$ [truncated newton]). The smoothing parameter was estimated at 2.46 from the data, using the divtime command. Standard deviations were calculated by summarizing the age of supported nodes over 700 randomly selected Bayesian trees, using the profile command (Schneider et al., 2004).

To constrain the molecular clock, only one fossil [Plagiochila groehnii Grolle \& Heinrichs baltic amber, at least 50 Mio y old; (Grolle and Heinrichs, 2003)] was available. As it only represents one sterile shoot, its sectional classification is difficult. As it shows affinities to $P$. sciophila of section Cucullatae (Grolle and Heinrichs, 2003), it was used to constrain the minimum age of the section to 50 Mio y. To account for the unsure placement it was alternatively used to restrain the age of the genus Plagiochila to this age.

To compensate for the lack of well identified fossils, two geological events were also used to constrain the molecular clock. However, this can lead to highly artificial calibrations, as many implications have to be made about historical distributions and climates.

Geological events used are the final drying of the Atacama desert, and the cooling of the Antarctic continent. The Atacama desert stretches from the chilenian Pacific Coast to the Andes between $16^{\circ} \mathrm{S}$ and $26^{\circ} \mathrm{S}$ and is one of the driest places on earth. It inhibits floral exchanges between the tropical Andes in the north and of temperate Patagonia in the south. The desert was formed about 150 million years ago (Hartley et al., 2005) and has since undergone frequent changes in humidity. The last time water was available in the desert was 4-6 million years ago, when rainfalls on the Andean plateaus provided for enough moisture to sustain a system of rivers and lakes (Hartley and Chong, 2002).

As Plagiochila dusenii and $P$. validissima occur only north $(P$. validissima) and south $(P$. dusenii) of the Atacama desert it seems reasonable to assume that they became separated either by the initial formation of the desert 150 million years ago (Hartley et al., 2005) or by 
the last change to hyperarid climate, 4-6 million years ago (Hartley and Chong, 2002). Therefore the minimum age of the corresponding node in the tree was set to either 150 or 4 million years.

The Antarctic continent has been almost inhabitable for liverworts for 30-35 million years. Earlier, climate was more favourable, ranging from warm and wet (ca. 60-45 Mio y ago) to cool and wet (ca. 45-35 Mio y ago) (Dingle et al., 1998). During this time the continent could have functioned as a land bridge between Australia / New Zealand and southern South America (Hill, 2001; McDaniel and Shaw, 2003; McLoughlin, 2001; Nelson and Ladiges, 2001; Sanmartin and Ronquist, 2004).

In this study Plagiochila hirta (Patagonia) and P. deltoidea / P. ramosissima (New Zealand / Tasmania) represent a case of closely related species that could have been separated by the rapid cooling of the Antarctic continent 35 million years ago. Accordingly the node ancestral to these species was restricted to a minimum age of 35 million years.

(Corresponding nodes in other studies have been dated to 80 Mio y ago (e.g. Shaw et al., 2002), based on the split up of Gondwanaland (McLoughlin, 2001). However, as Plagiochilaceae are most likely capable of crossing oceans by means of long range dispersal (e.g. Heinrichs et al., 2005a; Heinrichs et al., 2002b), the author favours the dating suggested above.)

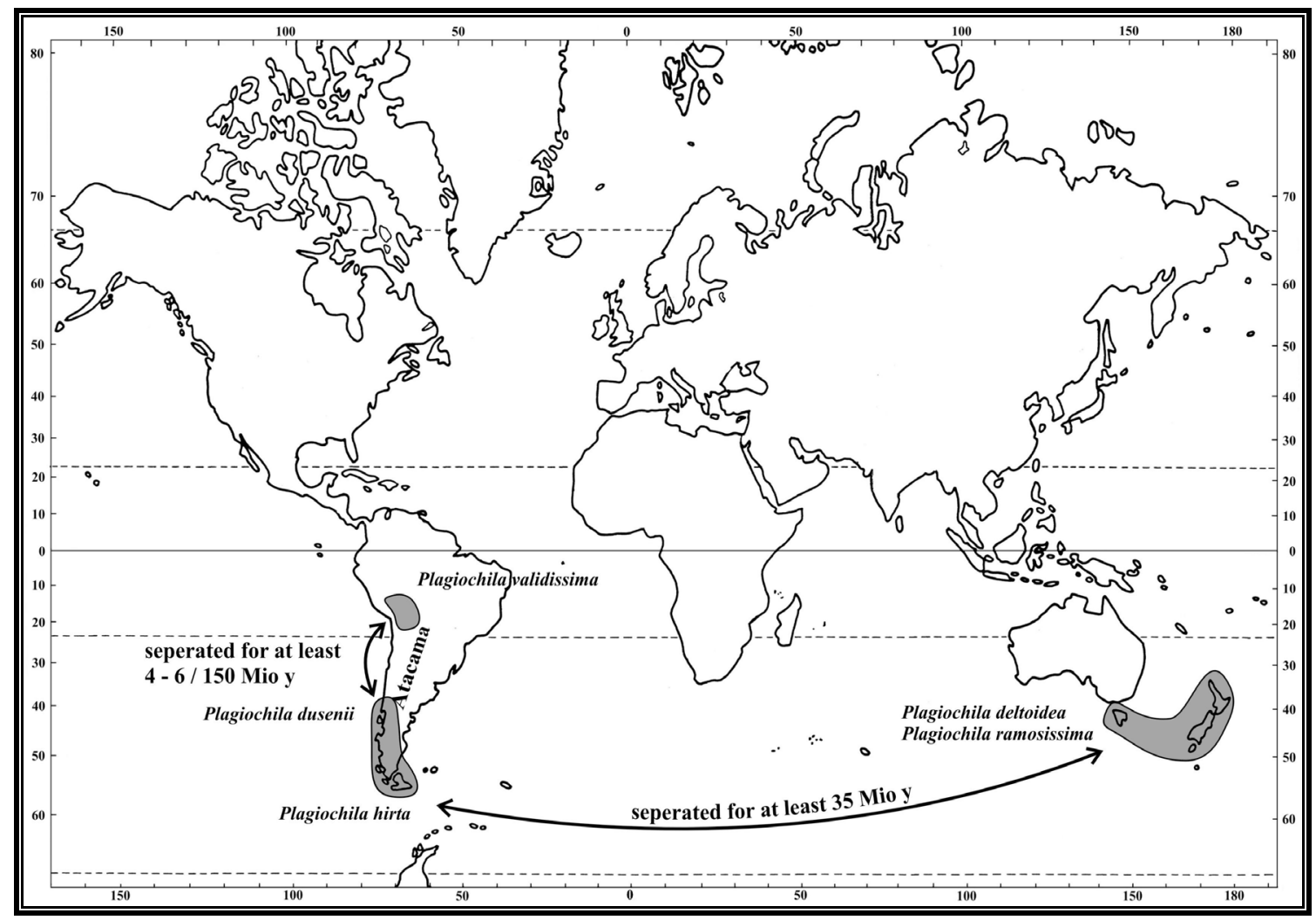

Figure 5 Map showing the distribution of species separated either by the Atacama dessert or the cooling of Antarctica. 


\section{Results and discussion}

\subsection{Secondary structures}

\subsubsection{ITS 1}

Folding of the ITS 1 region leads to a number of different possible secondary structures for each species (10 - 30 per species). However, by comparing the results distinct patterns could be recognized, leading to a basic structure that varies only slightly within the genus. The most common feature is a "bulb" composed of nine nucleotides that appears in nearly every folding (Fig. 6).

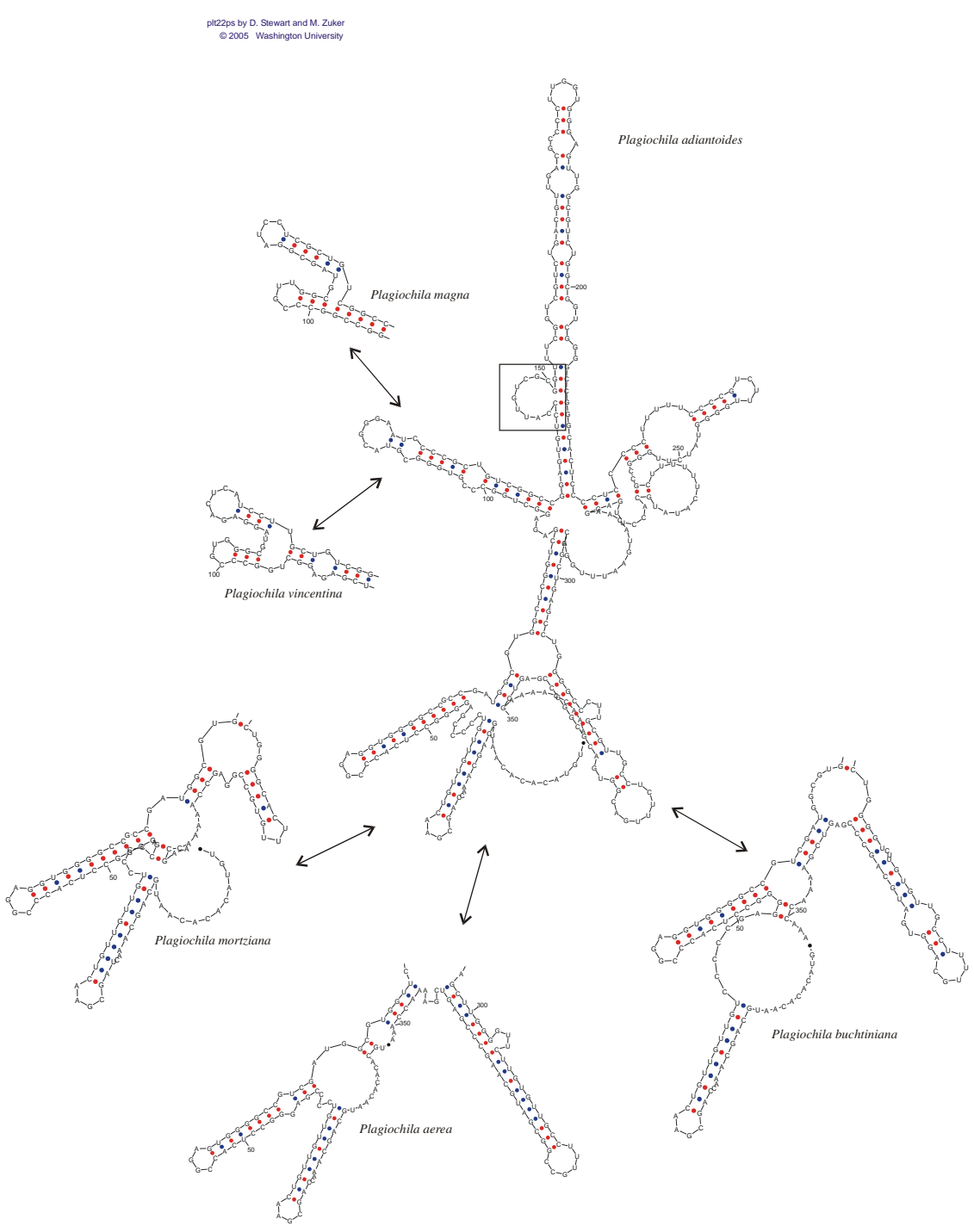

Figure 6 Secondary structure of ITS 1 of Plagiochila. Variations of the basic structure are indicated. The box indicates a highly conserved bulb of nine nucleotides. 


\subsubsection{ITS 2}

Folding of the ITS 2 region leads to a number of different possible secondary structures for each species (1 - 15). By comparison of the foldings a structure was found that appears to be highly conserved in Plagiochila (Fig. 7). It displays great similarities to that published for algae and flowering plants by Mai and Coleman (1997), supporting the hypothesis that functionality of the ITS region is maintained by secondary rather than primary structure (Coleman et al., 1998; Coleman and Mai, 1997; Coleman and Vacquier, 2002; Mai and Coleman, 1997; Musters et al., 1990; van der Sande et al., 1992).

As in ITS 1, the most common feature of ITS 2 is a bulb of $10-11$ nucleotides that appears in most of the possible structures (Fig. 7: box). Both the ITS 1 and the ITS 2 bulb are quite well conserved and contain $80-100 \%$ complementary bases to each other, respectively. Possibly, they provide for a binding site leading to the formation of a tertiary structure, that may be crucial for the maturation of $5.8 \mathrm{~S}$ rRNA. This hypothesis is contradicted by the finding that excision of ITS 2 in Saccaromyces cerevisiae L. is independent of ITS 1 (Musters et al., 1990; van der Sande et al., 1992; van Nues et al., 1994).

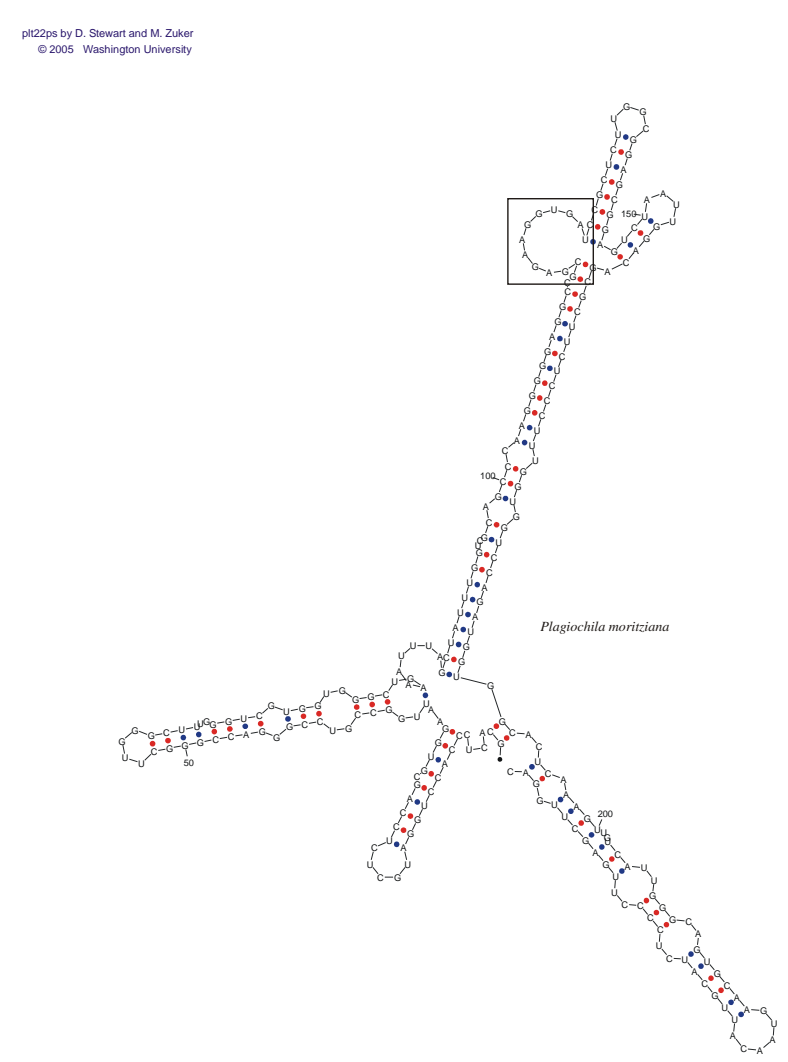

Figure 7 Secondary structure of ITS 2 of Plagiochila. The box indicates a highly conserved bulb of 10 nucleotides. 


\subsection{Distance plots}

Distance plots are a method to identify saturated mutations in a molecular dataset. As these might hamper the phylogenetic analyses some authors argument that they should be excluded (Cox et al., 2004). On the other hand, highly variable positions also contain phylogenetic information that will be lost (Yang, 1998).

Distance plots of the present dataset were constructed to identify saturated mutations and their impact on the resulting phylogeny.

The distance plot of the complete rps4 dataset shows a small deviation from the straight line (Tab. 7.a). The splitting of the data into transitions vs. transversions, as well as $1^{\text {st }} \& 2^{\text {nd }}$ vs. $3^{\text {rd }}$ codon positions, reveals a strong curvature for the combination $3^{\text {rd }}$ codon position transitions (Tab. 7.h). This suggests the occurrence of saturated mutations in the transitions of the $3^{\text {rd }}$ codon positions. The same pattern is found in the $r b c \mathrm{~L}$ dataset (Tab. 8).

In the ITS dataset slight deviations from the straight line can be detected as well (Tab. 9). However, they only hint at a small amount of saturated mutations in the dataset. (This is not surprising, as with the exclusion of unalignable positions prior to investigation the most saturated positions will already have been deleted.)

\section{Conclusions:}

The results of the distance plots of $r p s 4$ and $r b c \mathrm{~L}$ hint to possibly saturated mutations in the transitions of the $3^{\text {rd }}$ codon positions. The mutations of the ITS dataset seem to be relatively unsaturated. Therefore, the unmodified dataset and the dataset with excluded transitions at the $3^{\text {rd }}$ codon positions of rps 4 and $r b c \mathrm{~L}$ were analysed and compared to investigate possible impacts on the resulting topology. 
Table 7 Distance plots of the rps4-dataset

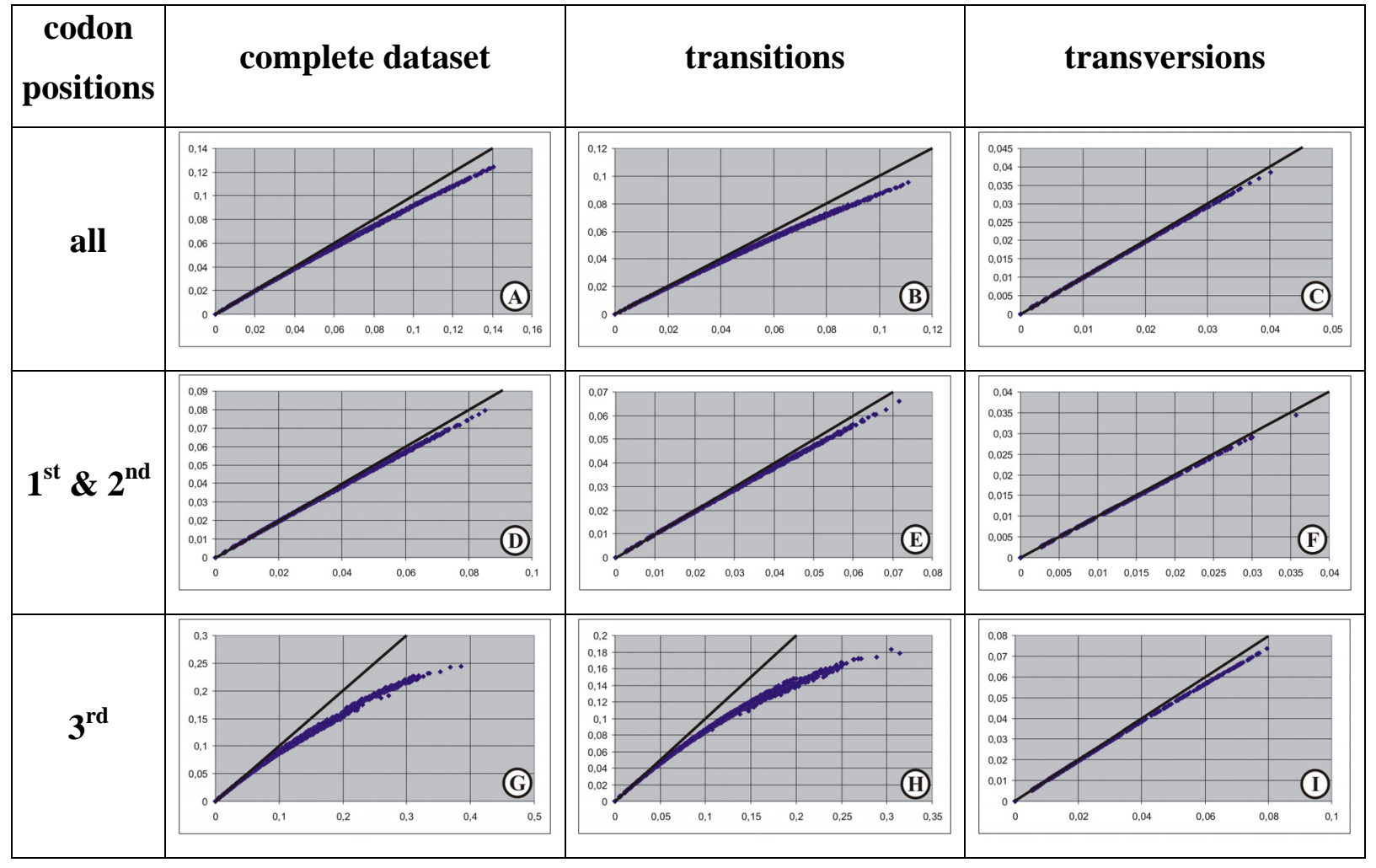

Table 8 Distance plots of the $r b c L$-dataset

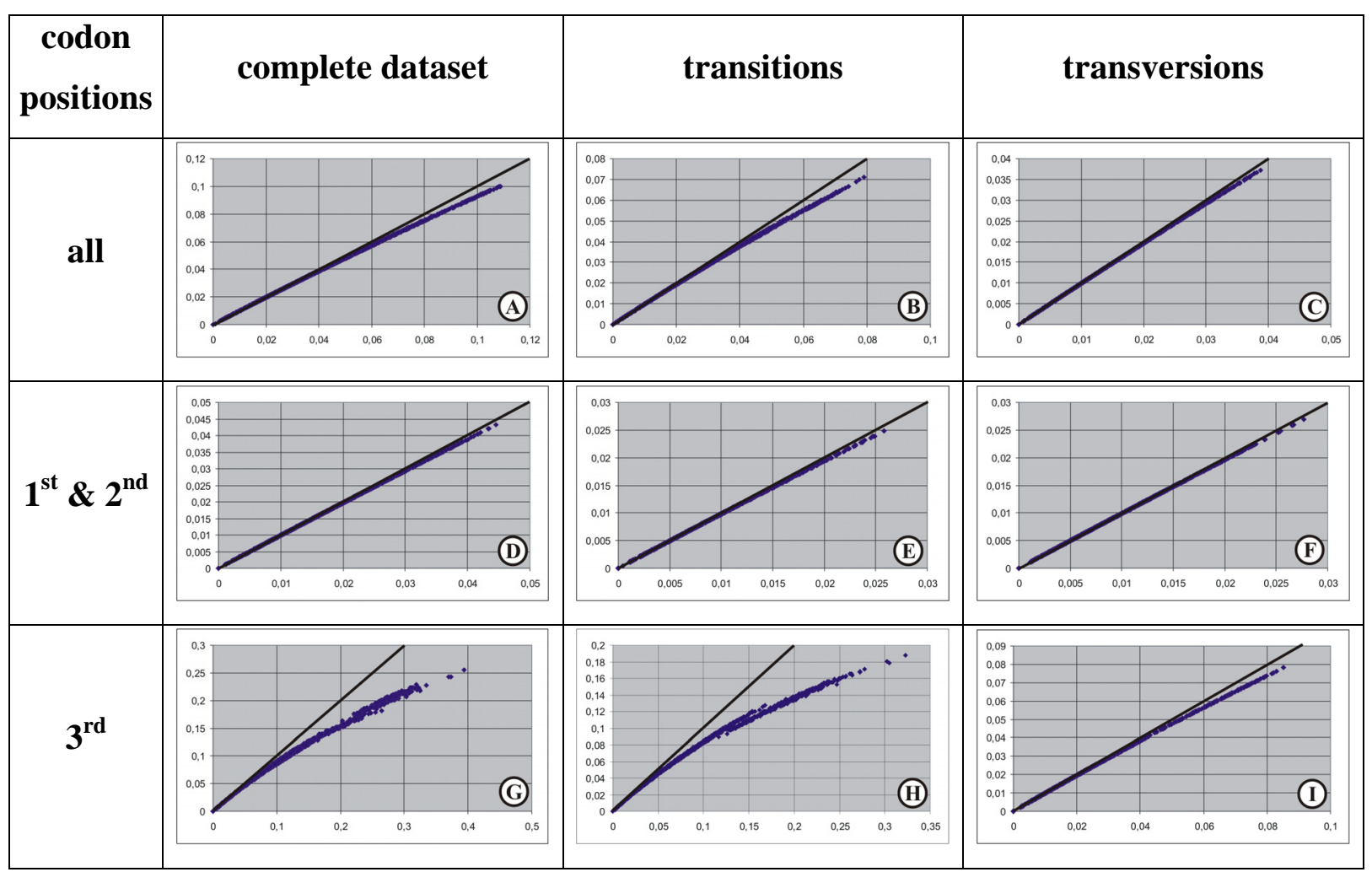


Table 9 Distance plots of the ITS-dataset

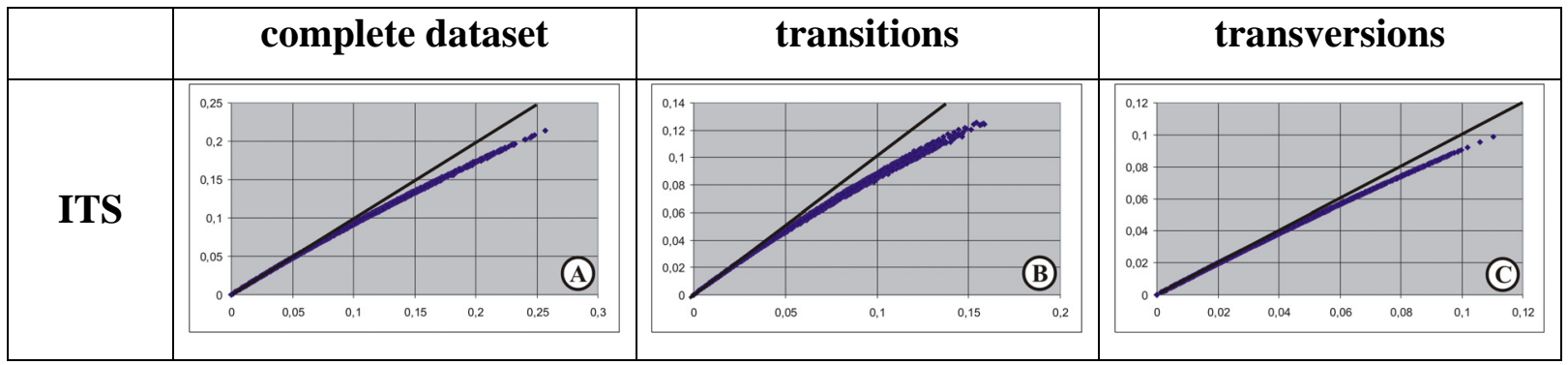

\subsection{Molecular circumscription of Plagiochilaceae}

Current morphological circumscriptions of Plagiochilaceae accept nine genera in the family: Acrochila, Chiastocaulon, Pedinophyllopsis, Pedinophyllum, Plagiochila, Plagiochilidium, Plagiochilion, Proskauera, and Xenochila. Except for Plagiochilidium and Xenochila rps4 and / or $r b c \mathrm{~L}$ sequences could be generated for at least one representative of each genus. With a vast number of $r b c \mathrm{~L}$ and rps4 sequences of liverworts now available in the international databases, the morphological concept can be evaluated against molecular data.

A molecular dataset for $r p s 4$ and $r b c L$ sequences was assembled (Tab. 15) using recent classifications of the systematics of liverworts as a guideline (Heinrichs et al., 2005b). Analyses where carried out using ML and MP methods (MrBayes, Ronquist and Huelsenbeck, 2003; PAUP*, Swofford, 2002).

In the rps4 dataset (Fig. 8a) the seven analysed genera (Acrochila, Chiastocaulon, Pedinophyllopsis, Pedinophyllum, Plagiochila, Plagiochilion, Proskauera) form a very well supported clade (Bayesian support $[\mathrm{PP}]=1.00$ ), as sister to Geocalycaceae (Chiloscyphus, Heteroscyphus) and Acrochila sister to Plagiochilaceae. One representative of Pedinophyllum (P. truncatum) is resolved as member of the "Jamesionelloideae" (Heinrichs et al., 2005b), whereas P. interruptum (type species of the genus) is firmly nested in Plagiochilaceae. Sister to both families is a clade comprised of Herbertaceae (Herbertus, Triandrophyllum), Lepicoleaceae (Lepicolea), and Lepidoziaceae (Lepidozia, Bazzania), as well as Trichocoleaceae (Trichocolea). Thus, the morphological concept of Plagiochilaceae is supported by rps 4 data with the exception of Pedinophyllum truncatum.

The analyses of the $r b c \mathrm{~L}$ dataset (Fig. 8b) lead to a very similar topology, with a highly supported Plagiochilaceae clade (PP = 1.00). Again Pedinophyllum interruptum (Plagiochilaceae) and P.truncatum (“Jamesionelloideae") are separated. Additionally, 
Acrochila does not fall within Plagiochilaceae but is resolved being sister to Adelanthus, "Jamesionelloideae" ( $\mathrm{PP}=1.00)$.

Exclusion of Adelanthus from the ML analyses does not lead to a repositioning of Acrochila in Plagiochilaceae. Instead, in MP analyses Acrochila is then resolved as member of Cephaloziaceae (Cephalozia, Nardia) rather than "Jamesonielloideae".

The position of Acrochila as a member of Plagiochilaceae seems at least doubtful and is in need of closer investigation. Thus, more $r b c \mathrm{~L}$ and $r p s 4$ sequences are needed to clarify the phylogenetic position of Acrochila. In addition, a closer investigation of Pedinophyllum interruptum and P. truncatum is needed; presumably these species belong to different genera. (Unpublished sequences of the author confirm the placement of $P$. truncatum in "Jamesionelloideae".) As a result of this, Acrochila will not be regarded as member of Plagiochilaceae but of "Jamesonielloideae" in this study.

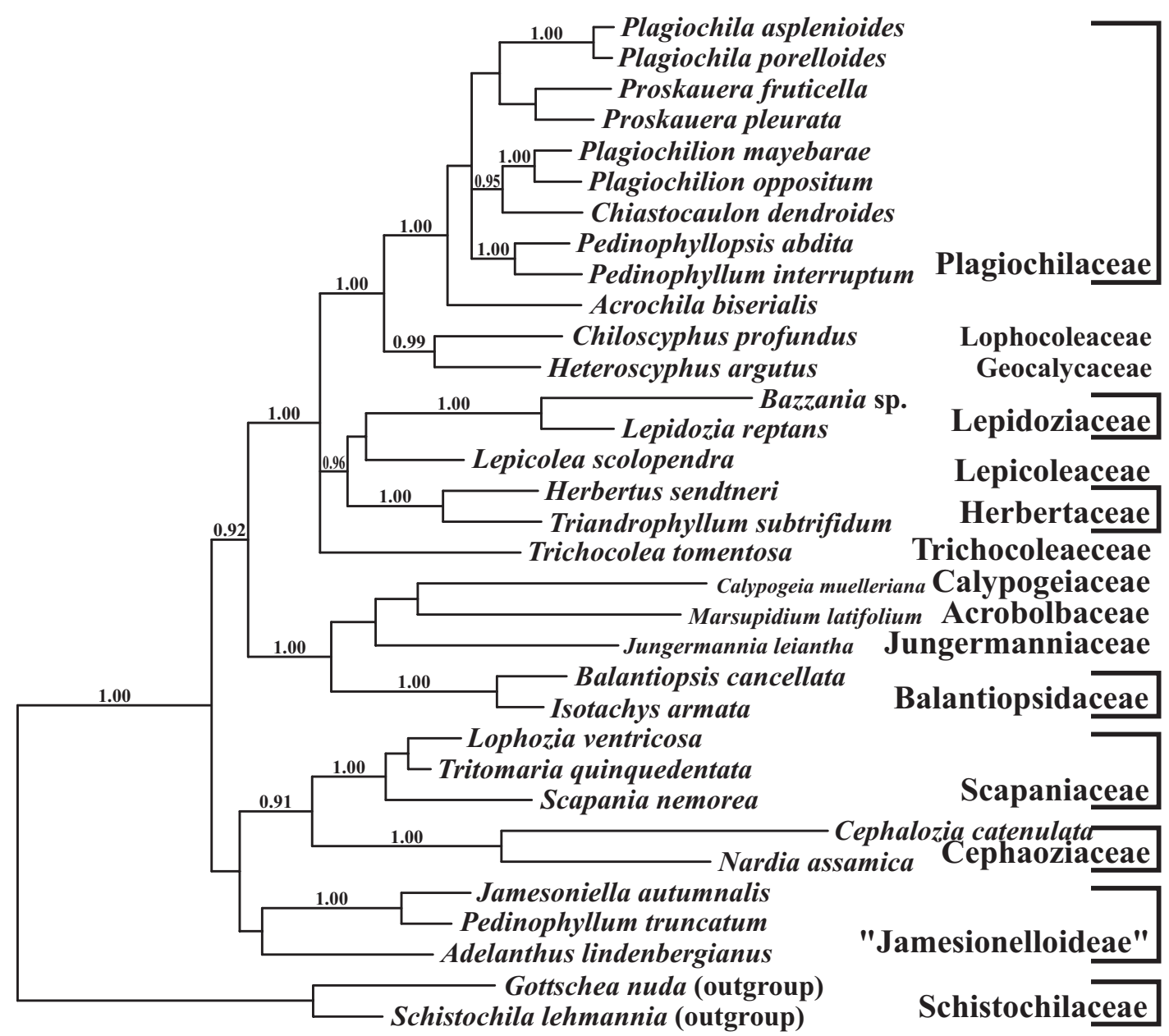

Figure 8a Phylogenetic tree resulting from a maximum likelihood analysis of the rps 4 dataset $(-\ln \mathrm{L}=4745.74149)$. Bayesian support $(\geq 0.90)$ is indicated above the branches. [Naming of the groups according to (Heinrichs et al., 2005b; Hentschel et al., 2006).] 


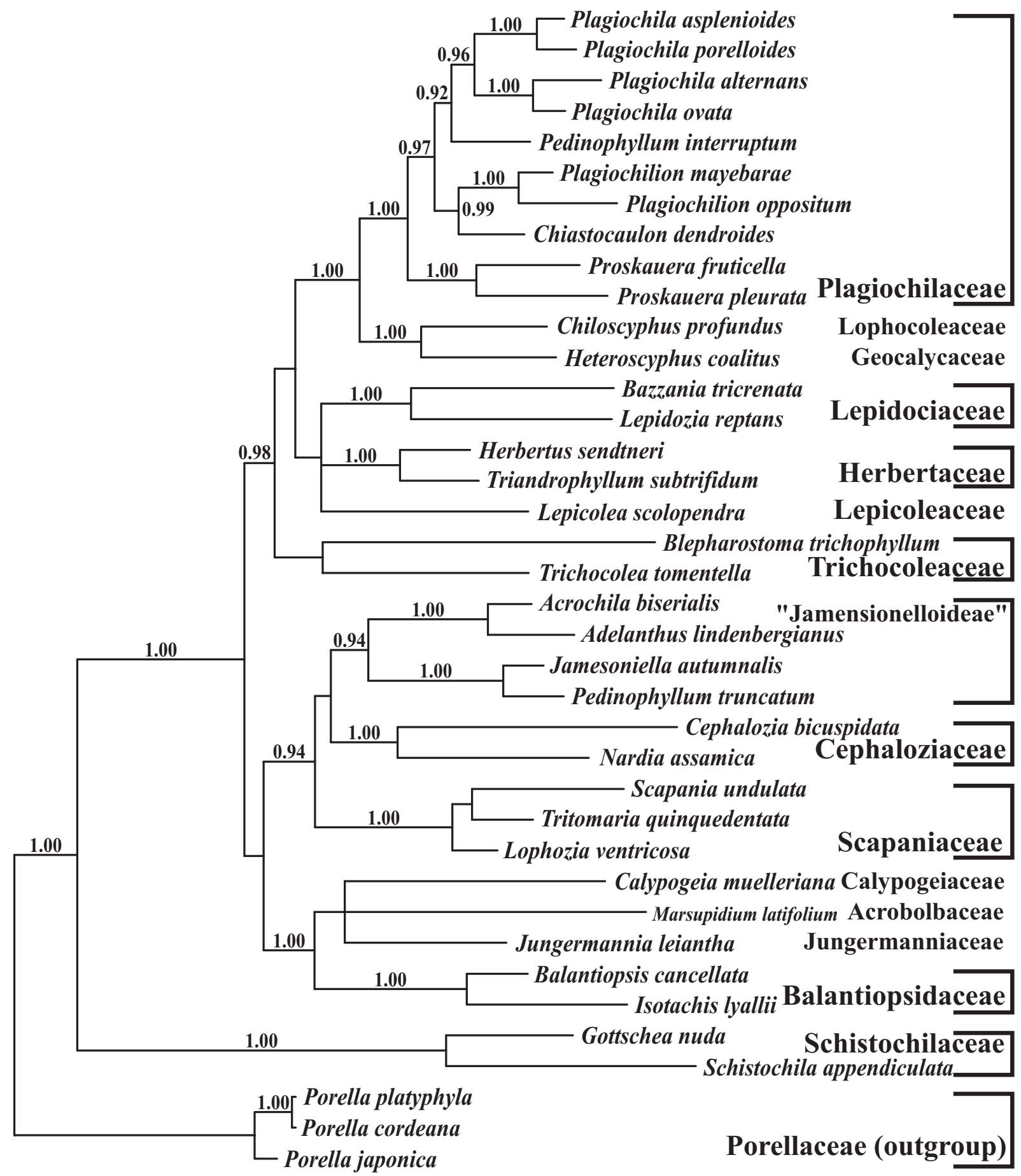

Figure 8b Phylogenetic tree resulting from a maximum likelihood analysis of the rbcL dataset $(-\ln \mathrm{L}=8513.13170)$. Bayesian support $(\geq 0.90)$ is indicated above the branches. [Naming of groups according to (Heinrichs et al., 2005b; Hentschel et al., 2006).] 


\subsection{Phylogenetic analyses}

\subsection{1 rps4}

\section{Maximum likelihood:}

The rps4 ML tree $(-\ln \mathrm{L}=5773.27074$, Fig. $13 / 14)$ shows a clear demarcation of the Plagiochilaceae from the Geocalycaceae. While Chiloscyphus profundus is grouped together with the assigned outgroup (Herbertus sendtneri), a long, well supported branch ( $\mathrm{PP}=0.96$ ) leads to the members of Plagiochilaceae included in the analysis.

The first clade of this ingroup is built up from representatives of three genera other than Plagiochila (Chiastocaulon, Plagiochilion, and Pedinophyllum) plus Plagiochila radiculosa, which is placed in a sister relationship to Pedinophyllum interruptum.

Next in the tree is a small, well supported clade containing Proskauera (Pr. fruticella and Pr. pleurata, followed by Pedinophyllopsis abdita which lacks close relatives in this analysis.

After that, a clade is found holding the members of Plagiochila sect. Alternantes [with a posterior probability (PP) of 1.00 in the Bayesian analyses] with $P$. crozetensis $(P$. sect. Durae) at the base. The rest of the tree can be divided into two groups.

The first group (Fig. 13) holds the representatives of Plagiochila sects. Arrectae, Rutilantes, Tayloriae, Glaucescentes, Duseniae, and Durae. As already revealed in earlier studies (e.g. Groth et al., 2002; Groth et al., 2004b), P. sects. Arrectae and Rutilantes are placed sister to each other. At the base of both, $P$. sect. Tayloriae is resolved. Sister to this clade are $P$. sects. Durae, Glaucescentes, and Duseniae. Nevertheless, none of these relationships receive statistical support.

The second group, (Fig. 14) is made up of the members of Plagiochila sects. Vagae, Plagiochila, Fruticosae, Trabeculatae, Peculiares, Poeltiae, Africanae, Cucullatae, Hylacoetes, Fuscoluteae, and Adiantoideae, as well as P. andina, which can not be assigned to any section. Aside from the well supported clade of $P$. sect. Adiantoideae, Fuscoluteae, and Hylacoetes (at the base of this part of the tree), the intersectional relationships are not supported. However, the most basal clade of the remaining part of the tree holds the representatives of $P$. sect. Cucullatae, as well as $P$. ericicola [which resolves with $P$. sect. Vagae, in Heinrichs et al., (2005a)]. The rest of the tree is divided into P. sect. Vagae, together with P. barteri [P. sect. Africanae (Heinrichs et al., 2005a)] and P. sects. 
Plagiochila, Fruticosae, Trabeculatae, Peculiares, and Poeltiae, sister to P. colorans [P. sect. Africanae (Heinrichs et al., 2005a)] and a well supported clade build of P. andina, P. renitens, and P. flabelliflora. The latter has not been recognized by morphology, nor is it found in the analyses of any other genetic markers.

Finally, ten of the eighteen included sections receive good statistical support (Alternantes, Arrectae, Durae, Glaucescentes, Tayloriae, Fuscoluteae, Poeltiae, Trabeculatae, Fruticosae, Vagae), the other are not supported statistically (Rutilantes, Duseniae, Hylacoetes, Cucullatae) or are not monophyletic (Adiantoideae, Africanae, Plagiochila, Peculiares) in this analysis.

The relationships between the sectional clades, while being congruent with those found in previous studies (e.g.: Groth et al., 2003; Groth et al., 2004b; Groth and Heinrichs, 2003), are only very weakly supported.

Six of the 128 ingroup species (Plagiochila adiantoides, P. crozetensis, P. ericicola, P. flabelliflora, P. renitens, P. validissima) do not group, as was also found in studies using ITS (e.g. Groth et al., 2003; Groth et al., 2004b) and the ITS and $r b c L$ analyses in this study, respectively. However, their position is better resolved when using a reduced dataset of two species per section only (data not shown).

\section{Maximum parsimony:}

In the maximum parsimony analyses 370,876 trees were found (935 steps, $\mathrm{CI}=0.410, \mathrm{RC}=$ $0.288, \mathrm{RI}=0.703$ ). The topology of the strict consensus tree (Fig. $15 / 16$ ) is congruent with the ML tree, including the position of several species (Plagiochila adiantoides, P. crozetensis, P. ericicola, P. flabelliflora, P. renitens, P. validissima) which are misplaced according to earlier studies (e.g.: Groth et al., 2003; Groth et al., 2004b; Groth and Heinrichs, 2003), the $r b c \mathrm{~L}$ and ITS analyses of this study. Again, their position is better resolved when using a reduced dataset of two species per section only.

Statistical support is less as compared to the ML tree. Only nine of the analysed eighteen sections (Glaucescentes, Poeltiae, Fruticosae, Trabeculatae, Fuscoluteae, Cucullatae, Rutilantes, Tayloriae, Alternantes) receive bootstrap values (BT) greater than or equal to 70 (Felsenstein, 1985; Hillis and Bull, 1993). The remaining sections are not supported (Arrectae, Durae, Vagae, Hylacoetes) or not monophyletic (Peculiares, Plagiochila, Adiantoideae, Africanae). Intersectional relationships are poorly resolved and poorly 
supported. Only Plagiochila sects. Hylacoetes, Adiantoideae, and Fuscoluteae are placed together $(\mathrm{BT}=65)$, as well as the upper half of the tree (Fig.16) which holds the sections Vagae, Poeltiae, Peculiares, Fruticosae, Trabeculatae, Plagiochila, Hylacoetes, Adiantoideae, Fuscoluteae, Cucullatae, and Africanae $(\mathrm{BT}=72)$.

\subsection{2 rbcL}

Maximum likelihood:

In the ML-rbcL tree (-ln L = 11137.07404, Fig. 17) Chiloscyphus profundus (Geocalycaceae) is clustered together with the assigned outgroup (Herbertus sendtneri, Herbertaceae).

A long well supported branch ( $\mathrm{PP}=1.00)$ leads to the rest of the tree. At the base of this tree, Plagiochila radiculosa is placed. The rest of the well supported topology $(\mathrm{PP}=0.99)$ can be divided into two groups.

The first group holds a clade with the members of Plagiochila sect. Alternantes, sister to Plagiochilion mayebarae, Plagiochilion oppositum, Pedinophyllum interruptum, Chiastocaulon dendroides, Proskauera fruticella, as well as Proskauera pleurata. The second group $(\mathrm{PP}=0.96)$ can again be split into two subgroups.

The first subgroup (Fig. 17) holds the representatives of P. sects. Arrectae, Rutilantes, Tayloriae, and Durae. As already revealed in earlier studies (e.g. Groth et al., 2002; Groth et al., 2004b), Plagiochila sects. Arrectae and Rutilantes are placed sister to each other (PP = 1.00). At the base of the two sections $P$. sect. Tayloriae can be found ( $\mathrm{PP}=1.00)$. Sister to this clade is $P$. sect. Durae. P. sects. Glaucescentes and Duseniae $(\mathrm{PP}=0.97)$ are nested at the base of this subtree.

The second subgroup (Fig. 18) is made up of the members of Plagiochila sects. Vagae, Plagiochila, Fruticosae, Trabeculatae, Peculiares, Poeltiae, Africanae, Cucullatae, Hylacoetes, Fuscoluteae, and Adiantoideae, as well as $P$. andina. At the base of this group Plagiochila andina, which has no close relatives in this analysis, can be found, followed by a clade of $P$. sect. Hylacoetes $(\mathrm{PP}=1.00)$ and Plagiochila adiantoides ( $P$. sect. Adiantoideae). After that, the supported $P$. sect. Fuscoluteae $(\mathrm{PP}=0.99)$ and Plagiochila cristata $(P$. sect. Adiantoideae) can be found. In the rest of the tree P. sects. Fruticosae, Plagiochila (PP = 0.99), and Plagiochila kiaeri and Plagiochila fusifera [P. sect. Vagae, (Heinrichs et al., 2005a)] are placed in a polytomy at the base of a clade holding the rest of the included 
species. Plagiochila sects. Vagae, Peculiares, Trabeculatae Cucullatae, Poeltiae and Africanae are placed in an unsupported relationship in this group.

Finally, eleven of the eighteen included sections receive good statistical support (Alternantes, Tayloriae, Glaucescentes, Duseniae, Durae, Hylacoetes, Fuscoluteae, Plagiochila, Poeltiae, Trabeculatae, Fruticosae), the other are not statistically supported (Arrectae, Rutilantes, Vagae), or are not monophyletic (Adiantoideae, Cucullatae, Peculiares).

The relationships between the sectional clades, while being congruent with those found in previous studies (Groth et al., 2003; Groth et al., 2004b; e.g. Groth and Heinrichs, 2003), are only partly supported.

Four of the 128 ingroup species (Plagiochila trapezoidea, P. strictifolia, P. kiaeri, P. fusifera) do not group, as was also found in studies using ITS or rps4 ((Heinrichs et al., 2005a), respectively the ITS and rps4 analyses in this study). However, Plagiochila trapezoidea and P. strictifolia are only represented by partial sequences (app. $1000 \mathrm{bp}$ ).

When using a reduced dataset of two species per section only, P. kiaeri and P. fusifera are also better resolved.

\section{Maximum parsimony:}

In the maximum parsimony analyses 92,005 trees were found (1628 steps, $\mathrm{CI}=0.367, \mathrm{RC}=$ $0.245, \mathrm{RI}=0.669$ ). The topology of the strict consensus tree (Figs. $19 / 20$ ) is congruent with the ML tree, including the position of Plagiochila trapezoidea, P. strictifolia, P. kiaeri, and P. fusifera which are misplaced according to earlier studies (Heinrichs et al., 2005a) and the rps4 and ITS analyses of this study. However, they are placed according to the rps 4 and ITS studies in an analysis with a reduced dataset.

Statistical support of the consensus tree is lower than of the ML analysis. While ten of the eighteen included sections receive stable bootstrap support (Trabeculatae, Poeltiae, Plagiochila, Fuscoluteae, Arrectae, Rutilantes, Durae, Hylacoetes, Tayloriae, Alternantes, Duseniae, Glaucescentes) is the rest unsupported (Fruticosae, Cucullatae) or not monophyletic (Vagae, Peculiares, Adiantoideae).

Intersectional relationships are only supported between Plagiochila sects. Arrectae, Rutilantes, and Tayloriae. 


\subsubsection{ITS-region}

\section{Maximum likelihood:}

In the ML-ITS tree $(-\ln L=9251.93627$, Fig. $21 / 22)$ the sole included member of the sister family (Chiloscyphus profundus, Geocalycaceae) of the Plagiochilaceae clusters with the outgroup (Herbertus sendtneri), while Plagiochilaceae itself forms a well supported (PP = 1.00) monophyletic group.

Several clades with representatives of all genera included in this study are found. Plagiochilion (P. mayebarae, P. oppositum), and Chiastocaulon dendroides are laced sister to the reminder of Plagiochilaceae. Pedinophyllopsis abdita, Pedinophyllum interruptum, and Plagiochila radiculosa form a clade which is placed sister to Plagiochila.

The remaining, well supported group ( $\mathrm{PP}=0.97$ ), holds the included representatives of the genus Plagiochila with Proskauera (Proskauera pleurata and Proskauera fruticella) at the base. The rest of the tree can be divided into two clades.

The first clade (Fig. 21) holds the members of Plagiochila sects. Glaucescentes, Duseniae, Alternantes, Durae, Tayloriae, Rutilantes, and Arrectae. The sections are monophyletic (except P. sects. Tayloriae and Durae) and well supported (PP $=0.96-1.00$, except $P$. sects. Tayloriae, Durae, and Duseniae). At the base of the group P. sects. Glaucescentes and Duseniae are placed sister to $P$. sect. Alternantes. Next is an assembly of $P$. sect. Durae (paraphyletic) and P. gymnoclada, member of $P$. sect. Tayloriae [see rps4 and rbcL-trees]. Last is a well supported clade of $P$. sects. Tayloriae (polyphyletic), Rutilantes, and Arrectae $(\mathrm{PP}=1.00)$.

The second clade (Fig. 22) holds the members of Plagiochila sects. Vagae, Africanae, Poeltiae, Cucullatae, Fruticosae, Trabeculatae, Plagiochila, Fuscoluteae, Adiantoideae, and Hylacoetes, as well as P. andina which has no close relatives in this analysis.

Of the relationships between the sectional clades, only two receive statistical support. First is the sister relationship between $P$. sects. Fruticosae and Trabeculatae ( $\mathrm{pP}=1.00)$. Second is the sister relationship between P. sect. Vagae and Africanae [PP $=1.00$, (Heinrichs et al., 2005a)].

Fifteen of the eighteen analysed sections receive good statistical support (except Plagiochila sects. Tayloriae, Duseniae and Durae) and sixteen are resolved as monophyletic (except $P$. sects. Tayloriae and Durae). The relationships between the sections are generally not supported. 


\section{Maximum parsimony:}

During the maximum parsimony analyses 14,917 trees were found (1756 steps, $\mathrm{CI}=0.347$, $\mathrm{RC}=0.220, \mathrm{RI}=0.633$ ). The topology of the strict consensus tree (Figs. 24/25) is congruent with the ML tree. Only Plagiochila trapezoidea is placed at the base of $P$. sect. Poeltiae ( $P$. sect. Plagiochila in the ML analysis, agreeing with the tree of the combined dataset).

Statistical support of the consensus tree is lower than of the ML analysis. While eleven of the eighteen included sections receive stable bootstrap support (Africanae, Fruticosae, Trabeculatae, Peculiares, Poeltiae, Cucullatae, Fuscoluteae, Adiantoideae, Arrectae, Alternantes, Glaucescentes) the rest is unsupported (Vagae, Plagiochila, Hylacoetes, Rutilantes, Durae, Duseniae) or not monophyletic (Tayloriae, Durae). Intersectional relationships are not supported.

\subsubsection{Combined dataset}

Maximum likelihood:

The phylogenies emanating from the analyses of the single genes differ in the positioning of several taxa (see remarks at the single gene analyses). As these incongruences can mostly be resolved when reducing the number of analysed species, they most likely result from too dense a taxon sampling. Thus, it was decided that the datasets should be analysed together, contrary to an ILD test (Farris et al., 1994) contradicting this course of action.

The ML-tree of the combined dataset $(-\ln \mathrm{L}=28254.4415$, Fig. $25 / 26)$ shows a clear demarcation of the Plagiochilaceae from the Geocalycaceae $(\mathrm{PP}=1.00)$. Chiloscyphus profundus is grouped together with the assigned outgroup (Herbertus sendtneri).

. Plagiochilion mayebarae and Plagiochilion oppositum with Chiastocaulon dendroides are placed at the base of Plagiochilaceae. The second clade consists of Pedinophyllopsis abdita and Pedinophyllum interruptum with Plagiochila radiculosa at the base.

The following clade (PP =1.00) holds Proskauera fruticella and Proskauera pleurata. At the base of the remaining tree $(\mathrm{PP}=1.00) P$. sect. Alternantes forms a well supported clade $(\mathrm{PP}=$ 1.00). The rest of the tree can be divided into two groups.

The first group (Fig. 25) holds the representatives of Plagiochila sects. Arrectae, Rutilantes, Tayloriae, Durae, Glaucescentes, and Duseniae. All sections are very well supported (PP = 1.00). As already revealed in earlier studies (e.g. Groth et al., 2002; Groth et al., 2004b), P. 
sects. Arrectae and Rutilantes are sister taxa ( $\mathrm{PP}=1.00)$. At the base of both, $P$. sect. Tayloriae is resolved $(\mathrm{PP}=1.00)$. Sister to this clade is $P$. sect. Durae $(\mathrm{PP}=1.00)$. At the base of the four sections $P$. sects. Glaucescentes $(\mathrm{PP}=1.00)$ and Duseniae are placed.

The second group (Fig. 26) is made up of the members of eleven well supported sections as well as Plagiochila andina (P. sects. Vagae, Africanae, Cucullatae, Plagiochila, Fruticosae, Trabeculatae, Peculiares, Poeltiae, Hylacoetes, Fuscoluteae, Adiantoideae).

At the base $P$. sects. Hylacoetes, Fuscoluteae, and Adiantoideae form a well supported triplet $(\mathrm{PP}=1.00)$. Next is Plagiochila andina, followed by a polytomy $(\mathrm{PP}=1.00)$ holding $P$. sects. Vagae and Africanae ( $\mathrm{PP}=1.00)$, P. sect. Cucullatae, as well as P. sects. Plagiochila, Fruticosae, Trabeculatae, Peculiares, and Poeltiae $(\mathrm{PP}=0.96)$. The relationships inside the latter are not well supported, except for the sister relationship of P. sects. Fruticosae and Trabeculatae $(\mathrm{PP}=1.00)$.

All of the included sections of Plagiochila receive statistical support in the Bayesian analyses (PP from 0.95 to 1.00). Also the relationships between the analysed genera of the Plagiochilaceae and the sections of Plagiochila are mostly well supported.

The ML analyses using one, three, or seven models of evolution resulted in the same topology (Fig. 25 / 26) although the number of statistically supported nodes decreased from 98 (one model) over 97 (three models) to 94 (seven models) (Buckley et al., 2002; Cox et al., 2004; Goffinet et al., 2004). 82 nodes are supported by all approaches.

When $3^{\text {rd }}$ codon position transitions were excluded from the dataset (as suggested by the results of the distance plots; Chapter 4.2) the topology of the resulting ML-tree (using one model of evolution) is identical to the full dataset topology. However, four sections (Plagiochila, Peculiares, Arrectae, Durae) as well as most of the deeper nodes no longer receive statistical support.

This shows that $3^{\text {rd }}$ codon position transitions contain phylogenetic information. By excluding these positions, valuable phylogenetic information is stripped from the dataset (Cox et al., 2004; Yang, 1998). 


\section{Maximum parsimony:}

The maximum parsimony analysis of the combined dataset leads to $17 ; 203$ equally parsimonious trees with a length of 4418 steps $(\mathrm{CI}=0.360, \mathrm{RC}=0.234, \mathrm{RI}=0.651)$. The strict consensus tree (Fig. $27 / 28$ ) is congruent with the ML-tree (Fig. $25 / 26$ ) of the combined dataset. The only difference is the placement of Plagiochila trapezoidea at the base of $P$. sect. Peculiares, instead of $P$. sect. Plagiochila, resolving the latter as polyphyletic.

Apart from Plagiochila sects. Africanae and Peculiares, , all included sections receive good bootstrap support. Of the deeper nodes (Fig. 27), nearly all relationships in the lower part of the tree are supported. Those in the upper half of the tree (Fig. 28), including the relationships between Plagiochila sects. Vagae, Africanae, Cucullatae, Fruticosae, Trabeculatae, Peculiares, Poeltiae, and Plagiochila are unsupported.

\section{Conclusions:}

The ML and MP analyses of the three different markers lead to trees that are statistically supported at different levels, reflecting the variation of the corresponding genes (Groth et al., 2004b; Groth and Heinrichs, 2003; Heinrichs, 2002).

The trees emanating from the MP analyses of the single markers are slightly less resolved and receive less statistical support than their ML counterparts, as the search options had to be restricted due to hardware limitations (see 3.4.5). However, they do not disprove the ML analyses.

The combined, 3-marker dataset leads to very well resolved ML and MP trees that contain more statistically supported nodes than the single marker trees (Fig. 25 / 26) (Groth et al., 2004b; Groth and Heinrichs, 2003).

The results of the homogenous and heterogeneous approaches (using 1, 3, or 7 models of evolution) show that only the number of statistically supported nodes and not the resulting topology were influenced by the number of models used (Fig. 9). The homogenous approach leads to the best supported tree, with the highest number of supported nodes. However, it is not clear whether this reflects true evolutionary history or merely an artefact of the calculation process (Buckley et al., 2002).

The following synonyms proposed earlier based on ITS data and / or morphological data are confirmed by the analyses of the combined dataset as well as the single gene trees: 
Plagiochila punctata (= P. patzschkei, Heinrichs et al., 2005c), P. bicuspidata (= P. rufescens, Groth et al., 2004a), P. porelloides (= P. satoi, So, 2001), and P. sciophila (= P. euryphyllon, So, 2001).

The synonomy of $P$. orbicularis with $P$. ovalifolia proposed by So (2001) is not supported by the molecular data.

Also the synonomy of $P$. duricaulis with $P$. hookeriana (Hässel de Menéndez, 1983; Hässel de Menéndez, 2004) can not be confirmed. However, the DNA voucher of P. hookeriana was based on a preliminary identification.

\subsubsection{Placement of Plagiochila andina Steph.}

The isolated position of Plagiochila andina at the base of the complex of the sections Vagae, Africanae, Cucullatae, Plagiochila, Fruticosae, Trabeculatae, Peculiares, and Poeltiae (PP = 1.00, MP-BT $=88$ ) suggest that this species represents an isolated lineage of the genus. However, the possibility that close relatives exist which have not been sampled yet cannot be ruled out.

Morphologically Plagiochila andina would best be placed in P. sect. Cucullatae. However, its placement in the molecular tree suggests that the similar morphology is the result of parallel evolution. The position of $P$. andina may require the erection of a new section in future. But, as the sporophyte of the species is unknown and only one voucher has been sequenced, this is postponed for later studies.

\subsubsection{Placement of Plagiochila radiculosa Mitt.}

According to molecular data ( $\mathrm{PP}=0.98$, no MP-BT support) Plagiochila radiculosa is sister to a clade outside Plagiochila, comprised of Pedinophyllopsis abdita and Pedinophyllum interruptum.

To retain Plagiochila as a monophyletic group, a new genus could be erected for P. radiculosa. However, no morphological autapomorphies are available (Inoue and Schuster, 1971). Another solution would be to combine P. radiculosa, Pedinophyllopsis abdita, and Pedinophyllum interruptum (and possibly other species of Pedinophyllum) into one genus. Synapomorphic for this group would be rhizoids present on the whole stem surface and not restricted to creeping sectors. However, this feature also occurs in Plagiochilion, P. sects. Peculiares and Poeltiae. Additionally, Pedinophyllum is characterised by 
monoecious condition in contrast to all other taxa of the Plagiochilaceae (Inoue, 1966b) and Pedinophyllopsis abdita is the only species in this clade with asexual reproduction by means of multicellular gemmae as well as brownish oil bodies (Hässel de Menéndez, 1990). Thus, the new genus would be heterogeneous with respect to morphological features characteristic of natural species groups within Plagiochilaceae (Heinrichs, 2002).

A third approach would be the placement of all involved taxa in an expanded genus Plagiochila. However, this would force Chiastocaulon and Plagiochilion to be included into Plagiochila also, as there is no statistical support for the sister relationship between Chiastocaulon / Plagiochilion and Plagiochila / Pedinophyllopsis / Pedinophyllum (Fig. 25 / 27). Also Proskauera would have to be re-included into Plagiochila.

Finally, it might be assumed tat the position of $P$. radiculosa in the tree does not reflect true evolutionary history but is caused by lack of closely related species missing in the dataset. The latter hypothesis is supported by the results of SH-tests analysing the effect on the likelihood score of the tree when repositioning Plagiochila radiculosa at various basal points in the Plagiochilaceae (Tab. 10). The results show that P. radiculosa can be moved to sister position of $P$. sect. Fruticellae, or of the whole ingroup without significantly changing the ML score (Fig. 9). In contrast, a similar repositioning of Pedinophyllum interruptum is not possible without significantly changing the ML score (Fig. 26).

Additionally, the overall number of morphological characters (Appendix, 7.2) shared between $P$. radiculosa and different basal groups in Plagiochilaceae increases as follows:

\begin{tabular}{|l|c|}
\hline Plagiochila radiculosa sister to: & Number of morphological characters shared: \\
\hline Chiastocaulon and Plagiochilion & 19 \\
\hline Pedinophyllopsis and Pedinophyllum & 22 \\
\hline Proskauera & 25 \\
\hline Plagiochila sect. Alternantes & 27 \\
\hline
\end{tabular}

The question as to the closest relative of Plagiochila radiculosa remains unresolved. An immediate relative in New Zealand and Australia, the area of occurrence of $P$. radiculosa, seems to be lacking (Inoue and Schuster, 1971). Since the Plagiochila-flora of southern South America is least well known, a relative might be looked for in this area. 
In view of the above, the placement of Plagiochila radiculosa will not be resolved here, to avoid potentially unnecessary changes in the systematics of the Plagiochilaceae. Further studies, especially on Plagiochilaceae of Patagonia, are recommended.

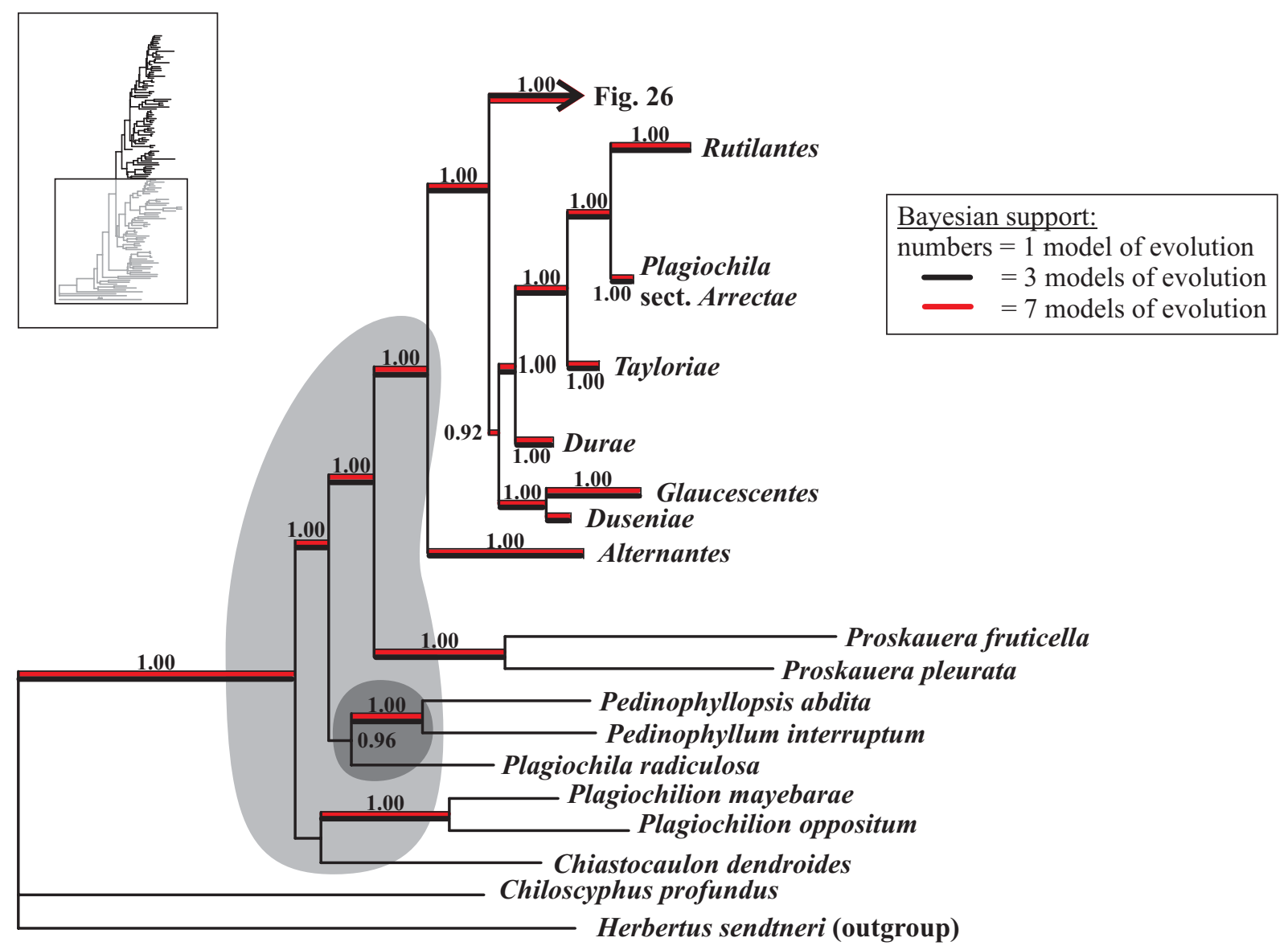

Lower part of the ML tree (combined dataset). Shaded areas indicate possible placements of Plagiochila radiculosa (light grey) and Pedinophyllum interruptum (dark grey), as indicated by SH-tests (Tab. 10 / 11). 
Table 10 Results of SH-tests, comparing the placement of Plagiochila radiculosa at various positions within the original ML tree. P values $<0.05$ indicate rejection of the tested topology.

\begin{tabular}{|c|c|c|c|}
\hline Tree & -ln L & Diff. to best tree & P \\
\hline original ML tree, identical to Fig. 25/26 & 28154.44115 & (best) & - \\
\hline Plagiochila radiculosa sister to Proskauera & 28168.66797 & 14.22683 & 0.245 \\
\hline P. radiculosa sister to Plagiochila and Proskauera & 28158.26714 & 3.82599 & 0.750 \\
\hline P. radiculosa between Plagiochila and Proskauera & 28167.25198 & 12.81083 & 0.275 \\
\hline P. radiculosa sister to P. sect. Alternantes & 28194.43880 & 39.99766 & $0.000^{*}$ \\
\hline P. radiculosa between P. sect. Alternantes and the rest of & 28193.94943 & 39.50828 & $0.000^{*}$ \\
\hline P. radiculosa at the base of Plagiochila, Proskauera, & 28162.52506 & 8.08392 & 0.480 \\
\hline Pedinophyllum, and Pedinophyllopsis & & & 0.330 \\
\hline P. radiculosa at the base of Plagiochilion and Chiastocaulon & 28165.05810 & 10.61696 & 0 \\
\hline
\end{tabular}

Table 11 Results of SH-tests, comparing the placement of Pedinophyllum interruptum at various positions within the original ML tree. $\mathrm{P}$ values $<0.05$ indicate rejection of the tested topology.

\begin{tabular}{|c|c|c|c|}
\hline Tree & $-\ln \mathbf{L}$ & Diff. to best tree & $\mathbf{P}$ \\
\hline original ML tree, identical to Fig. 25 / 26 & 28154.44115 & (best) & - \\
\hline $\begin{array}{c}\text { Pedinophyllum interruptum at the base of Plagiochila } \\
\text { radiculosa and Pedinophyllopsis abdita }\end{array}$ & 28168.27991 & 13.83877 & 0.290 \\
\hline $\begin{array}{c}\text { Pedinophyllum interruptum sister to Plagiochila, Proskauera, } \\
\text { P. radiculosa, and Pedinophyllopsis abdita }\end{array}$ & 28176.68302 & 22.24187 & $0.045^{*}$ \\
\hline $\begin{array}{l}\text { Pedinophyllum interruptum sister to Plagiochila and } \\
\text { Proskauera }\end{array}$ & 28176.68302 & 22.24187 & $0.045^{*}$ \\
\hline $\begin{array}{l}\text { Pedinophyllum interruptum between Plagiochila and } \\
\text { Proskauera }\end{array}$ & 28191.19614 & 36.75500 & $0.005^{*}$ \\
\hline Pedinophyllum interruptum sister to Proskauera & 28191.50525 & 37.06411 & $0.005^{*}$ \\
\hline $\begin{array}{l}\text { Pedinophyllum interruptum between P. sect. Alternantes and } \\
\text { the rest of Plagiochila }\end{array}$ & 28218.63582 & 64.19467 & $0.000 *$ \\
\hline Pedinophyllum interruptum sister to $P$. sect. Alternantes & 28218.63528 & 64.19467 & $0.000 *$ \\
\hline Pedinophyllum interruptum sister to Plagiochilion & 28194.68536 & 40.24421 & $0.005 *$ \\
\hline $\begin{array}{l}\text { Pedinophyllum interruptum sister to Plagiochilion and } \\
\qquad \text { Chiastocaulon }\end{array}$ & 28185.81009 & 31.36894 & $0.000 *$ \\
\hline Pedinophyllum interruptum sister to Plagiochilaceae & 28185.81009 & 31.36894 & $0.000 *$ \\
\hline
\end{tabular}




\subsection{Morphology mapping}

\subsubsection{Morphological delimitation of the genera of the Plagiochilaceae}

Of the nine genera currently accepted in the Plagiochilaceae, seven have been analysed in this study. By mapping the morphological characters of the single species on the ML tree of the 3gene analyses, the morphological concepts of the genera were evaluated (Appendix: 7.3).

The results show that the morphological concepts used to delimitate these genera still hold true (diagnostic characters are underlined).

Acrochila R.M.Schust., Journal of the Hattori Botanical Laboratory 26: 285. 1963.

Four species, one incorporated in this study:

Acrochila biserialis

Morphology:

Branching ventral intercalar, leaves laterally oppressed, underleaves missing, differentiation of a creeping stoloniform that gives rise to leafy shoots, asexual reproduction absent, oil bodies colourless, coarsely segmented, androecia simple, male bracts either free or overlapping in dorsal view, perianth cylindrical, unwinged, capsule shape globose, capsule wall with thickenings in all layers, thickenings of innermost layer ladder like or fenestrate, spores unicellular at time of release, elaters with two spirals.

Chiastocaulon Carl, Flora 126: 58. 1931.

One species incorporated in this study:

Chiastocaulon dendroides

Morphology:

Branching ventral intercalar, underleaves vestigial, differentiation of a creeping stoloniform that gives rise to leafy shoots, rhizoids restricted to creeping stoloniforms, scattered on stem surface, asexual reproduction by means of flabelliform branches, oil bodies colourless, coarsely segmented, androecia simple, perianth shape campanulate, unwinged, capsule shape globose, spores unicellular at time of release, elaters with one or two spirals. 
Pedinophyllopsis R.M.Schust. \& Inoue, Phytologia 47: 311. 1981.

One species incorporated in this study:

Pedinophyllopsis abdita

Morphology:

Branching lateral terminal, leaves laterally oppressed, underleaves well developed, no differentiation of a creeping stoloniform that gives rise to leafy shoots, rhizoids on creeping and arising shoots, scattered on stem surface, asexual reproduction by multicellular gemmae, oil bodies brownish, fine papillose, androecia simple, perianth shape campanulate, unwinged, capsule shape globose, capsule walls with thickenings in all layers, innermost layer ladder like or fenestrate, spores unicellular at time of release, elaters with two (three) spirals.

Pedinophyllum Lindenb., Bot. Not. :156. 1874.

Four species, one incorporated in this study:

Pedinophyllum interruptum

Morphology:

Branching lateral intercalar, no differentiation of a creeping stoloniform that gives rise to leafy shoots, rhizoids on creeping and arising shoots, scattered on stem surface, asexual reproduction missing, oil bodies colourless, fine papillose, $\underline{\text { monoecious, }}$ androecia simple, opposite male bracts free in dorsal view, perianth shape campanulate, mouth sometimes entire, perianth unwinged, capsule shape globose, capsule wall with thickenings in all layers, innermost layer with ladder like or fenestrate thickenings, spores unicellular at time of release, elaters bispiral.

Plagiochila Dumort., Recueil d'Observations sur les Jungermanniacées 14. 1835.

Approximately 450 species, 125 incorporated in this study:

see Tab. 7.1

$\underline{\text { dioecious, }} \underline{\text { laterally compressed perianth with dorsal keel (usually slightly longer then the }}$ ventral one), alternating (rarely opposite) leaves, branching lateral. 
Plagiochilion S.Hatt., Biosphaera 1:7. 1947.

Thirteen species, two incorporated in this study:

Plagiochilion mayebarae, Plagiochilion oppositum

Morphology:

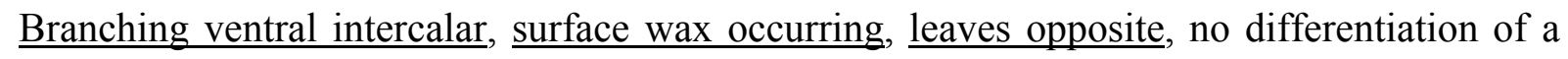
creeping stoloniform that gives rise to leafy shoots, rhizoids present on creeping and arising $\underline{\text { shoots, }}$ rhizoids fasciculated at ventral leaf bases, asexual reproduction missing, androecia simple, perianth shape cylindrical or campanulate, perianth unwinged, capsule shape globose, spores unicellular at time of release, elaters bispiral.

Proskauera Heinrichs \& J.J. Engel, Plant Systematics and Evolution 258: 235. 2006

Species incorporated in this study:

Plagiochila fruticella, P. pleurata

Morphological delimitation:

Branching lateral either terminal or intercalar, leaf surface with spherical papillae, no differentiation of creeping stoloniform, rhizoids restricted to creeping sectors of shoots, asexual reproduction absent, oil bodies colourless, fine papillose, androecia simple, male bracts free in dorsal view, perianth shape subrotundate or cylindrical to campanulate, with two or more keels, dorsal keel with one wing (Pr. fruticella) or unwinged, ventral keel always unwinged, capsule shape globose, capsule wall with thickenings in all layers, thickenings of $\underline{\text { innermost layer ladder like or fenestrate, }}$, spores unicellular at time of release, elaters bispiral.

\subsubsection{Morphological delimitation of the sections of Plagiochila}

The species analysed in this and earlier studies (e.g. Groth et al., 2003; Groth et al., 2004b; Heinrichs et al., 2005a; Heinrichs, 2002) can be grouped in 19 natural groups referred to as sections. Three sections (Tayloriae, Duseniae, Fruticellae) are mentioned for the first time in molecular studies.

The morphology of the sections is given as resulted from morphology mapping (Appendix: 7.3). Relevant characters are underlined, characters in [brackets] only known for a few species. Notes on the sections are given below the definitions. 
Plagiochila sect. Adiantoideae Lindenb., Spec. Hepat. V. 1843.

Species incorporated in this study:

Plagiochila adiantoides, P. cristata

Morphological delimitation:

Lateral intercalar branching dominating, leaves sometimes with ill defined vitta, leaf surface smooth, differentiation of a creeping stoloniform that gives rise to leafy shoots, rhizoids present on creeping shoots only, asexual reproduction rarely by caducous leaves, oil bodies colourless or opaque, coarsely segmented, androecia simple, opposite male bracts in dorsal view in most cases overlapping, perianth shape cylindrical, completely unwinged, seta short, capsule globose, epidermal and innermost layer of capsule wall with thickenings, thickenings of innermost layer of capsule wall variable, spores unicellular (rarely multicellular) at time of release, sporoderm baculate, elaters rough, with two spirals.

Plagiochila sect. Africanae Heinrichs, Taxon 54: 319. 2005.

Species incorporated in this study:

Plagiochila barteri, P. colorans

Morphological delimitation:

Branching lateral intercalar, leaves with ill defined vitta, surface smooth, differentiation of a creeping stoloniform that gives rise to leafy shoots, rhizoids only on creeping shoots, asexual reproduction absent, oil bodies colourless, papillose, androecia simple, perianth cylindrical, $\underline{\text { unwinged, }} \underline{\text { cell walls of epidermal layer with thickenings, innermost layer with ladder-like }}$ thickenings, sporoderm baculate, elaters bispiral, smooth.

Plagiochila sect. Alternantes Carl, Ann. Bryol. 2: 75. 1931.

Species incorporated in this study:

Plagiochila alternans, P. banksiana, P. chonotica, P. cymbiformis, P. duricaulis, P. gigantea, P. gregaria, $P$. hookeriana, $P$. latifrons, $P$. minutula, $P$. nobilis, $P$. ovata, $P$. retrospectans Morphological delimitation:

Branching lateral intercalar, leaves usually wide spreading, rarely laterally oppressed, leaf surface smooth, with or without differentiation of a creeping stoloniform that gives rise to leafy shoots, rhizoids restricted to lower parts of plants, rarely absent, asexual reproduction absent, oil bodies fine papillose to coarsely segmented, rarely homogenous, colourless, androecia generally simple, rarely fan shaped or gregarious (P. gregaria), male bracts in dorsal view free or overlapping, perianth shape cylindrical to campanulate ( $P$. banksiana, $P$. 
gregaria), perianths unwinged, dorsal keel of campanulate perianths with one wing, occasionally also ventral keel winged, seta long sometimes short, capsule shape cylindrical, capsule walls with thickenings in all layers, thickenings of innermost layer either discrete or completely confluent, spores unicellular at time of release, sporoderm verrucate vermiculate, elaters with two spirals, surface smooth.

Plagiochila sect. Arrectae Carl, Ann. Bryol. 2: 52. 1931.

Species incorporated in this study:

Plagiochila bifaria, P. bispinosa, P. lunata, P. pachyloma, P. punctata, P. retrorsa, P. rubescens, $P$. spinulosa, $P$. stricta

Morphological delimitation:

Branching lateral intercalar, distinct or ill defined vitta mostly present, leaf surface with small papilla or smooth, differentiation into creeping stoloniform that gives rise to leafy shoots, rhizoids restricted to creeping sectors of shoots, asexual reproduction by caducous leaves sometimes present, oil bodies colourless, homogenous to (rarely) coarsely segmented, androecia simple, male bracts overlapping in dorsal view, perianth completely covered by female bracts, perianth shape cylindrical to campanulate, with one dorsal and very rarely $(P$. trichostoma) with one ventral wing, capsule shape globose, valves with thickenings in all layers, Thickenings of innermost layer nodulose or discrete or confluent at base, spores unicellular at time of release, sporoderm baculate, elaters rough, with one or two spirals.

Plagiochila sect. Cucullatae Schiffner. Denkschr. Kaiserl. Akad. Wiss., Math.-Naturwiss. K1. 70: 160.1900 .

Species incorporated in this study:

Plagiochila bantamensis, P. integerrima, P. sandei, P. sciophila (Japan, USA), P. subplana Morphological delimitation:

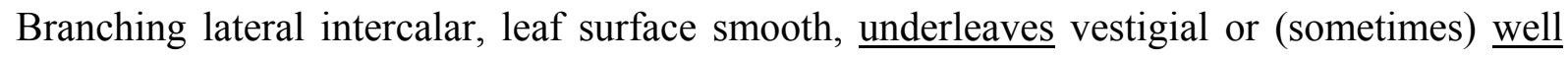
developed, rarely with paraphyllia on dorsal stem surface ( $P$. bantamensis), differentiation into creeping stoloniform that gives rise to leafy shoots, rhizoids restricted to creeping sectors of shoots, asexual reproduction absent, [oil bodies colourless, fine papillose,] androecia simple, rarely fan shaped ( $P$. bantamensis, $P$. sandei), opposite male bracts free in dorsal view (overlapping in $P$. integerrima), perianth cylindrical, rarely campanulate ( $P$. sciophila), keels unwinged, capsule shape globose, epidermal layer of capsule wall without thickenings, 
innermost layer with ladder like or fenestrate thickenings, spores unicellular at time of release, [sporoderm verrucate or baculate, elaters smooth] with two spirals.

Except for Plagiochila sciophila, all representatives of section Cucullatae possess a pseudocuculum (Heinrichs, 2002; Heinrichs et al., 2004c).

Plagiochila sect. Durae Carl, Ann. Bryol. 2: 123. 1931.

New synonyms: Plagiochila section Hirtae Carl, Ann. Bryol. 2: 122. 1931. Type: Plagiochila hirta Taylor.

Species incorporated in this study:

Plagiochila crozetensis, P. dura, P. heterodonta, P. bicornuta, P. deltoidea, P. hirta, P. ramosissima

Morphological delimitation:

Branching exclusively lateral intercalar, leaves mostly with ill defined vitta, surface smooth, differentiation into creeping stoloniform that gives rise to leafy shoots absent (only in P. ramosissima), rhizoids restricted to creeping sectors of shoots, asexual reproduction unknown, oil bodies colourless, coarsely segmented, androecia simple, opposite male bracts overlapping in dorsal view, perianth shape cylindrical or campanulate, dorsal keel with one wing, capsule shape globose, capsule wall with thickenings in all layers, those of innermost layer ladder like or fenestrate, spores unicellular at time of release, [sporoderm verrucate (only P. ramosissima known),] elaters with two spirals.

In his morphological circumscription Carl (1931a) stressed the small cells with strong, equally thickenings in P. dura as a character for the section. Recent work revealed that P. dura is the only known species with this feature (Groth et al., 2004b).

Plagiochila sect. Duseniae Carl, Ann. Bryol. 2: 126. 1931

Species incorporated in this study:

Plagiochila dusenii, Plagiochila validissima

Morphological delimitation:

Branching exclusively lateral intercalar, leaves with well defined vitta, leaf surface smooth, underleaves vestigial, [P. dusenii with paraphyllia on dorsal stem surface], differentiation into creeping stoloniform that gives rise to leafy shoots, rhizoids restricted to creeping sectors of shoots, asexual reproduction unknown, oil bodies colourless, fine papillose, androecia simple, 
perianth cylindrical to campanulate, unwinged, seta short, capsule shape globose, capsule wall with thickenings in all layers, thickenings of innermost layer ladder like or fenestrate, spores $\underline{\text { unicellular at time of release, sporoderm baculate, elaters with one or two spirals, surface }}$ rough.

Plagiochila sect. Fruticosae Inoue, The genus Plagiochila (Dum.) Dum. in Southeast Asia, 50. 1984

Species incorporated in this study:

Plagiochila frondescens, P. fruticosa, P. pulcherrima

Morphological delimitation:

Branching lateral intercalar or rarely lateral terminal (P. frondescens), leaf surface smooth, underleaves vestigial or well developed ( $P$. pulcherrima), paraphyllia absent or occurring on whole stem surface ( $P$. pulcherrima), differentiation into creeping stoloniform that gives rise to leafy shoots, rhizoids restricted to creeping stoloniforms, asexual reproduction generally absent, rarely by means of flabelliform branches (P. pulcherrima), [oil bodies unknown,] androecia simple, opposite male bracts overlapping in dorsal view, perianth cylindrical, perianths unwinged or dorsal keel with one wing (P. pulcherrima), seta short, capsule anatomy, elaters and spores unknown.

Plagiochila sect. Fuscoluteae Carl, Ann. Bryol. 2: 46. 1931.

Species incorporated in this study:

Plagiochila aerea, P. fuscolutea, P. heterophylla, P. longiramea, P. tabinensis

Morphological delimitation:

Branching type lateral intercalar or lateral terminal, plants with surface wax, leaves rarely with distinct or ill defined vitta, underleaves vestigial or well developed ( $P$. aerea, $P$. tabinensis), paraphyllia absent, only $P$. longiramea with paraphyllia on dorsal stem surface, differentiation into creeping stoloniform that gives rise to leafy shoots, rhizoids restricted to creeping stoloniforms, asexual reproduction unknown, oil bodies colourless, fine papillose, androecia simple, opposite male bracts overlapping in dorsal view, perianth shape cylindrical (campanulate in P. tabinensis), dorsal keel with one wing, seta short, capsule shape globose, capsule wall with thickenings in all layers, innermost layer with ladder like or fenestrate $\underline{\text { thickenings, }}$, spores at time of release unicellular, sporoderm baculate, elaters smooth with two spirals (P. aerea occasionally with one spiral). 
Plagiochila sect. Glaucescentes Carl, Ann. Bryol. 2: 70. 1931.

Species incorporated in this study:

Plagiochila buchtiniana, P. diversifolia,

Morphological delimitation:

Branching dominantly lateral terminal, leaves rarely with ill defined vitta, underleaves well developed, paraphyllia absent, differentiation into creeping stoloniform that gives rise to leafy shoots, rhizoids restricted to creeping stoloniforms, asexual reproduction unknown, oil bodies brownish, androecia simple, opposite male bracts free in dorsal view, perianth shape campanulate, dorsal keel with one wing, capsule shape globose, epidermal layer with thickenings, innermost layer hyaline, spores multicellular at time of release, sporoderm structure echinate baculate, elater surface smooth, with one to two spirals.

Plagiochila sect. Hylacoetes Carl, Ann. Bryol. 2: 43, 50. 1931.

Species incorporated in this study:

Plagiochila cucullifolia, P. ensiformis, P. flabelliflora, P. macrostachya, P. patriciae, P. superba, P. turgida, $P$. vincentina

Morphological delimitation:

Branching lateral intercalar (terminal branches occurring in P. vincentina), most species with ill defined vitta, leaf position alternating, some species with sub-opposite leaves ( $P$. turgida, P. macrostachya, $P$. flabelliflora), differentiation into creeping stoloniform that gives rise to leafy shoots, rhizoids restricted to creeping stoloniforms, asexual reproduction by caducous leaves frequent, oil bodies colourless or greenish ( . cucullifolia, $P$. turgida), fine papillose (to coarsely segmented), androecia fan shaped or gregarious, opposite male bracts free in dorsal view, rarely overlapping ( $P$. cucullifolia, $P$. ensiformis), perianth shape cylindrical (cylindrical - campanulate in P. ensiformis), dorsal keel with one wing (two in P. ensiformis), ventral keel unwinged, capsule shape globose, epidermal layer of capsule wall without thickenings, innermost layer with ladder like or fenestrate thickenings, spores unicellular at time of release (multicellular in P. cucullifolia), sporoderm baculate, elater surface smooth or rough, elaters with two, sometimes more spirals ( . cucullifolia, P. patriciae, P. turgida). 
Plagiochila sect. Peculiares Schiffner, Denkschr. Kaiserl. Akad. Wiss., Math.-Naturwiss. K1. 70: 160.1900 .

Species incorporated in this study:

Plagiochila magna, $P$. peculiares, $P$. renitens, $P$. semidecurrens

Morphological delimitation:

Branching type exclusively lateral intercalar, leaves with distinct vitta, no differentiation into creeping stoloniform that gives rise to leafy shoots, rhizoids not restricted to creeping shoots, asexual reproduction unknown, oil bodies colourless, androecia simple, [opposite male bracts overlapping,] perianth shape cylindrical, generally unwinged, only P. renitens with winged dorsal keel.

\section{Plagiochila sect. Plagiochila}

Species incorporated in this study:

Plagiochila asplenioides, P. britannica, P. hakkodensis, P. korthalsiana, P. orbicularis, P. ovalifolia, P. porelloides, P. trapezoidea

Morphological delimitation:

Branching exclusively lateral intercalar, leaves without vitta (except $P$. trapezoidea), paraphyllia absent (only $P$. trapezoidea with paraphyllia on dorsal stem surface), no differentiation into creeping stoloniform that gives rise to leafy shoots, rhizoids restricted to creeping stem sectors (only P. hakkodensis with rhizoids also on rising shoots), asexual reproduction unknown, oil bodies colourless, fine papillose to coarsely segmented, androecia simple (sometimes somewhat gregarious in P. trapezoidea), opposite male bracts overlapping in dorsal view, perianth shape cylindrical, unwinged (P. trapezoidea with winged dorsal keel), seta long, capsule elongated, capsule wall with thickenings in all layers (only P. trapezoidea with hyaline epidermis), innermost layer with ladder like or fenestrate thickenings, spores unicellular at time of release, sporoderm verrucate, elater surface smooth with two spirals $(P$. ovalifolia occasionally with three).

Plagiochila sect. Poeltiae Inoue, Bull. Natl. Sci. Mus., Tokyo 8: 39. 1965.

Species incorporated in this study:

Plagiochila carringtonii ssp. lobuchensis, $P$. poeltii

Morphological delimitation:

Branching type exclusively lateral intercalar, leaves laterally oppressed, paraphyllia absent or on dorsal stem surface, differentiation into creeping stoloniform that gives rise to leafy shoots 
occurring or not, rhizoids present on creeping and arising shoots, asexual reproduction unknown, oil bodies colourless, fine papillose, androecia simple, opposite male bracts overlapping in dorsal view, perianth shape cylindrical, perianth unwinged only occasionally with dorsal keel winged ( $P$. poeltii).

Plagiochila sect. Rutilantes Carl, Ann. Bryol. 2: 74. 1931.

Species incorporated in this study:

Plagiochila bicuspidata, P. exigua, P. gymnocalycina, P. maderensis, P. oresitropha, P. rutilans var. moritziana, $P$. rutilans var. rutilans, $P$. trichostoma

Morphological delimitation:

Branching exclusively lateral intercalar, leaves rarely with ill defined ( $P$. gymnocalycina) or distinct vitta (P. trichostoma, P. maderensis), differentiation into creeping stoloniform that gives rise to leafy shoots (not in $P$. exigua), rhizoids restricted to creeping stoloniforms (only P. exigua with rhizoids on creeping and rising shoots), cuticle smooth, asexual reproduction by means of caducous leaves frequent, oil bodies colourless, homogenous to coarsely segmented, [some species with distinct odour of peppermint], androecia simple, opposite male bracts overlapping or free in dorsal view, perianth cylindrical (campanulate in P. exigua), perianth unwinged ( $P$. trichostoma with winged dorsal keel) not, or only basally covered by $\underline{\text { female bracts, }}$ capsule globose, capsule walls with thickenings in all layers, $\underline{\text { innermost layer }}$ with nodulose or discrete or confluent thickenings, spores unicellular at time of release, sporoderm baculate, elaters smooth or rough with one or to spirals.

Plagiochila sect. Tayloriae Carl, Ann. Bryol. suppl. 2: 140. 1931.

New synonyms: Plagiochila sect. Annotinae Carl, Ann. Bryol. suppl. 2:143. 1931. Type: Plagiochila annotina Lindenb.

Species incorporated in this study:

Plagiochila annotina, P. circinalis, P. fasciculata, P. fusca, P. gymnoclada, P. lyallii, P. stephensoniana

Morphological delimitation:

Branching lateral intercalar, rarely with lateral terminal (mostly fertile) branches (P. fasciculata, P. stephensoniana, P. lyallii), leaves wide spreading (P. circinalis with laterally oppressed leaves), ill defined vitta frequently occurring, differentiation into creeping stoloniform that gives rise to leafy shoots (except P. gymnoclada, P. lyallii), rhizoids restricted to creeping sectors of shoots, asexual reproduction unknown, oil bodies colourless, 
[fine papillose to coarsely segmented,] androecia fan shapes or gregarious (simple in P. annotina), opposite male bracts overlapping in dorsal view (free in P. gymnoclada), perianth shape cylindrical (subrotundate in P. stephensoniana), dorsal keel of perianth with one wing, ventral keel with one wing or unwinged ( $P$. fusca, P. lyallii), capsule globose, capsule wall with thickenings in all layers, innermost layer with ladder like or fenestrate to nodulose or discrete or confluent thickenings, spores unicellular at time of release (multicellular in P. annotina), elaters with two spirals.

The section has already been redefined by Inoue and Schuster (1971). The morphological definition is here extended and species formerly assigned to other sections have been included.

The species assigned to section Annotinae by Inoue and Schuster (1971) other than P. annotina tentatively fit into section Tayloriae (P. circumdentata with gregarious androecia, P. baylisii with rare terminal branches bearing perianths). However, the morphological evidence is inconsistent.

Plagiochila sect. Trabeculatae S.Hatt. ex Inoue, Journal of the Hattori Botanical Laboratory 20: 75.1958.

Species incorporated in this study:

Plagiochila flexuosa, P. trabeculata

Morphological delimitation:

Branching exclusively lateral intercalar, differentiation into creeping stoloniform that gives rise to leafy shoots present or not, rhizoids restricted to creeping shoots or not, asexual reproduction unknown, androecia simple, opposite male bracts overlapping in dorsal view, perianth shape campanulate, perianth unwinged ( $P$. trabeculata) or with winged dorsal and ventral keel ( $P$. flexuosa), capsule shape globose, spores unicellular at time of release, elaters with two spirals.

Plagiochila sect. Vagae Lindenb. Species Hepatarum (fasc. 5): XV. 1843.

Species incorporated in this study:

Plagiochila abietina, P. angustitexta, P. arbuscula, P. corrugata, P. deflexirama, P. disticha, $P$. divergens, $P$. effusa, $P$. ericicola, $P$. fastigiata, $P$. fusifera, $P$. heterostipa, $P$. incerta, $P$. javanica, P. junghuniana, P. kiaeri, P. lastii, P. massalongoana, P. montagnei, P. obtusa, P. 
parvifolia, P. patentissima, $P$. raddiana, P. salacensis, $P$. streimannii, $P$. strictifolia, $P$. squamulosa, P. subtropica, P. teysmanii

Morphological delimitation:

Branching lateral terminal, leaves wide spreading (laterally oppressed in P. abietina), underleaves vestigial or well developed, paraphyllia rare ( $P$. abietina, P. obtusa), differentiation into creeping stoloniform that gives rise to leafy shoots present or not, rhizoids restricted to creeping shoots (in P. obtusa, P. salacensis, P. subtropica although on arising shoots), asexual reproduction by means of propagules (except P. abietina, P. propinqua, P. salacensis, P. arbuscula), asexual reproduction by means of caducous leaves rare (P. massalongoana, P. salacensis, P. parvifolia, P. subtropica), [oil bodies colourless, coarsely segmented,] androecia simple, [opposite male bracts overlapping in dorsal view (free in P. fusifera, P. parvifolia)], perianth shape cylindrical or campanulate, dorsal keel with one wing (unwinged in P. effusa, P. abietina, P. corrugata, P. massalongoana, P. arbuscula), P. salacensis although with winged ventral keel, capsule globose, [capsule walls with thickenings in all layers, thickenings of innermost layers mixed, spores uni- or multicellular at time of release, sporoderm verrucate or baculate, elaters rough or smooth, with one or two spirals]. 


\subsubsection{Distribution of homoplastic, synapomorphic, and autapomorphic morphological characters in Plagiochila / Plagiochilaceae}

The family Plagiochilaceae has long been known for its notorious morphological plasticity (Carl, 1931a; Heinrichs, 2002; Inoue, 1984; Inoue and Schuster, 1971; So, 2001). Therefore, morphological characters synapomorphic for natural groups in this family are scarce. By morphology mapping on the tree the distribution of morphological characters on the tree their synapomorphic / homoplastic states within Plagiochilaceae are shown.

(The ML tree of the combined dataset [Figs. 25/26] is here treated as the "true" evolutionary history on which the characters are plotted. Nevertheless, it is obvious to the author that it only represents one likely history, based on the data incorporated in this study and the methods used in achieving this phylogeny.)

The 34 morphological characters incorporated in this study were inspected with respect to their homoplastic, synapomorphic, and autapomorphic nature, regarding the species analysed in this study.

Regarding the species analysed in this study five characters could be identified as synapomorphic for natural species groups in Plagiochilaceae.

However, when taking in account species analysed in earlier studies, two character states can no longer be regarded as synapomorphic. Thus, Plagiochila boryana, member of section Hylacoetes also possesses (flat) papillae on the leaf surface (Heinrichs et al., 2005a) otherwise only known from members of section Arrectae regarding the species analysed in this study. Additionally, the only synapomorphic character of the family of Plagiochilaceae, the twokeeled perianths, are also known from other Hepaticae [e.g. Geocalycaceae, (Schuster and Engel, 1982)].

Thus, only three synapomorphic characters remain for natural species groups in Plagiochilaceae, one gametophytic and two sporophytic ones. However, the total number of morphological characters is quite small and the sporophytic features are only partly known (Appendix, 7.2). 
$\underline{\text { Synapomorphic characters of the gametophyte }}$

1. Leaf surface: (0) smooth, (1) with small papillae, (2) with spherical papillae (synapomorphy of Proskauera)

\section{Synapomorphic characters of the sporophyte}

1. Sporoderm structure: (0) verrucate, (1) baculate, (2) echinate - baculate (synapomorphy of Plagiochila sect. Glaucescentes)

2. innermost layer of capsule wall: (0) with thickenings, (1) without thickenings (synapomorphy of Plagiochila sect. Glaucescentes)

Autapomorphic characters are also rare in Plagiochilaceae. Of the analysed species only Plagiochila dura [small cells with strong, equally thickenings (Carl, 1931a)] and Proskauera pleurata [pluriplicate perianth (Inoue and Schuster, 1971)] can be identified by autapomorphic characters.

Homoplastic characters are common in Plagiochilaceae. While some are largely restricted to few sections or genera and only appear in a few species outside of this groups (e.g. terminal branching, fan-shaped androecia), others are scattered over the tree and have been evolved and lost multiple times (e.g. laterally oppressed leaves, coarsely segmented or fine papillose oil bodies).

The morphological plasticity in Plagiochilaceae is so large that not only single characters are homoplastic between natural groups but complete character sets. For example, Plagiochila sect. Plagiochila and P. sect. Alternantes share the same set of morphological features but are only distantly related according to molecular studies (Fig. 25 / 26).

Homoplasy of morphological characters in spore plants is not uncommon as studies in other groups [e.g. Amblystegiaceae (Vanderpoorten et al., 2002) and Grammitidaceae (Ranker et al., 2004)] reveal. It occurs to such an extent that natural groups identified on the base of genetic markers sometimes cannot satisfactorily be defined by morphology (Vanderpoorten et al., 2002). However, in other cases it has been shown that morphological characters that were hitherto neglected are informative for phylogenetic analyses (Heinrichs et al., 2000b; Ranker et al., 2004). 


\subsubsection{Usefulness of different morphological markers at different taxonomical levels in Plagiochilaceae (and other groups)}

Evaluating the results of the morphology mapping it appears that some of the characters used in this study are more fit to discriminate natural groups below genus level (e.g. occurrence of a vitta, leaf surface, mode of asexual reproduction, androecia [simple or fan-shaped], length of seta, capsule shape, distribution and form of thickenings in the capsule walls) while others only vary among the genera (insertion of rhizoids, sexual condition) or families (number of perianth keels). Some are able to separate groups at different taxonomical levels (branching type, occurrence of surface wax, leaf position, position of rhizoids, colour of oil bodies).

Most of the studied characters are fit to discriminate natural groups below genus level, only a few allow for separating the genera of Plagiochilaceae.

Comparing the taxonomic power of sporophytic and gametophytic characters, the value of sporophytic characters seems to be restricted to taxonomical questions below genus level, in those of the gametophyte to all levels from species to family. These findings are consistent with similar work on Amblystegiaceae (Vanderpoorten et al., 2002), where it was shown that sporophytic characters were not fit to answer taxonomical questions above genus level, as they mostly represent adaptations to the habitat. The opposite, however, is true in Lejeuneaceae and most other families of Liverworts, were sporophytic characters are more conservative, as the sporophyte is well protected from environmental pressure by gametophytic structures (Gradstein, 1975; Gradstein, 1994; Gradstein et al., 2003). 


\subsection{Biogeography}

The results of the biogeographical analyses vary only slightly between the five different step matrices used to define dispersal costs. All reconstructions agree in the basic dispersal patterns, with the exception of the colonization of Africa that has either been reached directly from South America (Matrix I \& IV) or via the northern hemisphere (Matrix II, III \& V). Both possibilities have been discussed in literature (Davis et al., 2002; Renner, 2004; van Zanten and Gradstein, 1988). However, it should be kept in mind that the presented results are based on a static model ignoring continental drift, changes in wind currents, as well as prehistoric climates. The observed distribution patterns may be based on completely different dispersal and extinction events.

\subsubsection{Current and historical distribution of the sections of Plagiochila}

The current distribution of the sections of Plagiochila are achieved by plotting the distribution of the analysed species on the ML tree (Figs. 25 / 26). Hypothetical historical distributions are reconstructed using MacClade (Ballard and Sytsma, 2000; Maddison and Maddison, 2000). Maps of the current distribution for the sections of Plagiochila are given. The assumed origin of the sections as well as different migration and colonization events are indicated as deducted from MacClade analyses. Distributions of species not analysed in this study are shaded in light grey. 


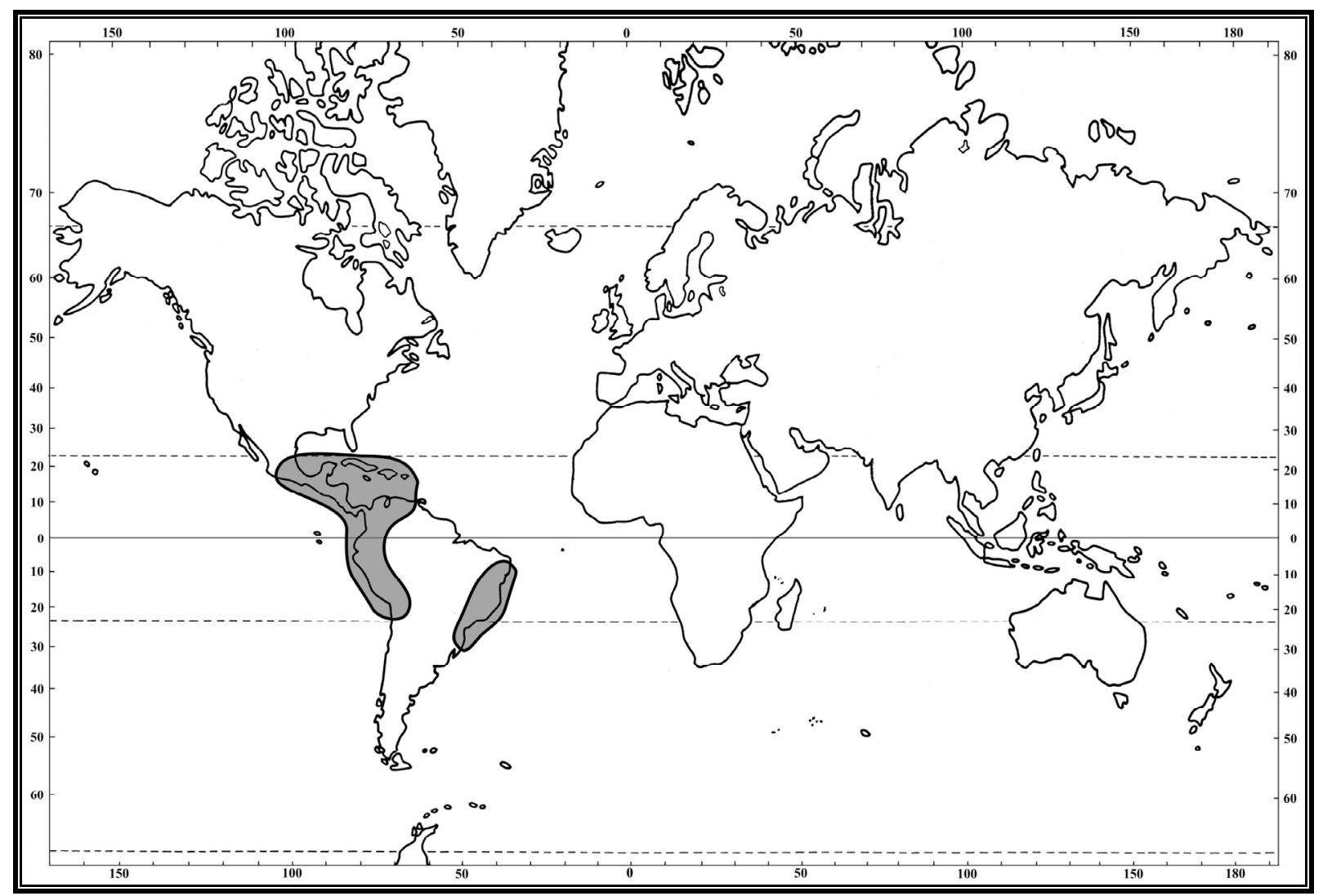

Distribution of Plagiochila sect. Adiantoideae

The section occurs in Central America, the West Indies, northern South America, and SE Brazil. It has possibly originated in northern South America. 


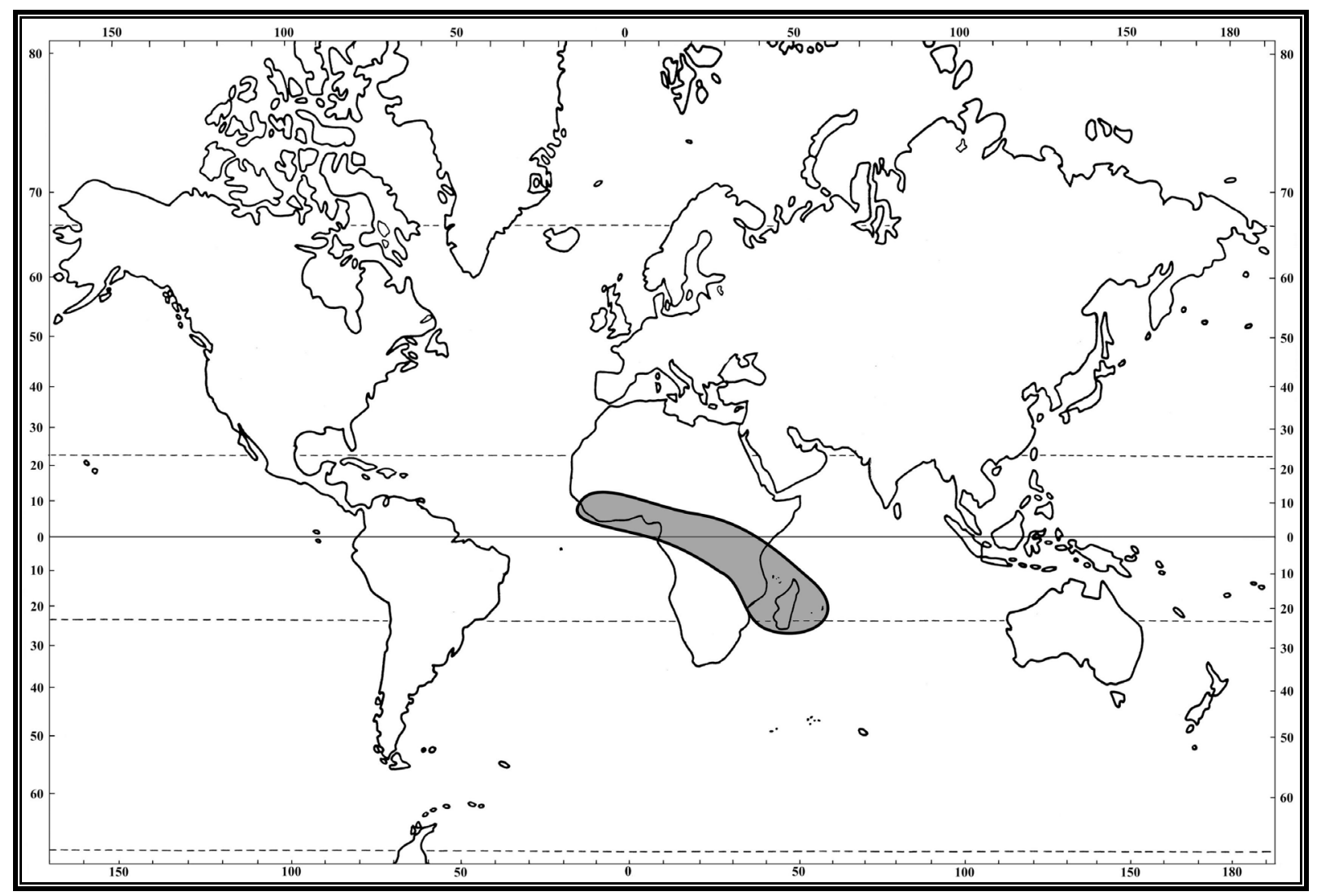

Distribution of Plagiochila sect. Africanae

The section is the only section of Plagiochila restricted to Africa and Madagascar. It occurs from western over central Africa to Madagascar, reaching as far eastwards as Reunion. It has possibly originated in East Africa. 


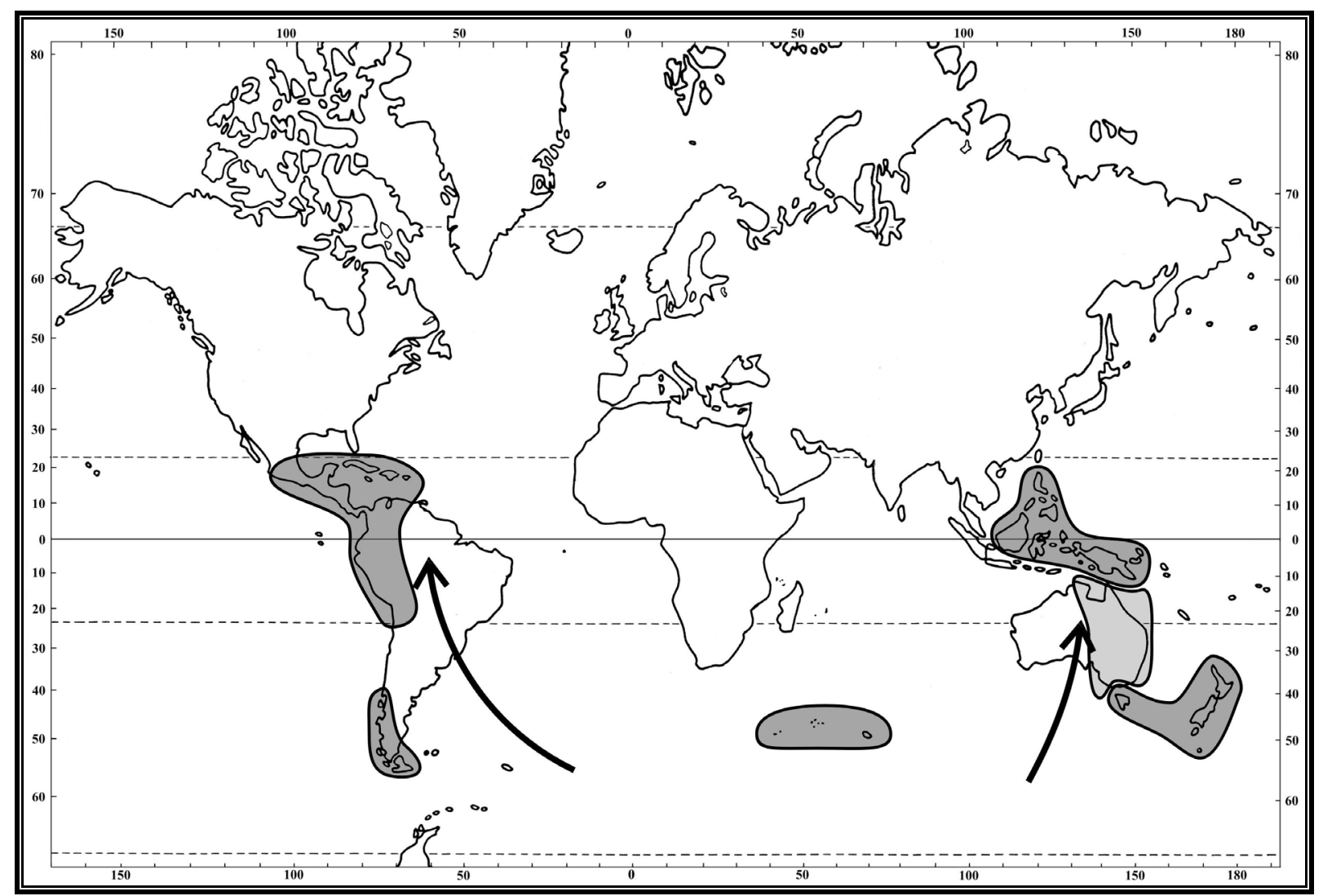

Distribution of Plagiochila sect. Alternantes

The relationships between the species in the section are generally not statistically supported. Therefore, it is difficult to reconstruct the historical distribution of this group. However, the MacClade reconstructions suggest an origin in Antarctica / New Zealand from which South America and Asia have been colonized later. Several species occur also in Australia. 


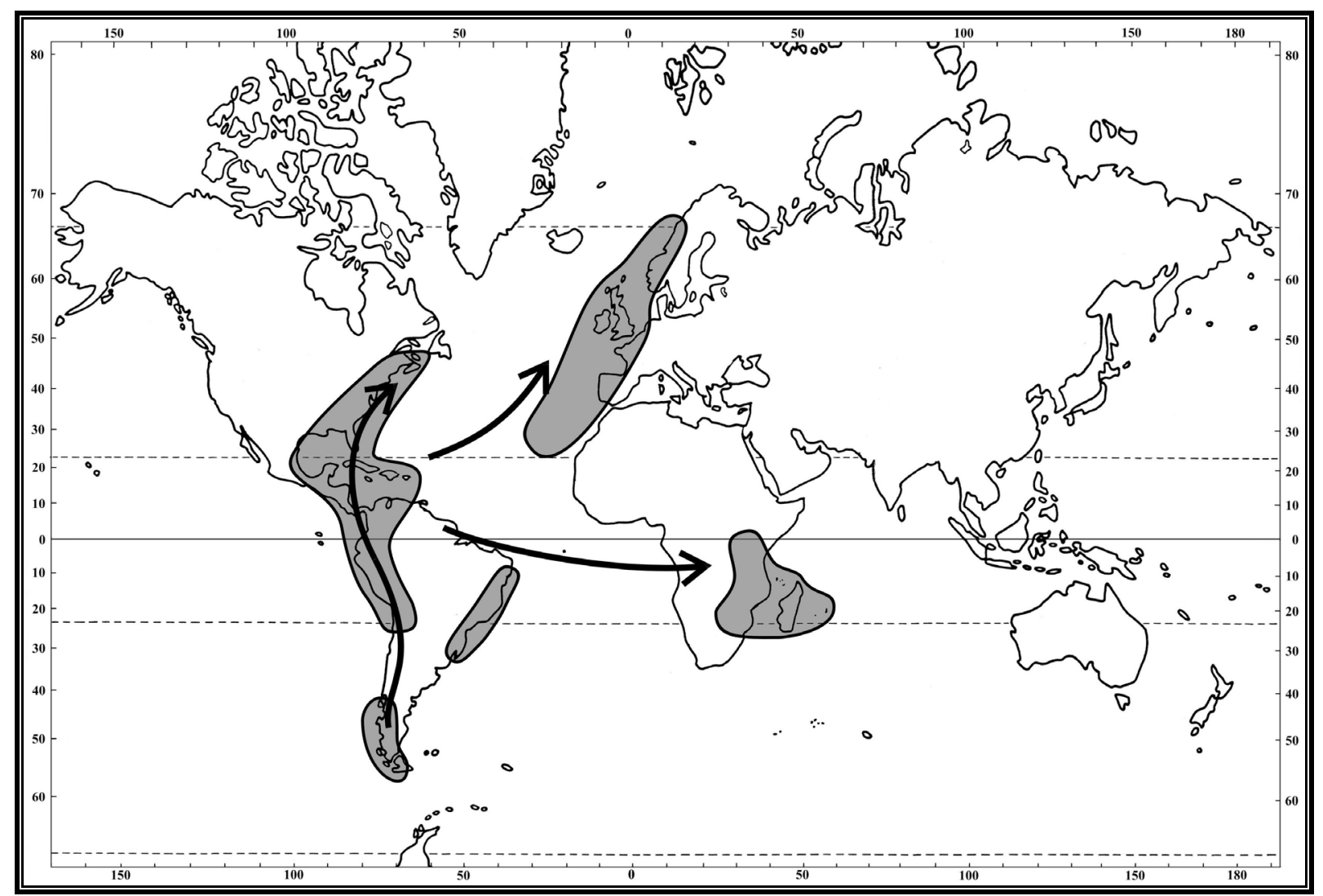

Distribution of Plagiochila sect. Arrectae

According to the MacClade reconstructions Plagiochila sect. Arrectae has colonized America from Patagonia reaching as far as East North America. Europe and Africa have been reached later, probably by long range dispersal events (Lindner et al., 2004). P. lunata (Africa) has most likely spread from $P$. spinulosa-like ancestors. 


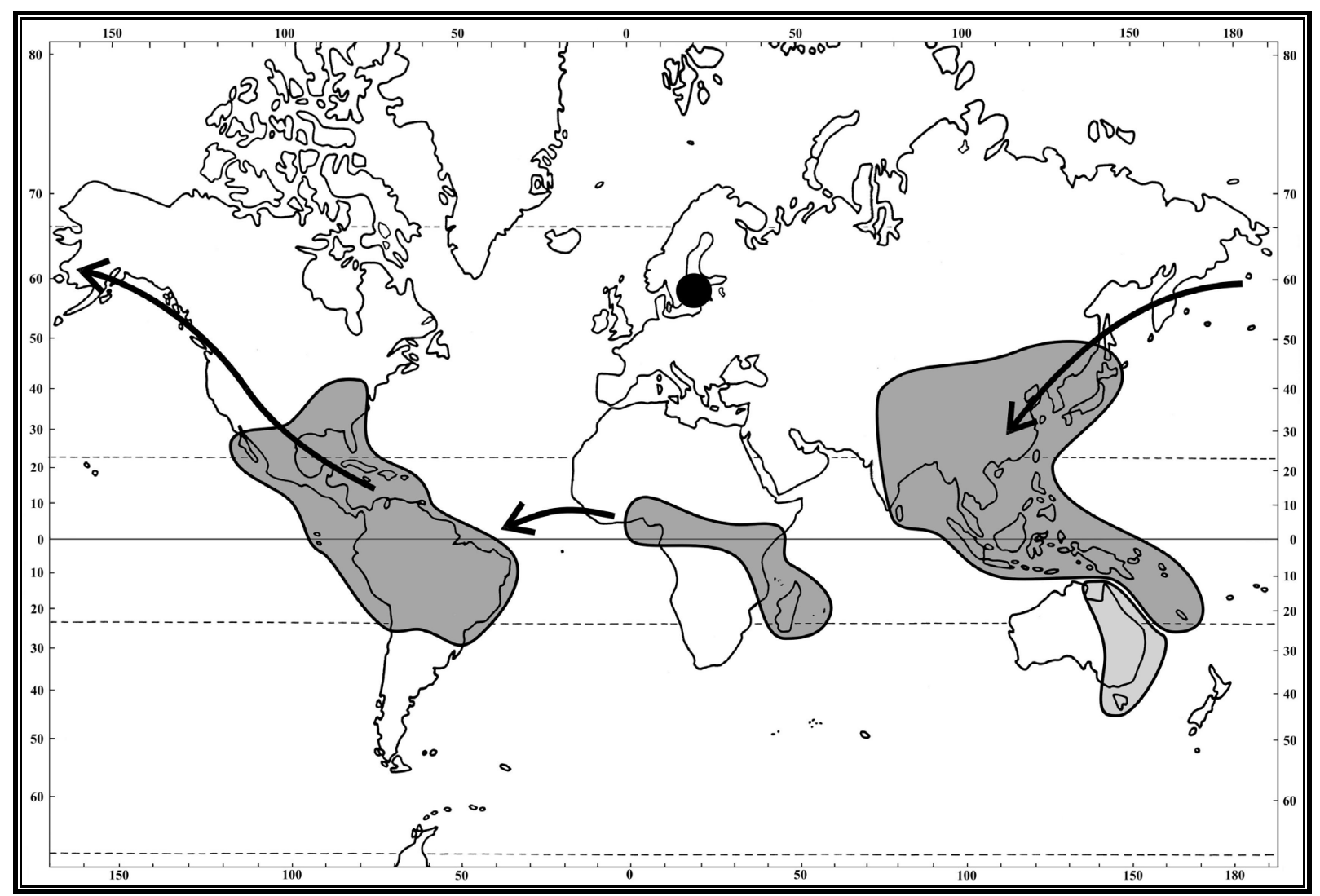

Distribution of Plagiochila sect. Cucullatae

Possibly originating in East Africa, Plagiochila section Cucullatae has spread across the Atlantic to America according to MacClade reconstructions. Later, East Asia has been reached. The occurrence of an baltic amber fossil [Plagiochila groehnii morphologically closely related to P. sciophila (Japan, USA), (Grolle and Heinrichs, 2003), black dot] hints to a greater distribution of the section in Eocene. Also the crossing of the Atlantic via an northern land connection in during Eocene (Davis et al., 2002), seems possible The climate at this time was much warmer and supported tropical vegetation at northern altitudes (Davis et al., 2002; Wolfe, 1975). 


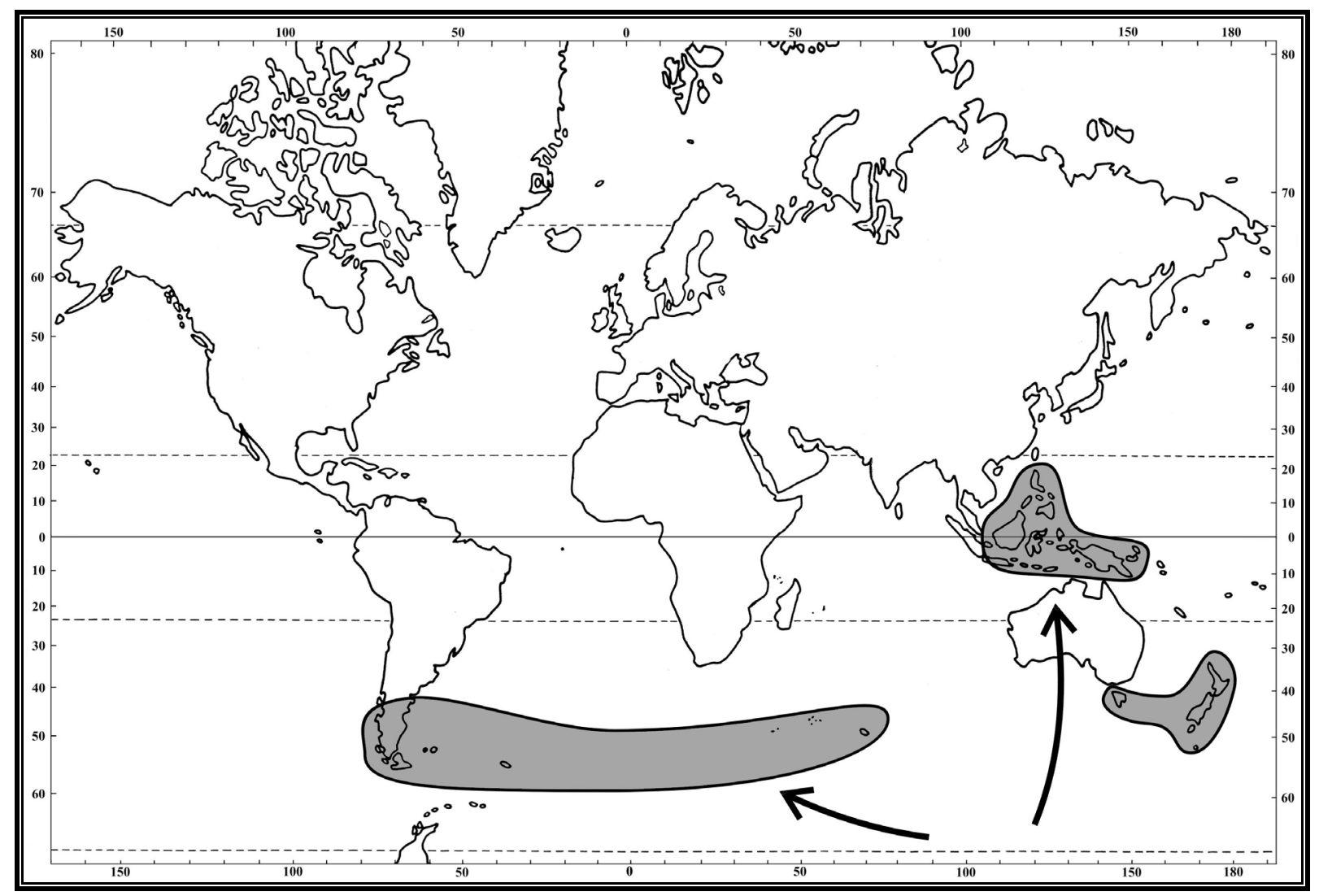

Distribution of Plagiochila sect. Durae

According to the biogeographical reconstructions the origin of Plagiochila sect. Durae most likely lies in Antarctica from which the today's distributions in New Zealand, Tasmania, Indonesia, and Patagonia have been reached. 


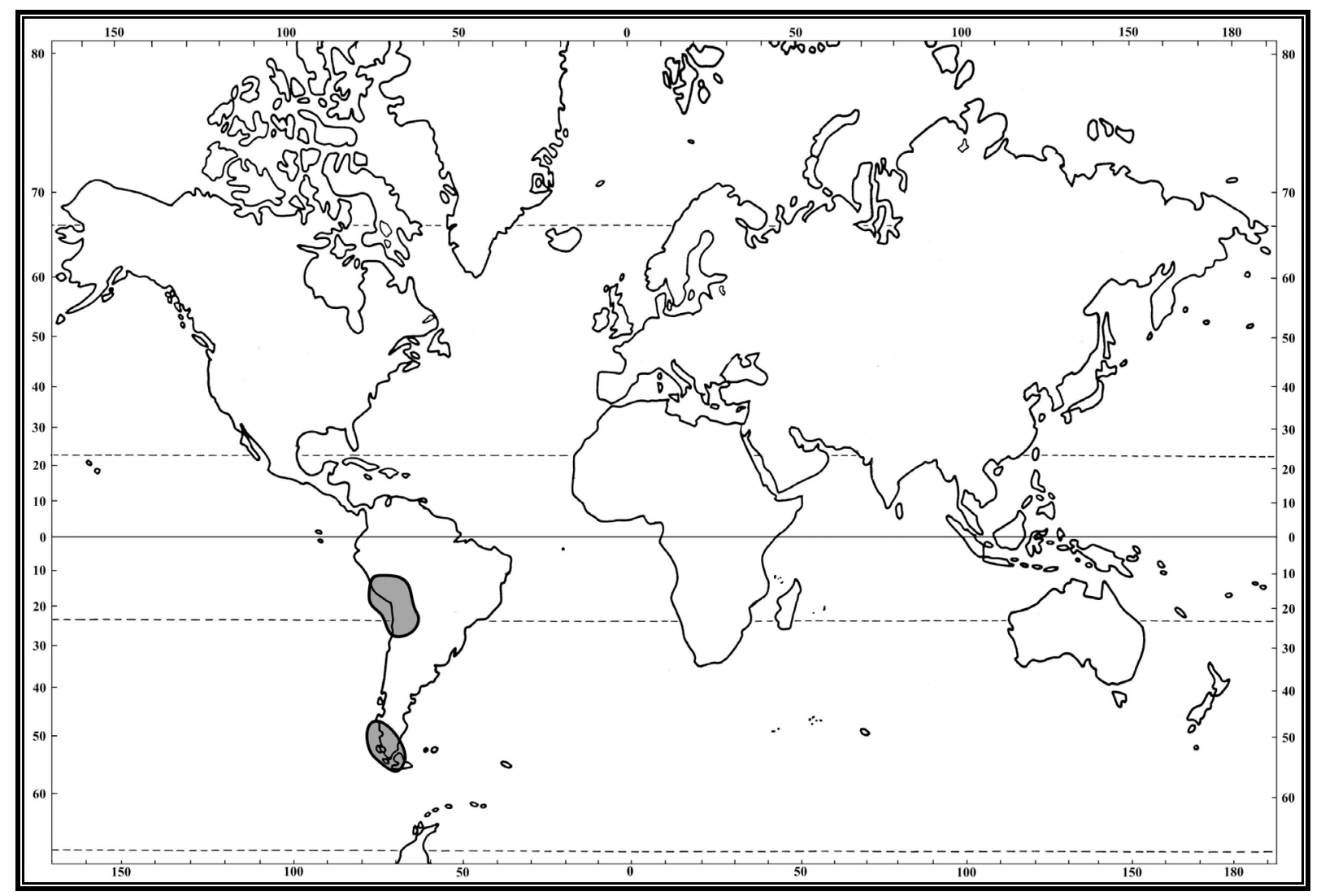

Distribution of Plagiochila sect. Duseniae

It is unclear whether Plagiochila sect. Duseniae originated in Patagonia or Bolivia. However, the reconstructed distribution at deeper nodes of the phylogeny favour the first possibility. 


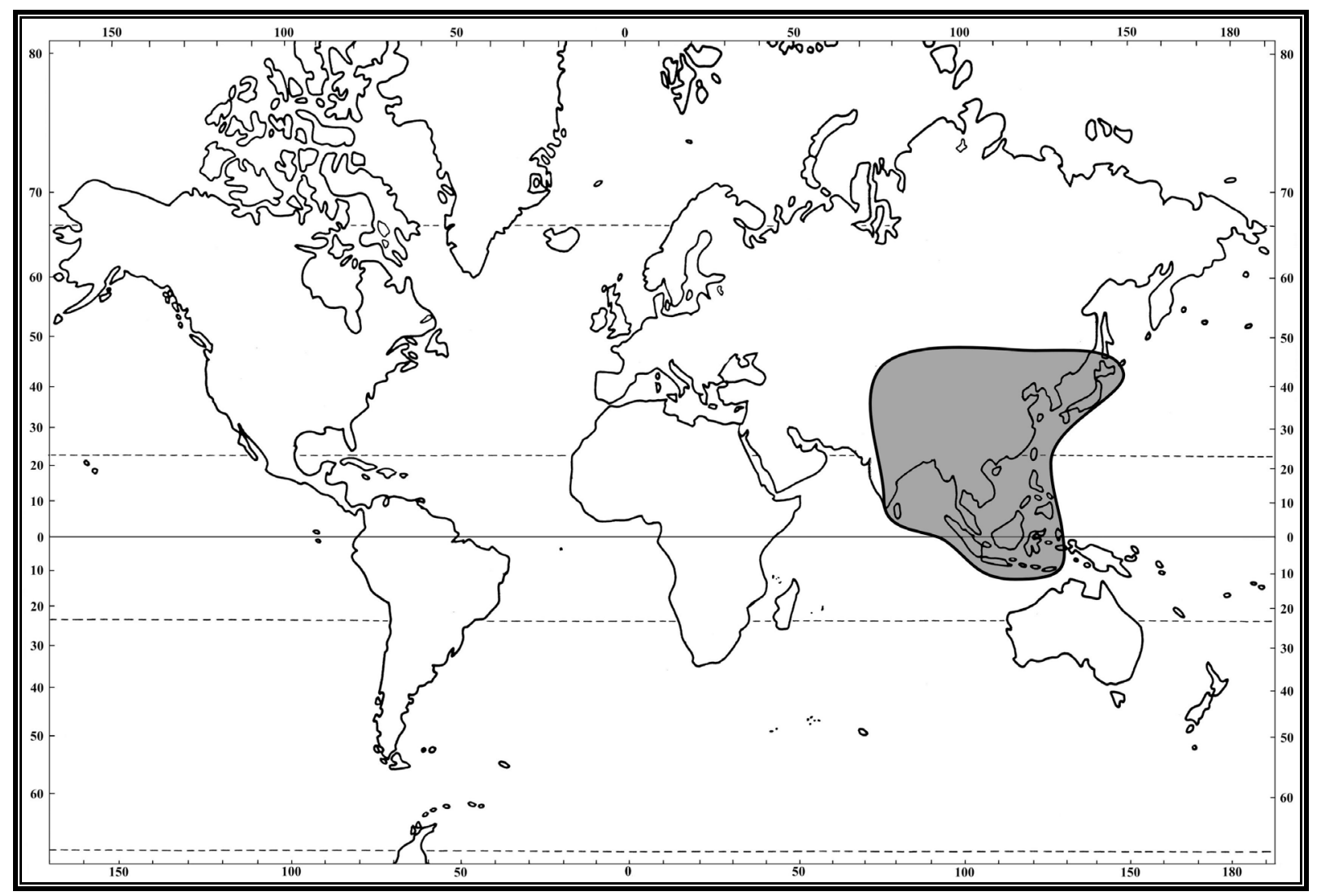

Distribution of Plagiochila sect. Fruticosae

The section Fruticosae has possibly originated on SE Asia and only reached as far as China. 


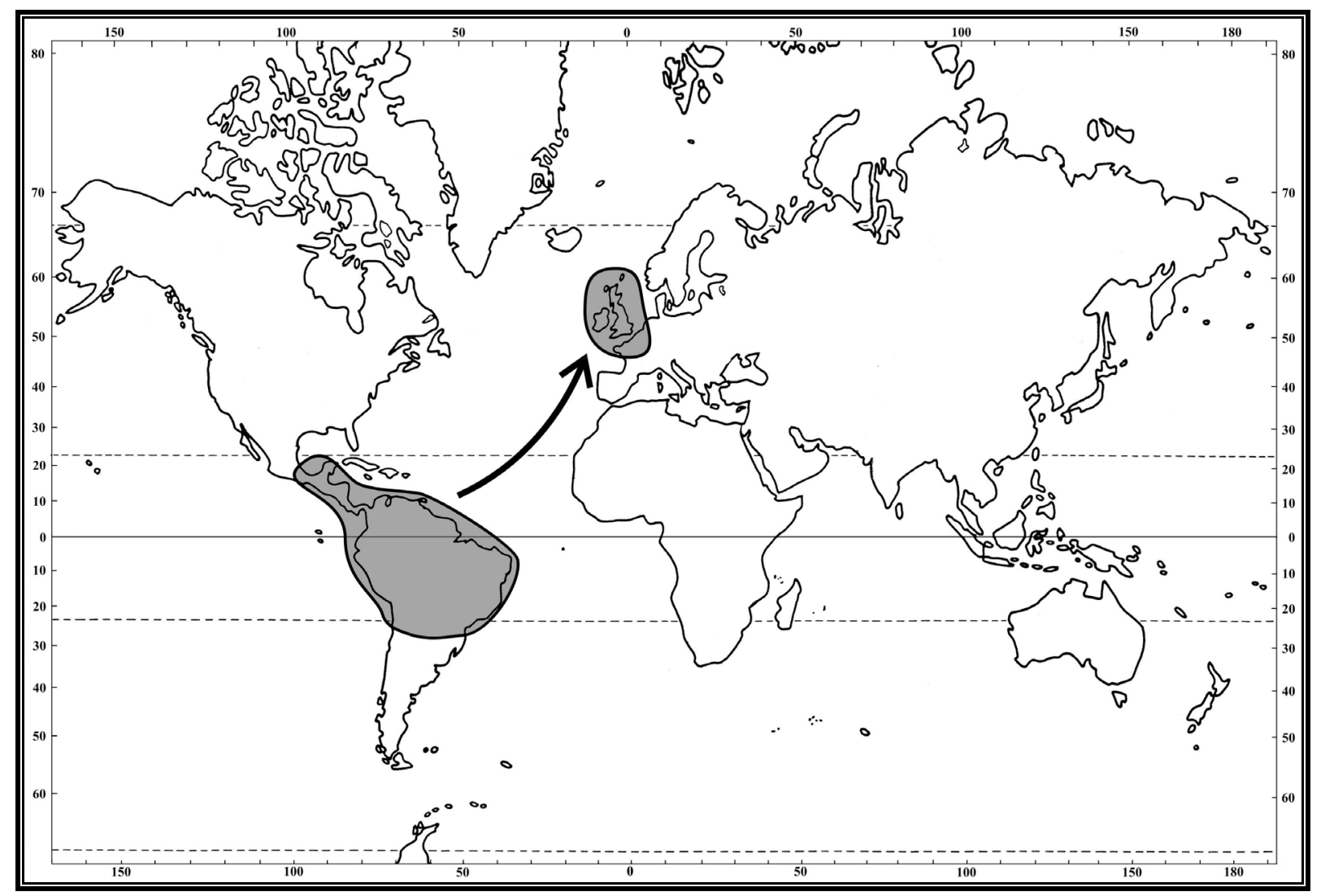

Distribution of Plagiochila sect. Fuscoluteae

Plagiochila sect. Fuscoluteae has possibly evolved in Northern South America. Europe has been reached only lately by a long range dispersal event (Heinrichs, 2002). 


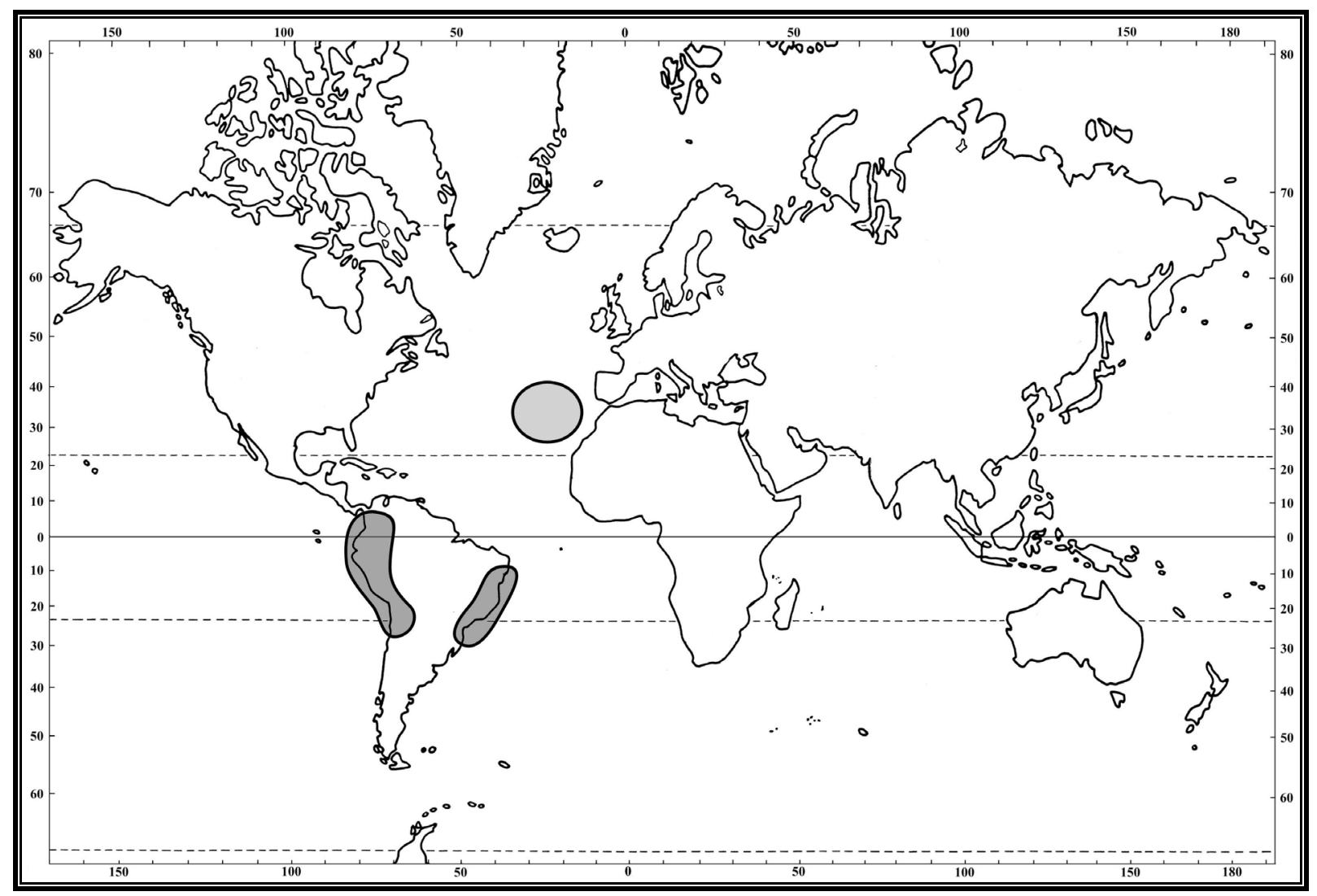

Distribution of Plagiochila sect. Glaucescentes

Plagiochila sect. Glaucescentes possibly originated in Northern South America. The distribution of $P$. longispina on the Azores has most likely been reached later by long range dispersal (Heinrichs et al., 2000a). However, the latter species was not included in this study. 


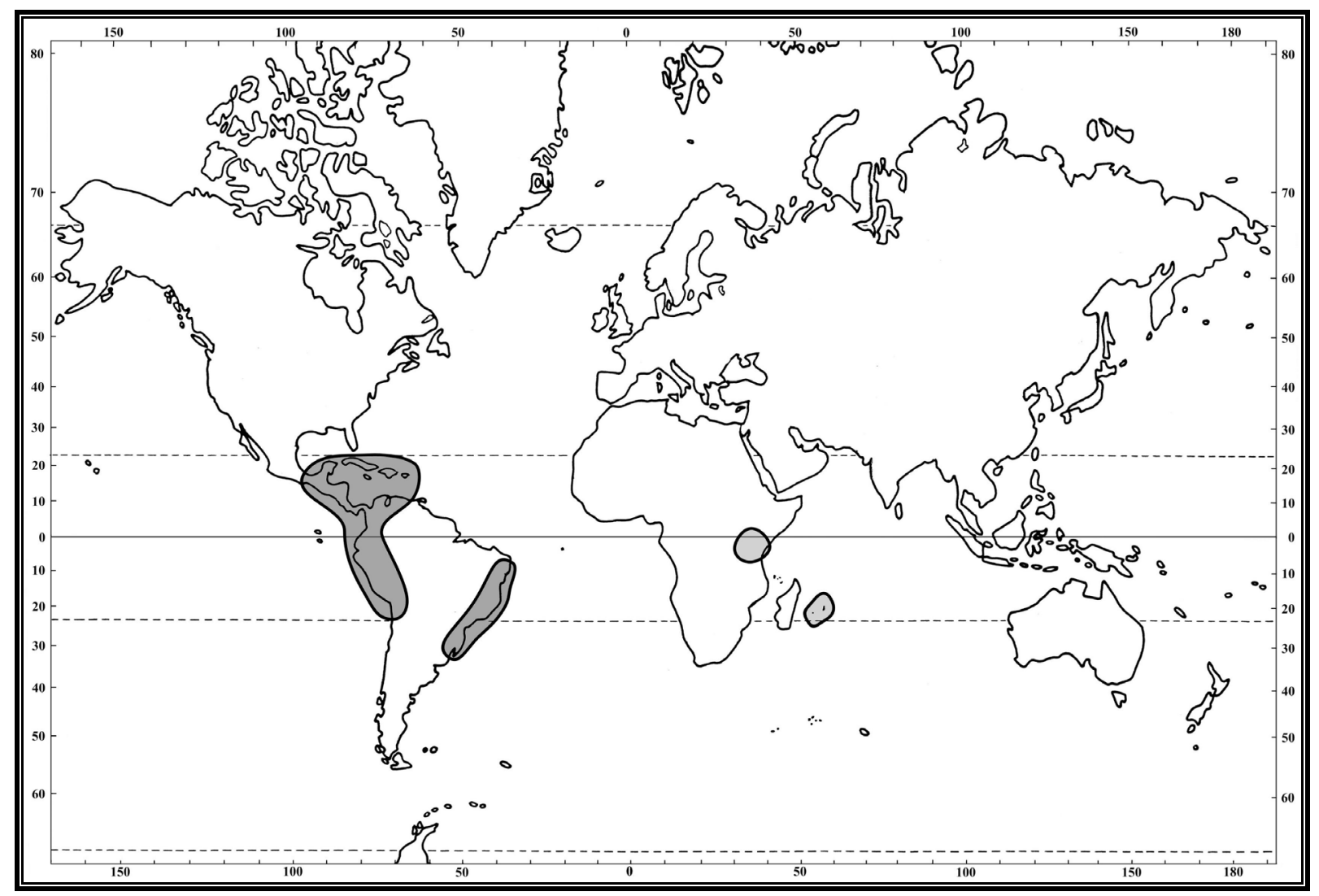

Distribution of Plagiochila sect. Hylacoetes

The members of Plagiochila sect. Hylacoetes analysed in this study are restricted to Central and South America. However, P. boryana (not in study) has reached Africa and Madagascar by long range dispersal (Heinrichs et al., 2005a). The origin of this section possibly lies in northern South America. 


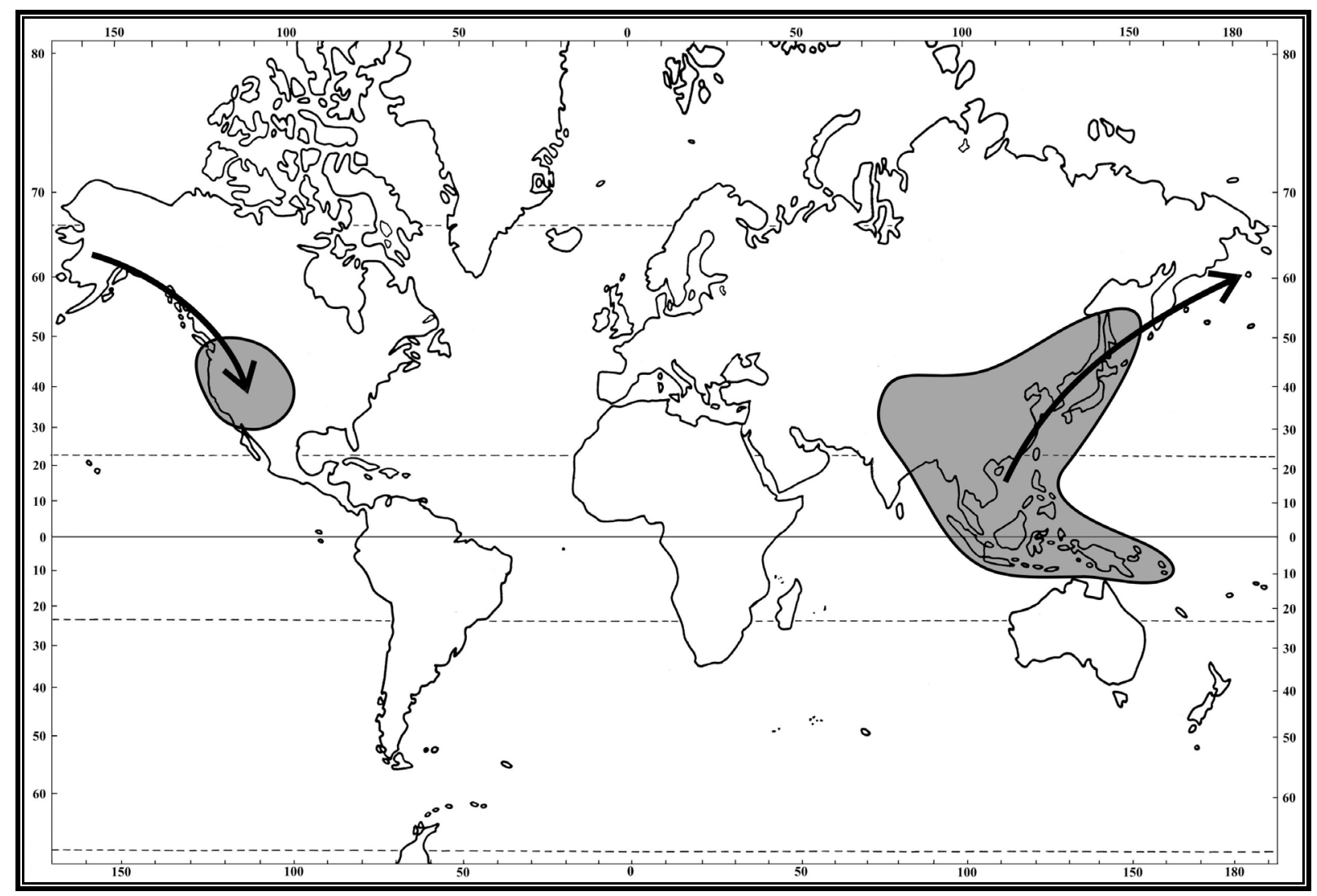

Distribution of Plagiochila sect. Peculiares

According to MacClade reconstructions the origin of this section lies in SE Asia, from which it has reached as far as West North America possibly across the Bering Street. 


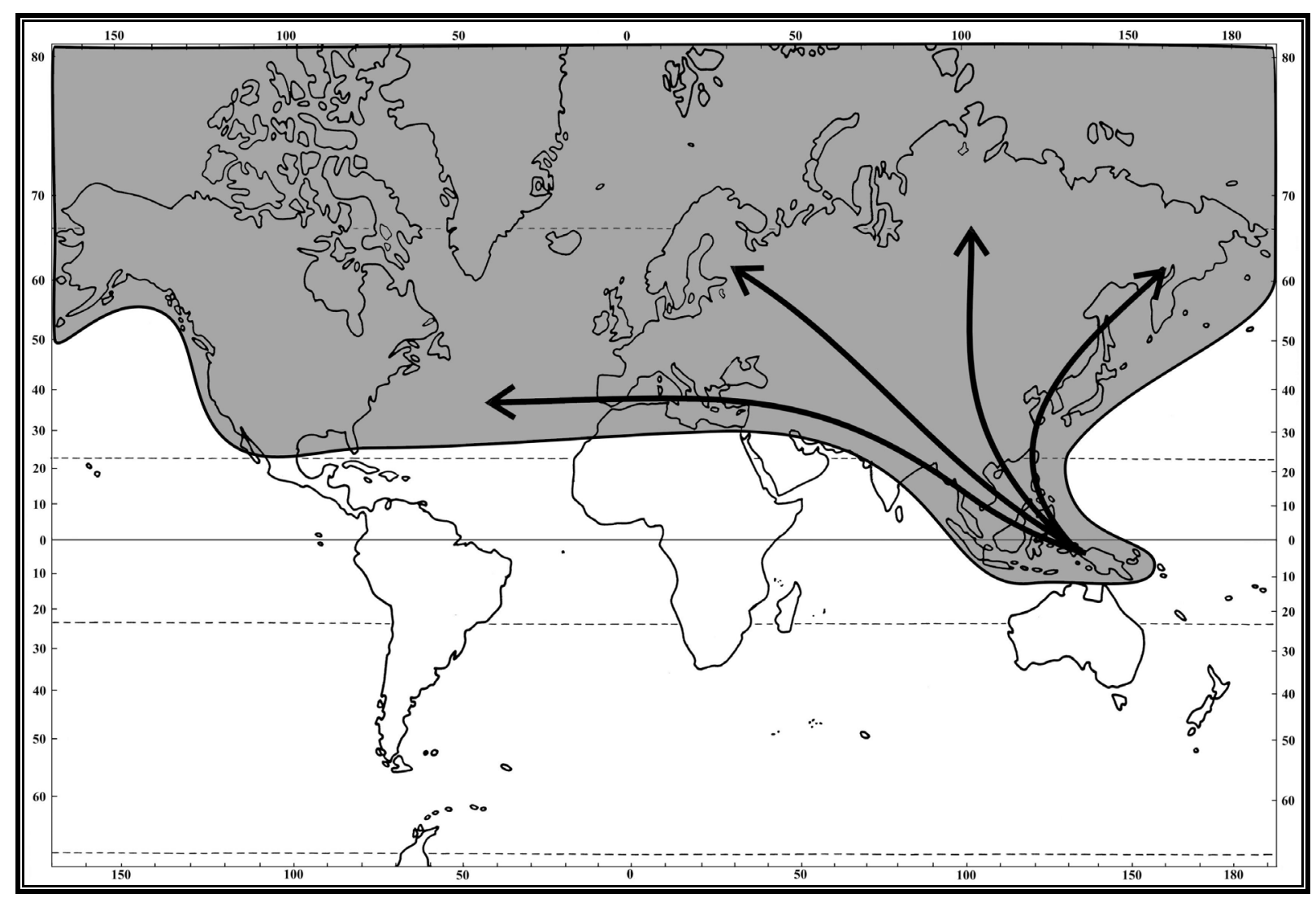

Distribution of Plagiochila sect. Plagiochila

The origin of $P$. sect. Plagiochila possibly lies in SE Asia from which it has colonized the complete northern hemisphere. 


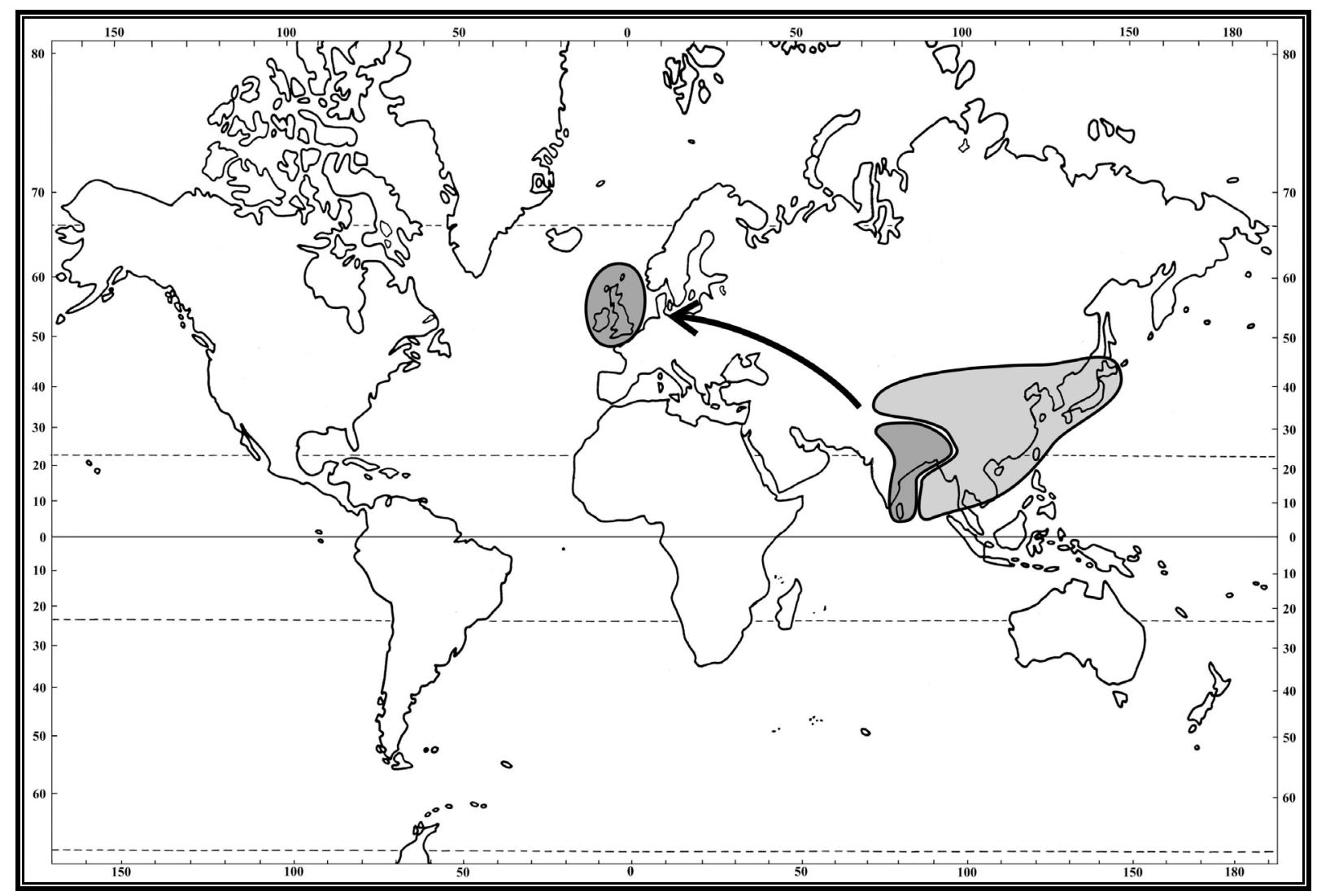

Distribution of Plagiochila sect. Poeltiae

While the core distribution of Plagiochila sect. Poeltiae lies in the East Asia, according to MacClade reconstructions, it has reached Europe with one subspecies, putatively via long range dispersal. Several species not analysed in this study are known from eastern Asia (So, 2001). 


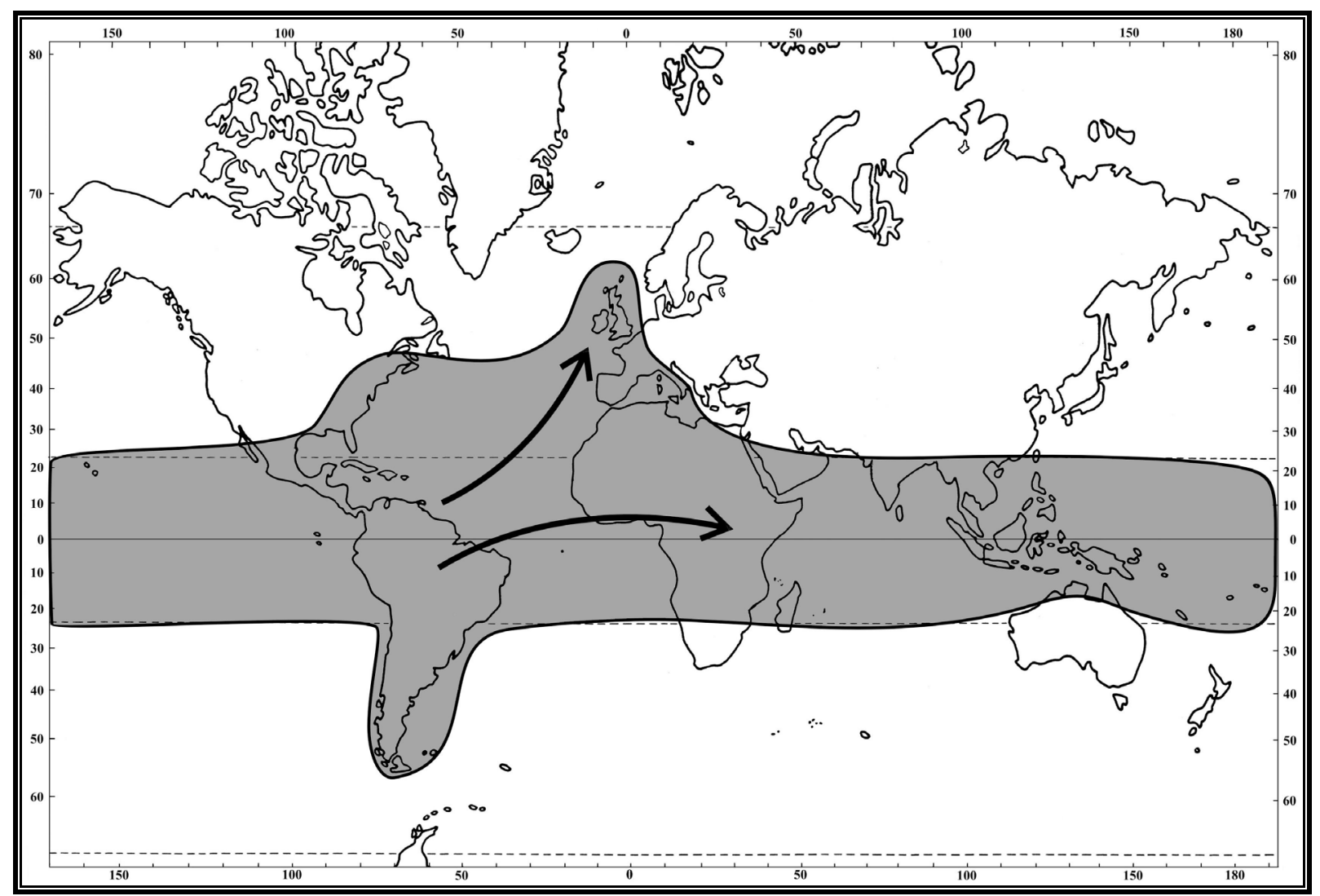

Distribution of Plagiochila sect. Rutilantes

According to MacClade reconstructions the origin of this section possibly lies in Northern South America, from where the rest of the distribution has been reached. However, most of the actual pantropical distribution is owed to $P$. exigua alone. The singe endemic species (P. maderensis) is known from Madeira (Rycroft et al., 2004). 


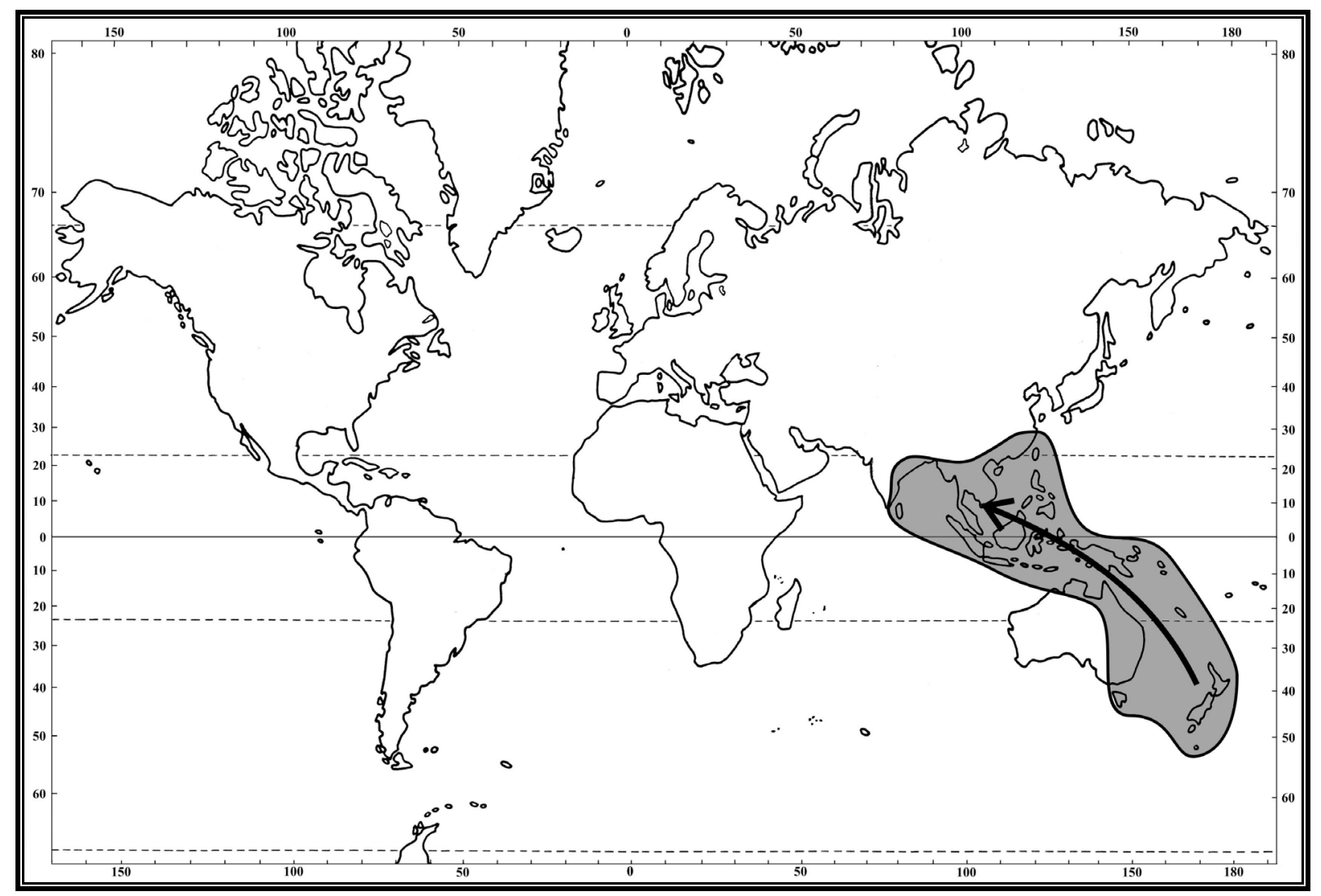

Distribution of Plagiochila sect. Tayloriae

According to the MacClade reconstructions Plagiochila sect. Tayloriae possibly originated in Antarctica and has colonized its current distribution range from south to north. 


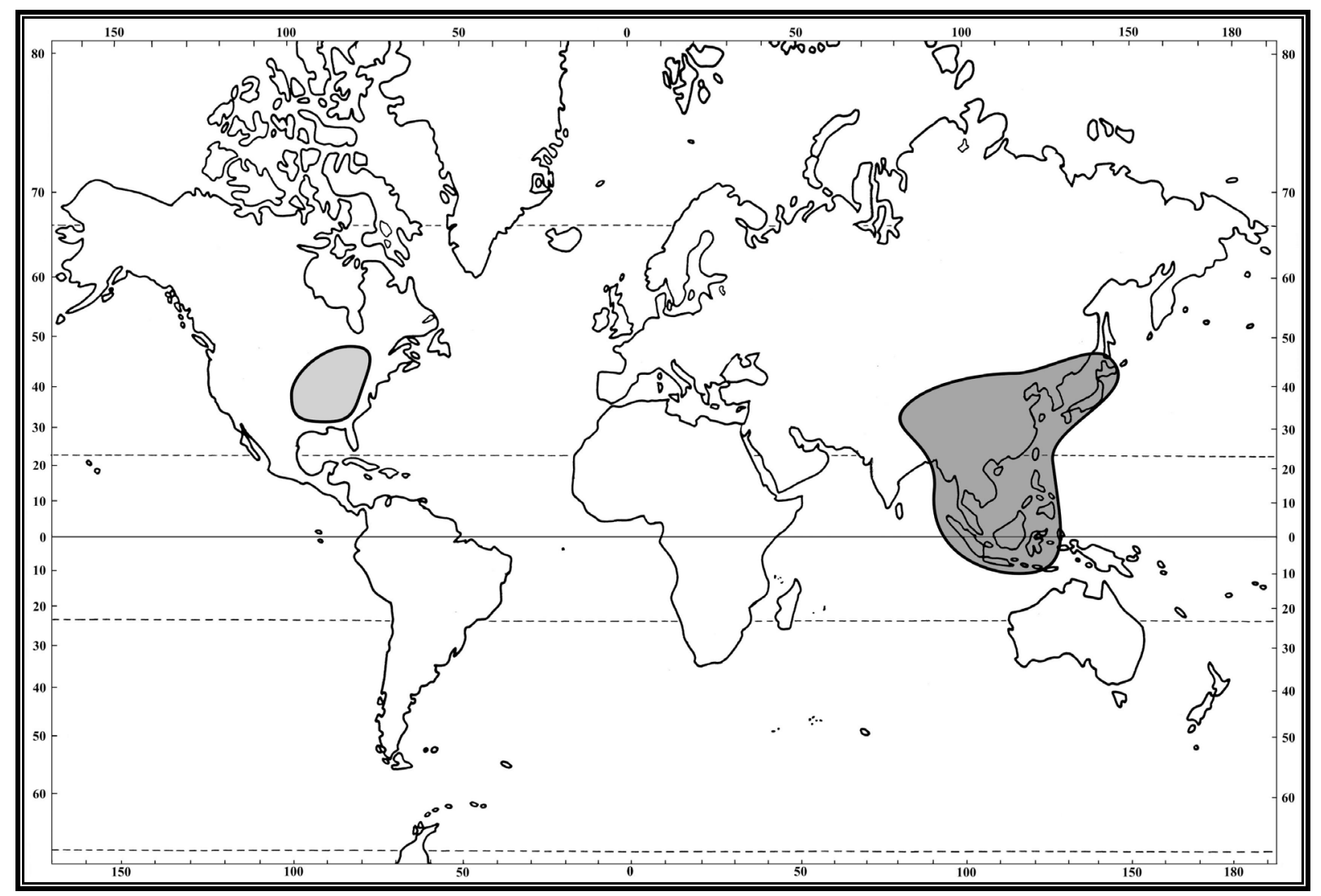

Distribution of Plagiochila sect. Trabeculatae

The section has originated most likely in SE Asia and has reached as far as China and USA [P. austinii, P. sullivantii, (Heinrichs et al., 2004c)]. American species were not included in this study. 


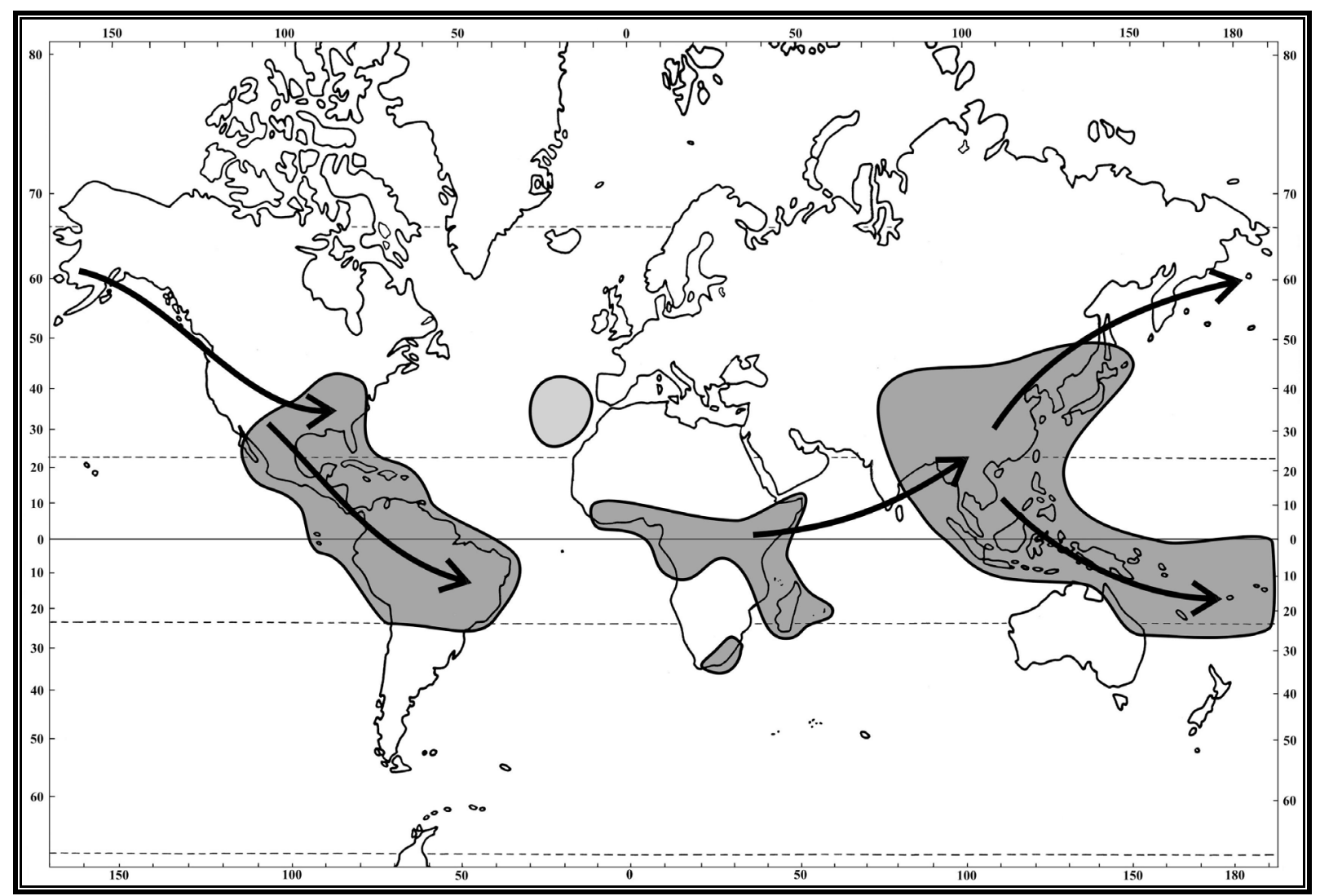

Distribution of Plagiochila sect. Vagae

The distribution patterns of $P$. sect. Vagae are the most interesting of the sections of Plagiochila. According to MacClade reconstructions P. sect. Vagae may have originated in Africa and has since then colonized the tropical regions of the world in two distinct waves. Both times the colonisation went from west to east, first reaching Asia and later America, possibly across the Bering Street or using pacific islands as step stones. The occurrence of $P$. virginica in Macaronesia (Heinrichs et al., 2002b) is most likely caused by long range dispersal from South America, however, this species was not included in this study. 


\subsubsection{Current and historical distribution of the genera of Plagiochilaceae}

Distributions of the genera of Plagiochilaceae are visualized by plotting the distributions of the single species on the ML tree $(25 / 26)$. Hypothetical historical distributions are reconstructed using MacClade (Maddison and Maddison, 2000).

According to these analyses, all included genera have possibly originated in Austral-Asia. Maps of the current distribution of the analysed species for Acrochila, Chiastocaulon, Plagiochilion, Pedinophyllopsis, and Pedinophyllum are given.

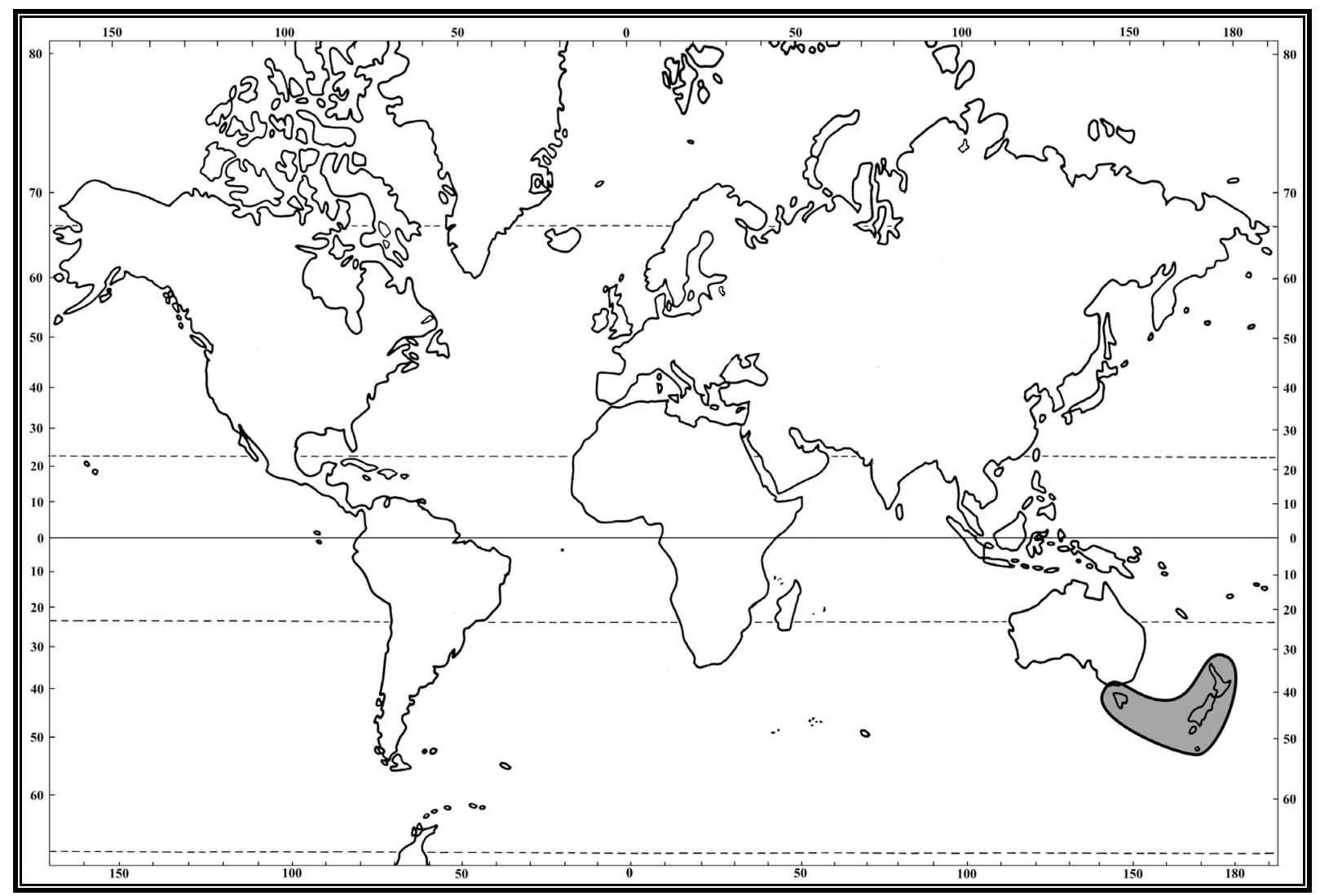

Distribution of Acrochila biserialis: New Zealand, Tasmania 


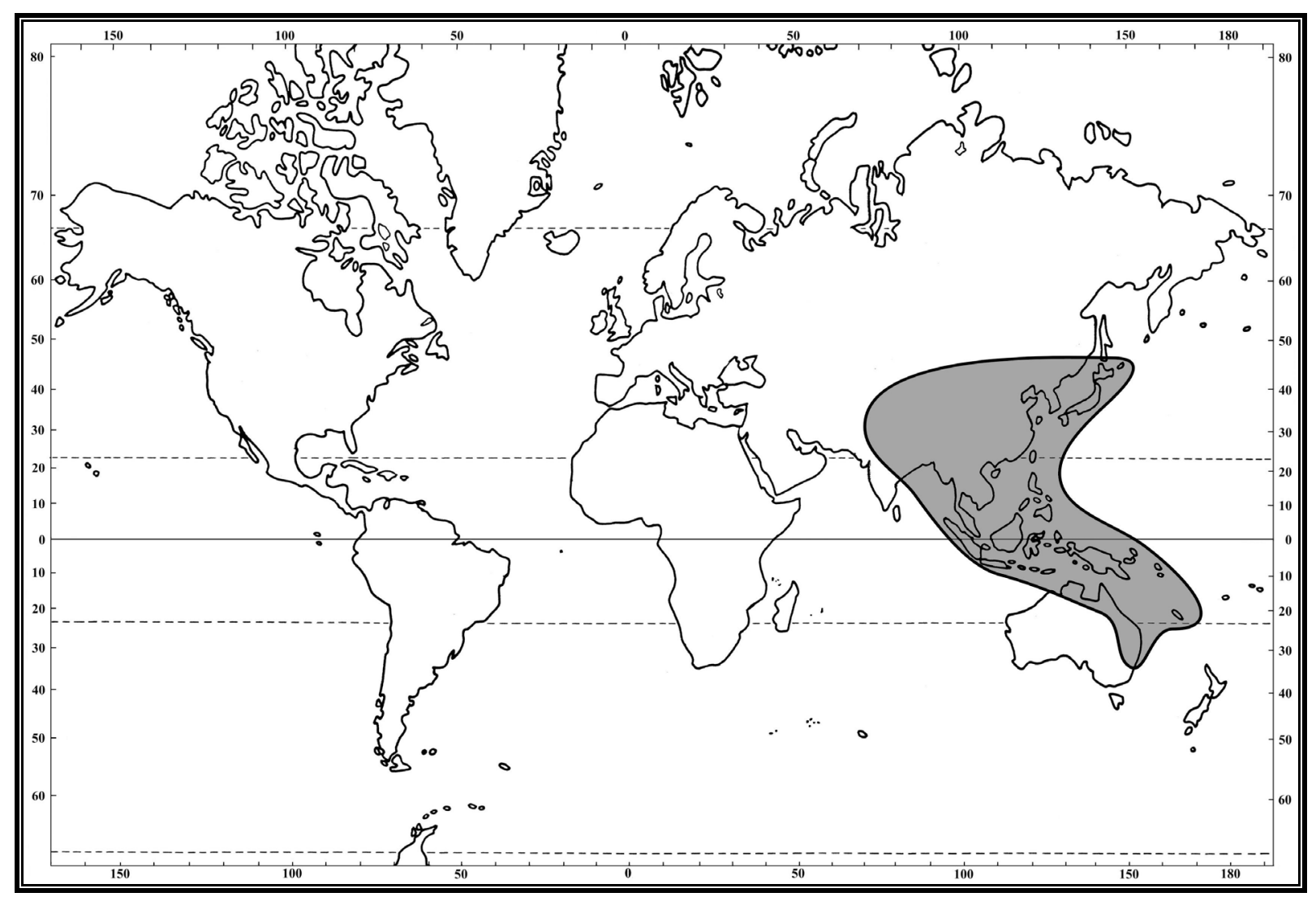

Distribution of Chiastocaulon dendroides : Asia and Australasia.

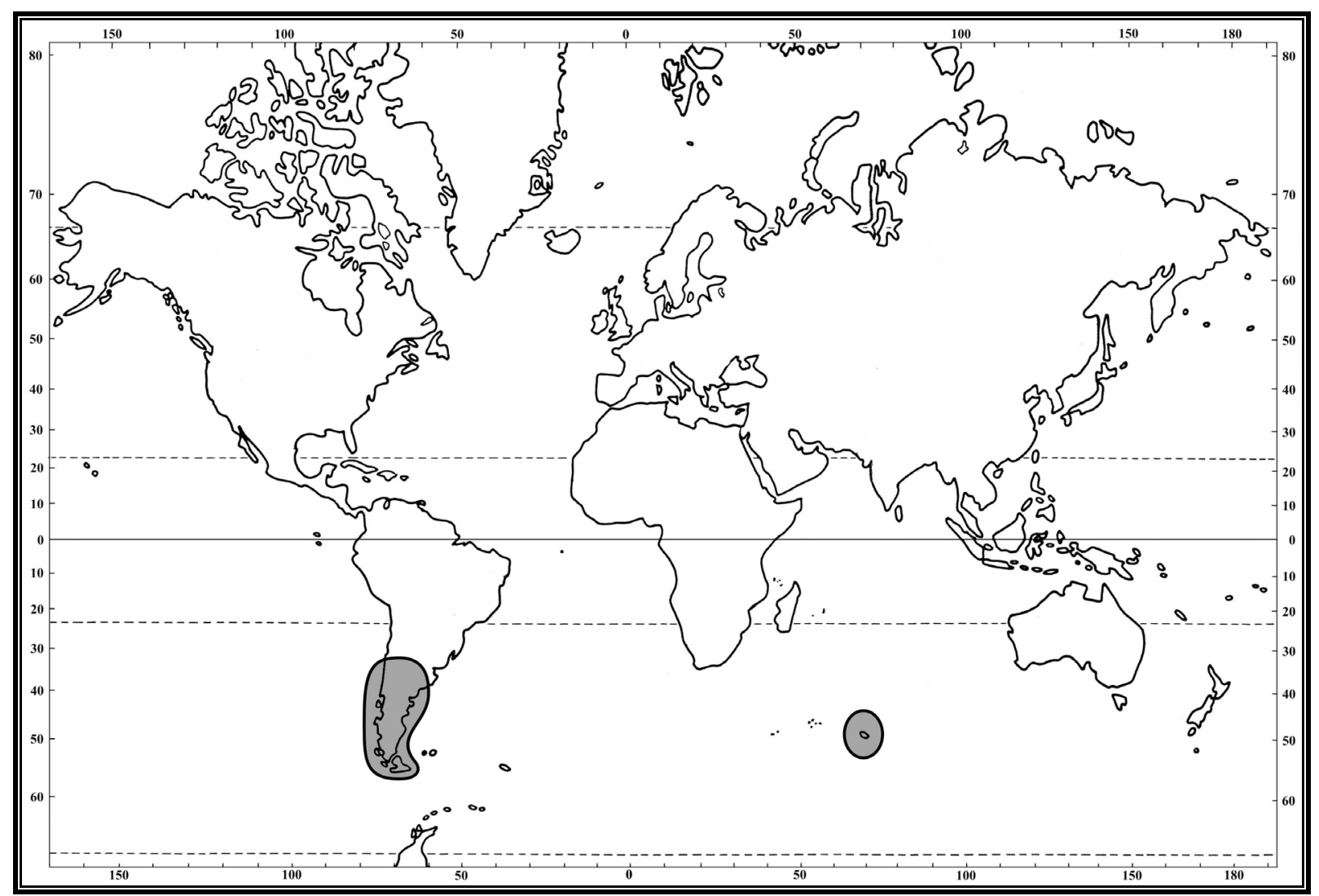

Distribution of Pedinophyllopsis abdita: Patagonia, Subantarctic Islands 


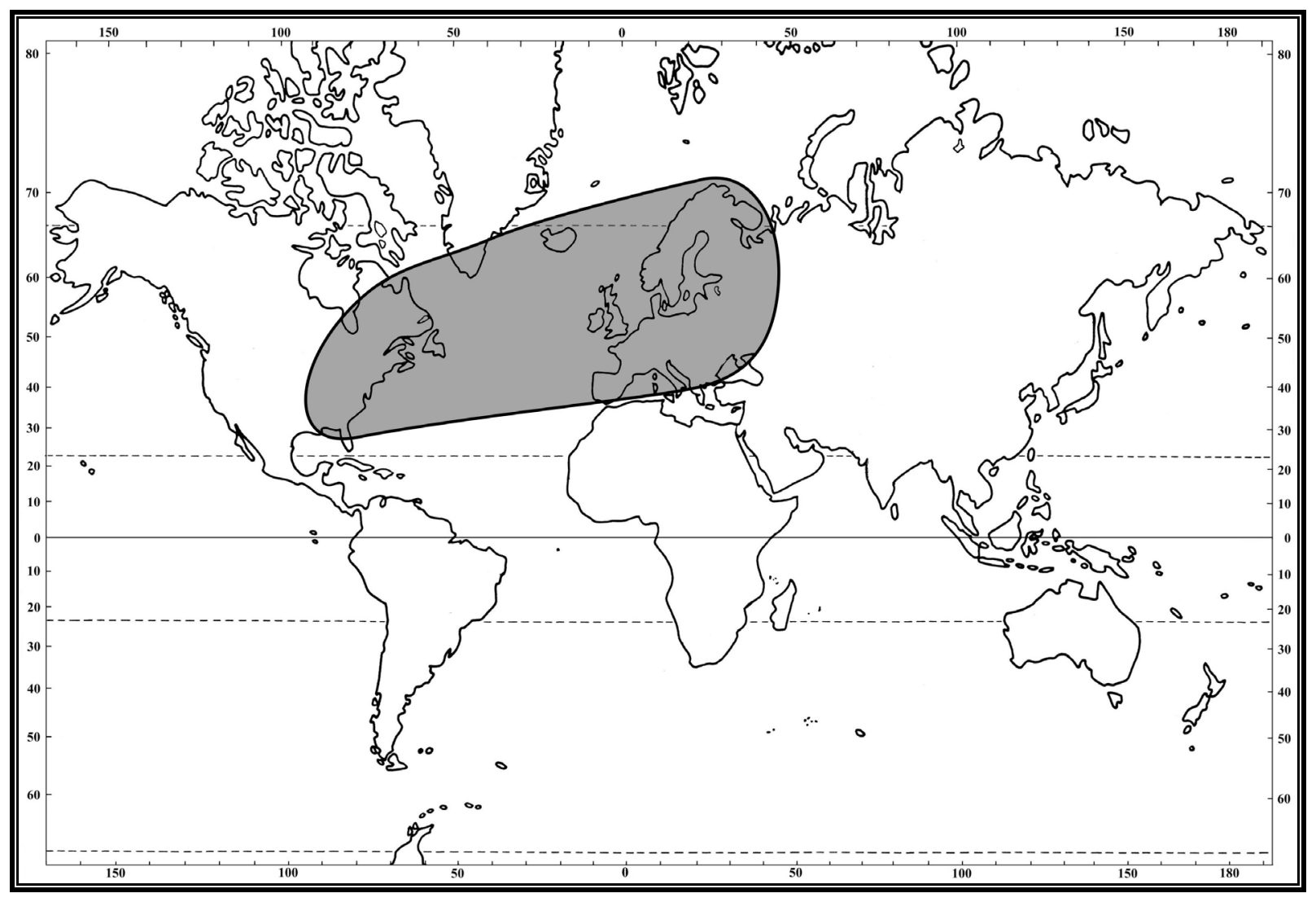

Distribution of Pedinophyllum interruptum: NE USA and Europe.

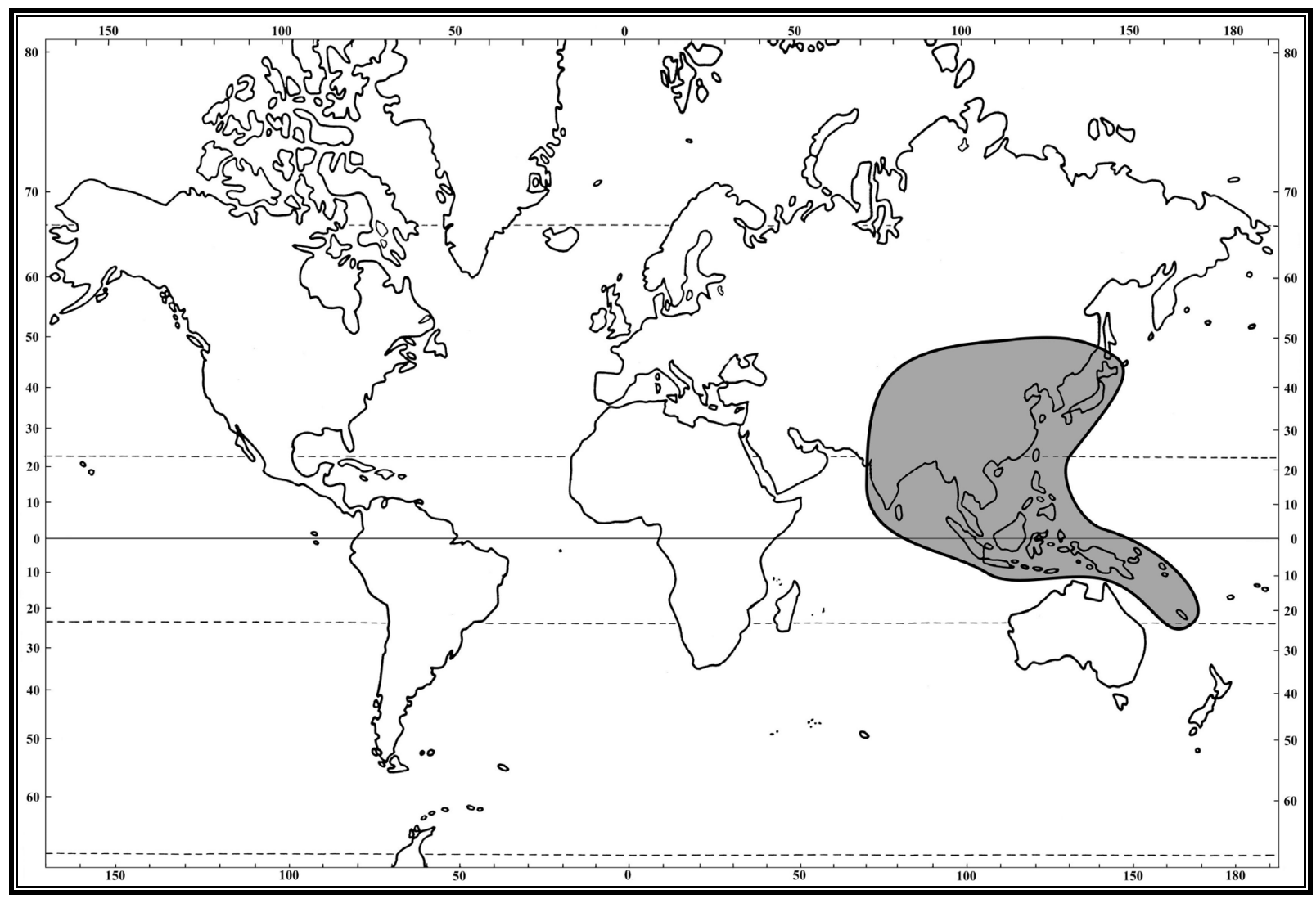

Distribution of Plagiochilion mayebarae and P. oppositum: Central to SE Asia.

79 


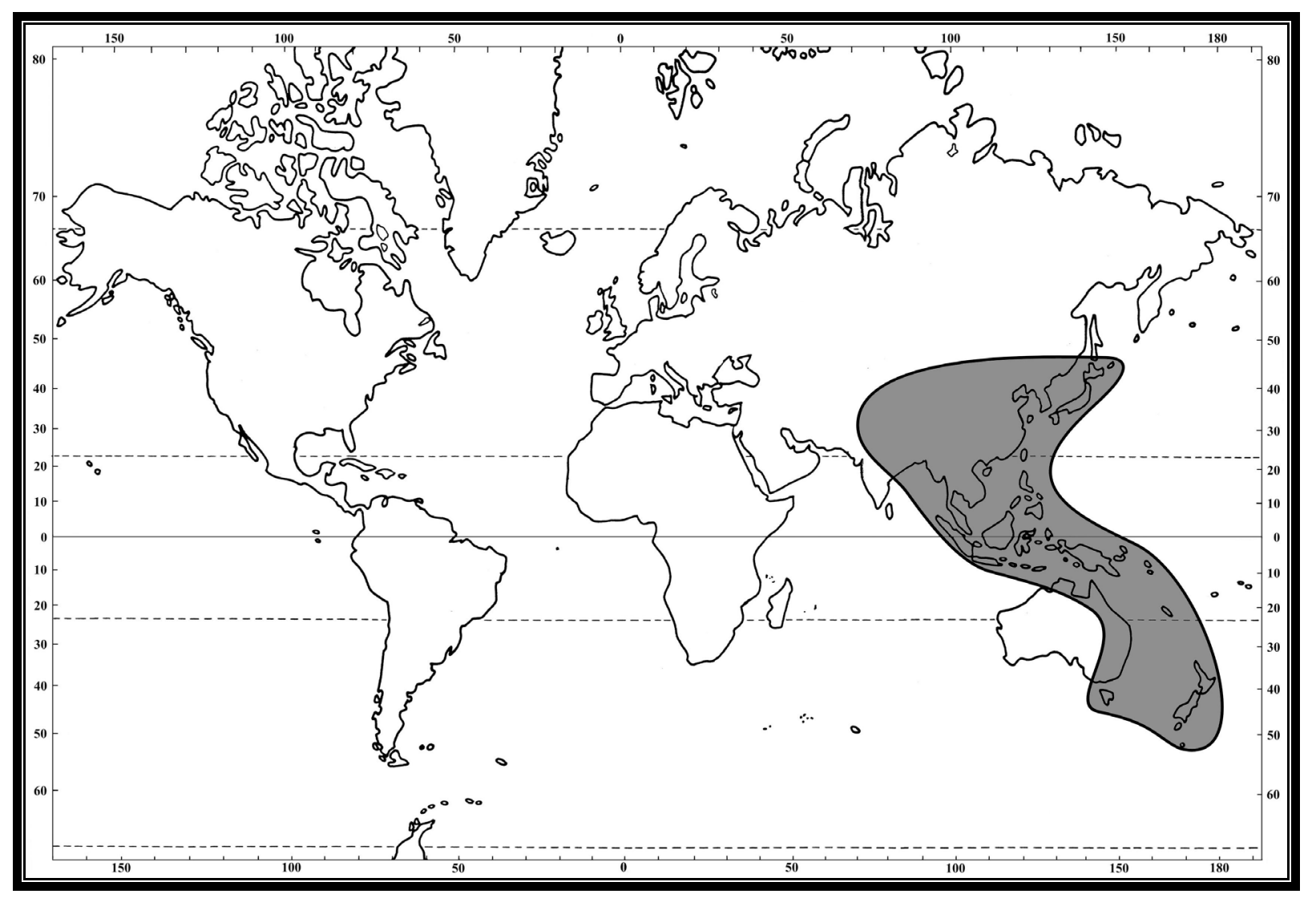

Distribution of Proskauera: Asia and Australasia. 


\subsubsection{Origin and dispersion of Plagiochilaceae}

With the hypotheses of the geographic origin of the sections of Plagiochila and the genera of Plagiochilaceae based on the biogeographical analyses, it is for the first time possible to reconstruct possible dispersal events of the phylogenetic backbone that led to the current distribution of the family.

According to the results of the biogeographical reconstructions Plagiochilaceae have possibly originated on the landmasses nowadays located south of Asia (Australia, New Zealand) (Fig. 10). The basalmost genera of the family (Chiastocaulon, Plagiochilion) originated in that region, Pedinophyllum, Pedinophyllopsis, Plagiochila, and Proskauera appear in Australia.

Of the sections of Plagiochila, Alternantes are the first to appear in Australia / New Zealand. After that the range of the main lineage extends to Antarctica, Patagonia, and northern South America where it splits into two major clades.

From the first clade $P$. sects. Glaucescentes and Duseniae originate out of Patagonia / northern South America, followed by P. sect. Durae from Patagonia / Antarctica. From the latter distribution the eastern part gives rise to $P$. sect Tayloriae in New Zealand, while the western part is ancestral to $P$. sects. Arrectae (Patagonia) and Rutilantes (northern South America).

From the second clade in northern South America the sections Hylacoetes, Fuscoluteae, Adiantoideae, as well as Plagiochila andina arise. After that the main lineage switches to Africa and east Asia (It is unclear whether Africa has been reached directly from South America or from northern latitudes. Step matrices I \& IV favour the first possibility, while II, III \& V indicate the latter). The African part of the distribution is the ancestor to $P$. sects. Cucullatae, Africanae, and Vagae, while P. sects. Poeltiae, Peculiares, Plagiochila, Trabeculatae, and Fruticosae have originated in east Asia. 


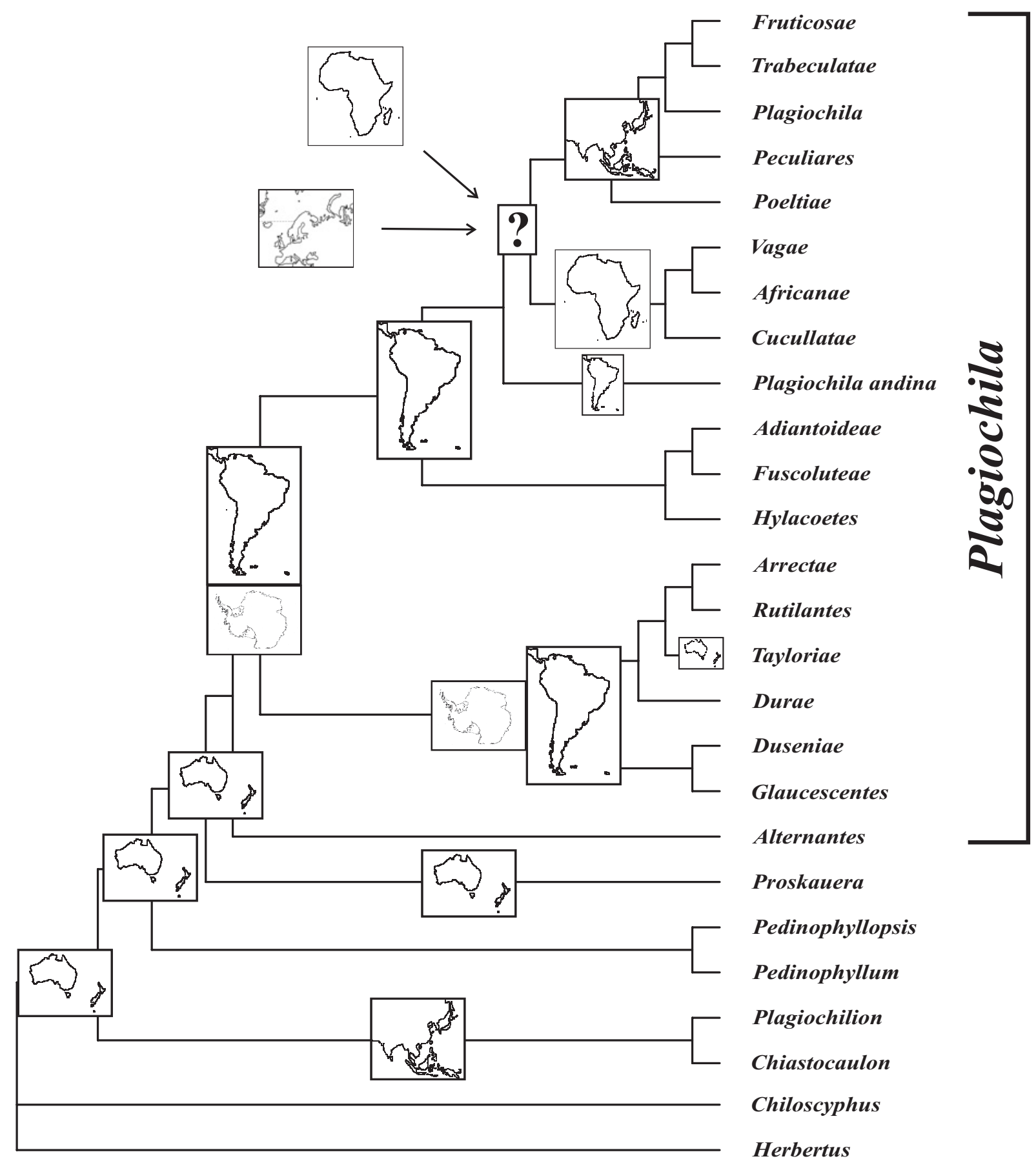

Figure 10 Geographic origin and dispersion of Plagiochilaceae. Chiloscyphus and Herbertus were placed as outgroup for this analysis. 


\subsubsection{Dispersal patterns in Plagiochilaceae}

Summarizing the knowledge of the possible origin of natural species groups of Plagiochilaceae and the hypothetical dispersal routes taken to achieve current distribution, the following dispersal patterns are proposed:

America could initially have been colonised via Patagonia. Only Peculiares and Vagae have possibly arrived across the Bering Street. Section Cucullatae might have crossed the Atlantic Ocean from Africa.

The ancestors of the African species of Plagiochilaceae are nowadays found in South America. No African species originating in Asia could be identified in this study.

Asia has been colonized from south to north by the oldest lineages of the family and from Africa or the East Holarctic by the youngest.

The current European Plagiochila flora originates in the Neotropics and Asia.

The Pacific Ocean has been crossed at least four times most likely using the Bering Street as the shortest way (Cucullatae, Peculiares, Trabeculatae, Vagae). Direct crossing using wind currents or islands as step stones is also possible (Ballard and Sytsma, 2000; Muñoz et al., 2004; Sanmartin and Ronquist, 2004; Wright et al., 2000). However, the latter models could not be evaluated, as no specimens from pacific islands were available for study.

The Atlantic Ocean has been crossed several times by species of different sections (Arrectae, Cucullatae, Fuscoluteae, Plagiochila, Rutilantes) and likely once by the "main lineage". Most of these crossings have possibly been from west to east, only representatives of $P$. sect. Cucullatae have gone from east to west. Whether the crossing of the main lineage has been taken place in the current tropics near the equator, or across a northern land bridge during Eocene (Davis et al., 2002) is unclear. Both possibilities are supported by the biogeographical reconstructions.

The Indian Ocean has been crossed several times by representatives of the sections Cucullatae, Rutilantes, and Vagae from west to east (most likely using the Indian subcontinent as a step stone) but never from Asia to Africa according to the results of this study.

The possibility of long range dispersal across the Atlantic ocean has already been discussed in literature (e.g. Renner, 2004; van Zanten and Gradstein, 1988). Van Zanten and Gradstein 
(1988) investigated the possibility of long range dispersal events in liverworts. Based on spore germination experiments, they demonstrated that long range dispersal by wind across the Atlantic is feasible in widespread species. Based on meteorological evidence they argued for east $\rightarrow$ west dispersal from Africa to America.

Renner (2004) lists 110 angiosperm genera with distributions across the Atlantic younger than 95 million years. Based on the splitting of America and Africa 119 - 105 Mio y ago (McLoughlin, 2001) these genera must have crossed the Atlantic or alternatively been introduced from the north according to Renner. She (2004) describes several different possibilities for these crossings (sea currents, wind currents, distribution by birds) in angiosperms.

Renner identifies sea currents as possible vectors for both directions across the Atlantic, while wind currents would mainly transport material from east to west according to current climatic data. According to the studies birds only rarely function as vectors across the Atlantic.

While in both works (Renner, 2004; van Zanten and Gradstein, 1988) west $\rightarrow$ east wind driven long range dispersal events across the Atlantic are identified, meteorological evidence is scarce. Only one possible trans ocean "Weasterly" could be identified (Grodsky et al., 2003).

As in this study of Plagiochila wind driven west $\rightarrow$ east dispersal across the Atlantic ocean is also proposed, it could be concluded that the occurrence of rare "Weasterlies" might be enough to establish single trans ocean distributions.

Recent papers (e.g. Davis et al., 2002) focus on the possibility that disjunct distributions across the Atlantic Ocean have resulted from migrations over (Eocene) land connections in the North Atlantic, followed by southward migration to Africa and SE Asia. The biogeographical reconstructions in this work are unclear at this point, allowing both possibilities, the crossing of the Atlantic Ocean directly to Africa or over Eastern Holarctic. The existence of an Eocene baltic amber fossil of Plagiochila groehnii (Grolle and Heinrichs, 2003), supports the North Atlantic hypothesis for Plagiochilaceae. Unfortunately, no fossils from North America are available. 


\subsubsection{Comparison between the distribution patterns of Plagiochilaceae and other groups}

The distribution patterns in Plagiochilaceae generally match those found for other bryophytes (Gradstein et al., 1983; Herzog, 1926; Schofield and Crum, 1972; Shaw, 2001). It can also be confirmed that distributions found on family level in higher plants occur on species or section level (Gradstein et al., 1983; Grolle, 1969; Shaw, 2001; Shaw et al., 2003b; Urmi, 1999).

Some of the areas found are highly disjunctive (Neotropics - Europe [Arrectae, Fuscoluteae, Glaucescentes], Neotropics - Africa [Arrectae, Hylacoetes], East Asia - North America [Peculiares], Patagonia - New Zealand [Alternantes, Durae], Himalayan - Europe [Poeltiae]). It has been controversially discussed whether these kind of distributions are the result of recent dispersal (Gradstein et al., 1983; Groth et al., 2003; Heinrichs et al., 2004a; Muñoz et al., 2004; Renner, 2004; van Zanten, 1977; van Zanten and Gradstein, 1988; van Zanten and Pócs, 1981) or ancient fragmentations (Meissner et al., 1998; Schaumann et al., 2003; Schaumann et al., 2004; Stech et al., 2002; Stech and Frey, 2004). Based on the phylogenetic analyses in this and earlier studies, the following hypotheses of the origin for most of these distributions in Plagiochilaceae can be formulated.

In the sections Arrectae and Hylacoetes [and one species of Glaucescentes not studied here, (Heinrichs et al., 2002b)] the sequences of the species distributed in Europe and Africa are very similar to the same species from the Neotropics [ Plagiochila punctata (Figs. 25 / 26), P. bifaria, P. boryana, P. stricta (Heinrichs et al., 2005a; Heinrichs et al., 2005c; Rycroft et al., 2002)]. Had the populations been separated by the opening of the Atlantic Ocean about $119-$ 105 Mio y ago (McLoughlin, 2001), a greater genetic diversity would be expected (Heinrichs et al., 2005a). Thus, long range dispersal events are here favoured to explain these disjunctions.

The disjunct ranges of the sections Alternantes and Durae between Patagonia and New Zealand / Australia can either be the result of long range dispersal by wind currents (Muñoz et al., 2004), or of an old vicariance event at the break-up of Gondwanaland (Meissner et al., 1998; Schaumann et al., 2003; Schaumann et al., 2004; Stech et al., 2002; Stech and Frey, 2004). In the last case the populations would have been separated for at least $35 \mathrm{Mio}$, when the cooling of the Antarctic continent finally isolated New Zealand / Australia and Patagonia 
from each other (Hill, 2001; McDaniel and Shaw, 2003; McLoughlin, 2001; Nelson and Ladiges, 2001; Sanmartin and Ronquist, 2004).

In both sections not the same species (as in Arrectae and Hylacoetes) but different species form the disjunct range of the group. The long branches leading to the species hint to greater genetic variation as would be expected in case of long range dispersal (Figs. 25 / 26). This leads to the conclusion that vicariance might be the reason for this disjunct range. However, long range dispersal, followed by extinction of the species in the original habitat is another possible explanation for this kind of distribution.

The East Asian - North American distribution of sections Cucullatae and Peculiares is maintained by Plagiochila sciophila and P. semidecurrens in this study [but also occurs in section Trabeculatae (Heinrichs et al., 2004c)]. From the samples analysed here, the hypotheses of long range dispersal versus vicariance can not be evaluated. However, as this distribution is well known from other bryophytes (Herzog, 1926; Schofield and Crum, 1972; Shaw, 2001) and higher plants (Schroeder, 1998; Shaw, 2001; Shaw et al., 2003a) it has received much interest. Almost all authors agree that it represents the fragments of a larger distribution which has been connected via the Bering Street during some time in the Tertiary.

For the Himalayan - European distribution of section Poeltiae it is likely that the single European species Plagiochila carringtonii has reached Europe by long range dispersal, as the closest relatives of the section originate in East Asia. 


\subsection{Molecular clock}

Molecular clock analyses could offer valuable insight in the history of Plagiochilaceae. Despite the fact that only few time constrains are available, the results fit to the dispersal events of Plagiochilaceae as assumed by the biogeographical analyses (Figs. 11/12, Tab. 12). However, the results should be taken carefully and revised when more data is available.

For constraining the molecular clock several alternatives were tested as follows.

The amber fossil of Plagiochila groehnii (Grolle and Heinrichs, 2003) was used to restrict the age of either $P$. sect. Cucullatae or the genus Plagiochila to a minimum age of 50 Mio y. (Final dating resulted in an age of $39.52 \pm 1.65$ million years for section Cucullatae.)

The split of Plagiochila dusenii and $P$. validissima was assumed by the author to be caused by the formation of the Atacama dessert 150 Mio y ago (Hartley et al., 2005), or by the last change to hyperarid climate of this desert 4-6 Mio y ago (Hartley and Chong, 2002). According to the results of the final dating the split is $47.83 \pm 1.98$ Mio y old, corresponding with neither date. This points to the fact that the Atacama may have only small influence on the distributions of Plagiochilaceae, as is also suggested by the occurrence of P. bicuspidata north and south of the Atacama, seemingly unhindered in its distribution by the dessert.

The split between Plagiochila hirta and P. deltoidea / P. ramosissima was assumed by the author to be caused by the final cooling of Antarctica 35 million years ago (Dingle et al., 1998).

Combinations of time constrains used:

\begin{tabular}{|c|c|c|}
\hline $\begin{array}{c}\text { amber fossil of Plagiochila } \\
\text { groehnii }\end{array}$ & $\begin{array}{c}\text { Atacama-split (P. dusenii }-\boldsymbol{P} . \\
\text { validissima })\end{array}$ & $\begin{array}{c}\text { Antarctica-spilt (P. hirta - } \\
\text { P. deltoidea / P. ramosissima })\end{array}$ \\
\hline \multirow{2}{*}{$\begin{array}{c}\text { Section Cucullatae restrained to } \\
50 \text { million years }\end{array}$} & restrained to 4 million years & \\
\cline { 2 - 2 } & restrained to 150 million years & \\
\hline $\begin{array}{c}\text { Plagiochila restrained to } 50 \\
\text { million years }\end{array}$ & restrained to 4 million years & restrained to 35 million years \\
\cline { 2 - 2 } & restrained to 150 million years & \\
\hline
\end{tabular}

In all possible combinations of the time constrains mentioned above (see table), the split of P. hirta and P. deltoidea / P. ramosissima (restricted to a minimum age of 35 million years) was calculated at about 35.5 million years. Consequently this node was used to calibrate the molecular clock. However, it should be noticed that this calibration point can be highly 
artificial and that the correct date for the splitting might be much older or younger. Nevertheless, it might serve as a first attempt to calibrate a molecular clock for Plagiochilaceae, regarding the lack of a set of dated fossils.

This calibration leads to the following results (Fig. 11, Tab. 12):

The age of the family was calculated at approximately 138 Mio y. Plagiochila emerges $106.34 \pm 4.21$ Mio y ago (Fig. 12). At this time Australia / New Zealand (possible origin of Plagiochilaceae) and Antarctica still formed the super continent Gondwanaland, though Africa and India had already lost contact (McLoughlin, 2001).

The colonization of Patagonia as deducted from the biogeographical analyses (Chapter 4.7) could be dated to $90.63 \pm 3.26$ Mio y ago. As South America, in contrast to Africa and India, was not separated from Gondwanaland until 35 Mio y ago (McLoughlin, 2001), a range extension of Plagiochilaceae in this direction is very likely.

After that the biogeographical analyses assume a colonisation of Africa from South America, either directly across the Atlantic Ocean or via a northern land connection from North America to Europe / Eastern Holarctic. Considering the calculated time of $65.75 \pm 3.34$ Mio y for this event, the climate at northern altitudes was warmer than today (Wolfe, 1975) sustaining a tropical Plagiochilaceae flora. The existence of an Eocene amber fossil (Grolle and Heinrichs, 2003) from the baltic sea proves the occurrence of Plagiochilaceae in this area only 10 million years later.

On the other hand, the Atlantic Ocean between South America and Africa was narrower than today, possibly allowing for easier spore dispersal from one continent to the other.

From Africa (or the eastern Holarctic), Asia was colonized 53.18 \pm 2.89 Mio y ago, before the Indian sub-continent reached the Asian mainland 43 Mio y ago (McLoughlin, 2001).

All of the analysed sections appear less than 60 Mio y ago and are therefore younger than most of the lineages of Angiosperms (Davis et al., 2002; Schneider et al., 2004; Wikstrom et al., 2001). Thus, compared to other studies in basal and higher land plants (Bremer et al., 2004; Knapp et al., 2005; Schneider et al., 2004), Plagiochilaceae are a relatively young group of an old lineage (Kenrick and Crane, 1997; Knoop, 2004; Qiu et al., 1998). 


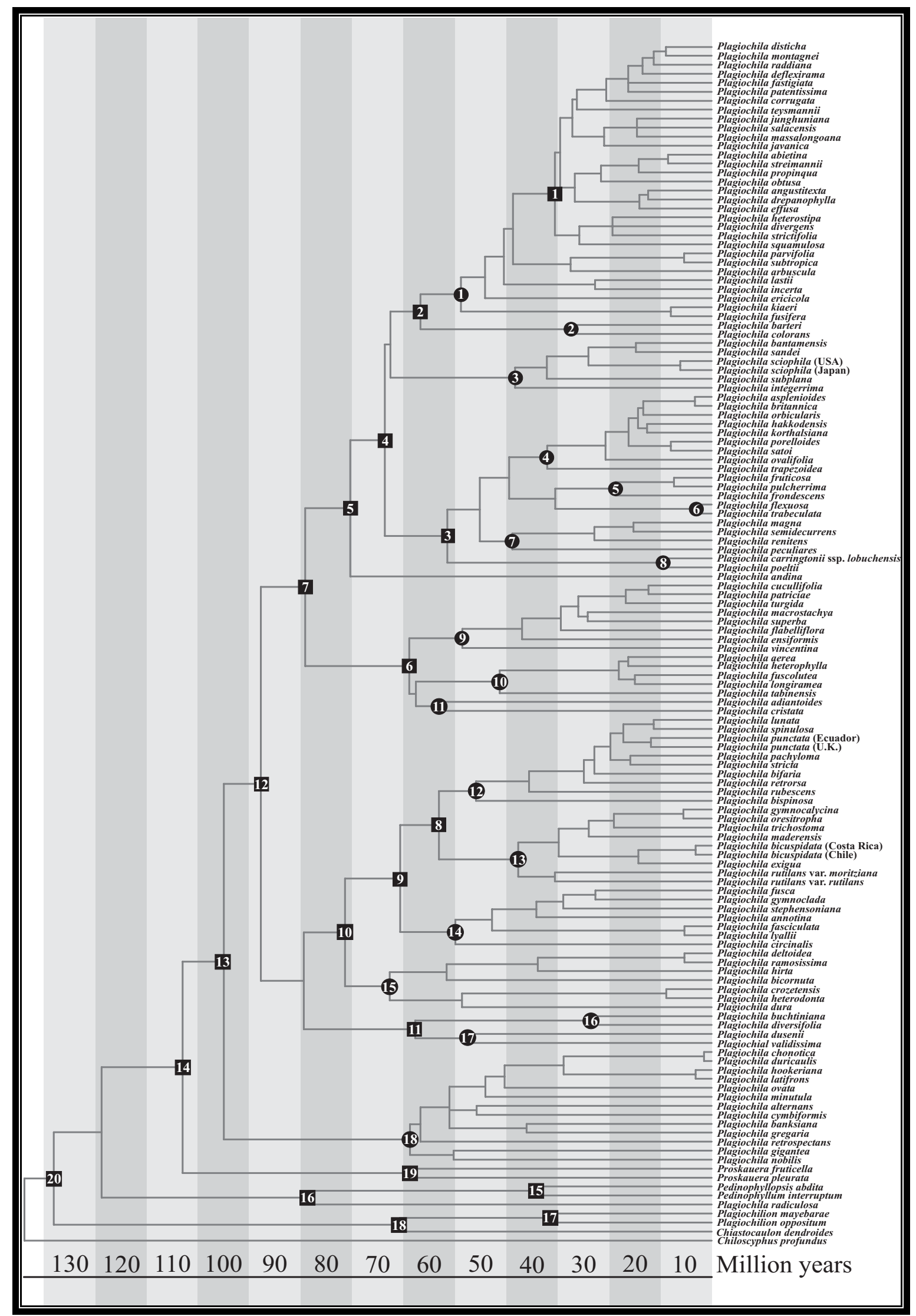

Figure 11 Chronogram of Plagiochilaceae and Chiloscyphus. Numbered points refer to sections of Plagiochila. Numbered boxes refer to nodes with Bayesian support above section level. 


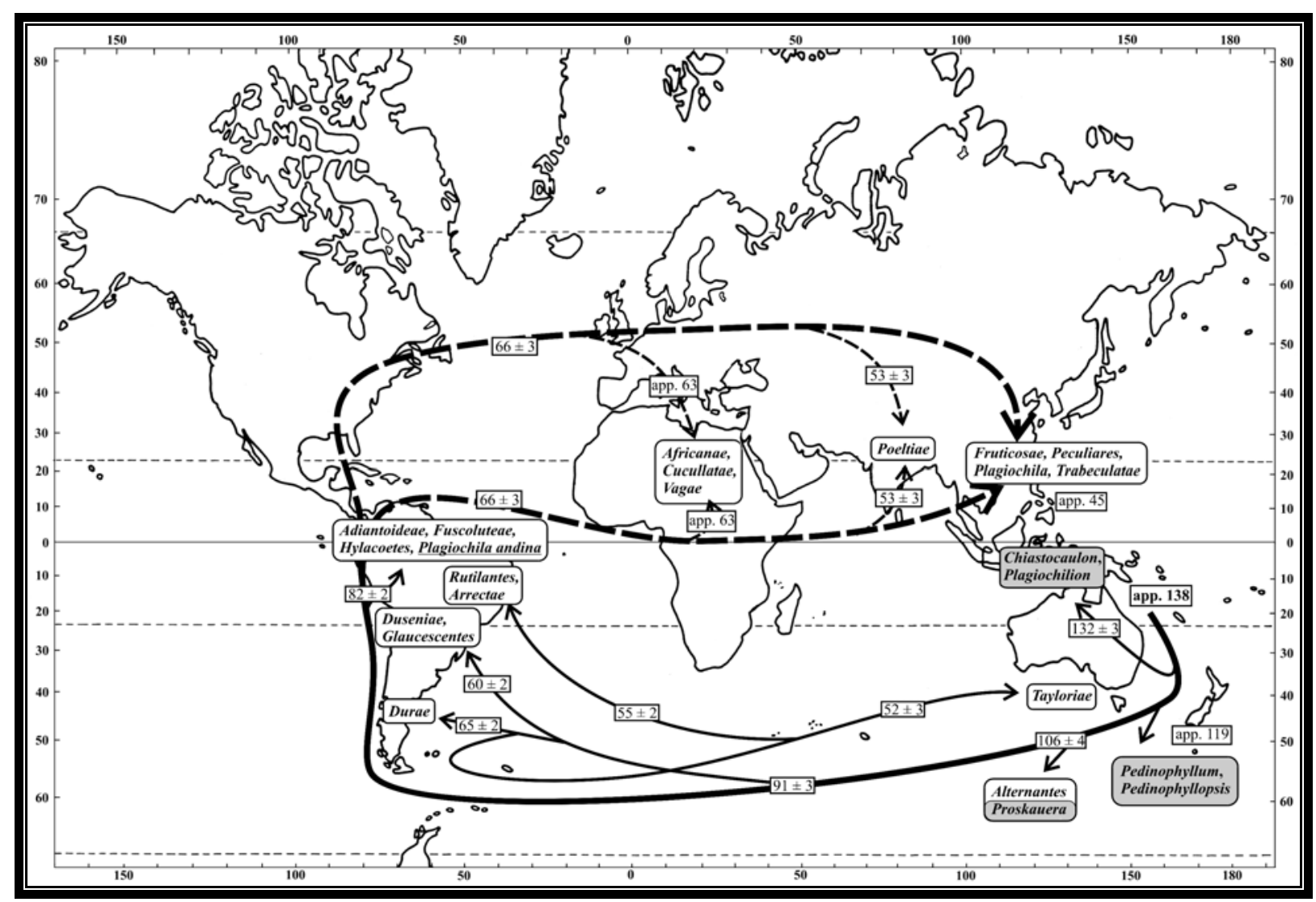

Figure 12 Assumed dispersal routes of Plagiochilaceae. Dates of splitting events are given in million years rounded to whole number (Tab. 12). Approximate dates refer to unsupported nodes. Rounded boxes indicate lineages $($ white $=$ sections of Plagiochila, grey $=$ other genera of Plagiochilaceae). Stroked arrows refer to alternative dispersal routes across the Atlantic Ocean. 
Table 12 Age of selected nodes of Plagiochilaceae. Ages are given in million years.

\begin{tabular}{|c|c|c|c|c|c|}
\hline node description & node & mean & $\begin{array}{l}\text { standard } \\
\text { deviation }\end{array}$ & minimum age & maximum age \\
\hline Adiantoideae & (11) & 54.88 & 8.18 & 41.76 & 71.30 \\
\hline Africanae & 2 & 28.47 & 4.37 & 22.61 & 62.08 \\
\hline Alternantes & $(18$ & 60.70 & 5.35 & 32.81 & 75.17 \\
\hline Arrectae & (12) & 47.44 & 1.73 & 42.45 & 56.45 \\
\hline Cucullatae & 3 & 39.53 & 1.65 & 31.83 & 52.22 \\
\hline Glaucescentes & $(16$ & 23.56 & 1.72 & 16.42 & 30.02 \\
\hline Fruticosae & 6 & 19.36 & 1.14 & 14.29 & 26.74 \\
\hline Fuscoluteae & (10) & 42.64 & 3.82 & 34.07 & 57.37 \\
\hline Duseniae & (1) & 47.83 & 1.98 & 37.25 & 61.48 \\
\hline Durae & (15) & 64.76 & 1.88 & 58.12 & 76.22 \\
\hline Hylacoetes & 9 & 50.18 & 3.53 & 38.65 & 66.46 \\
\hline Peculiares & 9 & 40.14 & 2.50 & 28.07 & 56.14 \\
\hline Plagiochila & 4 & 33.10 & 3.45 & 27.18 & 50.95 \\
\hline Poeltiae & 8 & 9.79 & 0.72 & 6.72 & 12.76 \\
\hline Rutilantes & 13 & 38.94 & 1.50 & 34.66 & 46.35 \\
\hline Tayloriae & (14) & 51.54 & 2.07 & 40.58 & 61.47 \\
\hline Trabeculatae & 6 & 2.98 & 0.35 & 2.38 & 4.00 \\
\hline Vagae & (1) & 50.41 & 2.59 & 41.74 & 65.07 \\
\hline $\begin{array}{l}\text { second colonisation wave of section } \\
\text { Vagae }\end{array}$ & 1 & 31.57 & 2.86 & 25.81 & 60.00 \\
\hline $\begin{array}{l}\text { separation of sections Africanae and } \\
\text { Vagae }\end{array}$ & $\mathbf{2}$ & 58.57 & 2.36 & 51.79 & 72.85 \\
\hline split of Poeltiae & 3 & 53.18 & 2.89 & 36.31 & 70.65 \\
\hline colonisation of Africa & 4 & 65.75 & 3.34 & 54.83 & 76.87 \\
\hline split of Plagiochila andina & 5 & 72.66 & 2.38 & 65.70 & 85.52 \\
\hline $\begin{array}{l}\text { split between Hylacoetes and } \\
\text { Adiantoideae / Fuscoluteae }\end{array}$ & 6 & 60.82 & 3.93 & 50.42 & 81.27 \\
\hline $\begin{array}{l}\text { colonization of northern South } \\
\text { America by the main lineage }\end{array}$ & 7 & 81.70 & 2.37 & 74.45 & 90.63 \\
\hline split between Arrectae and Rutilantes & $\mathbf{8}$ & 54.87 & 1.94 & 49.16 & 65.22 \\
\hline $\begin{array}{l}\text { split between Arrectae / Rutilantes and } \\
\text { Tayloriae }\end{array}$ & $\mathbf{9}$ & 62.63 & 2.14 & 56.20 & 74.42 \\
\hline $\begin{array}{l}\text { split between Arrectae / Rutilantes / } \\
\text { Tayloriae and Durae }\end{array}$ & 10 & 73.71 & 2.49 & 66.30 & 92.34 \\
\hline $\begin{array}{l}\text { split between Glaucescentes and } \\
\text { Duseniae }\end{array}$ & 11 & 59.64 & 2.39 & 48.60 & 71.68 \\
\hline $\begin{array}{l}\text { colonisation of Patagonia by the main } \\
\text { lineage }\end{array}$ & 12 & 90.63 & 3.26 & 78.49 & 100.64 \\
\hline split of Alternantes and rest of genus & 13 & 98.06 & 2.98 & 89.96 & 110.81 \\
\hline genus Plagiochila & 14 & 106.35 & 4.21 & 96.69 & 131.46 \\
\hline $\begin{array}{l}\text { split of Pedinophyllopsis and } \\
\text { Pedinophyllum }\end{array}$ & 15 & 35.13 & 6.18 & 21.25 & 62.42 \\
\hline $\begin{array}{l}\text { origin of the Pedinophyllopsis / } \\
\text { Pedinophyllum clade }\end{array}$ & 16 & 81.07 & 12.38 & 53.35 & 111.29 \\
\hline genus Plagiochilion & 17 & 32.56 & 4.33 & 21.90 & 68.56 \\
\hline genus Chiastocaulon & 18 & 62.68 & 5.07 & 32.41 & 107.72 \\
\hline genus Proskauera & 19 & 60.83 & 4.98 & 50.95 & 73.57 \\
\hline split of Acrochila and Plagiochilaceae & 20 & 132.26 & 3.13 & 109.44 & 133.55 \\
\hline
\end{tabular}




\section{Discussion and Conclusions}

The first aim of this study was to construct a phylogenetic tree of Plagiochilaceae. Three different genetic markers were sequenced (ITS, $r p s 4, r b c \mathrm{~L}$ ) for 120 species of Plagiochila and seven species of other genera (Acrochila biserialis, Chiastocaulon dendroides, Pedinophyllopsis abdita, Pedinophyllum interruptum, Plagiochilion mayebarae, Plagiochilion oppositum, Proskauera fruticella, Proskauera pleurata).

Secondary structures of the ITS1 and ITS2 sequences were determined, leading to one stable structure for each marker. The results are congruent with literature, further strengthening the hypothesis that function of these spacers is maintained by structure rather than primary sequence (Coleman et al., 1998; Coleman and Mai, 1997; Coleman and Vacquier, 2002; Mai and Coleman, 1997; Musters et al., 1990; van der Sande et al., 1992).

Some sequences of the rps4 and $r b c \mathrm{~L}$ dataset (Plagiochila adiantoides, Plagiochila porelloides, Pedinophyllum interruptum, Chiastocaulon dendroides, Pedinophyllopsis abdita, Acrochila biserialis, Plagiochilion mayebarae, Plagiochilion oppositum) together with other sequences from GenBank, chosen based on recent literature (Heinrichs et al., 2005b), were used to evaluate the morphological concept of Plagiochilaceae against molecular data. The results are biased. While the rps 4 dataset supports the family in its current circumscription, in the $r b c \mathrm{~L}$ dataset Acrochila biserialis is placed outside Plagiochilaceae. Thus, the placement of Acrochila in Plagiochilaceae seems at least doubtful.

Additionally, it was found that Pedinophyllum interruptum and Pedinophyllum truncatum are placed in different clades in the rps4 and $r b c \mathrm{~L}$ trees ( $P$. interruptum in Plagiochilaceae, P. truncatum in "Jamesionelloideae", sensu Heinrichs et al., 2005b). As P. interruptum is the type of Pedinophyllum (Schuster, 1959) P. truncatum will have to be excluded from the genus in further studies on Pedinophyllum. (Unpublished sequences of the author support this finding.)

The datasets of all three markers were analysed separately. The differences between the resulting trees are most likely caused by too dense a taxon sampling as they vanish when reducing the number of included taxa, allowing for a combined analysis of the datasets.

The combined analyses led to a tree that is better resolved and statistically supported than the single gene trees (Cox et al., 2004; Davis, 2004; Goffinet et al., 2004; Groth et al., 2004b; Groth and Heinrichs, 2003). Distance plots of the single markers suggested saturated mutations in the transitions of the $3^{\text {rd }}$ codon positions of rps4 and $r b c L$ (Cox et al., 2004). However, their exclusion greatly reduced the resolution of the tree (Yang, 1998). 
In Plagiochila 18 well supported groups could be identified, referred to as sections (Groth et al., 2003; Groth et al., 2004b; Groth and Heinrichs, 2003; Heinrichs, 2002). Two of these, sections Duseniae, and Tayloriae are represented for the first time in molecular analyses.

Thirty four morphological characters, evaluated from literature, were mapped on the ML tree of the combined analyses, using MacClade (Maddison and Maddison, 2000). The results show that the morphological delimitation of the analysed genera holds true.

At the sectional level in Plagiochila, morphology mapping showed a high degree of homoplasy in these groups (Groth et al., 2003; Groth et al., 2004b; Groth and Heinrichs, 2003; Heinrichs, 2002). Only the section Glaucescentes could be defined by synapomorphic characters (e.g. Heinrichs et al., 2000b); the rest has to be defined by sets of characters which do not occur in all species of the section (Heinrichs, 2002). Autapomorphic characters are rare in Plagiochila. Only Plagiochila dura can be identified by unique morphological characters. It is shown that sporophytic characters in Plagiochilaceae tend to be more able to answer systematic questions at low taxonomic levels, while gametophytic characters are able to distinguish higher taxonomical groups. This was also found in Amblystegiaceae, where it could be shown that sporophytic characters are adaptations to the habitat of the species (Vanderpoorten et al., 2002). Nevertheless, due to the limited number of characters and the lack of sporophytes for many species, this might be changed by extensive morphological work on Plagiochilaceae. In other groups of liverworts, however, sporophyte characters are more abundant than gametophytic characters (Gradstein, 1994; Gradstein et al., 2003; Weis, 2001)

The ML tree of the combined dataset also allows insight in the phylogenetic structure of both the family and the genus Plagiochila. The genera Chiastocaulon, Plagiochilion, Pedinophyllopsis, Pedinophyllum, and Proskauera are placed at the base of the tree, while Plagiochila represents the crown group (Plagiochilidium and Xenochila were not analysed) (Figs. 25 / 26). The molecular differences between the single genera of the family, albeit well supported, are small.

Chiastocaulon and Plagiochilion are placed sister to each other, both sharing ventral intercalar branches. Also Pedinophyllopsis abdita and Pedinophyllum interruptum form a clade, accompanied by Plagiochila radiculosa. All three taxa are characterized by rhizoids occurring on the whole plant (and are not restricted to lower parts of the stem). However, it could be shown that the placement of Plagiochila radiculosa is instable and that greater morphological affinities exist to basal representatives of Plagiochila. 
The question arises whether the division of Plagiochilaceae into one very big and several very small genera is justified. While the phenomenon of one giant genus next to some very small genera in one family is not uncommon in botany (e.g. Hendrichs et al., 2004b; Hendrichs et al., 2004a; Martins and Barkman, 2005; Shaw et al., 2003a), in Plagiochilaceae generic delimitation is hampered by the low number of morphological characters separating the groups. The difficulties in classifying Plagiochila radiculosa illustrate the problems in the systematics of this family.

Nearly all species nowadays assigned to genera of Plagiochilaceae other then Plagiochila have originally been assigned to this genus. They have only later been excluded, based on few morphological differences (Pedinophyllum = monoecious; Plagiochilion $=$ sub-opposite leaves; Chiastocaulon, Plagiochilion $=$ ventral intercalar branching, Proskauera $=$ spherical papillae). Plagiochila is defined by dioecious condition, alternating (rarely opposite) leaves, lateral branching, and a laterally compressed perianth with dorsal keel. The reintroduction of the smaller genera into the genus would eliminate all diagnostic characters of Plagiochila except for the laterally compressed perianth [which also occurs in other Hepaticae (Schuster and Engel, 1982)].

It is also possible to break up Plagiochila and accept the sections as genera. However, the lack of morphological synapomorphies for these groups would result in a great number of ill defined genera. Another option is the division of Plagiochila into few larger units.

Many attempts have been made to subdivide Plagiochila into several subgenera of various sizes (e.g. Carl, 1931a; Inoue, 1984; Inoue and Schuster, 1971; Schuster, 1959; Schuster, 1980). However, molecular methods have led to either exclusion as an own genus or synonymy with other subgenera (e.g. Groth et al., 2003; Groth et al., 2004b; Groth and Heinrichs, 2003; Heinrichs, 2002).Heinrichs 200x

Based on molecular data the sections of the genus are grouped in three clades. Adiantoideae, Fuscoluteae, and Hylacoetes form a well supported group [clade "A", as discussed in Groth and Heinrichs (2003)]. Sister to this group would be the clade comprised of sections Vagae, Africanae, Cucullatae, Plagiochila, Fruticosae, Trabeculatae, Peculiares, and Poeltiae [clade "B”, (Groth and Heinrichs, 2003)]. The sections Arrectae, Rutilantes, Tayloriae, Durae, and Glaucescentes [clade "C", (Groth and Heinrichs, 2003)] form the third group. None of these three clades can be defined by morphological characters.

They may be defined based on their origin, however, as assumed by the biogeographical analyses. Accordingly, clade A is strictly neotropical in origin, while clade B possibly originated in Africa. Clade C possibly originated in Patagonia and Antarctica. 
The placement of species in these clades is only possible by molecular investigations. Therefore, a subdivision of Plagiochila into major clades that are easily recognized seems not possible at the moment. It is concluded that the present subdivision of the family into one very big and several small genera is justified; the inclusion of the small genera in Plagiochila or the break up of the giant genus leads to groups with poorer morphological circumscription than the current ones.

The second aim of this study was to identify the possible geographic origin and the favoured dispersal routes and mechanisms of the family. This was achieved by plotting the current distribution of the analysed species on the ML tree and reconstructing the historical distributions using MacClade (Maddison and Maddison, 2000). The model resulting from these analyses places the origin of the family (and all analysed genera) in Australasia. After that Plagiochila has possibly extended its range over South America to Africa, from which Asia has been colonized. It remains unclear whether Africa has been colonized directly from South America across a considerably smaller Atlantic Ocean, or by a land connection between North America and Europe. Climatic data and fossil record support the latter possibility. However, it is also possible that the observed distribution patterns of the family result from completely different dispersal routes, followed by several extinction events. For example, Africa has undergone several drought periods greatly reducing the local flora (Axelrod and Raven, 1978)

Together with the dispersal routes of the sections of Plagiochila, it appears that the family basically disperses across land masses. Over-sea dispersal is possible, but not the rule.

It seems likely that most of the long range dispersal events are based on wind driven spores, as these have the highest possibility to survive the environmental stress during the travel (van Zanten and Gradstein, 1988). According to recent literature on this topic, wind driven long range dispersal across the Atlantic is most likely to occur from east to west, accounting for the prevailing wind currents (Renner, 2004; van Zanten and Gradstein, 1988). Western winds across the Atlantic are extremely rare (Grodsky et al., 2003; Renner, 2004). However, as some dispersal events in Plagiochilaceae possibly have occurred from South America to Africa, it is concluded that regular wind currents may not be necessary to establish stable populations by long range dispersal. Of course, wind currents may also change during greater time scale, providing the necessary west $\rightarrow$ east vector. 
The centre of clade diversity can be found in Asia (11 sections, 8 genera), where the oldest and youngest elements of the family meet. Nevertheless, the diversity in South America is only slightly lower (12 sections, 1 genus), while Africa (6 sections, 1 genus) is relatively poor with respect to Plagiochilaceae.

The third and final aim of this study was to test the possibility of calibrating a molecular clock. Although only three time constrains are available, some results could be achieved. Putting together the calculated ages for the main lineage of Plagiochila / Plagiochilaceae and the assumed dispersal events, it appears that the family has always extended its range to the closest landmasses. It is also shown that while liverworts are assumed to be the oldest extant lineage of land plants (Kenrick and Crane, 1997; Knoop, 2004; Qiu et al., 1998), Plagiochilaceae are relatively young.

\section{Future aspects}

The analyses of approximately $25 \%$ of the species of Plagiochilaceae (So and Grolle, 2000a) led to a very well resolved and supported topology of the family. The molecular data will allow for quick and sure placement of new species into this framework.

However, more data on the Patagonian flora as well as a more closely sampling of the genera of Plagiochilaceae other than Plagiochila is needed to revise the position of Plagiochila radiculosa and finally circumscribe the molecular delimitation of the family.

The morphological analyses revealed a lack of characters to define natural species groups in Plagiochilaceae. While this has also been found in other plant groups (Ranker et al., 2004; Vanderpoorten et al., 2002), it might be possible to increase the number of systematically relevant morphological characters by evaluating so far neglected features (Ranker et al., 2004).

The biogeographical analyses in combination with the molecular clock allowed to develop historical dispersal scenarios for the family. A future integration of phylogenetic and (paleo-) climatic data might further shed light on the historical distributions of Plagiochilaceae. 


\section{Literature}

Akaike, H. (1974). New Look at Statistical-Model Identification. Ieee Transactions on Automatic Control. AC19: 716 - 723.

Álvarez, I. and J. F. Wendel (2003). Ribosomal ITS sequences and plant phylogenetic inference. Molecular Phylogenetics and Evolution. 29: 417 - 434.

Axelrod, D. I. and P. H. Raven. (1978) Late Cretaceous and Tertiary vegetation history of Africa. In: Biogeography and ecology in southern Africa. Werger, M. J. A. (Editors). Dr. W. Junk bv, The Hague, The Netherlands. 77 - 130.

Ballard, H. E. and K. Sytsma (2000). Evolution and biogeography of the woody hawaiian violets (Viola, Violaceae): arctic origins, herbaceous ancestry and bird dispersal. Evolution. 54: 1521 - 1532.

Barker, F. K. and F. M. Lutzoni (2002). The utility of the incongruence length difference test. Systematic Biology. 51: 625 - 637.

Bremer, K., E. M. Friis, and B. Bremer (2004). Molecular phylogenetic dating of asterid flowering plants shows early Cretaceous diversification. Systematic Biology. 53: 496 505.

Buch, H. (1936) Suomen Maksasammalet. Helsinki. 1 - 116, Figures 1 - 35.

Buch, H., A. W. Evans, and F. Verdoorn (1938). A preliminary check list of the Hepaticae of Europe and America (north of Mexico). Annals of Bryology. 10: 3 - 8.

Buckley, T. R. (2002). Model misspecification and probabilistic tests of topology: Evidence from empirical data sets. Systematic Biology. 51: 509 - 523.

Buckley, T. R., P. Arensburger, C. Simon, and G. K. Chambers (2002). Combined data, Bayesian phylogenetics, and the origin of the New Zealand cicada genera. Systematic Biology. 51: 4 - 18. 
Buckley, T. R. and C. W. Cunningham (2002). The effects of nucleotide substitution model assumptions on estimates of nonparametric bootstrap support. Molecular Biology and Evolution. 19: 394 - 405.

Carl, H. (1931a). Die Arttypen und die systematische Gliederung der Gattung Plagiochila Dum. Annals of Bryology. suppl. 2: 1 - 170.

Carl, H. (1931b). Morphologische Studien an Chiastocaulon Carl, einer neuen Lebermoosgattung. Flora. 126: 45 - 60.

Coleman, A. W. and J. C. Mai (1997). Ribosomal DNA ITS-1 and ITS-2 sequence comparisons as a tool for predicting genetic relatedness. Journal of Molecular Evolution. 45: 168 - 177.

Coleman, A. W., R. M. Preparata, B. Mehrotra, and J. C. Mai (1998). Derivation of the secondary structure of the ITS-1 transcript in Volvocales and its taxonomic correlations. Protist. 149: 135 - 146.

Coleman, A. W. and V. D. Vacquier (2002). Exploring the phylogenetic utility of ITS sequences for animals: A test case for abalone (Haliotis). Journal of Molecular Evolution. 54: 246 - 257.

Cox, C. J., B. Goffinet, A. J. Shaw, and S. B. Boles (2004). Phylogenetic relationships among the mosses based on heterogeneous Bayesian analysis of multiple genes from multiple genomic compartments. Systematic Botany. 29: 234 - 250.

Darlu, Pierre and Guillaume Lecointre (2002). When Does the Incongruence Length Difference Test Fail? Molecular Biology and Evolution. 19: 432 - 437.

Davis, C. C., C. D. Bell, S. Mathews, and M. J. Donoghue (2002). Laurasian migration explains Gondwanan disjunctions: Evidence from Malpighiaceae. Proceedings of the National Academy of Sciences of the United States of America. 99: 6833 - 6837.

Davis, E. C. (2004). A molecular phylogeny of leafy liverworts (Jungermanniidae: Marchantiophyta). Monographs in systematic botany from the Missouri Botanical Garden. 98: 61 - 86. 
De Luna, E., A. E. Newton, A. Withey, D. Gonzalez, and B. D. Mishler (1999). The transition to pleurocarpy: A phylogenetic analysis of the main diplolepidous lineages based on rbcL sequences and morphology. Bryologist. 102: 634 - 650.

Dingle, R. V., S. A. Marenssi, and M. Lavelle (1998). High latitude Eocene climate deterioration: evidence from the northern Antarctic Peninsula. Journal of South American Earth Sciences. 11: 571 - 579.

Dugas, M. (1929). Contribution a l'étude du genre "Plagiochila" Dum. Annales des Sciences Naturelles, Botanique, Série.10. 11: 1 - 199.

Evans, A. W. (1939). The classification of the Hepaticae. The botanical review. 5: 49 - 96.

Farris, James S., Mari Kallersjo, Arnold G. Kluge, and Carol Bult (1994). Testing Significance of Incongruence. Cladistics. 10: 315 - 319.

Felsenstein, J. (1985). Confidence-Limits on Phylogenies - An Approach Using the Bootstrap. Evolution. 39: 783 - 791.

Goffinet, B., A. J. Shaw, C. J. Cox, N. J. Wickett, and S. B. Boles (2004). Phylogenetic inferences in the Orthotrichoideae (Orthotrichaceae, Bryophyta) based on four loci from all genomes. Monographs in systematic botany from the Missouri Botanical Garden. 98: 270 - 289.

Gottsche, A. C. M, J. B. G. Lindenberg, and C. G. Nees ab Esenbeck. (1844) Synopsis hepaticarum. Meissner, Hamburg.

Gradstein, S. R. (1975). A Taxonomic Monograph of the Genus Acrolejeunea (Hepaticae). Bryophytorum Bibliotheca. 4: 1 - 162.

Gradstein, S. R. (1994). Lejeuneaceae: Ptychantheae, Brachiolejeuneae. Flora Neotropica Monograph. 62: 1 - 216.

Gradstein, S. R. (1995) Diversity of Hepaticae and Anthocerotae in montane forests of the tropical Andes. In: Biodiversity and conservation of Neotropical montane forests. 
Churchill, S. P., Balslev, H., Forero, E., and Luteyn, J. L. (Editors). The new York Botanical Garden, New York. 321 - 334.

Gradstein, S. R., T. Pócs, and J. Váña (1983). Disjunct Hepaticae in Tropical America and Africa. Acta Botanica Hungarica. 29: 127 - 171.

Gradstein, S. R. and M. E. Reiner-Drehwald (1995). Szweykowskia, a new genus of Plagiochilaceae (Hepaticae) from tropical America. Fragmenta floristica et geobotanica. 40: 31 - 38 .

Gradstein, S. R., M. E. Reiner-Drehwald, and H. Schneider (2003). A phylogenetic analysis of the genera of Lejeuneaceae (Hepaticae). Botanical Journal of the Linnean Society. 143: $391-410$.

Grodsky, S. A., J. A. Carton, and S. Nigam (2003). Near surface westerly wind jet in the Atlantic ITCZ. Geophysical Research Letters. 30

Grolle, R. (1960). Über Plagiochila monoica St., P. carnosa Herz. und P. lobata Kaal. und ihre Beziehungen zu Pedinophyllum. Nova Hedwigia. 2: 287 - 291.

Grolle, R. (1969) Grossdisjunktionen in Artarealen lateinamerikanischer Lebermoose. In: Biogeography and Ecology in South America. Fittkau, E. J., Illies, J., Klinge, H., Schwabe, G. H, and Sioli, H. (Editors). Junk, The Hague, 562 - 582.

Grolle, R. (1983). Nomina generica Hepaticarum: references, types and synonymies. Acta Botanica Fennica. 121: 1 - 62.

Grolle, R. and J. Heinrichs (1999). Redescription and synonymy of Plagiochila aerea Taylor 1846 (Hepaticae), first described as Lycopodium pinnatum by Lamarck 1792. Nova Hedwigia. 68: 511 - 525.

Grolle, R. and J. Heinrichs (2003). Eocene Plagiochila groehnii sp. nov. - the first representative of Plagiochilaceae in Baltic amber. Cryptogamie Bryologie. 24: 289 293. 
Groth, H and J. Heinrichs (2005). Maximum likelihood analyses of chloroplast gene $r b c \mathrm{~L}$ sequences indicate relationships of Syzygiella (Jungermanniopsida) with Lophoziaceae rather than Plagiochilaceae. Cryptogamie, Bryologie. 26: 49 - 57.

Groth, H., F. A. Hartmann, R. Wilson, and J. Heinrichs (2004a). NrITS sequences and morphology indicate a synonymy of the Patagonian Plagiochila rufescens Steph. and the Central American Plagiochila bicuspidata Gottsche. Cryptogamie, Bryologie. 25 (1): 19 - 28 .

Groth, H. and J. Heinrichs (2003). Reinstatement of Chiastocaulon Carl (Plagiochilaceae), based on evidence from nuclear ribosomal ITS and chloroplast gene rps4 sequences. Plant Biology. 5: 615 - 622.

Groth, H., G. Helms, and J. Heinrichs (2002). The systematic status of Plagiochila sects. Bidentes Carl and Caducilobae Inoue (Hepaticae) inferred from nrDNA ITS sequences. Taxon. 51: 675 - 684 .

Groth, H., M. Lindner, and J. Heinrichs (2004b). Phylogeny and biogeography of Plagiochila (Plagiochilaceae) based on nuclear and chloroplast DNA sequences. Monographs in systematic botany from the Missouri Botanical Garden. 98: 365 - 387.

Groth, H., M. Lindner, R. Wilson, F. A. Hartmann, M. Schmull, S. R. Gradstein, and J. Heinrichs (2003). Biogeography of Plagiochila (Hepaticae): natural species groups span several floristic kingdoms. Journal of Biogeography. 30: 965 - 978.

Hall, T. A. (1999). BioEdit: a user-friendly biological sequence alignment editor and analysis program for Windows 95/98/NT. Nucleid Acids Symposium. 41: 95 - 98.

Hartley, A. J. and G. Chong (2002). Late Pliocene age for the Atacama Desert: Implications for the desertification of western South America. Geology. 30: 43 - 46.

Hartley, A. J., G. Chong, J. Houston, and A. E. Mather (2005). 150 million years of climatic stability: evidence from the Atacama Desert, northern Chile. Journal of the Geological Society. 162: 421 - 424. 
Hässel de Menéndez, G. G. (1983). Informaciones nomenclaturales sobre las especies del genéro Plagiochila (Hepaticae) de Argentina y Chile. Boletin de la sociedad Argentina da Botanica. 22: 87 - 129.

Hässel de Menéndez, G. G. (1990). Patagonian bryophytes 11. On Arctoscyphus ronsmithii Hässel (Hepatophyta), a new genus and species, with comments on Pedinophyllopsis Schust. et Inoue. Lindbergia. 16: 133 - 137.

Hässel de Menéndez, G. G. (2004). Andinopatagonian species of Plagiochila (Plagiochilaceae, Marchantiophyta). I. sectio Robustae Carl emend. Hässel and II. sectio Equitantes Carl emend. Hässel. Journal of the Hattori Botanical Laboratory. 96: 245 - 260.

He-Nygrén, X., I. Ahonen, A. Juslén, D. Glenny, and S. Piippo (2004). Phylogeny of Liverworts - beyond a leaf and a thallus. Monographs in systematic botany from the Missouri Botanical Garden. 98: 87 - 118.

He-Nygrén, X. and S. Piippo (2003). Phylogenetic relationships of the generic complex Chiloscyphus - Lophocolea - Heteroscyphus (Geocalycaceae, Hepaticae): Insights from three chloroplast genes and morphology. Annales Botanici Fennici. 40: 317 329.

Heinrichs, J, M Lindner, Henk Groth, J Hentschel, K Feldberg, C Renker, J J Engel, M von Konrat, D G Long, and H Schneider (2006). Goodbye or welcome Gondwana? insights into the phylogenetic biogeography of the leafy liverwort Plagiochila with a description of Proskauera, gen. nov. (Plagiochilaceae, Jungermanniales). Plant Systematics and Evolution. 258: 227 - 250.

Heinrichs, J, M. Lindner, S. R. Gradstein, H. Groth, V. Buchbender, A. Solga, and E. Fischer (2005a). Origin and subdivision of Plagiochila (Jungermanniidae: Plagiochilaceae) in tropical Africa based on evidence from nuclear and chloroplast DNA sequences and morphology. Taxon. 54: 317 - 333. 
Heinrichs, J. (2002). A taxonomic revision of Plagiochila sect. Hylacoetes, sect. Adiantoideae and sect. Fuscoluteae in the Neotropics with a preliminary subdivision of Neotropical Plagiochilaceae into nine lineages. Bryophytorum Bibliotheca. 58: 1 - 184, App. 1-5.

Heinrichs, J., H. Anton, S. R. Gradstein, and R. Mues (2000a). Systematics of Plagiochila sect. Glaucescentes Carl (Hepaticae) from tropical America: a morphological and chemotaxonomical approach. Plant Systematics and Evolution. 220: 115 - 138.

Heinrichs, J., H. Anton, S. R. Gradstein, R. Mues, and I. Holz (2000b). Surface wax, a new taxonomic feature in Plagiochilaceae. Plant Systematics and Evolution. 225: 225 233.

Heinrichs, J. and S. R. Gradstein (2000). A revision of Plagiochila sect. Crispatae and sect. Hypnoides (Hepaticae) in the Neotropics. I. Plagiochila disticha, P.montagnei and P.raddiana. Nova Hedwigia. 70: 161 - 184.

Heinrichs, J., S. R. Gradstein, and R. Grolle (1998). A revision of the neotropical species of Plagiochila (Dumort.) Dumort. (Hepaticae) described by Olof Swartz. Journal of the Hattori Botanical Laboratory. 85: 1 - 32.

Heinrichs, J., S. R. Gradstein, H. Groth, and M. Lindner (2003). Plagiochila cucullifolia var. anomala var. nov from Ecuador, with notes on discordant molecular and morphological variation in Plagiochila. Plant Systematics and Evolution. 242: 205 216.

Heinrichs, J., S. R. Gradstein, R. Wilson, and H. Schneider (2005b). Towards a natural classification of liverworts (Marchantiophyta) based on the chloroplast gene $r b c \mathrm{~L}$. Cryptogamie, Bryologie. 26: 131 - 150.

Heinrichs, J., H. Groth, S. R. Gradstein, D. S. Rycroft, W. J. Cole, and H. Anton (2001). Plagiochila rutilans (Hepaticae): A poorly known species from tropical America. Bryologist. 104: 350 - 361.

Heinrichs, J., H. Groth, I. Holz, D. S. Rycroft, C. Renker, and T. Proschold (2002a). The systematic position of Plagiochila moritziana, P. trichostoma, and P. deflexa based on 
ITS sequence variation of nuclear ribosomal DNA, morphology, and lipophilic secondary metabolites. Bryologist. 105: 189 - 203.

Heinrichs, J., H. Groth, M. Lindner, K. Feldberg, and D. S. Rycroft (2004a). Molecular, morphological, and phytochemical evidence for a broad species concept of Plagiochila bifaria (Hepaticae). Bryologist. 107: 28 - 40.

Heinrichs, J., H. Groth, M. Lindner, C. Renker, T. Pócs, and T. Pröschold (2004b). Intercontinental distribution of Plagiochila corrugata (Plagiochilaceae, Hepaticae) inferred from nrDNA ITS sequences and morphology. Botanical Journal of the Linnean Society. 146: 469 - 481.

Heinrichs, J., M. Lindner, and H. Groth (2004c). Sectional Classification of the North American Plagiochila (Hepaticae, Plagiochilaceae). The Bryologist. 107: 489 - 496.

Heinrichs, J., M. Lindner, H. Groth, and C. Renker (2005c). Distribution and synonymy of Plagiochila punctata (Taylor) Taylor, with hypotheses on the evolutionary history of Plagiochila sect. Arrectae (Plagiochilaceae, Hepaticae). Plant Systematics and Evolution. 250: 105 - 117.

Heinrichs, J., M. Lindner, and T. Pocs (2004d). nrDNA internal transcribed spacer data reveal that Rhodoplagiochila R.M Schust. (Marchantiophyta : Jungermanniales) is a member of Plagiochila sect. Arrectae Carl. Organisms Diversity \& Evolution. 4: 109 - 118.

Heinrichs, J., T. Pröschold, C. Renker, H. Groth, and D. S. Rycroft (2002b). Plagiochila virginica A. Evans rather than P. dubia Lindenb. \& Gottsche occurs in Macaronesia; placement in sect. Contiguae Carl is supported by ITS sequences of nuclear ribosomal DNA. Plant Systematics and Evolution. 230: 221 - 230.

Heinrichs, J., D. S. Rycroft, H. Groth, and W. J. Cole (2002c). Morphological and phytochemical studies of Plagiochila papillifolia Steph., a Neotropical liverwort new to Europe. Journal of Bryology. 24: 119 - 126.

Heinrichs, J., M. Sauer, and R. Grolle (2002d). Lectotypification and synonymy of Plagiochila sect. Vagae Lindenb. (Hepaticae). Cryptogamie, Bryologie. 23: 5 - 9. 
Hendrichs, M., S. Michalski, D. Begerow, F. Oberwinkler, and F. H. Hellwig (2004a). Phylogenetic relationships in Carex, subgenus Vignea (Cyperaceae), based on ITS sequences. Plant Systematics and Evolution. 246: 109 - 125.

Hendrichs, M., F. Oberwinkler, D. Begerow, and R. Bauer (2004b). Carex, subgenus Carex (Cyperaceae). A phylogenetic approach using ITS sequences. Plant Systematics and Evolution. 246: 89 - 107.

Hentschel, J, R Wilson, M. Burghardt, H.-J. Zündorf, H. Schneider, and J. Heinrichs (2006). Reinstatement of Lophocoleaceae (Jungermanniopsida) based on chloroplast gene rbcL data: exploring the importance of female involucres for the systematics of Jungermanniales. Plant Systematics and Evolutin. 258: 211 - 226.

Herzog, T. (1926) Geographie der Moose. G.Fischer, Jena.

Hill, R. S. (2001). Biogeography, evolution and palaeoecology of Nothofagus (Nothofagaceae): the contribution of the fossil record. Australian Journal of Botany. 49: $321-332$.

Hillis, D. M. and J. J. Bull (1993). An Empirical-Test of Bootstrapping as a Method for assessing confidence in phylogenetic analysis. Systematic Biology. 42: 182 - 192.

Huelsenbeck, J. P. and F. Ronquist (2001). MRBAYES: Bayesian inference of phylogenetic trees. Bioinformatics. 17: 754 - 755.

Inoue, H. (1964). The genus Plagiochilion. Journal of the Hattori Botanical Laboratory. 27: $51-72$.

Inoue, H. (1966a). Contributions to Knowledge of Plagiochilaceae of Southeastern Asia .8. Genus Plagiochilidium Herz. Botanical Magazine-Tokyo. 79: 345 - \&.

Inoue, H. (1966b). Contributions to the Knowledge of the Plagiochilaceae of Southeastern Asia, IX. Plagiochila autoica Steph. with a Review of Pedinophyllum. Bulletin of the Natural Science Museum Tokyo. 9: 571 - 575. 
Inoue, H. (1984) The genus Plagiochila in Southeast Asia. Academic Scientific Books, Tokyo. 1 - 142.

Inoue, H. (1987). Steereochila, a new genus of the Plagiochilaceae from the Neotropics. Memoirs of the New York Botanical Garden. 45: 279 - 282.

Inoue, H. and R. M. Schuster (1971). A Monograph of the New Zealand and Tasmanian Plagiochilaceae. Journal of the Hattori Botanical Laboratory. 34: 1 - 225.

Jones, E. W. (1962). African Hepatics XV. Plagiochila in tropical Africa. Transactions of the British Bryological Society. 4: 254 - 325.

Jørgensen, E. (1934) Norges levermoser. Berg.Mus.Skrif., 1 - 343, Kart. I-XXV.

Kenrick, Paul and Peter R. Crane (1997). The origin and early evolution of plants on land. Nature. 389: 33 - 39.

Knapp, Michael, Karen Stockler, David Havell, Frederic Delsuc, Federico Sebastiani, and Peter J. Lockhart (2005). Relaxed Molecular Clock Provides Evidence for LongDistance Dispersal of Nothofagus (Southern Beech). PLoS Biology. 3: e14

Knoop, V. (2004). The mitochondrial DNA of land plants: peculiarities in phylogenetic perspective. Current Genetics. 46: 123 - 139.

Langley, C. H. and W. M. Fitch (1974). Examination of Constancy of Rate of Molecular Evolution. Journal of Molecular Evolution. 3: 161 - 177.

Larget, B. and D. L. Simon (1999). Markov chain Monte Carlo algorithms for the Bayesian analysis of phylogenetic trees. Molecular Biology and Evolution. 16: 750 - 759.

Lemmon, A. R. and E. C. Moriarty (2004). The importance of proper model assumption in Bayesian phylogenetics. Systematic Biology. 53: 265 - 277.

Lewis, L. A., B. D. Mishler, and R. Vilgalys (1997). Phylogenetic relationships of the liverworts (Hepaticae), a basal embryophyte lineage, inferred from nucleotide 
sequence data of the chloroplast gene rbcL. Molecular Phylogenetics and Evolution. 7: 377 - 393.

Lindenberg, J. B. G. (1839) Monographia Hepaticarum Generis Plagiochilae. Henry \& Cohen, Bonn.

Lindner, M., T. Pócs, and J. Heinrichs (2004). On the occurence of Plagiochila stricta on Madagascar, new to Africa. Journal of the Hattori Botanical Laboratory. 96: 261 271 .

Maddison, D. R. and Maddison, W. P. (2000). MacClade 4: Analysis of Phylogeny and Character Evolution. Sinauer Associates, Sunderland, Massachusetts.

Maddison, D. R., D. L. Swofford, and W. P. Maddison (1997). Nexus: An extensible file format for systematic information. Systematic Biology. 46: 590 - 621.

Maddison, W P and Maddison, D R (2006). Mesquite: A modular system for evolutionary analysis.

Mai, J. C. and A. W. Coleman (1997). The internal transcribed spacer 2 exhibits a common secondary structure in green algae and flowering plants. Journal of Molecular Evolution. 44: 258 - 271.

Martins, Talline R. and Todd J. Barkman (2005). Reconstruction of Solanaceae Phylogeny Using the Nuclear Gene SAMT. Systematic Botany. 30: 435 - 447.

Mathews, D. H., J. Sabina, M. Zuker, and D. H. Turner (1999). Expanded sequence dependence of thermodynamic parameters improves prediction of RNA secondary structure. Journal of Molecular Biology. 288: 911 - 940.

McDaniel, S. F. and A. J. Shaw (2003). Phylogeographic structure and cryptic speciation in the trans-antarctic moss Pyrrhobryum minoides. Evolution. 57: 205 - 215.

McLoughlin, S. (2001). The breakup history of Gondwana and its impact on pre-Cenozoic floristic provincialism. Australian Journal of Botany. 49: 271 - 300. 
Meissner, K., J. P. Frahm, M. Stech, and W. Frey (1998). Molecular divergence patterns and infrageneric relationship of Monoclea (Monocleales, Hepaticae) - Studies in austral temperate rain forest bryophytes 1. Nova Hedwigia. 67: 289 - 302.

Müller, J., J. Heinrichs, and S. R. Gradstein (1999). A revision of Plagiochila sect. Plagiochila in the neotropics. Bryologist. 102: 729 - 746.

Müller, K. (1951) Die Lebermoose Europas (Musci hepatici). In: Dr. L. Rabenhorst's Kryptogamen-Flora, 3.Auflage. Leipzig. 3: 161 - 320, Figures 34 - 50.

Muñoz, J, A. M. Felicisimo, F. Cabezas, A. R. Burgaz, and I. Martinez (2004). Wind as a long-distance dispersal vehicle in the Southern Hemisphere. Science. 304: 1144 1147.

Musters, W., K. Boon, C. A. F. M. van der Sande, H. van Heerikhuizen, and R. J. Planta (1990). Functional-Analysis of transcribed Spacers of Yeast Ribosomal DNA. Embo Journal. 9: 3989 - 3996.

Nadot, S., R. Bajon, and B. Lejeune (1994). The Chloroplast Gene Rps4 As A Tool for the Study of Poaceae Phylogeny. Plant Systematics and Evolution. 191: 27 - 38.

Nelson, G. and P. Y. Ladiges (2001). Gondwana, vicariance biogeography and the New York School revisited. Australian Journal of Botany. 49: 389 - 409.

Nylander, J. A., F. Ronquist, J. P. Huelsenbeck, and J. L. Nieves-Aldrey (2004). Bayesian phylogenetic analysis of combined data. Systematic Biology. 53: 47 - 67.

Ohyama, K., H. Fukuzawa, T. Kohchi, H. Shirai, T. Sano, S. Sano, K. Umesono, Y. Shiki, M. Takeuchi, Z. Chang, S. Aota, H. Inokuchi, and H. Ozeki (1986). Chloroplast gene organization deduced from complete sequence of liverwort Marchantia polymorpha chloroplast DNA. Nature. 322: 572 - 574.

Page, R. D. M. (1996). TreeView: An application to display phylogenetic trees on personal computers. Computer Applications in the Biosciences. 12: 357 - 358. 
Posada, D. and T. Buckley (2004). Model selection and model averaging in phylogenetics: advantages of akaike information criterion and bayesian approaches over likelihood ratio tests. Systematic Biology. 53: 793 - 808.

Posada, D. and K. A. Crandall (1998). MODELTEST: testing the model of DNA substitution. Bioinformatics. 14: 817 - 818.

Qiu, Y. L., Y. Cho, J. C. Cox, and J. D. Palmer (1998). The gain of three mitochondrial introns identifies liverworts as the earliest land plants. Nature. 394: 671 - 674.

Ranker, T. A., A. R. Smith, B. S. Parris, J. M. O. Geiger, C. H. Haufler, S. C. K. Straub, and H. Schneider (2004). Phylogeny and evolution of grammitid ferns (Grammitidaceae): a case of rampant morphological homoplasy. Taxon. 53: 415 - 428.

Renker, C., J. Heinrichs, T. Pröschold, H. Groth, and I. Holz (2002). ITS sequences of nuclear ribosomal DNA support the generic placement and the disjunct range of Plagiochila (Adelanthus) carringtonii. Cryptogamie Bryologie. 23: 23 - 29.

Renner, S. (2004). Plant dispersal across the tropical Atlantic by wind and sea currents. International Journal of Plant Sciences. 165: S23 - S33.

Ronquist, F (1996). DIVA version 1.1., available by anonymous FTP from Uppsala University (ftp.uu.se or ftp.systbot.uu.se).

Ronquist, F. and J. P. Huelsenbeck (2003). MrBayes 3: Bayesian phylogenetic inference under mixed models. Bioinformatics. 19: 1572 - 1574.

Rycroft, D. S., W. J. Cole, J. Heinrichs, H. Groth, C. Renker, and T. Pröschold (2002). Phytochemical, morphological, and molecular evidence for the occurrence of the neotropical liverwort Plagiochila stricta in the Canary Islands, new to Macaronesia. Bryologist. 105: 363 - 372.

Rycroft, D. S., H. Groth, and J. Heinrichs (2004). Reinstatement of Plagiochila maderensis (Jungermanniopsida : Plagiochilaceae) based on chemical evidence and nrDNA ITS sequences. Journal of Bryology. 26: 37 - 45. 
Saiki, R. K., D. H. Gelfand, S. Stoffel, S. J. Scharf, R. Higuchi, G. T. Horn, K. B. Mullis, and H. A. Erlich (1988). Primer-directed enzymatic Amplification of DNA with a thermostable DNA-Polymerase. Science. 239: 487 - 491.

Sanderson, M. J. (2002). Estimating absolute rates of molecular evolution and divergence times: A penalized likelihood approach. Molecular Biology and Evolution. 19: 101 109.

Sanderson, M. J. (2003). r8s: inferring absolute rates of molecular evolution and divergence times in the absence of a molecular clock. Bioinformatics. 19: 301 - 302.

Sanmartin, I. and F. Ronquist (2004). Southern Hemisphere biogeography inferred by eventbased models: Plant versus animal patterns. Systematic Biology. 53: 216 - 243.

Schaumann, F., W. Frey, G. Hässel de Menéndez, and T. Pfeiffer (2003). Geomolecular divergence in the Gondwanan dendroid Symphyogyna complex (Pallaviciniaceae, Hepaticophytina, Bryophyta). Flora. 198: 404 - 412.

Schaumann, F., T. Pfeiffer, and W. Frey (2004). Molecular divergence patterns within the Gondwanan liverwort genus Jensenia (Pallaviciniaceae, Hepaticophytina, Bryophyta). Studies in Austral temperate rain forest bryophytes 25. Journal of the Hattori Botanical Laboratory. 96: 231 - 244.

Schiffner, V. (1900a) Die Hepaticae der Flora von Buitenzorg. Brill, Leiden.

Schiffner, V. (1900b). Exposito plantarum in itinere Suo Indico Annis 1893/94 suspecto collectarum. Akademie der Wissenschaften in Wien Mathematisch Naturwissenschaftliche Klasse Denkschriften. 70: 155 - 218.

Schneider, H., E. Schuettpelz, K. M. Pryer, R. Cranfill, S. Magallon, and R. Lupia (2004). Ferns diversified in the shadow of angiosperms. Nature. 428: 553 - 557.

Schofield, W. B. and H. A. Crum (1972). Disjunctions in bryophytes. Annales of the Missouri Botanical Garden. 59: 174 - 202.

Schroeder, F. G. (1998) Lehrbuch der Pflanzengeographie. Quelle und Meyer, Wiesbaden. 
Schuster, R. M. (1959). A monograph of the nearctic Plagiochilaceae I. American Midland Naturalist. 62: 1 - 166, Figures 1 - 14.

Schuster, R. M. (1980) The Hepaticae and Anthocerotae of North America, east of the hundredth meridian. Columbia University Press, New York. 1 - 1334, Figures 476 774.

Schuster, R. M. and J. J. Engel (1982). Austral Hepaticae .16. Gondwanalandic, Leptoscyphoideae (Geocalycaceae). Lindbergia. 8: 65 - 74.

Shaw, A. J. (2001). Biogeographic patterns and cryptic speciation in bryophytes. Journal of Biogeography. 28: 253 - 261.

Shaw, A. J., C. J. Cox, and S. B. Boles (2003a). Global patterns in peatmoss biodiversity. Molecular Ecology. 12: 2553 - 2570.

Shaw, A. J., S. F. McDaniel, O. Werner, and R. M. Ros (2002). New frontiers in bryology and lichenology - Phylogeography and phylodemography. Bryologist. 105: 373 - 383.

Shaw, A. J., O. Werner, and R. M. Ros (2003b). Intercontinental Mediterranean disjunct mosses: Morphological and molecular patterns. American Journal of Botany. 90: 540 550.

Shimodaira, H. and M. Hasegawa (1999). Multiple comparisons of log-likelihoods with applications to phylogenetic inference. Molecular Biology and Evolution. 16: 1114 1116.

So, M. L. (2000a). Plagiochila sect. Contiguae (Hepaticae) in Australasia and the Pacific, with description of Plagiochila subjavanica sp nov. Australian Systematic Botany. 13: $803-815$.

So, M. L. (2000b). Plagiochila sect. Plagiochila (Hepaticae) in SE Asia and Melanesia, with descriptions of two new species. New Zealand Journal of Botany. 38: 425 - 432.

So, M. L. (2001). Plagiochila (Hepaticae, Plagiochilaceae) in China. Systematic Botany Monographs. 60: 1 - 214. 
So, M. L. and R. Grolle (2000a). Checklist of Plagiochila (Hepaticae) in Asia. Journal of the Hattori Botanical Laboratory. 88: 199 - 243.

So, M. L. and R. Grolle (2000b). Studies on Plagiochila sect. Plagiochila (Hepaticae) in East and South Asia. Journal of Bryology. 22: 17 - 28.

Spruce, R. (1885). Hepaticae of the Amazon and the Andes of Peru and Ecuador. Transactions and Proceedings of the Botanical Society of Edinburgh. 15: 1 - 589, plates I - XXII.

Stech, M. and W. Frey (2004). Molecular circumscription and relationships of selected Gondwanan species of Haplomitrium (Calobryales, Haplomitriopsida, Hepaticophytina) - Studies in austral temperate rain forest bryophytes 24. Nova Hedwigia. 78: 57 - 70.

Stech, M., T. Pfeiffer, and W. Frey (2002). Molecular generic classification of the Hypopterygiaceae (Bryopsida) with the description of a new genus, Arbusculohypopterygium gen. nov. Studies in austral temperature rain forest bryophytes 10. New Zealand Journal of Botany. 40: 207 - 221.

Stephani, F. (1901) Species Hepaticarum. Volume II. Acrogynae. Georg \& C, Geneva.

Swofford, D. L. (2002) PAUP* Phylogenetic Analysis Using Parsimony (*and Other Methods). Version 4. Sinauer Associates, Sunderland.

Taberlet, P., L. Gielly, G. Pautou, and J. Bouvet (1991). Universal Primers for Amplification of 3 Noncoding Regions of Chloroplast DNA. Plant Molecular Biology. 17: 1105 1109.

Takhtajan, A. L. (1978) Floristitscheskie Oblasti Zemli. Leningrad.

Tsubota, H., T. Arikawa, H. Akiyama, E. De Luna, D. Gonzalez, M. Higuchi, and H. Deguchi (2002). Molecular phylogeny of hypnobryalean mosses as inferred from a large-scale dataset of chloroplast $r b c \mathrm{~L}$, with special reference to the Hypnaceae and possibly related families. Hikobia. 13: 645 - 665. 
Urmi, E. (1999). Über die relative Grösse von Arrealen bei Kryptogamen und Phanerogamen. Haussknechtia, Beihefte. 9: 377 - 389.

van der Sande, C. A. F. M., M. Kwa, R. W. Vannues, H. van Heerikhuizen, H. A. Raue, and R. J. Planta (1992). Functional analysis of Internal Transcribed Spacer 2 of Saccharomyces cerevisiae ribosomal DNA. Journal of Molecular Biology. 223: 899 910.

van Nues, R. W., J. M. J. Rientjes, C. A. F. M. van der Sande, S. F. Zerp, C. Sluiter, J. Venema, R. J. Planta, and H. A. Raue (1994). Separate Structural Elements Within Internal Transcribed Spacer 1 of Saccharomyces cerevisiae Precursor RibosomalRNA Direct the Formation of 17S and 26S Ribosomal-RNA. Nucleic Acids Research. 22: 912 - 919.

van Zanten, B. O. (1977). Experimental studies on trans-oceanic long-range dispersal of moss spores in the Southern Hemisphere. Bryophytorum Bibliotheca. 13: 715 - 733.

van Zanten, B. O. and S. R. Gradstein (1988). Experimental Dispersal Geography of Neotropical Liverworts. Beihefte zur Nova Hedwigia. 90: 41 - 94.

van Zanten, B. O. and T. Pócs (1981). Distribution and dispersal of Bryophytes. Advances in Bryology. 1: 480 - 562.

Vanden Berghen, C. (1981). Le genre Plagiochila (Dum.) Dum. (Hepaticae) à Madagascar et aux Mascareignes, principalement d'après les récoltes de M. Onraedt. Bulletin de Jardin Botanique National Belgique. 51: 41 - 103.

Vanderpoorten, A., L. Hedenas, C. J. Cox, and A. J. Shaw (2002). Phylogeny and morphological evolution of the Amblystegiaceae (Bryopsida). Molecular Phylogenetics and Evolution. 23: 1 - 21.

Verdoorn, F. (1932). Classification of hepatics. Manual of Bryology. 413 - 432.

Weis, G. (2001). Morphologische und anatomische Untersuchungen der Sporophyten bei den Jubulaceae Klinggr. und Lejeuneaceae Casares-Gil (Hepaticae) und deren systematische Bedeutung. Bryophytorum Bibliotheca. 57: 1 - 307. 
Wikstrom, N., V. Savolainen, and M. W. Chase (2001). Evolution of the angiosperms: calibrating the family tree. Proceedings of the royal society of London Series B Biological science. 268: 2211 - 2220.

Wilson, R., S. R. Gradstein, J. Heinrichs, H. Groth, A. L. Ilkiu Borges, and F. A. Hartmann (2004). Phylogeny of Lejeuneaceae: A cladistic analysis of chloroplast gene $r b c \mathrm{~L}$ sequences and morphology with preliminary comments on the mitochondrial nad4-2 spacer region. Monographs in systematic botany from the Missouri Botanical Garden. 98: 189 - 202.

Wolfe, J. A. (1975). Some aspects of plant geography of the Northern Hemisphere during the late Cretaceous and Tertiary. Annales of the Missouri Botanical Garden. 62: 264 279.

Wright, S. D., C. G. Yong, J. W. Dawson, D. J. Whittaker, and R. C. Gardner (2000). Riding the ice age El Nino? Pacific biogeography and evolution of Metrosideros subg. Metrosideros (Myrtaceae) inferred from nuclear ribosomal DNA. Proceedings of the National Academy of Sciences of the United States of America. 97: 4118 - 4123.

Yang, Z. H. (1998). On the best evolutionary rate for phylogenetic analysis. Systematic Biology. 47: 125 - 133.

Zuker, M. (2003). Mfold web server for nucleic acid folding and hybridization prediction. Nucleic Acids Research. 31: 3406 - 3415. 


\section{Appendix}

\subsection{Trees}
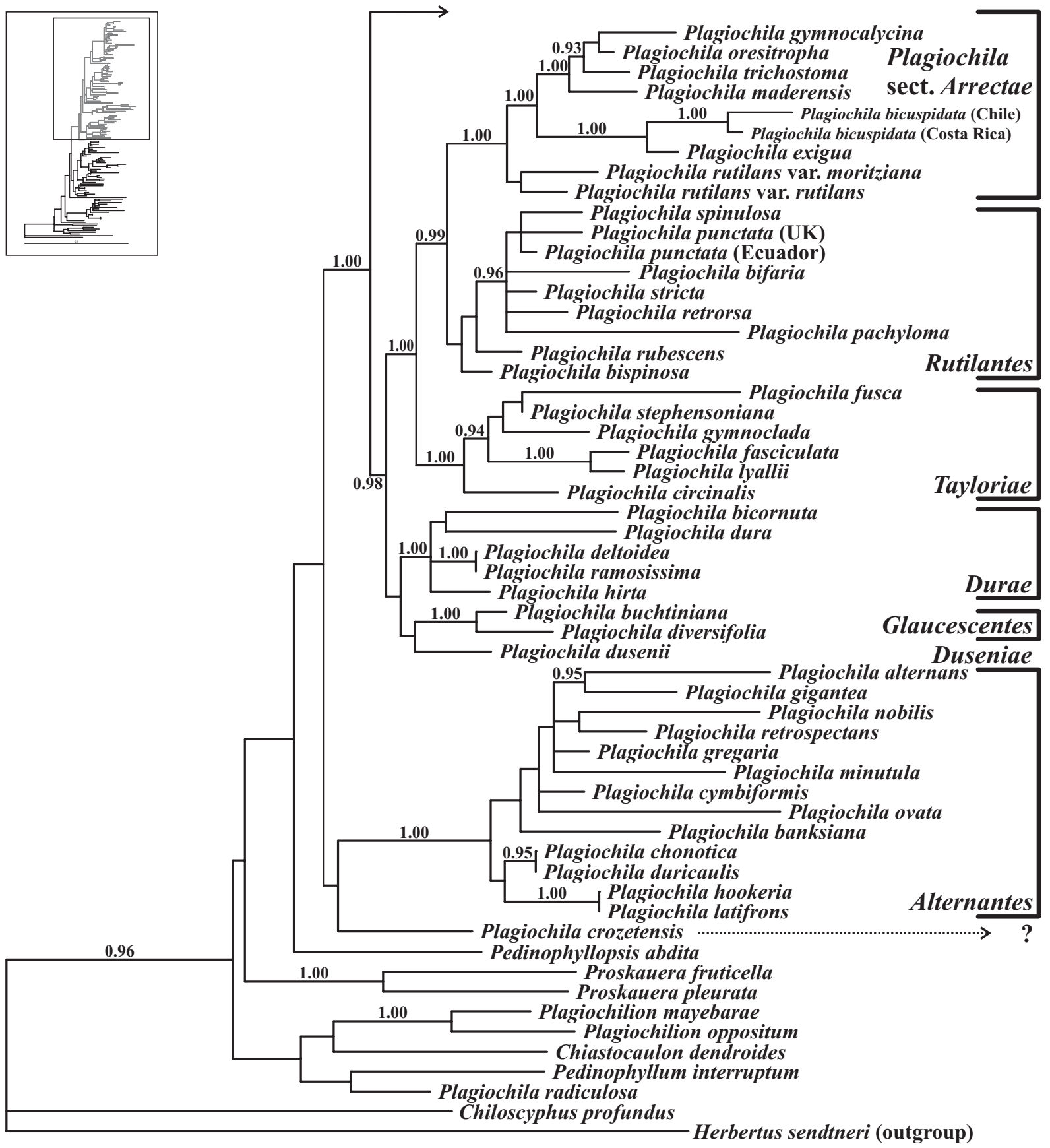

Figure 13 Lower part of the tree resulting from a maximum likelihood analysis of the rps 4 dataset $(-\ln L=5773.27074)$. Bayesian Support $(\geq 0.90)$ is indicated above the branches. 


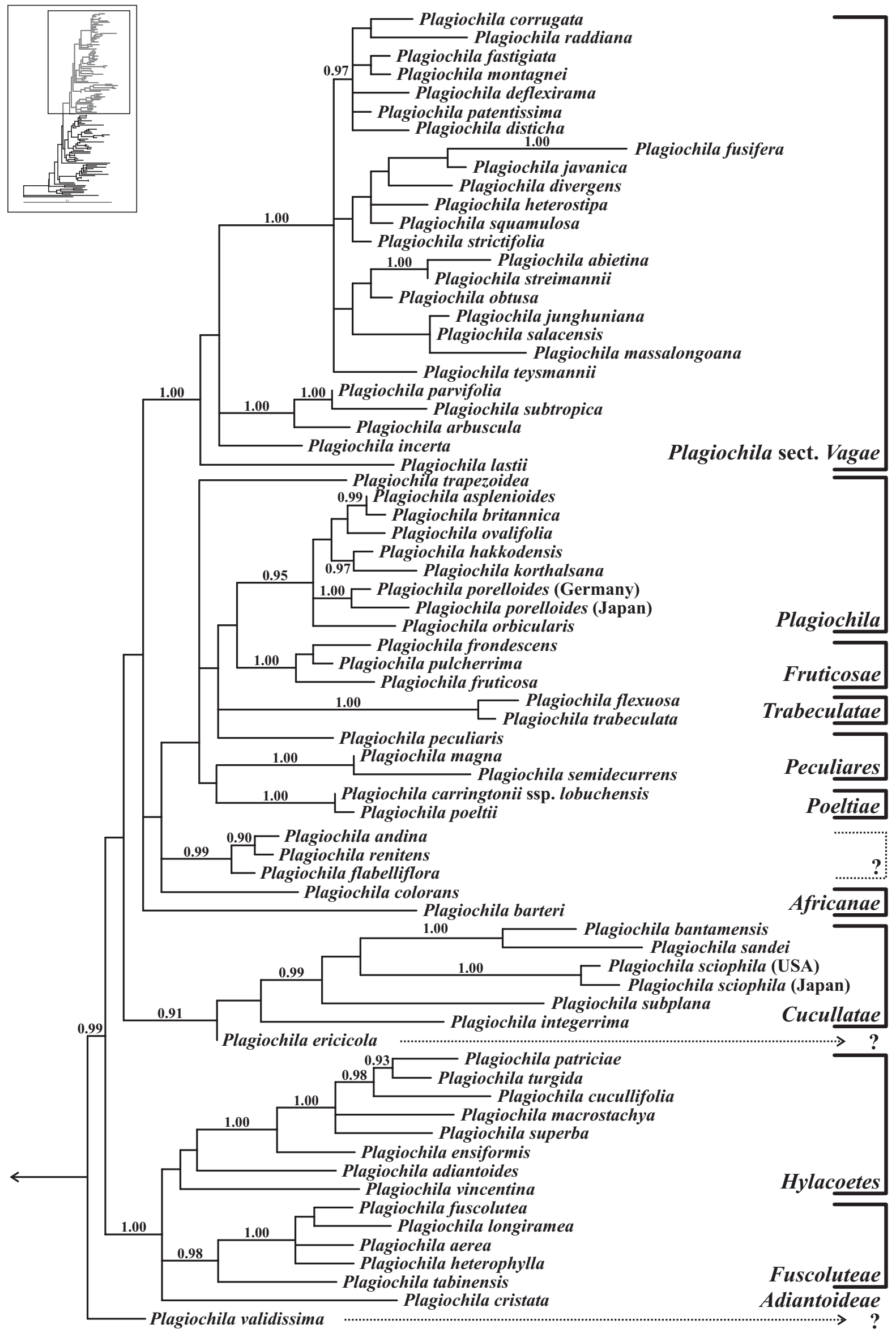

Figure 14 Upper part of the tree resulting from a maximum likelihood analysis of the rps4 dataset $(-\ln L=5773.27074)$. Bayesian Support $(\geq 0.90)$ is indicated above the branches. 


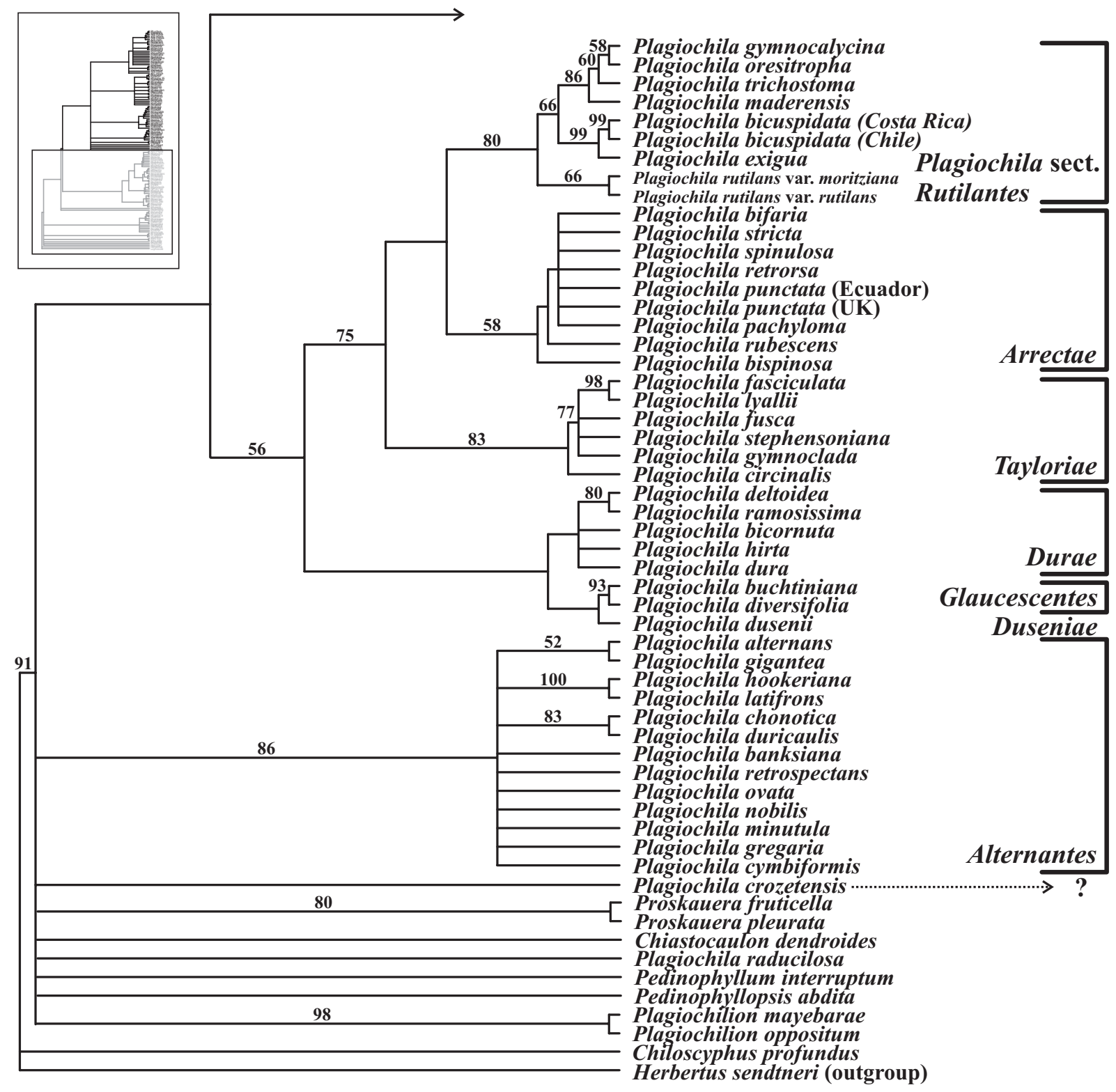

Figure 15 Lower part of the tree resulting from a maximum parsimony analysis of the rps 4 dataset (strict consensus of 370876 trees, length 935 steps, $\mathrm{CI}=0.410, \mathrm{RC}=0.288, \mathrm{RI}=$ $0.703)$. Bootstrap support $(\geq 50)$ is indicated above the branches. 


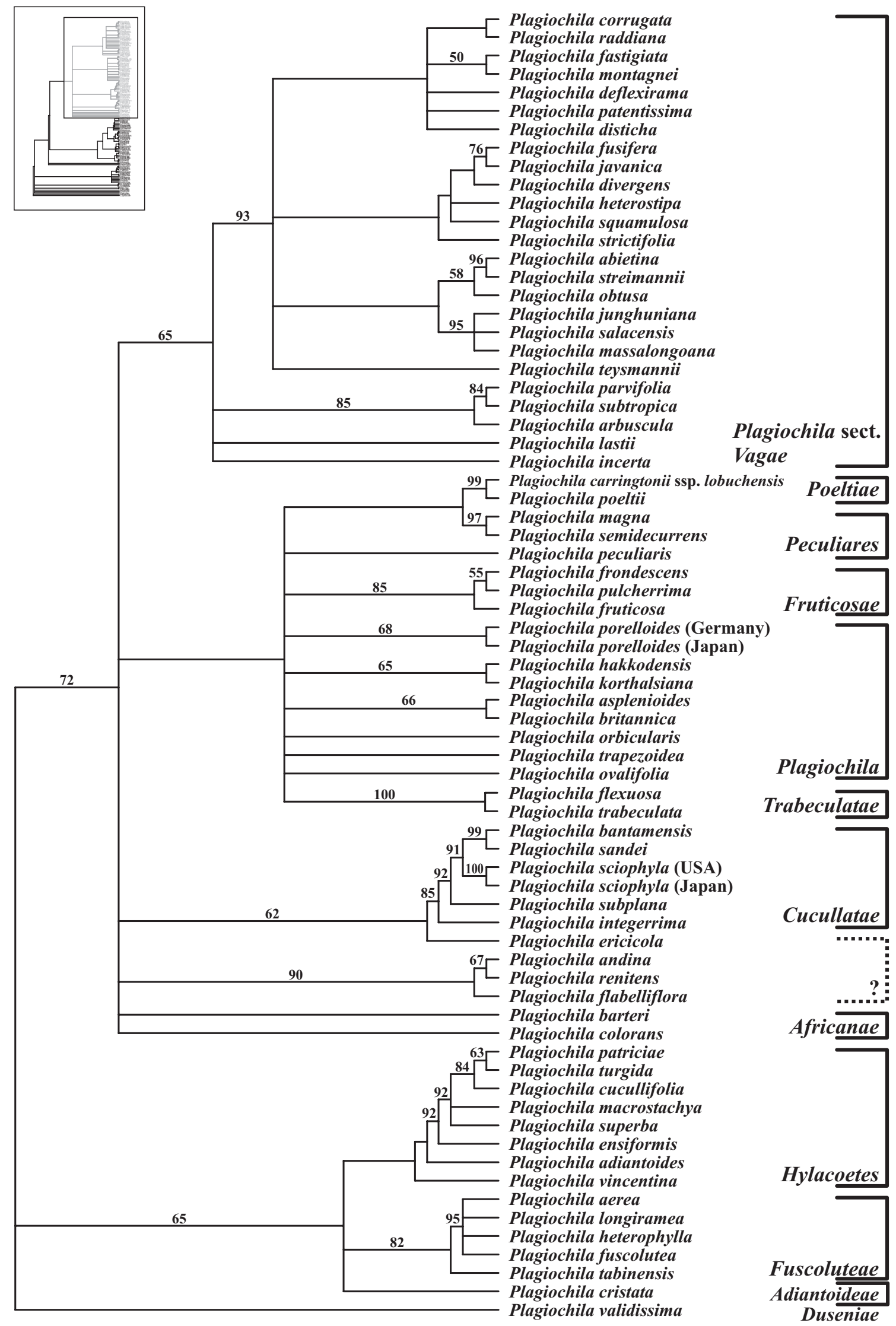

Figure 16 Lower part of the tree resulting from a maximum parsimony analysis of the rps 4 dataset (strict consensus of 370876 trees, length 935 steps, $\mathrm{CI}=0.410, \mathrm{RC}=0.288, \mathrm{RI}=$ 0.703). Bootstrap support $(\geq 50)$ is indicated above the branches. 

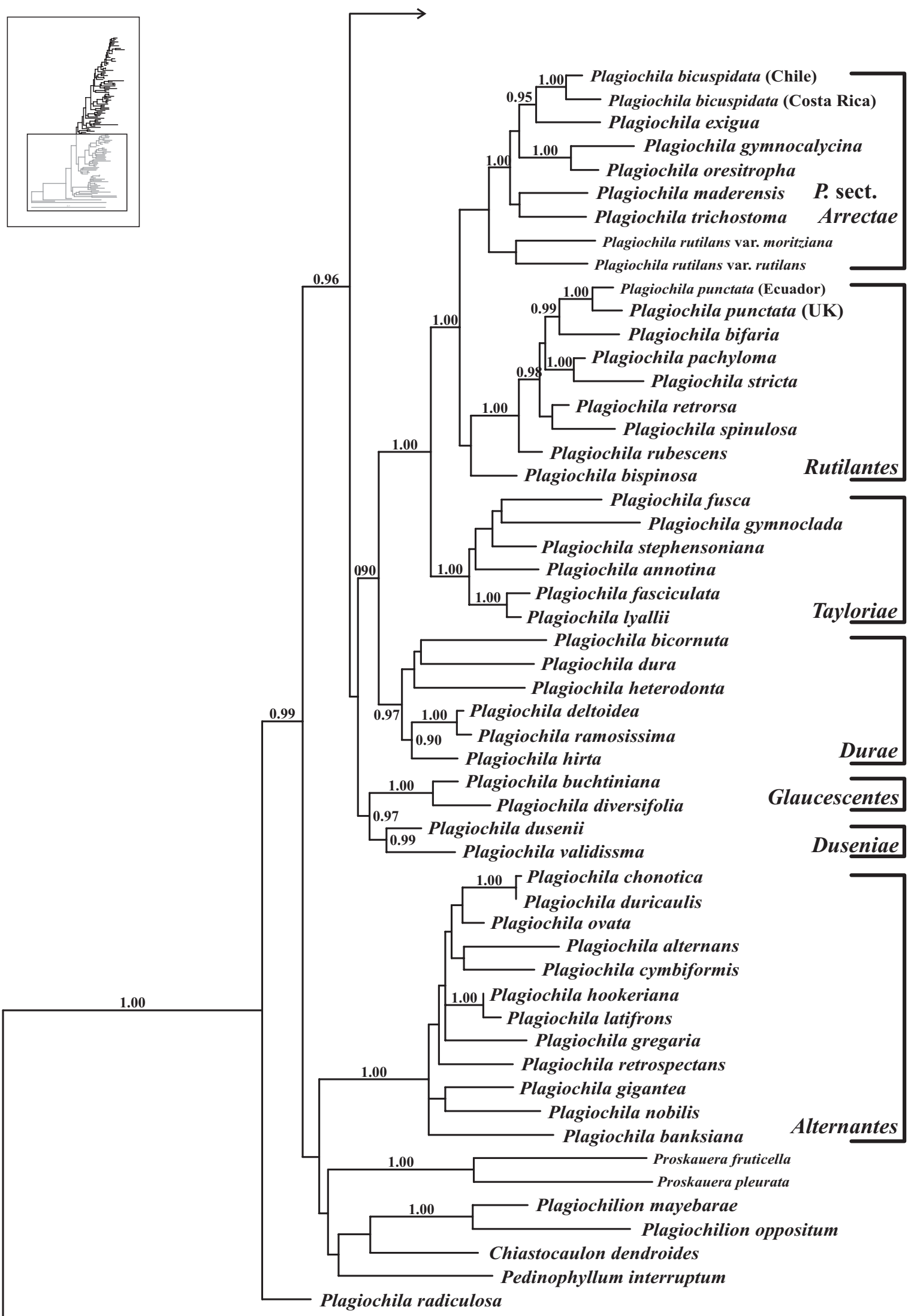

Herbertus sendtneri (outgroup)

Chiloscyphus profundus

Figure 17 Lower part of the tree resulting from a maximum likelihood analysis of the $r b c \mathrm{~L}$ dataset $(-\ln \mathrm{L}=11137.07404)$. Bayesian Support $(\geq 0.90)$ is indicated above the branches. 


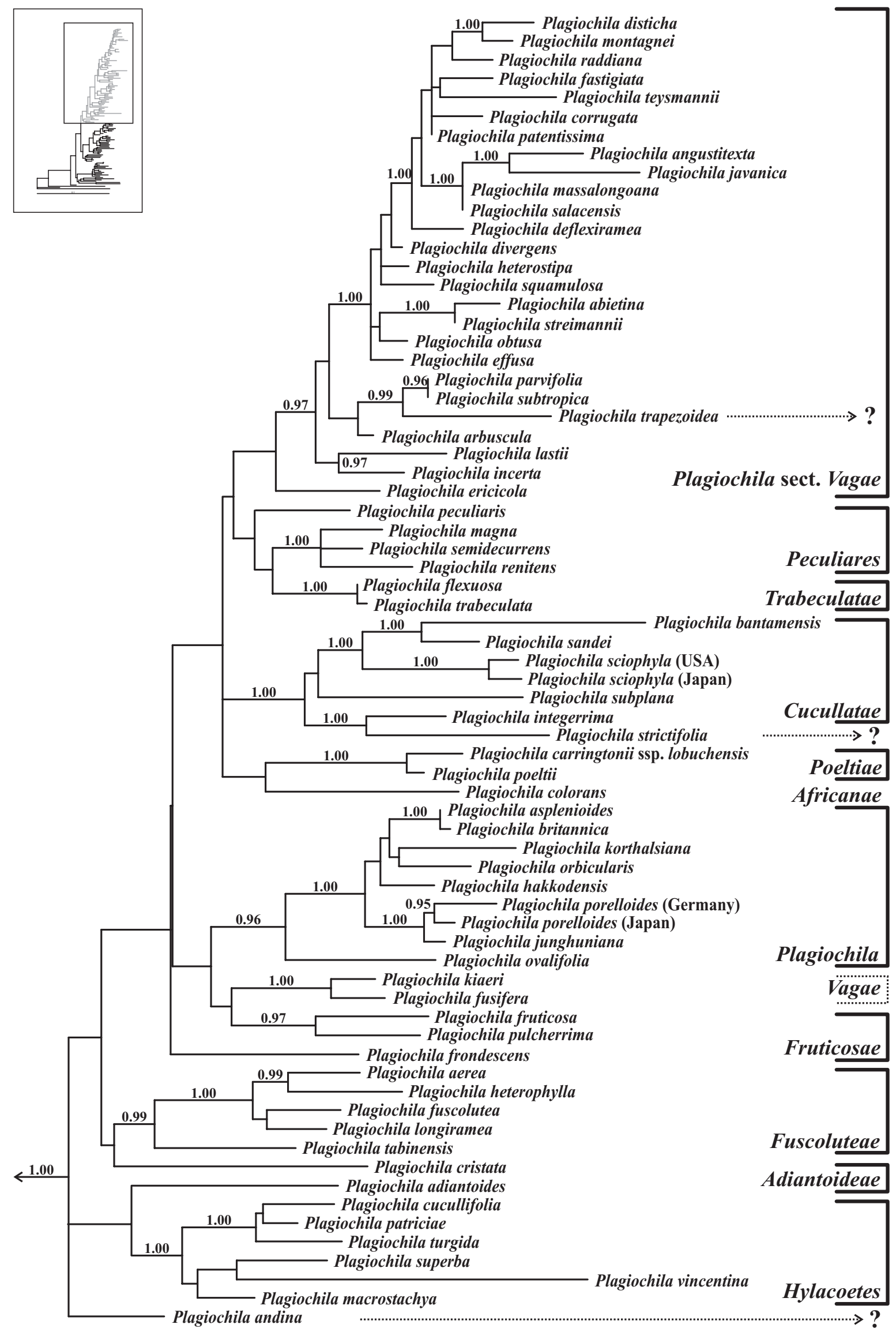

Figure 18 Upper part of the tree resulting from a maximum likelihood analysis of the $r b c \mathrm{~L}$ dataset $(-\ln \mathrm{L}=11137.07404)$. Bayesian Support $(\geq 0.90)$ is indicated above the branches. 


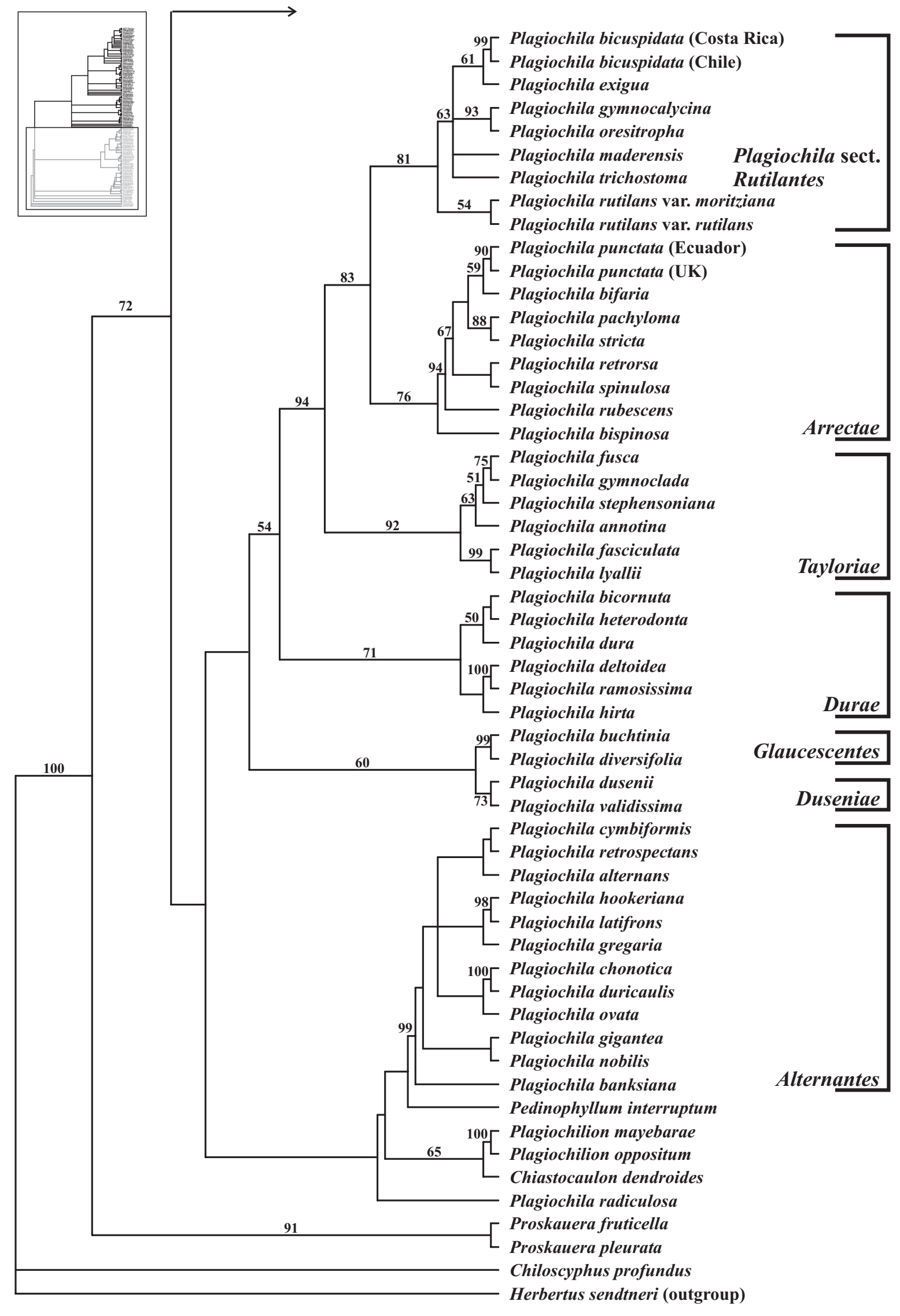

Figure 19 Lower part of the tree resulting from a maximum parsimony analysis of the $r b c \mathrm{~L}$ dataset (strict consensus of 92005 trees, length 1628 steps, $\mathrm{CI}=0.367, \mathrm{RC}=0.245, \mathrm{RI}=$ $0.669)$. Bootstrap support $(\geq 50)$ is indicated above the branches. 


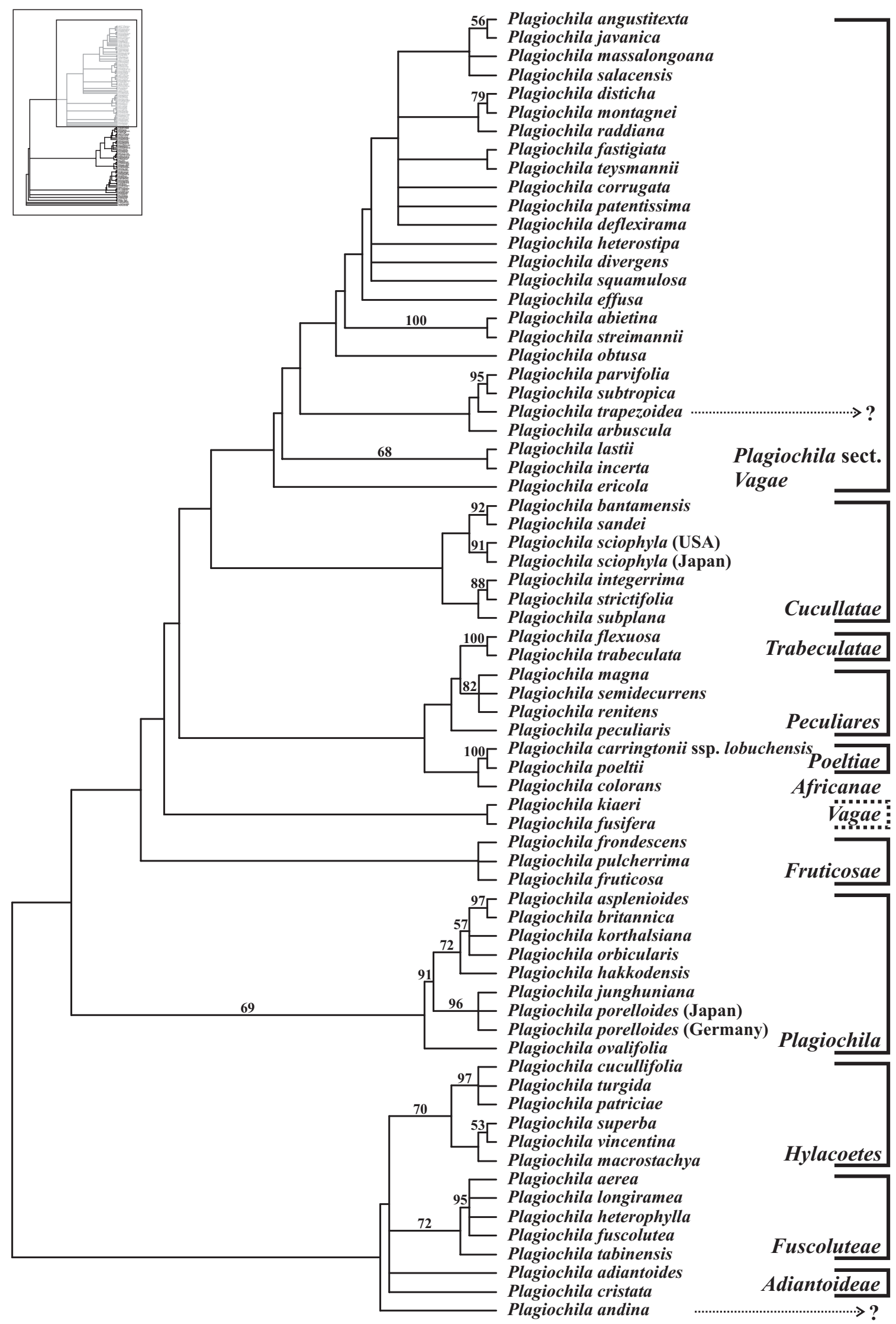

Figure 20 Upper part of the tree resulting from a maximum parsimony analysis of the $r b c \mathrm{~L}$ dataset (strict consensus of 92005 trees, length 1628 steps, $\mathrm{CI}=0.367, \mathrm{RC}=0.245, \mathrm{RI}=$ 0.669). Bootstrap support $(\geq 50)$ is indicated above the branches. 


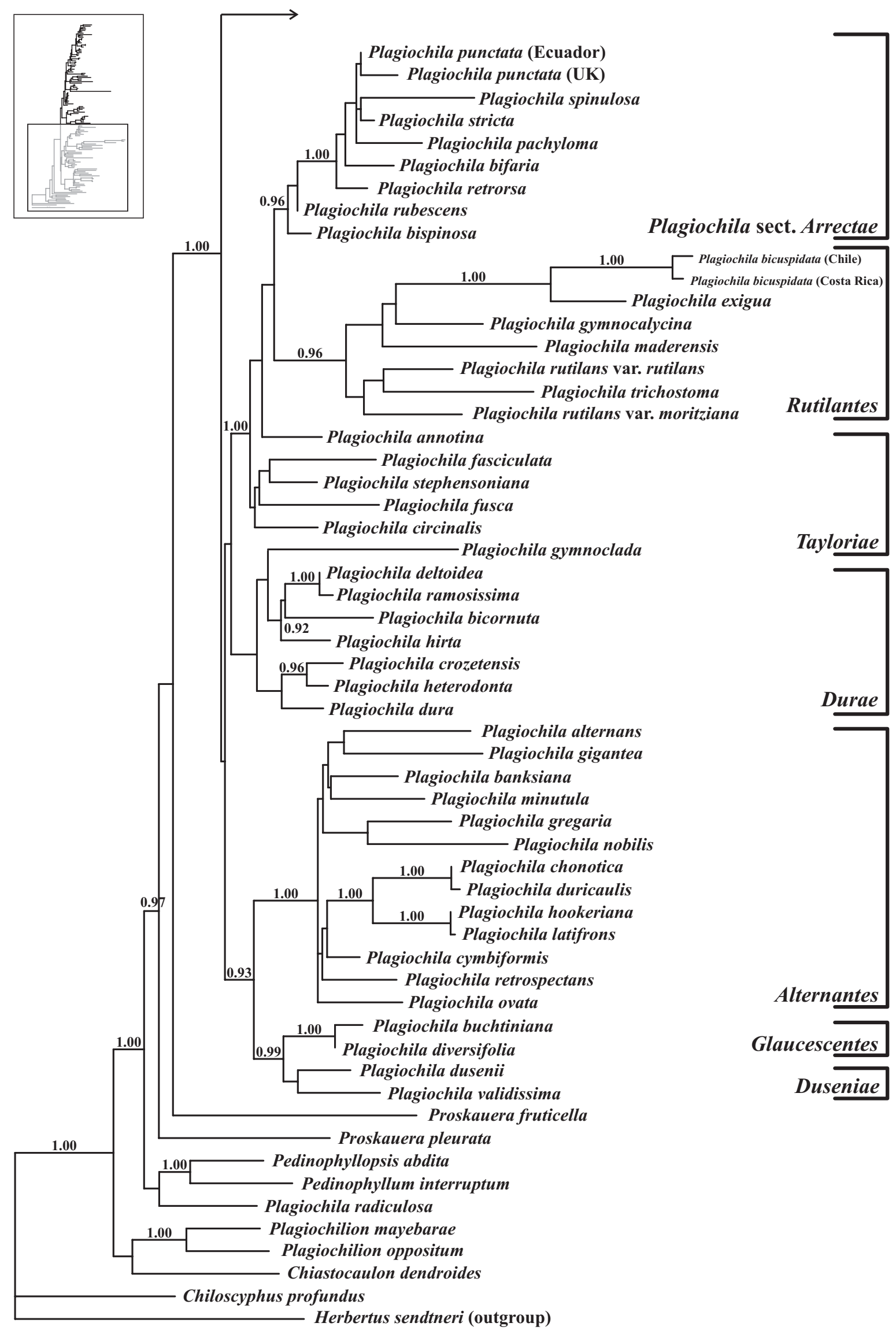

Figure 21 Lower part of the tree resulting from a maximum likelihood analysis of the ITS dataset $(-\ln L=9251.93627)$. Bayesian Support $(\geq 0.90)$ is indicated above the branches. 


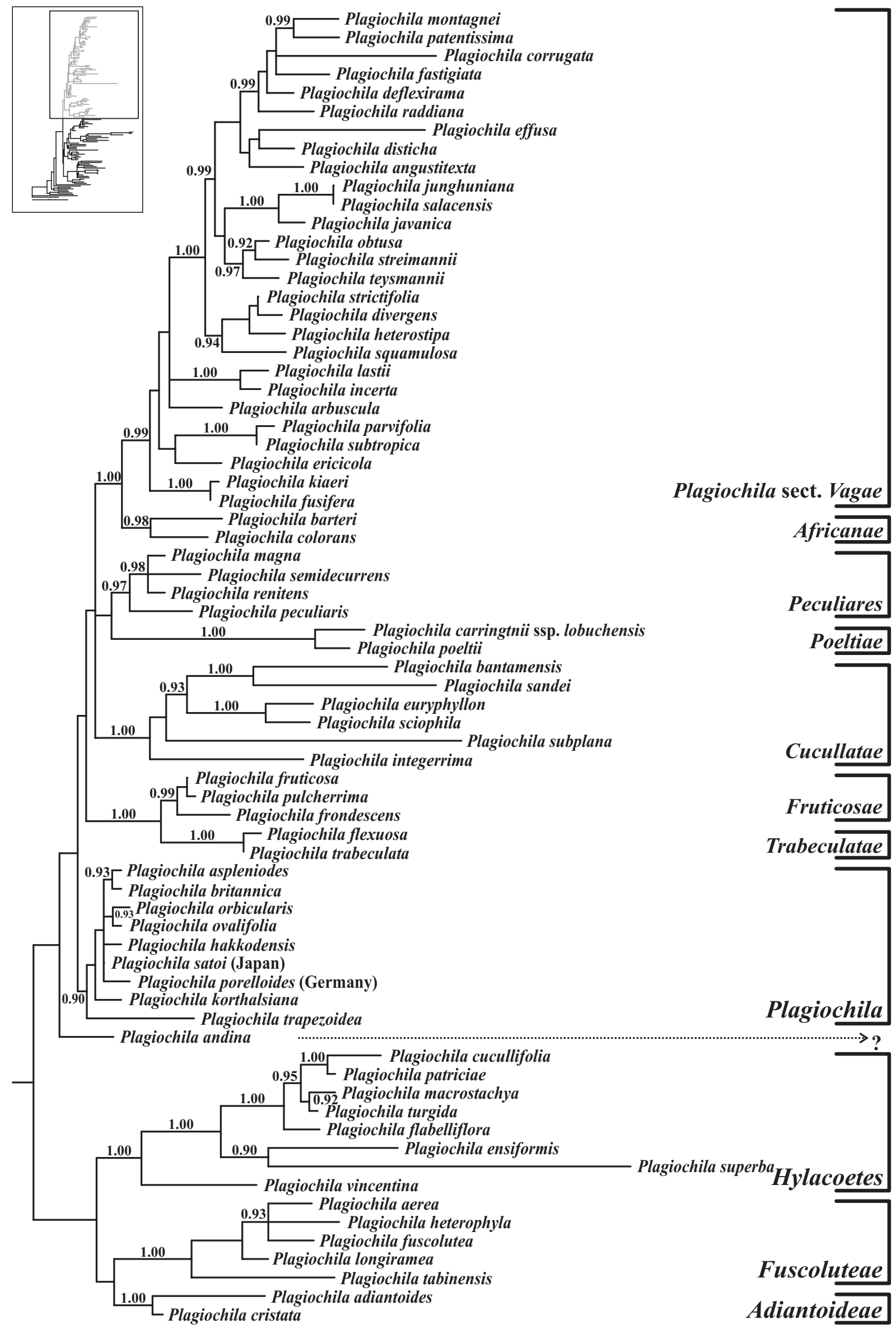

Figure 22 Upper part of the tree resulting from a maximum likelihood analysis of the ITS dataset $(-\ln L=9251.93627)$. Bayesian Support $(\geq 0.90)$ is indicated above the branches. 


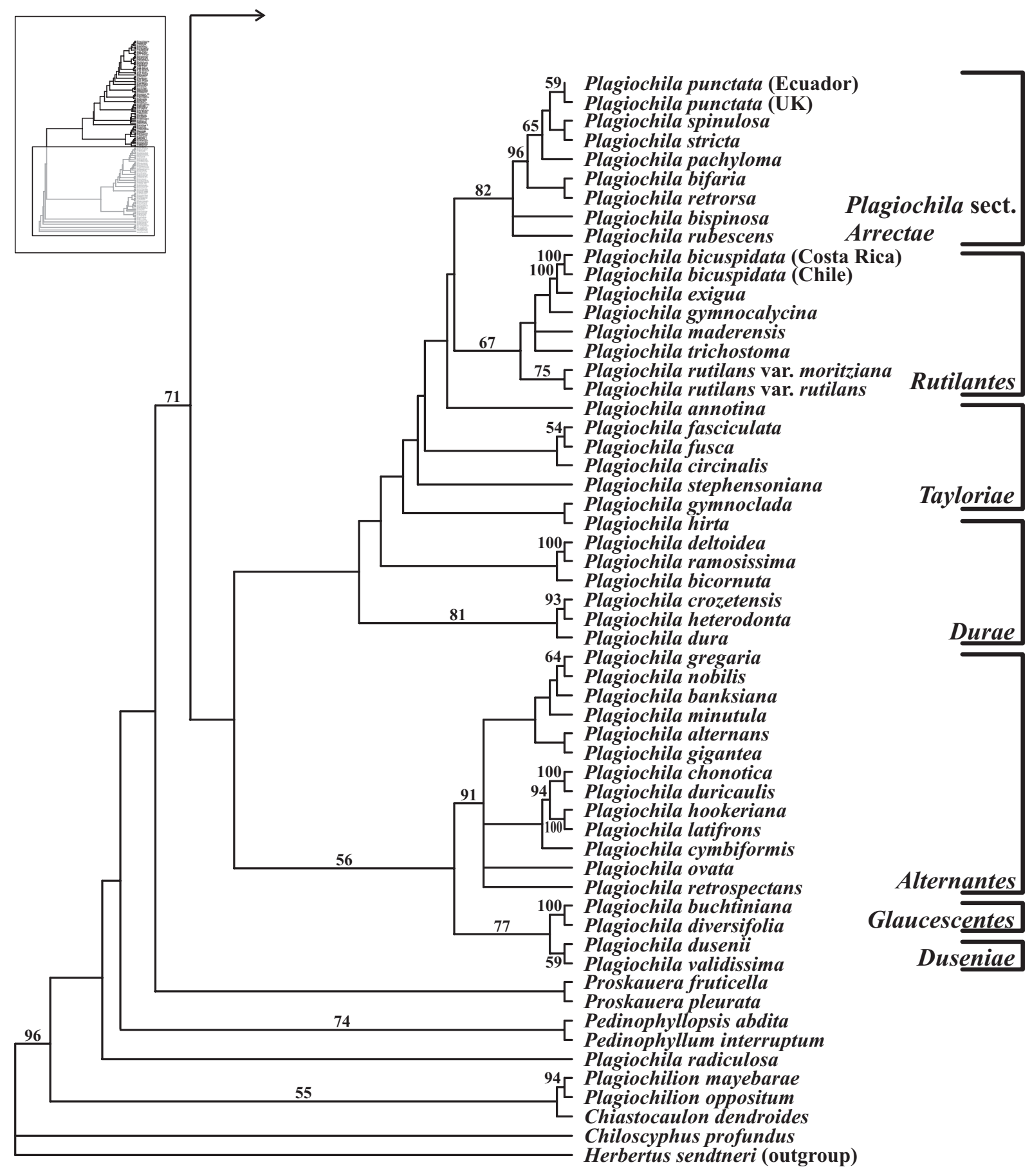

Figure 23 Lower part of the tree resulting from a maximum parsimony analysis of the ITS dataset (strict consensus of 14917 trees, length 1756 steps, $\mathrm{CI}=0.347, \mathrm{RC}=0.220, \mathrm{RI}=$ 0.633). Bootstrap support $(\geq 50)$ is indicated above the branches. 


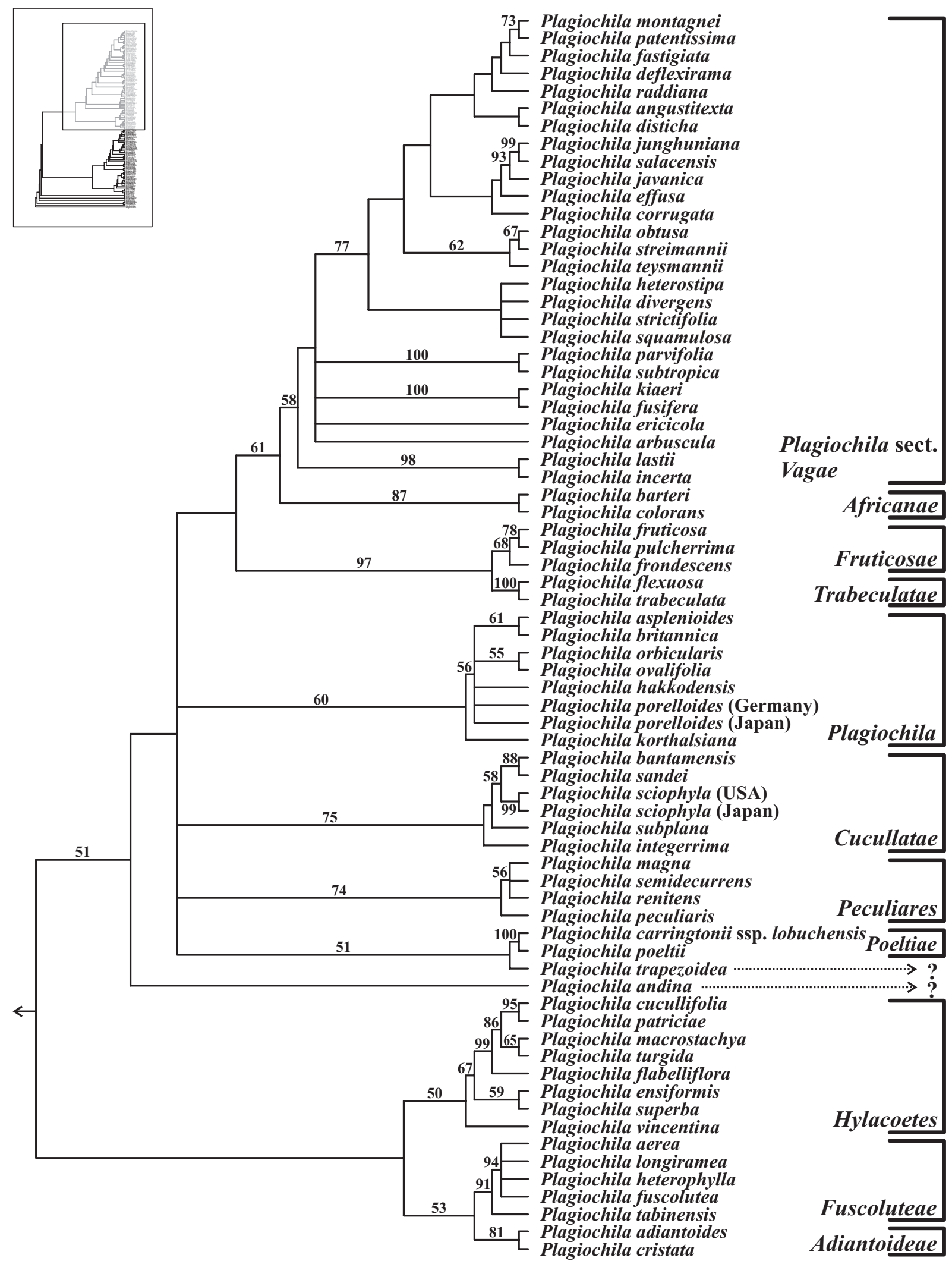

Figure 24 Upper part of the tree resulting from a maximum parsimony analysis of the ITS dataset (strict consensus of 14917 trees, length 1756 steps, $\mathrm{CI}=0.347, \mathrm{RC}=0.220, \mathrm{RI}=$ $0.633)$. Bootstrap support $(\geq 50)$ is indicated above the branches. 

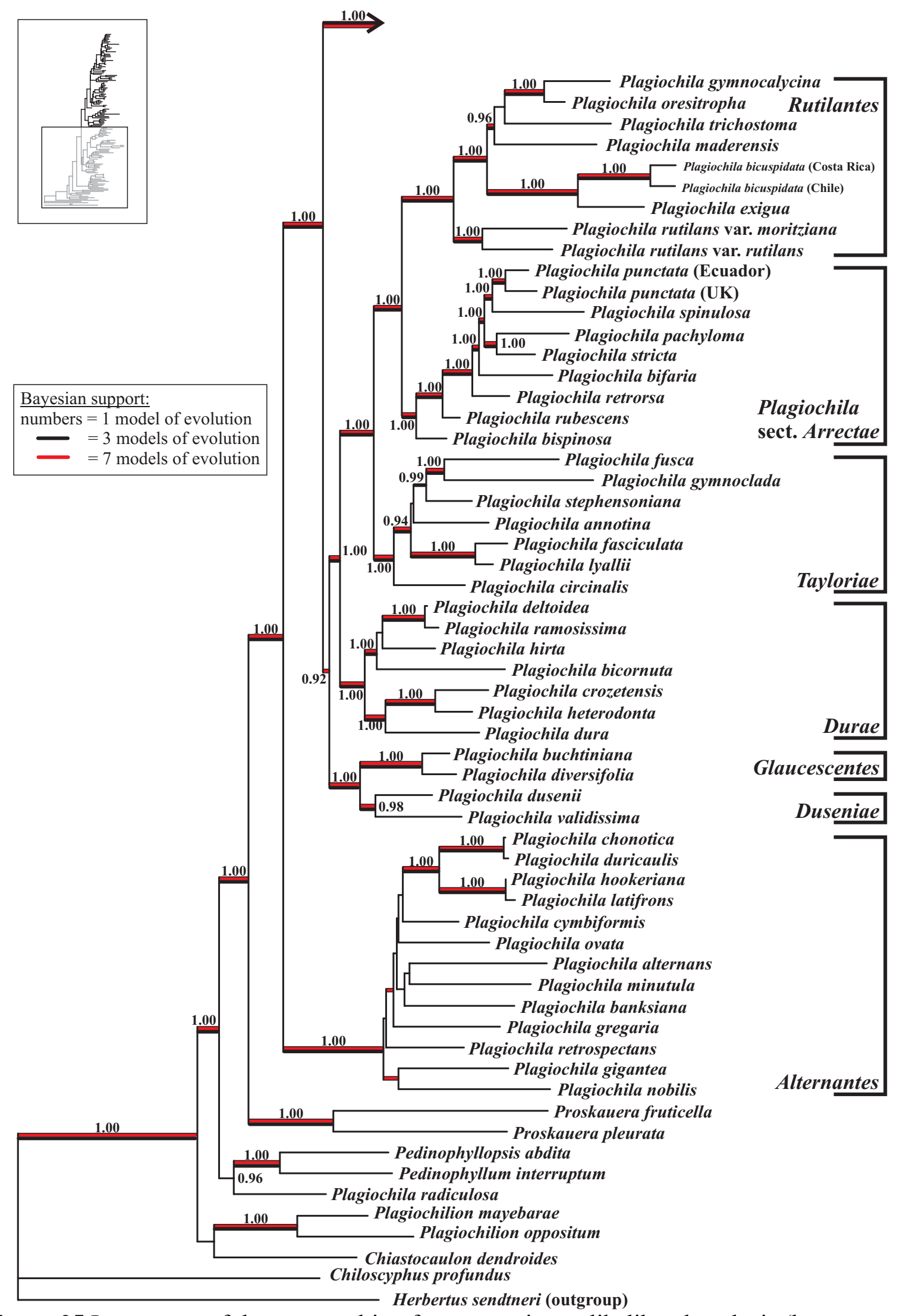

Figure 25 Lower part of the tree resulting from a maximum likelihood analysis (homogenous approach) of the combined dataset $(-\ln L=28154.44115)$. Bayesian support $(\geq 0.90)$ is indicated above the branches. Branches supported by heterogeneous approaches are indicated in black (3 models) or red ( 7 models). 


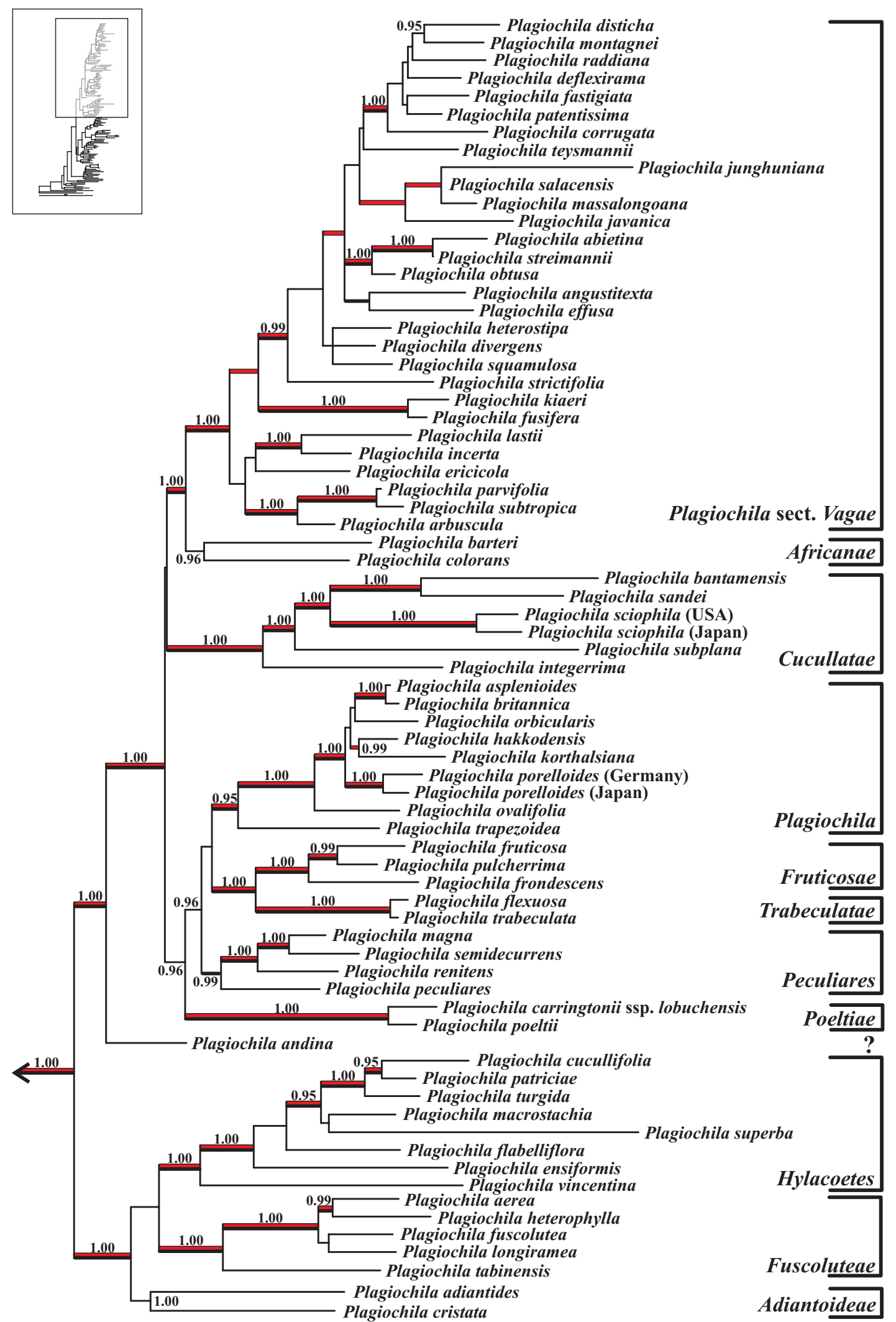

Figure 26 Upper part of the tree resulting from a maximum likelihood analysis (homogenous approach) of the combined dataset $(-\ln \mathrm{L}=28154.44115)$. Bayesian support $(\geq 0.90)$ is indicated above the branches. Branches supported by heterogeneous approaches are indicated in black (3 models) or red ( 7 models). 


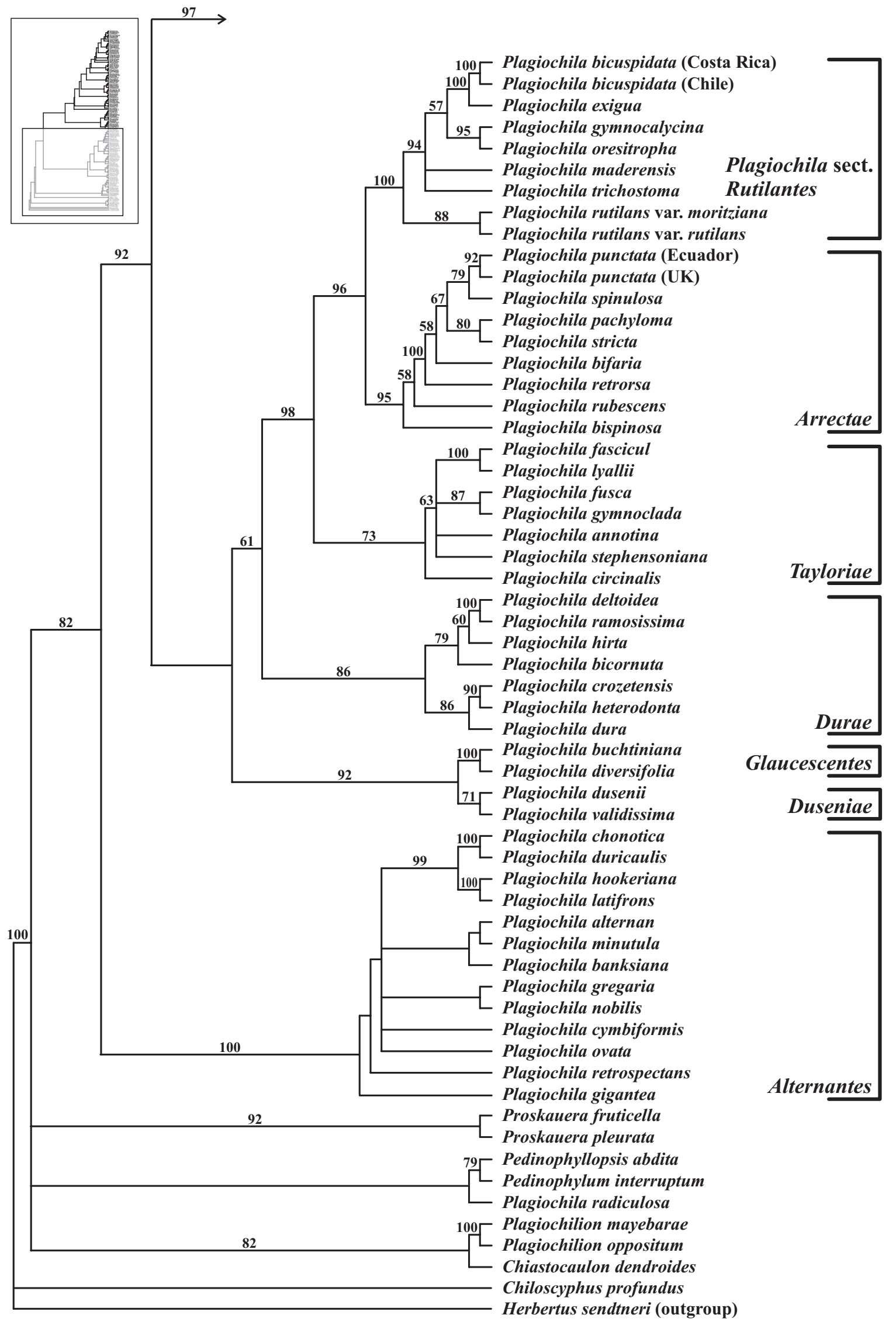

Figure 27 Lower part of the tree resulting from a maximum parsimony analysis of the combined dataset (strict consensus of 17203 trees, length 4418 steps, $\mathrm{CI}=0.360, \mathrm{RC}=0.234$, $\mathrm{RI}=0.651)$. Bootstrap support $(\geq 50)$ is indicated above the branches. 


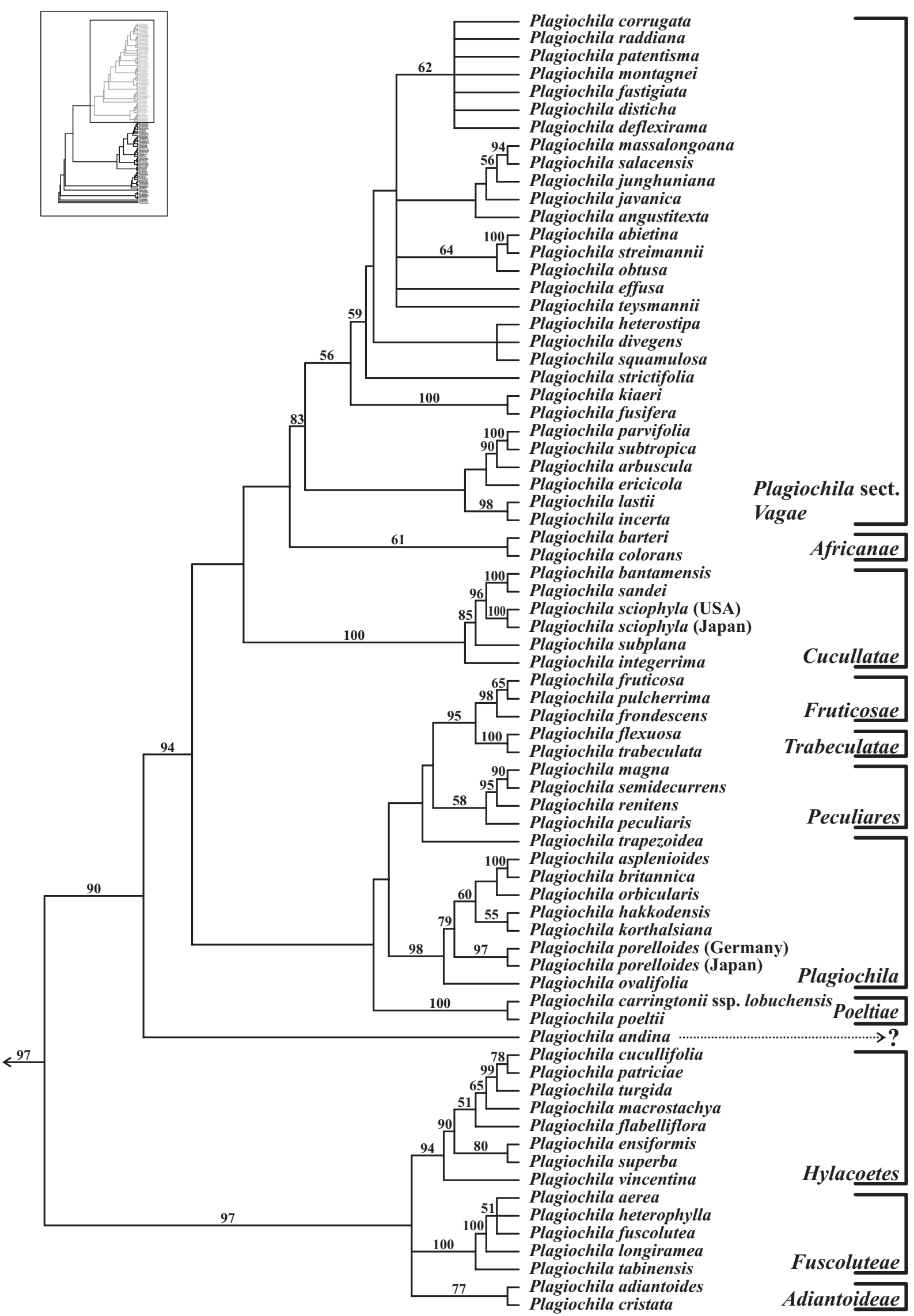

Figure 28 Upper part of the tree resulting from a maximum parsimony analysis of the combined dataset (strict consensus of 17203 trees, length 4418 steps, $\mathrm{CI}=0.360, \mathrm{RC}=0.234$, $\mathrm{RI}=0.651)$. Bootstrap support $(\geq 50)$ is indicated above the branches. 


\subsection{Morphology matrix}

Acrochila biserialis Chiastocaulon dendroides Chiloscyphus profundus Herbertus sendtneri Plagiochila abietina

$P$. adiantoides

$P$. aerea

$P$. alternans

$P$. andina

$P$. annotina

$P$. arbuscula

$P$. asplenioides

$P$. banksiana

$P$. bantamensis

P. barteri

P. bicornuta

P. bicuspidata (Costa Rica)

P. bicuspidata (Chile)

P. bifaria

$P$. britannica

$P$. buchtiniana

P. carringtonii ssp. lobuchensis

$P$. circinalis

$P$. corrugata

P. cristata

P. cucullifolia

$P$. cymbiformis

$P$. deflexirama

P. deltoidea

$P$. disticha

$P$. divergens

P. diversifolia

$P$. drepanophylla

P. dusenii

$P$. effusa

$P$. ensiformis

$P$. exigua

$P$. fasciculata

P. flabelliflora

P. flexuosa

$P$. frondescens

$P$. fruticosa

$P$. fusca

$P$. fuscolutea

$P$. fusifera

P. gigantea

$P$. gregaria

$P$. gymnocalycina

P. gymnoclada

$P$. hakkodensis

$P$. heterophylla

$P$. heterostipa

$P$. hookeriana

$P$. integerrima

$P$. javanica

$P$. junghuniana

$P$. korthalsiana

$P$. lastii

$P$. longiramea $\begin{array}{r}11111111112222222222333333 \\ \hline\end{array}$

$\frac{123456780123450000110400000 ? 00000 ? ? 1}{2100000001 ? ? 000001}$ $50000001012000010110 ? 1000000 ? ? ? 0 ? ? \odot$ 4000०००200210010050010010000000०??1 21010002011100000410100100000000112 $110000015 ? ? ? 0000 ? ? 1 ? ? 10000 ? ? ? ? ? ? ? ? ?$ 00000001012000000110100000000010111 40100002012000000210100010000000100 00000001012000000210100000010000001 $0000000101200000021 ? ? 10000 ? ? ? ? ? ? ? ?$ $0000000001200000021010001100 ? ? ? 1 ? ? 1$ $1000000101200000 ? ? 10100000 ? ? ? ? ? ? ? ?$

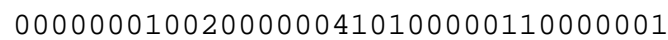
00000001002000000210010011 ????????

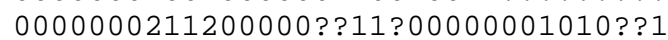
$00001001012000000210 ? 00000 ? ? 110 ? 101$ $0000000100200000 ? ? 1$ ?????????????? 0000000101200100001000000000001 ??10 $0000000101200100001000000000001 ? ? 10$ 01010401012001000010400010000010110 00000001002000000110100000110000001 $100010020 ? ? ? 000012100100100001 \mathrm{~N} 1200$ $01000001001000000210121000 ? ? ? ? ? ? ? ?$ $01000001012000000111100011000040 ? ? 1$ 10000002012010000110140000000021110 40001001012001000110400000000020111 01001001012000001211100010001001142 $0000000100000000 ?$ ? ?????????????? $10000001012010000110110010000024 ? ? 5$ $00001001002000000110110010000000 ? ? 1$ 10000002012010000110400010000020111 $1000000101201000 ? ? 10 ? 10010 ? ? ? ? ? ? ? ?$ $100000020 ? ? ? 000012100100100001 \mathrm{~N} 1200$ $1000000100201000 ? ? 10 ? 00010 ? ? ? ? ? ? ? ? ?$ 00010001112000000210440040000000210 $100000010 ? ? ? ? ? ? ? ?, 1 ? ? 10000 ? ? ? ? ? ? ? ? ?$ 00001001012000000211440020001000101 $00000001001001000010410 ? ? ? ? ? ? ? ? ? ? ?$ 4000100101200000०411100011000040??1 $0000001101200100 ? ? 11000010001000141$ $0000000100100000 ? ? 10110011$ ???????? 4000000101200000??10?100000??????? $0000000101200000 ?$ ?10110000???????? $00001001012000000 ? 11100040000000 ? ? ?$ 00110001012000000510101010000000101 $100000010 ? ? ? 1000 ? ? 10010010 ? 0 ? ? ? ? ? ? ?$ 40000001012000000210?00000110010??1 $00000001002000000111111010 ? ? ? ? ? ? ? ?$ $00001001012001000010 ? 00000 ? ? ? ? ? ? ? ?$ $0000000100200000 ? ? 11000014 ? ? ? ? ? ? ? ?$

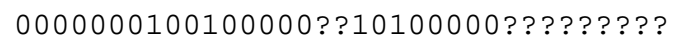
40100001012000000210100000000000101 $100000010 ? ? ? ? ? ? ? ? 10 ? 10010 ? ? ? ? ? ? ? ?$ 00000001002000000110000000110010001 $0000000101200000 ? ? 101000000$ ??????? $1000000101201000 ? ? 10110010000001 ? ? 0$ $1000000100201000 ? ? 10 ? 10010 ? ? ? ? ? ? ? ?$ $० 000000100 ? ? 0000 ? ? 10100000 ? ? ? ? ? ? ? ?$ $100000020 ? ? ? ? ? ? ? ? ? 10 ? 00010 ? ? ? ? ? ? ? ? \odot$ 00101001112000000210100010000000101 
11111111112222222222333333

P. lyallii

P. macrostachya

$P$. maderensis

$P$. magna

P. massalongoana

$P$. montagnei

$P$. nobilis

$P$. obtusa

$P$. ovalifolia

P. ovata

P. pachyloma

P. parvifolia

$P$. patriciae

$P$. peculiaris

P. poeltii

$P$. porelloides (Germany)

$P$. porelloides (Japan)

$P$. propinqua

P. pulcherrima

P. punctata (Ecuador)

P. punctata (U.K.)

$P$. raddiana

$P$. radiculosa

$P$. ramosissima

$P$. renitens

$P$. retrorsa

$P$. retrospectans

$P$. rutilans var. moritziana

$P$. rutilans var. rutilans

$P$. salacensis

$P$. sandei

P. sciophila USA

$P$. sciophila Japan

$P$. semidecurrens

$P$. spinulosa

$P$. stephensoniana

$P$. stricta

$P$. strictifolia

$P$. subplana

$P$. subtropica

$P$. superba

$P$. tabinensis

P. teysmannii

P. trabeculata

P. trapezoidea

$P$. trichostoma

P. turgida

$P$. validissima

$P$. vincentina

Pedinophyllopsis abdita

Pedinophyllum interruptum

Plagiochilion mayebarae

Plagiochilion oppositum

Proskauera pleurata

Proskauera fruticella
12345678901234567890123456789012345 40001001002000000111?00010000000?01 00001011012001000211000010001000141 $000100010120000004 ? ? ? ? ? ? ? ? ? ? ? ? ? ? ? ?$ $0001000100100000 ? ? 1 ? ? 00000 ? ? ? ? ? ? ? ?$ $1000000100201100 ? ? 1 ? ? 00000 ? ? ? ? ? ? ? ? ?$ 10000002012010000110100010000011111 $00000001012000000 ? 14 ? 00000 ? ? ? ? ? ? ? ?$ $4000000121101000 ? ? 1 ? ? 10014$ ???????? $0000000100200000 ? ? 1010000011$ ???०??2 00000001012000000210100000110000001 ०?०??1010???01000010100010000010110 $1000000201201100 ? ? 1001101000$ ???00?1 00001001012000000111000010001000142 $0001000100200000 ? ? 1 ? ? 00000 ? ? ? ? ? ? ? ?$ $0100000111100000 ? ? 10110010 ? ? ? ? ? ? ? ? ?$ $0000000100200000051010000011 ? ? ? ? ? 1$ 0000000100200000051010000011 ?????1 40000000100200000??101000000000000?० ?000000551200001??10110010???????? $000101010 ? ? ? 01000410410010000010110$ $000101010 ? ? ? 01000410410010000010110$ $100000020120100001101000100000 ? 0111$ $00000001011000000210 ? 00000000004 ? ? 1$ $000010010120000001101000100000000 ? 1$ $00010001001000000 ? 10 ? 00010 ? ? ? ? ? ? ? ?$

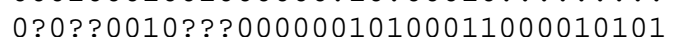
$01000001012000000210 ? 00000 ? ? ? ? ? ? ? ?$ 00000001012000000010100000000010401 00000001012000000010100000000010401 $1000000101100100 ? ? 1 ? ? 10011000011$ ??० 00000001012000000211000000001000101 $00000001002000000210 ? ? ? ? ? ? ? ? ? ? ? ? ? ?$ $0000000101200000 ?+10 ? 10000 ? ? ? ? ? ? ? ?$ $00010001001000000 ? 101000000 ? ? ? ? ? ? ?$ $000041010 ? ? ? 01000410 ? 00010 ? ? ? ? ? ? ? ?$ 400000010120000004111200??०00040??1 00000101012001000010100010000010110 100000010???1000??10?10010?0???1?? 00000001012000000510000040001000001 $1000000100101100 ? ? 1011$ ?010???????? 00001001012001000511000010001000101 4010000501200000021??10010???????? $1000000101201000 ? ? 10 ? 10010 ? ? ? ? ? ? ? ? ?$ $0000000101200000 ? ? 1011000000 ? ? ? 0 ? ? 1$ $00010001102000000 ? 14100010111000 ? ? 1$ 00010001012000000010100030000010101 00000011012001001211000010001000112 0001000101200000021 ??????????????? 40000001012001000111000030001000111 $11000002001000101210 ? 10000 ? 00000 ? ? 1$ $00000001001000000200011000 ? 00000 ? ? 1$ $2010001500110000 ? ? 10 ? 1000000 ? ? ? 0 ? ? 1$

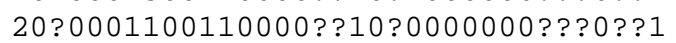
$000002010 ? ? ? 00000210020200000000 ? ? 1$ $1000020100200000 ? ? 10 ? 40010 ? ? ? ? ? ? ? ?$ 


\subsection{Morphological reconstructions}

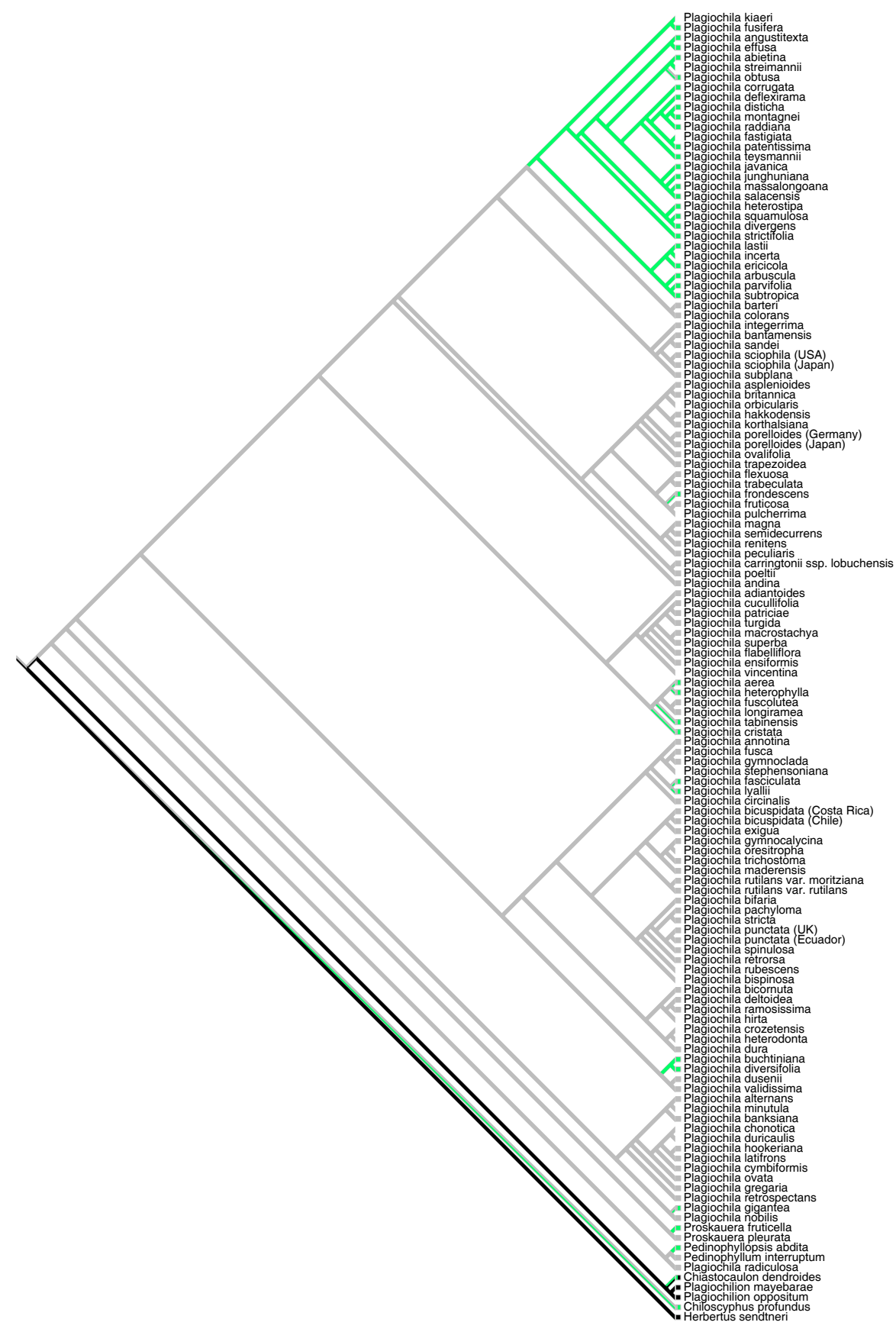

Parsimony reconstruction of the ancestral states of the trait "(dominating) branching type" in the family Plagiochilaceae, with the states: lateral intercalar (grey), lateral terminal (blue), ventral intercalar (black). Steps: 17. Uncertain or polymorphic states are multicoloured. 


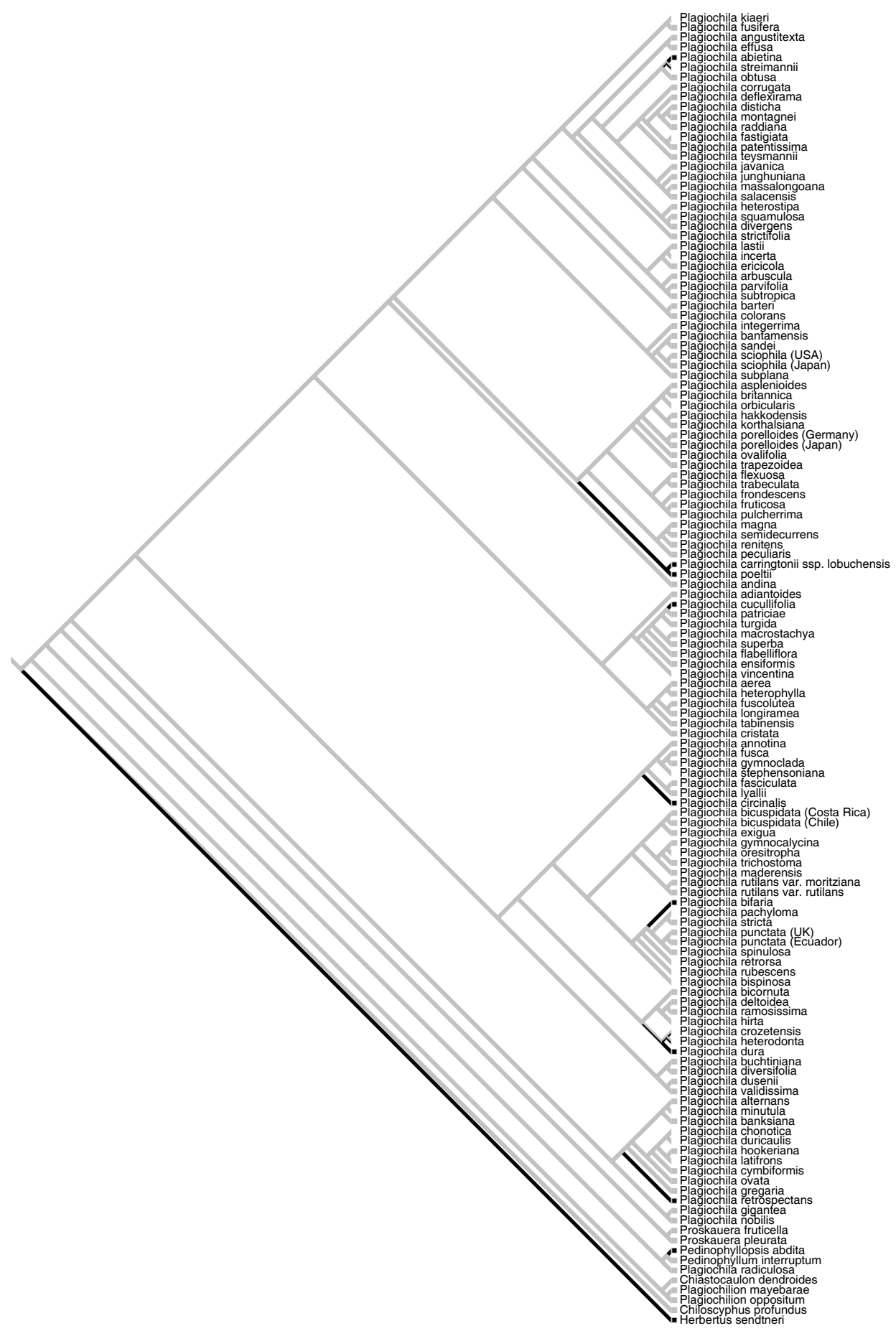

Parsimony reconstruction of the ancestral states of the trait "leaves laterally oppressed" in the family Plagiochilaceae, with the states: no (grey), yes (black). Steps: 9. Uncertain or polymorphic states are multicoloured. 


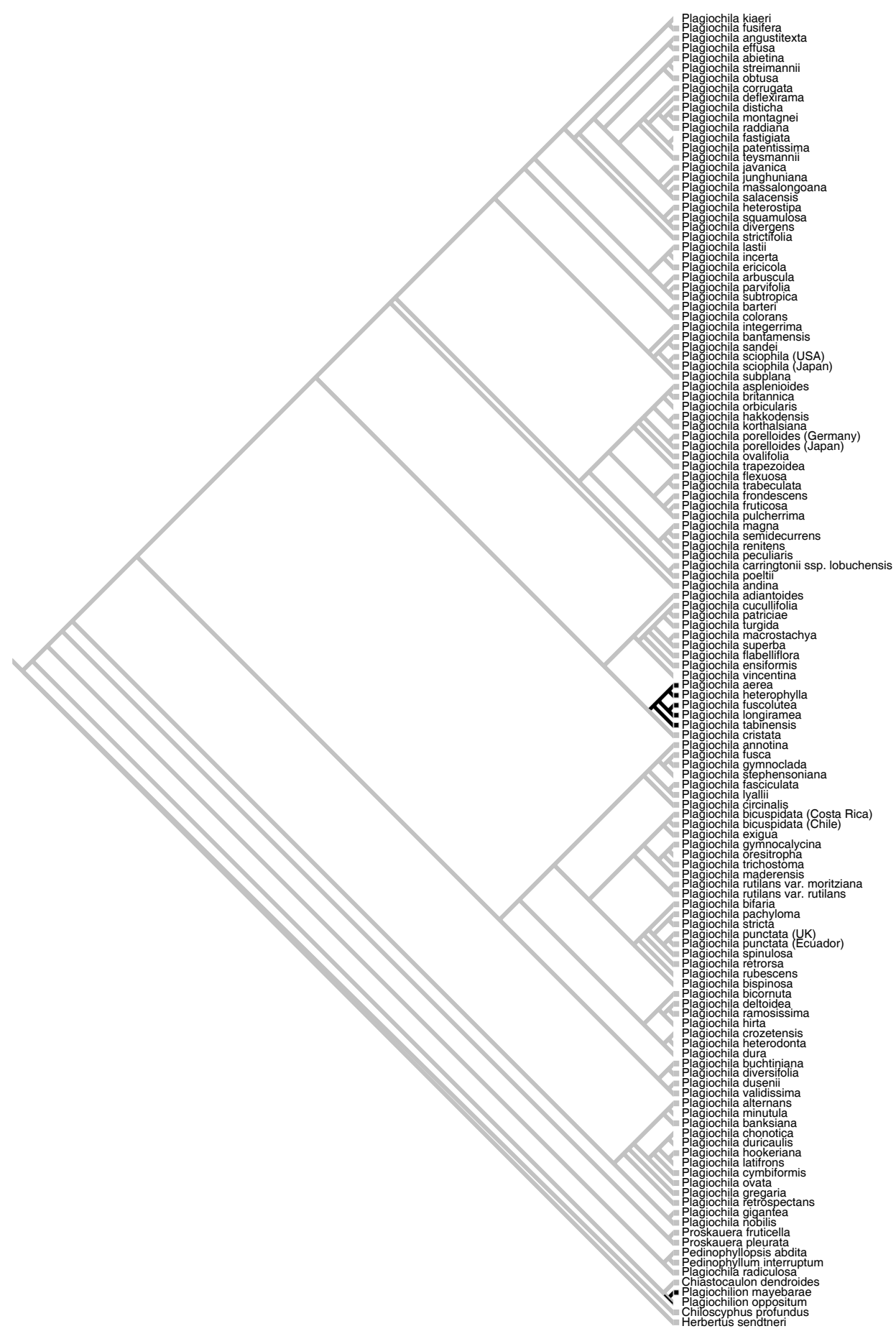

Parsimony reconstruction of the ancestral states of the trait "surface wax" in the family Plagiochilaceae, with the states: absent (grey), present (at least on some leaves or stem sectors) (black). Steps: 2. Uncertain or polymorphic states are multicoloured. 


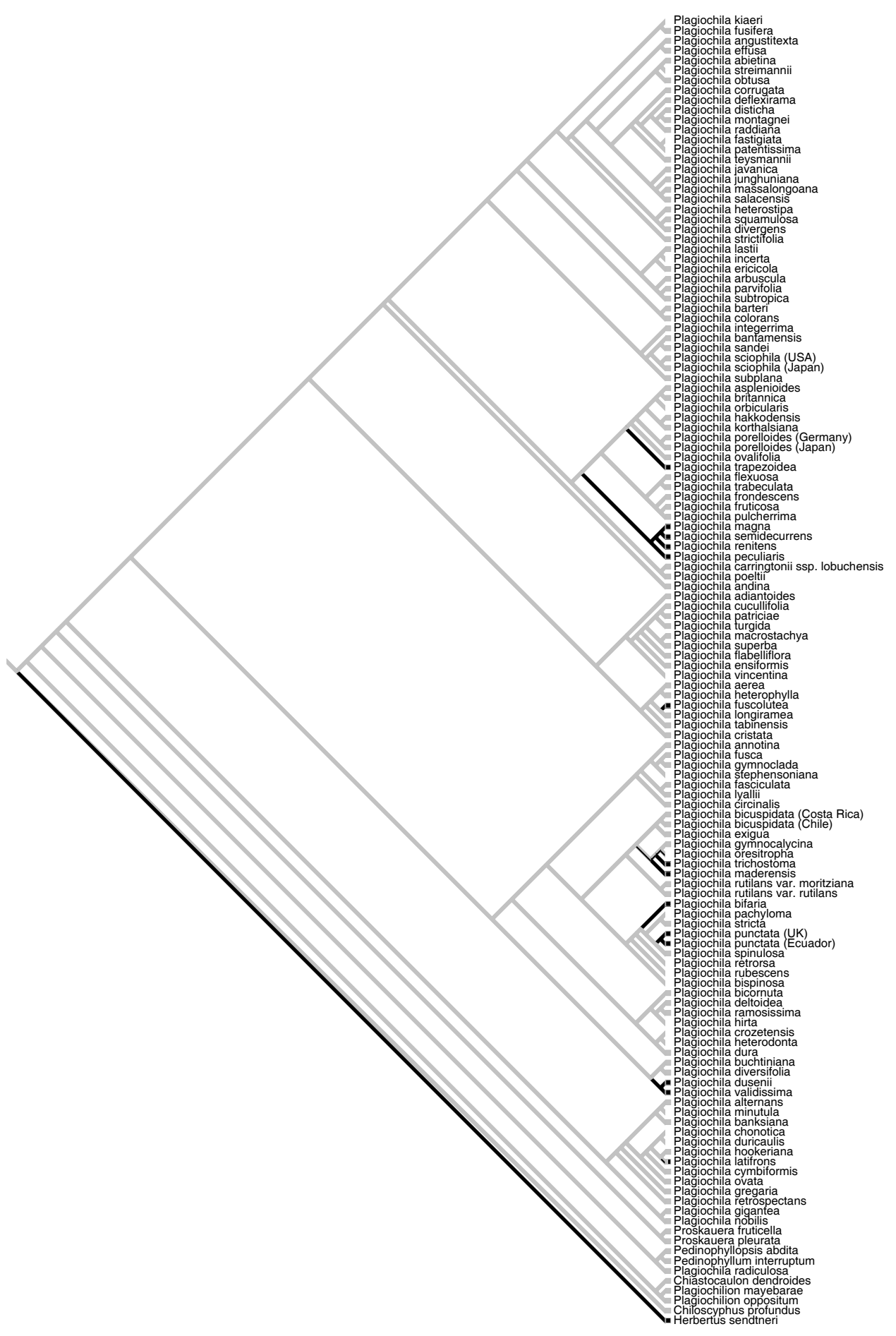

Parsimony reconstruction of the ancestral states of the trait "(well defined) vitta" in the family Plagiochilaceae, with the states: absent (grey), present (black). Steps: 10. Uncertain or polymorphic states are multicoloured. 


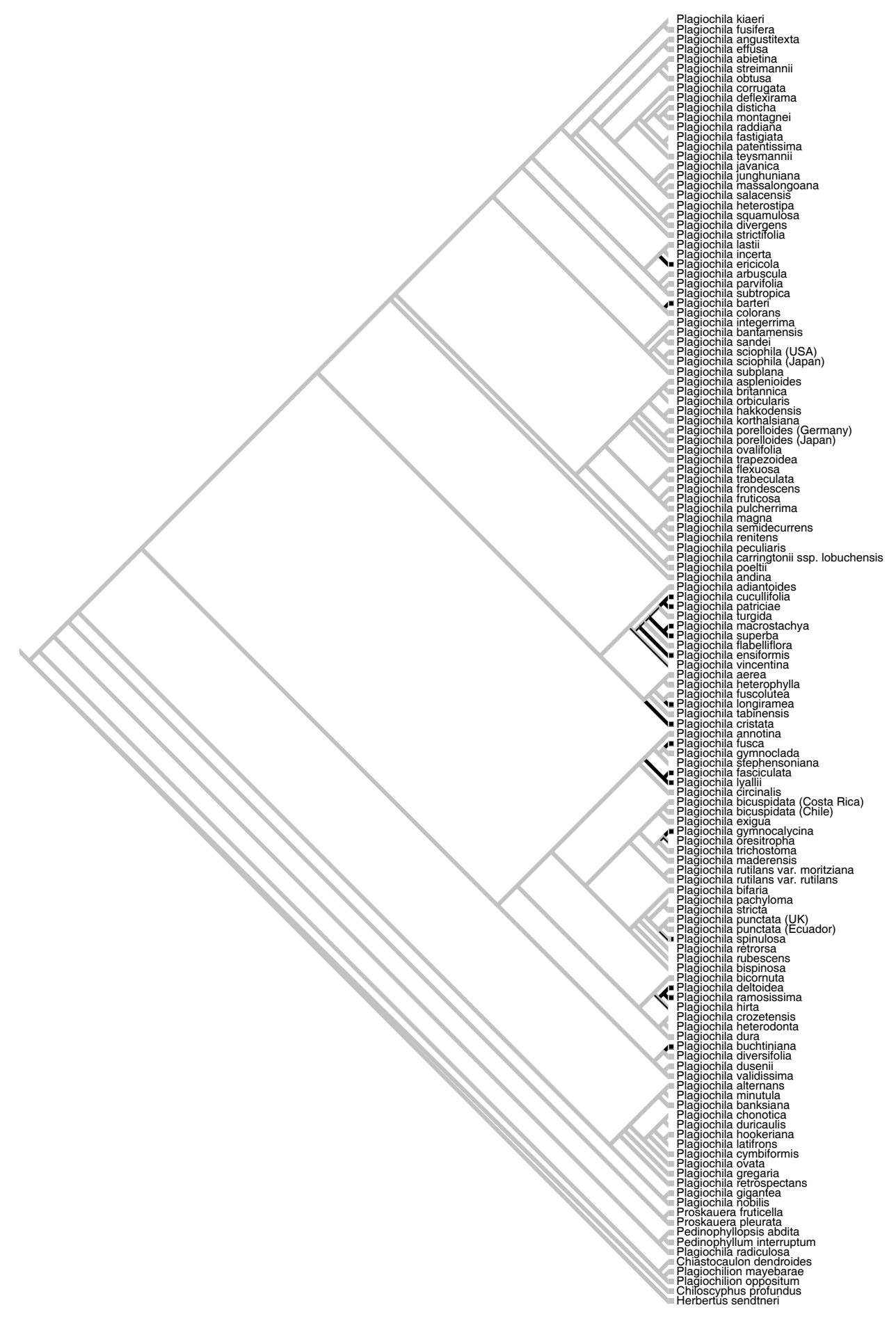

Parsimony reconstruction of the ancestral states of the trait "ill defined vitta" in the family Plagiochilaceae, with the states: absent (grey), present (black). Steps: 13. Uncertain or polymorphic states are multicoloured. 


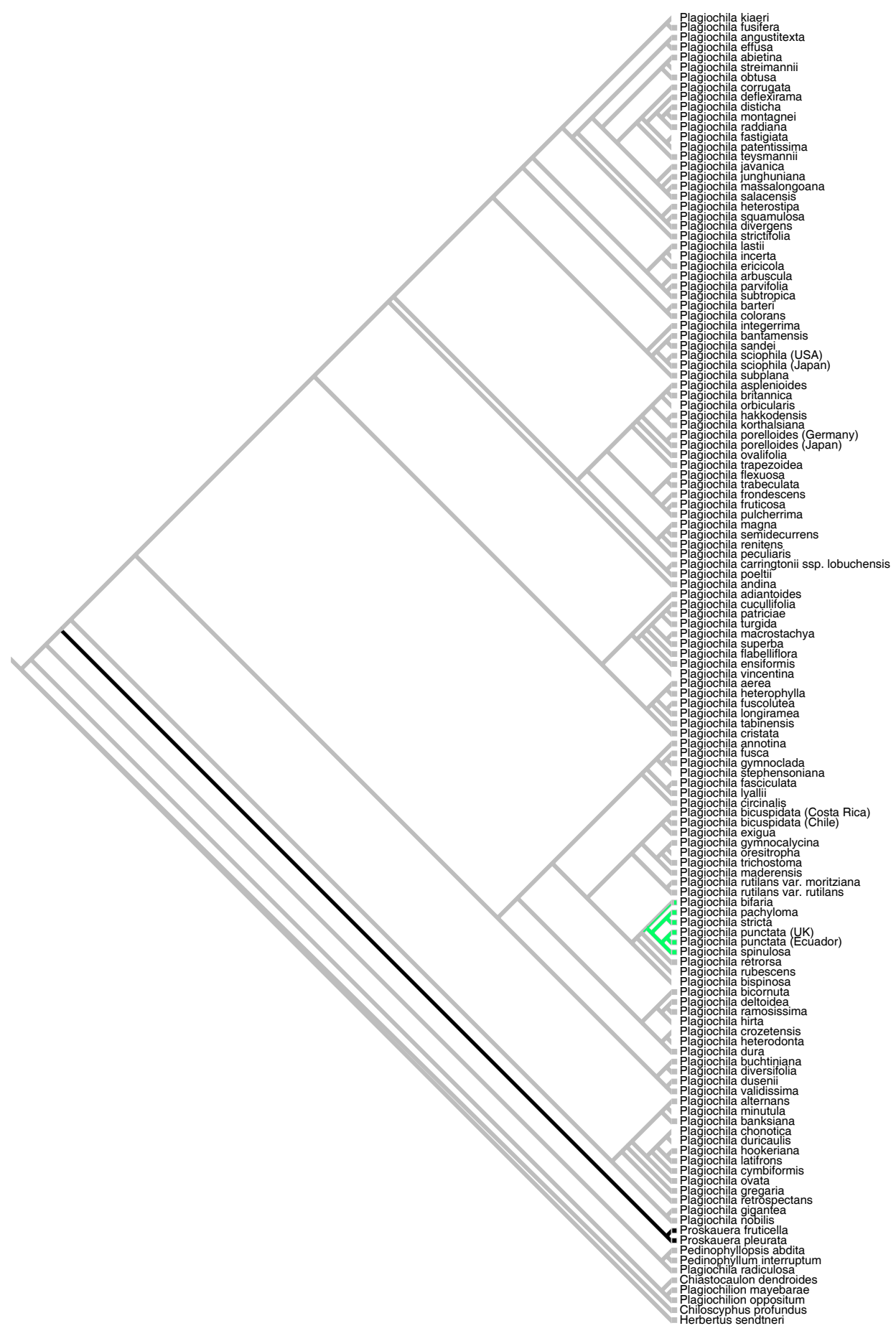

Parsimony reconstruction of the ancestral states of the trait "leaf surface" in the family Plagiochilaceae, with the states: smooth (grey), with small papillae (green), with spherical papillae (black). Steps: 3. Uncertain or polymorphic states are multicoloured. 


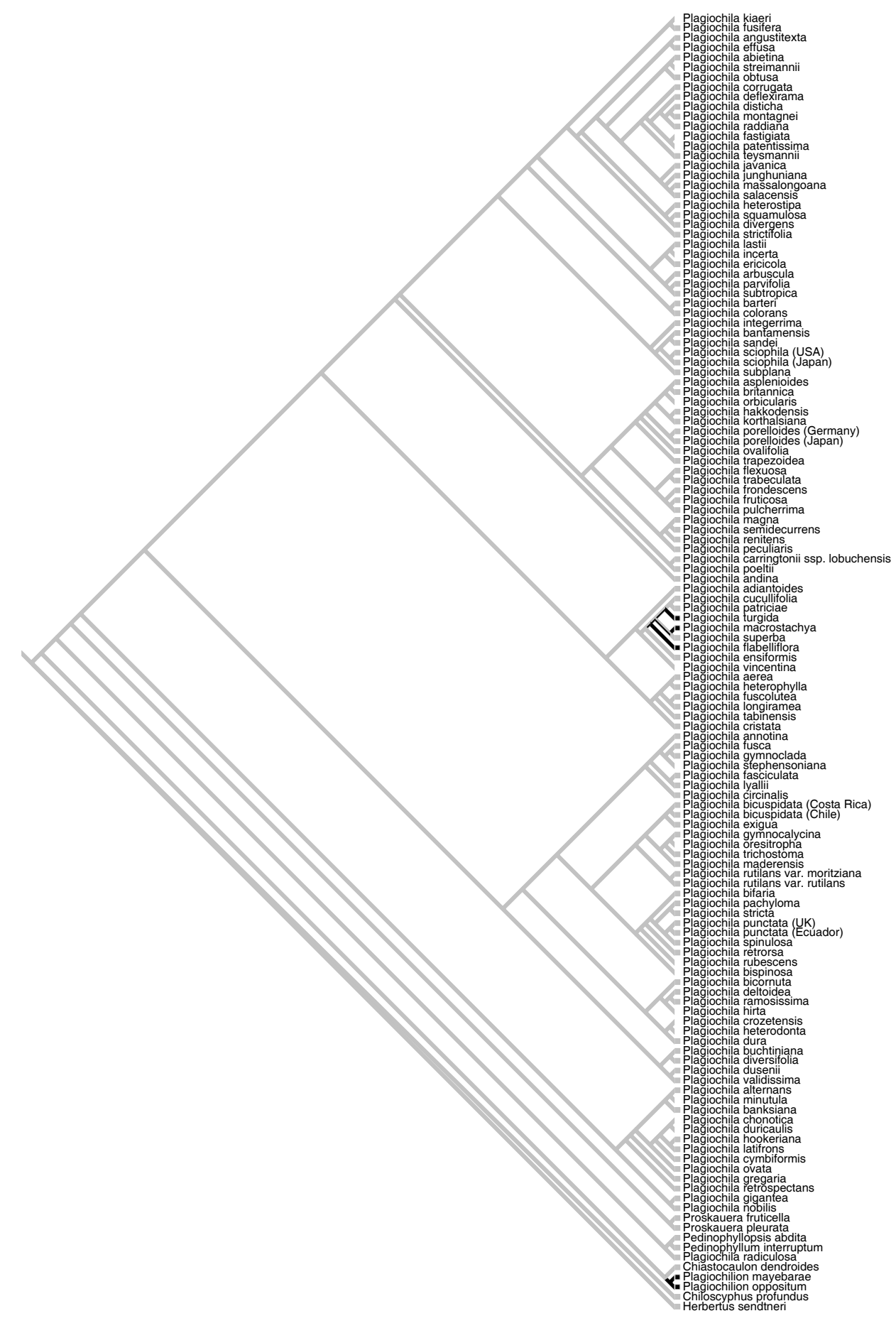

Parsimony reconstruction of the ancestral states of the trait "leaf position" in the family Plagiochilaceae, with the states: alternating (grey), (sub-) opposite (black). Steps: 4. Uncertain or polymorphic states are multicoloured. 


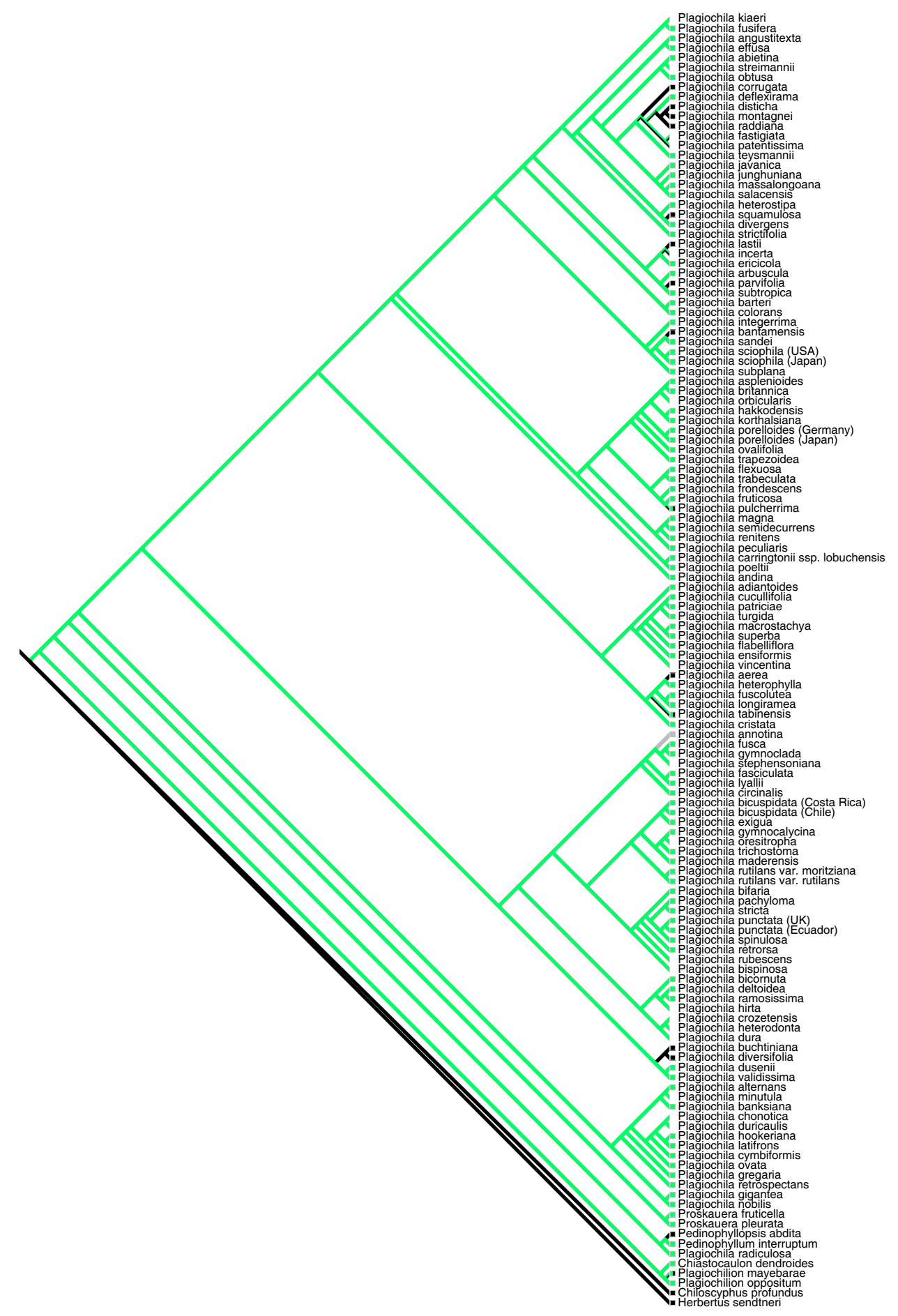

Parsimony reconstruction of the ancestral states of the trait "underleaves" in the family Plagiochilaceae, with the states: completely missing (grey), vestigial (green), well developed (black). Steps: 14. Uncertain or polymorphic states are multicoloured. 


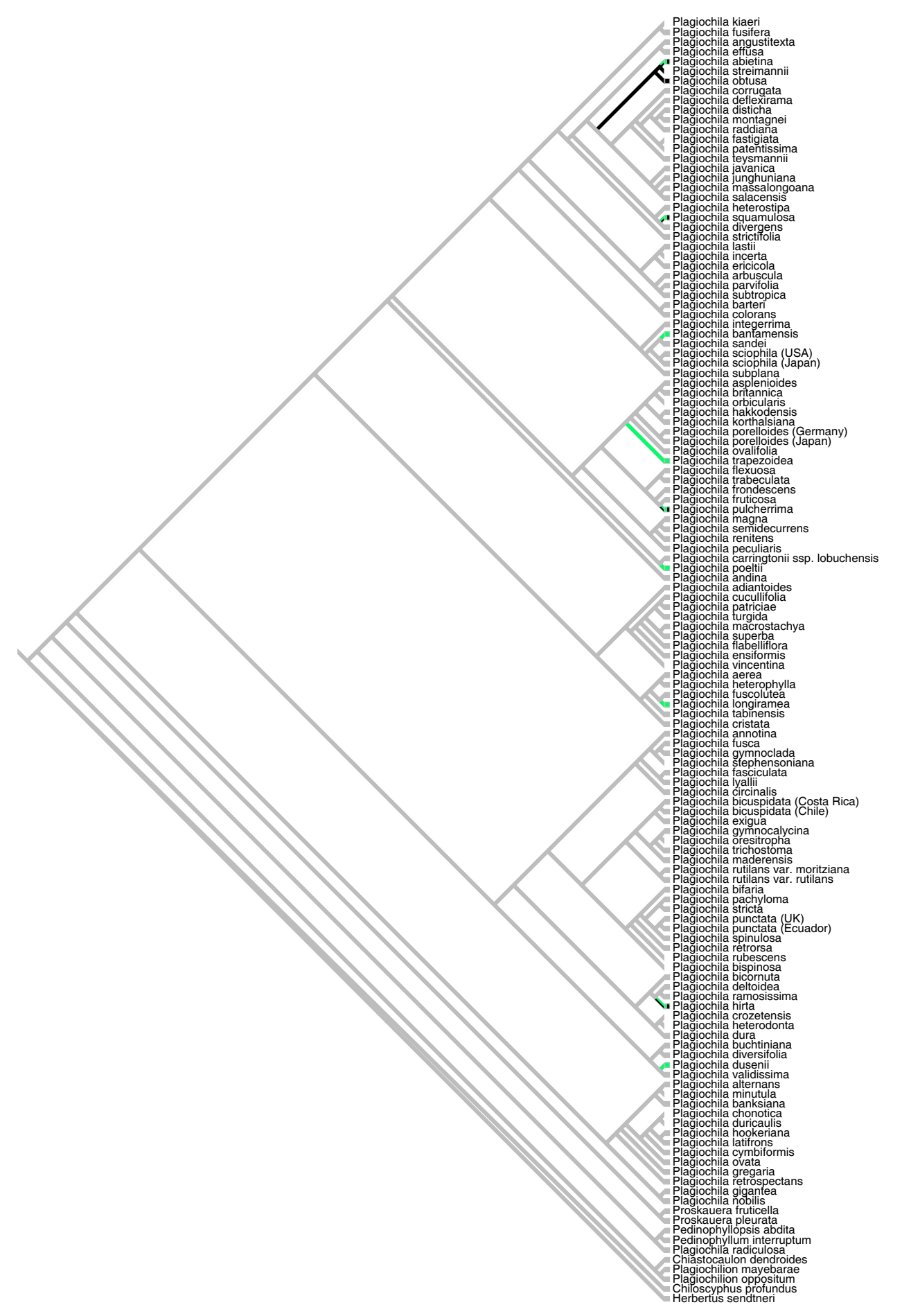

Parsimony reconstruction of the ancestral states of the trait "paraphyllia" in the family Plagiochilaceae, with the states: absent (grey), on dorsal stem surface (green), on ventral stem surface (black). Steps: 13. Uncertain or polymorphic states are multicoloured. 


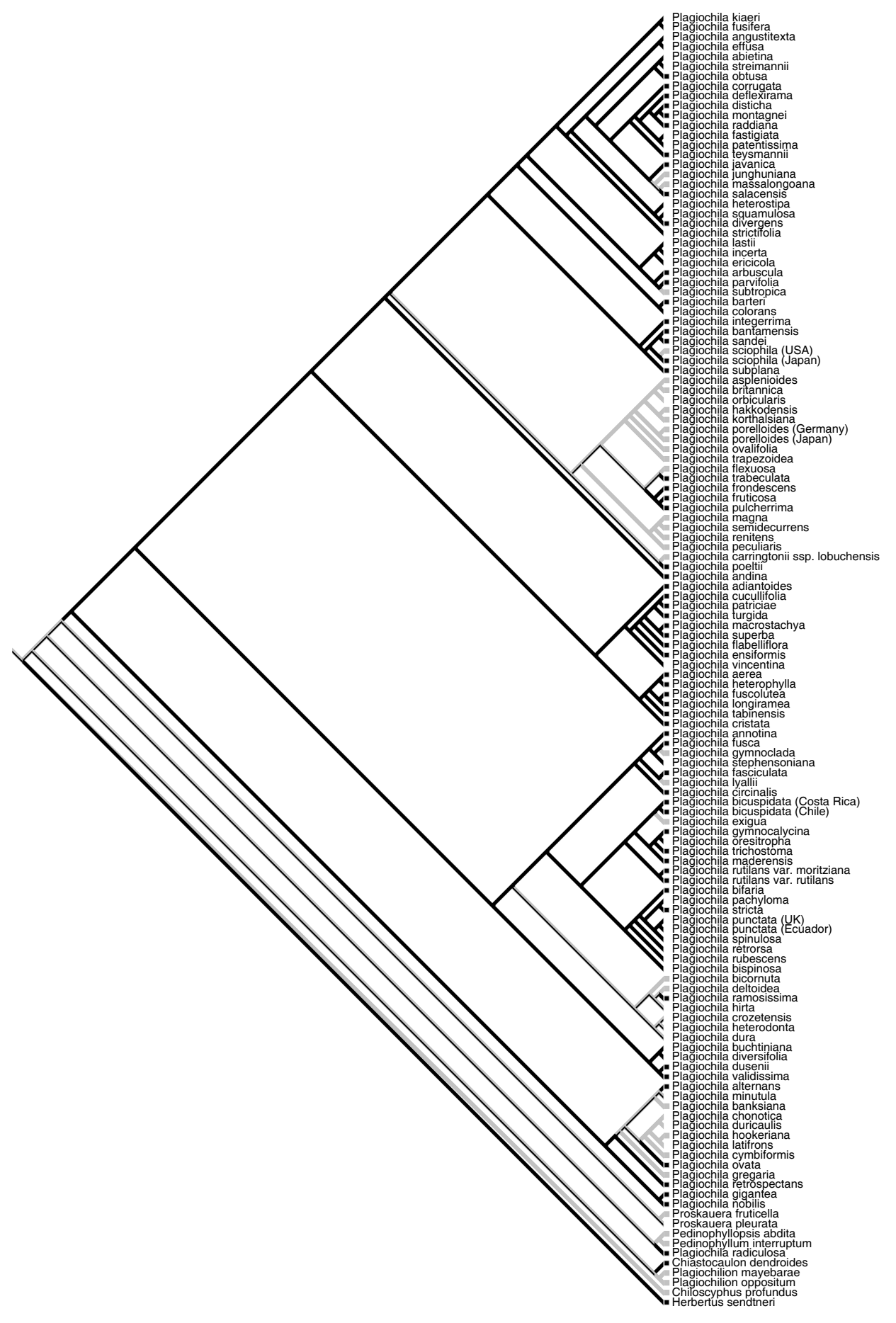

Parsimony reconstruction of the ancestral states of the trait "differentiation of a (creeping) stoloniform that gives rise to (ascending) leafy shoots" in the family Plagiochilaceae, with the states: no (grey), yes (black). Steps: 20. Uncertain or polymorphic states are multicoloured. 


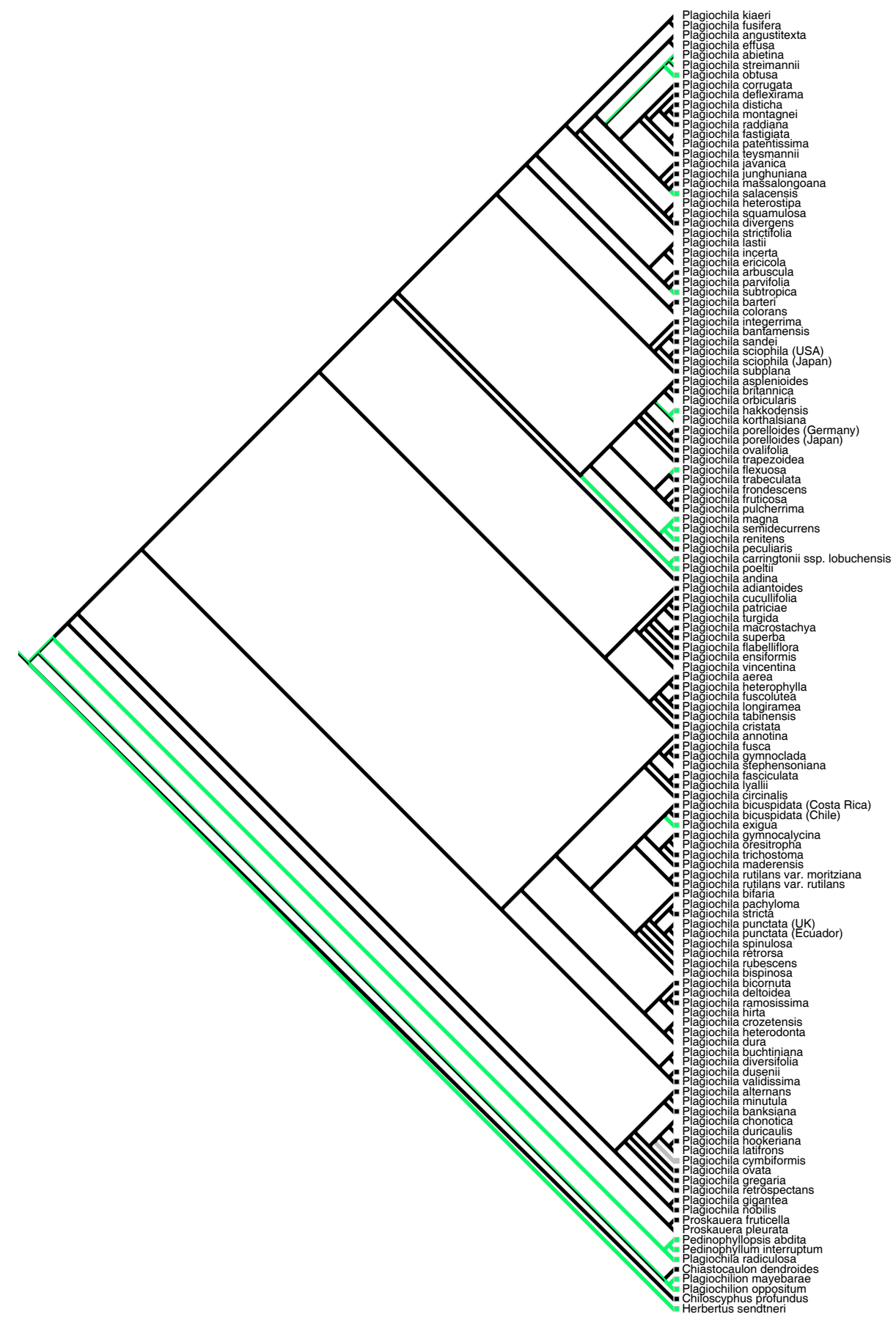

Parsimony reconstruction of the ancestral states of the trait "rhizoids" in the family Plagiochilaceae, with the states: absent (grey), present on creeping and leafy sectors of shoots (green), present on creeping sectors of shoots only (black). Steps: 12. Uncertain or polymorphic states are multicoloured. 


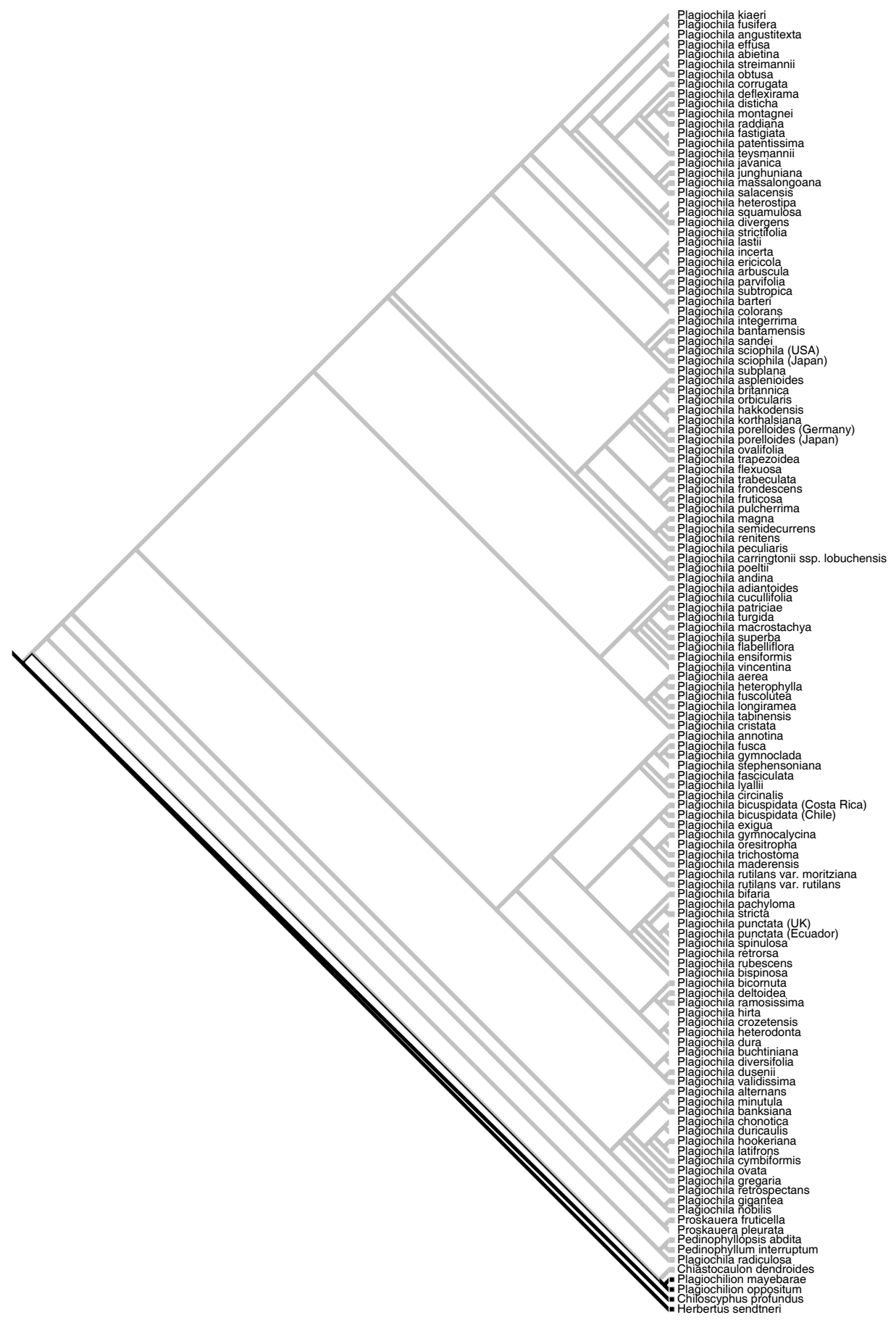

Parsimony reconstruction of the ancestral states of the trait "position of rhizoids" in the family Plagiochilaceae, scattered on stem surface (grey), fasciculated at ventral leaf base (black). Steps: 2. Uncertain or polymorphic states are multicoloured. 


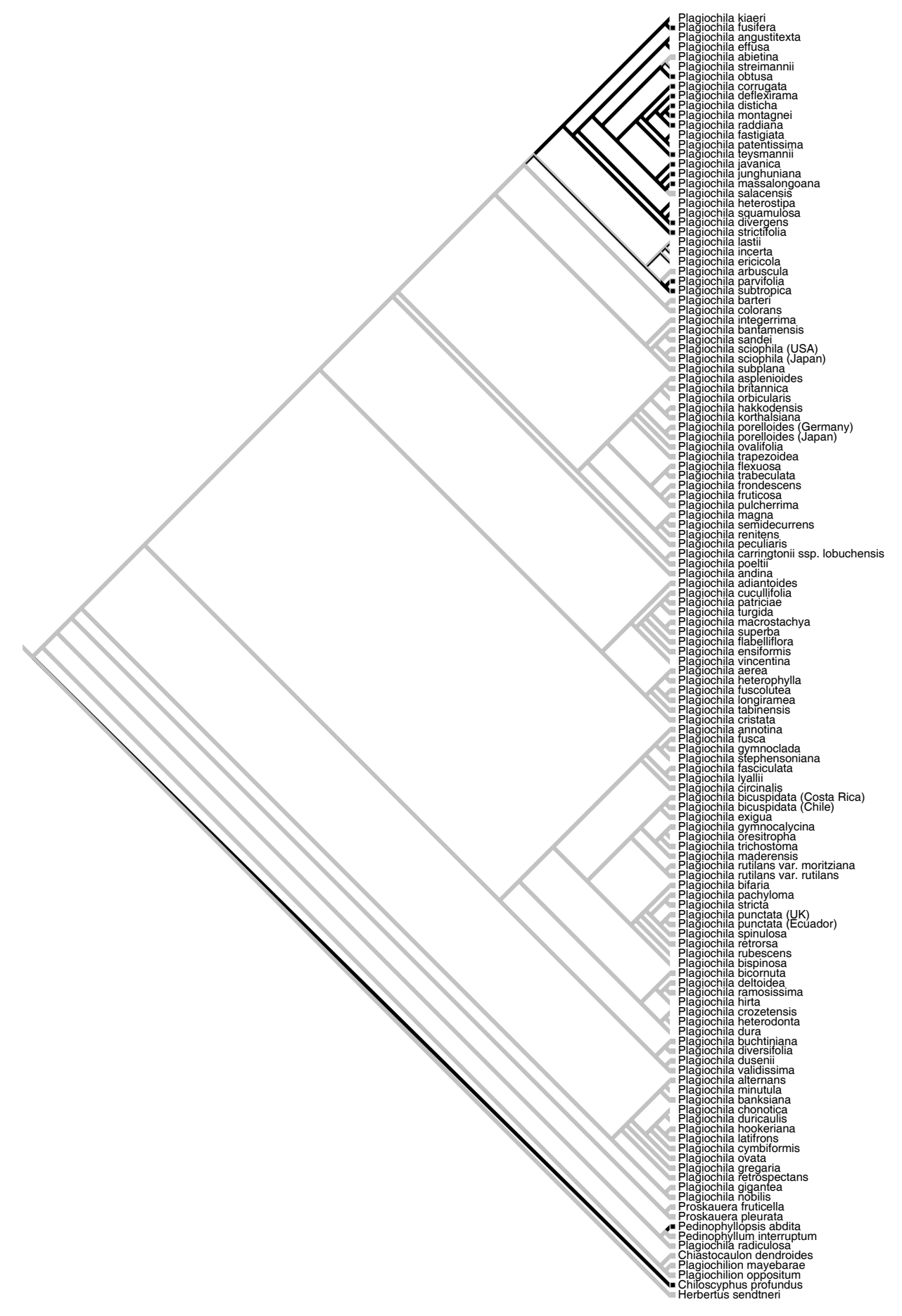

Parsimony reconstruction of the ancestral states of the trait "asexual reproduction by propagules" in the family Plagiochilaceae, with the states: no (grey), yes (black). Steps: 6. Uncertain or polymorphic states are multicoloured. 


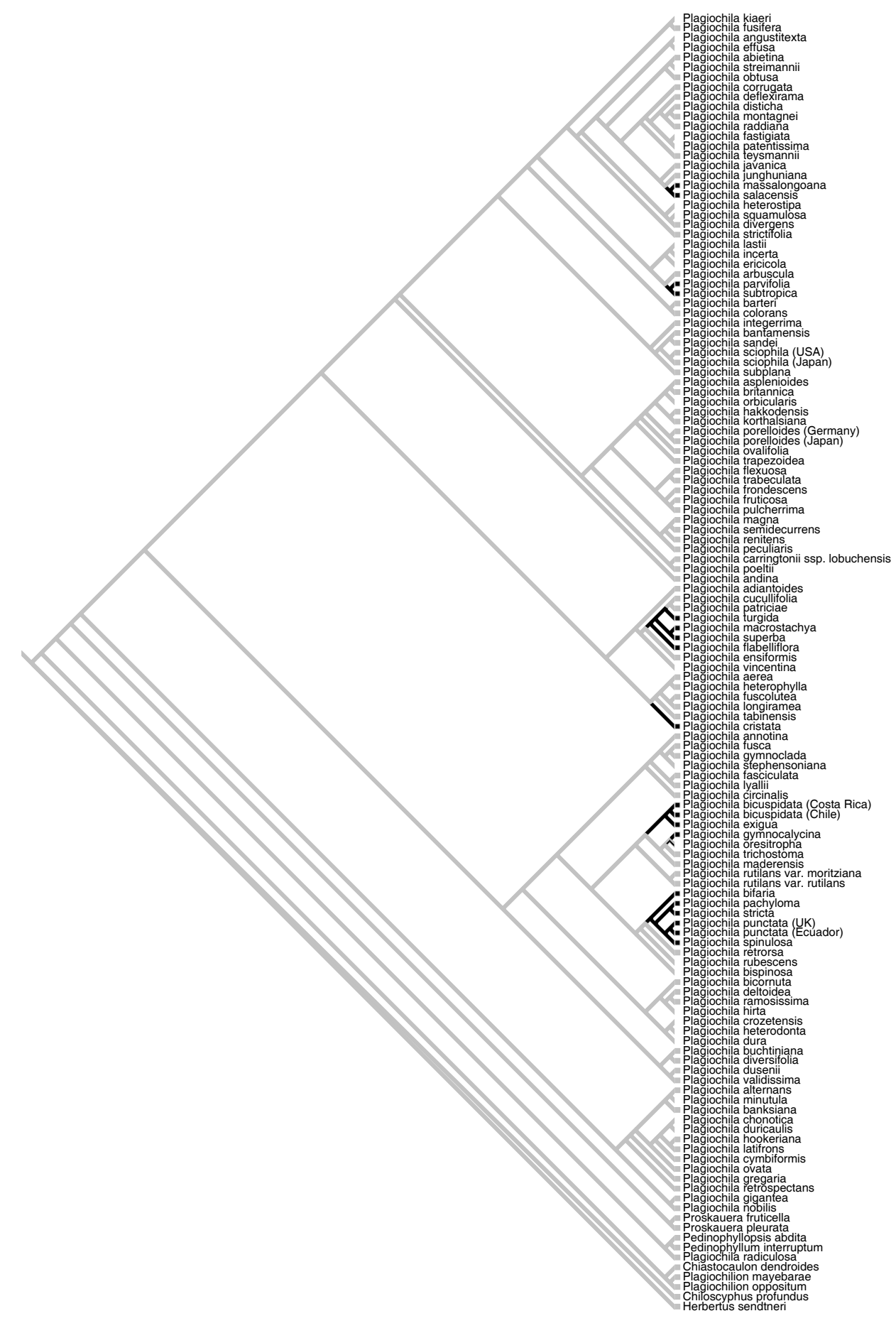

Parsimony reconstruction of the ancestral states of the trait "asexual reproduction by caducous leaves" in the family Plagiochilaceae, with the states: no (grey), yes (black). Steps: 8. Uncertain or polymorphic states are multicoloured. 


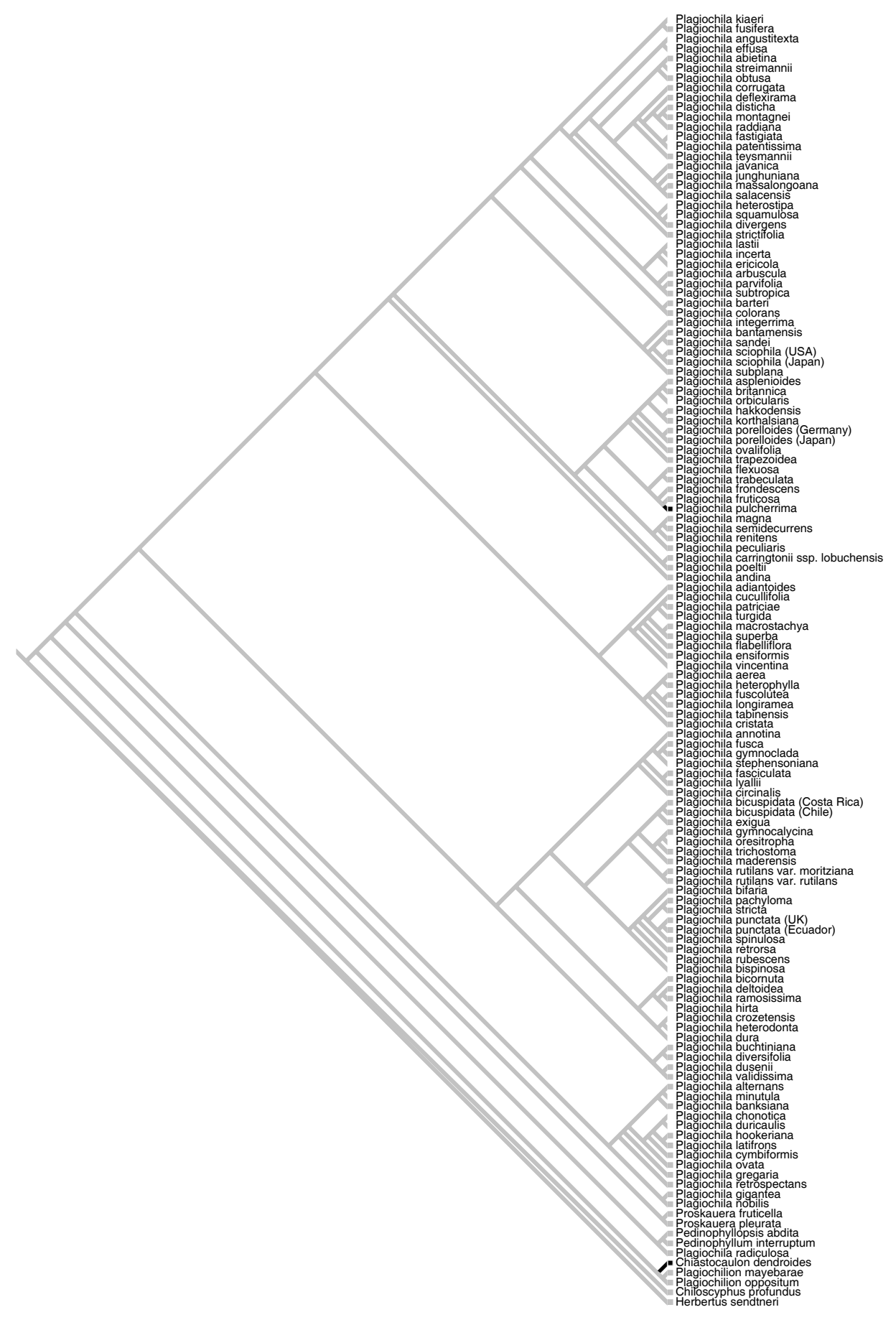

Parsimony reconstruction of the ancestral states of the trait "asexual reproduction by flagelliform branches" in the family Plagiochilaceae, with the states: no (grey), yes (black). Steps: 2. Uncertain or polymorphic states are multicoloured. 


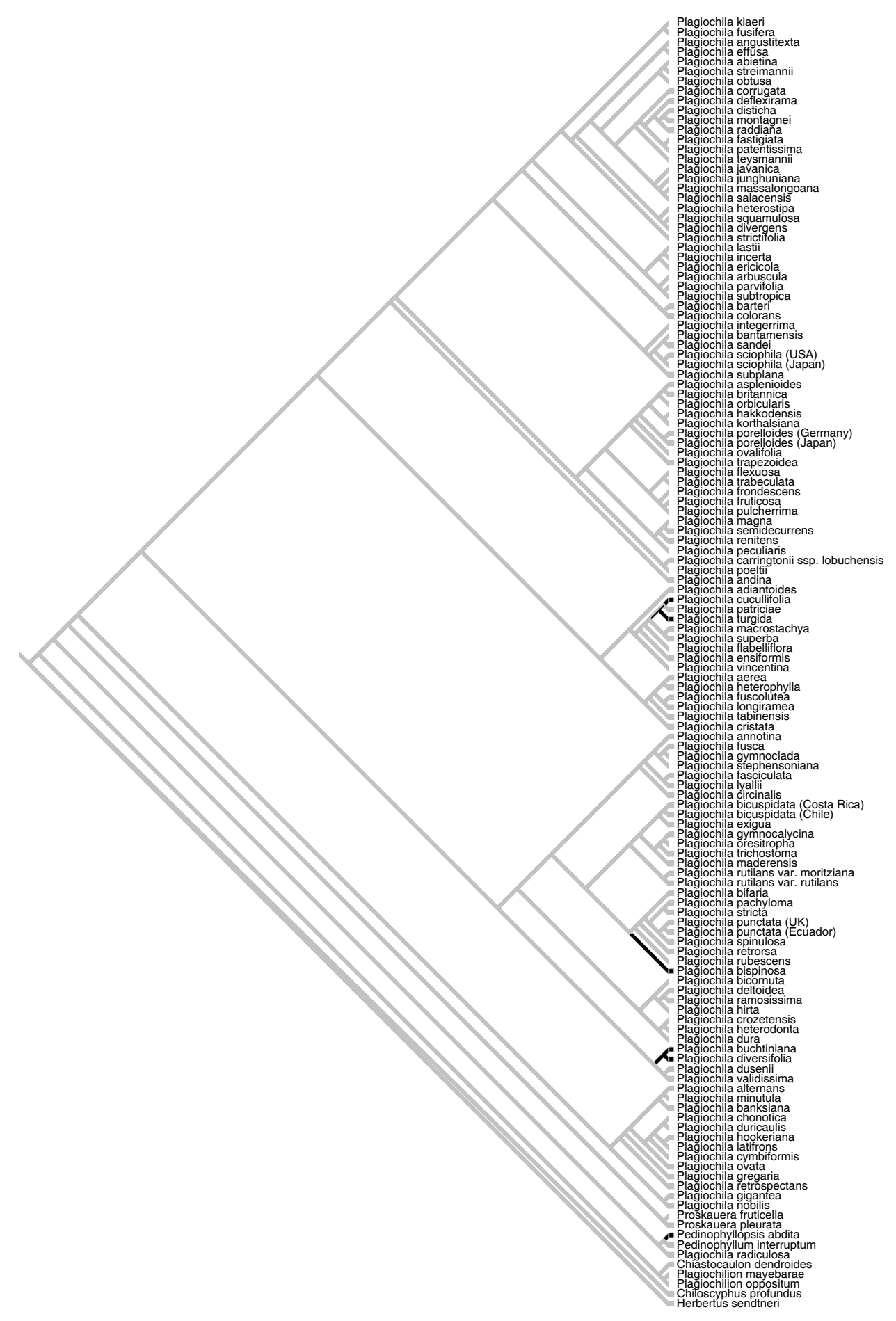

Parsimony reconstruction of the ancestral states of the trait "colour of oil bodies" in the family Plagiochilaceae, with the states: colourless, opaque (grey), brownish (black). Steps: 5. Uncertain or polymorphic states are multicoloured. 


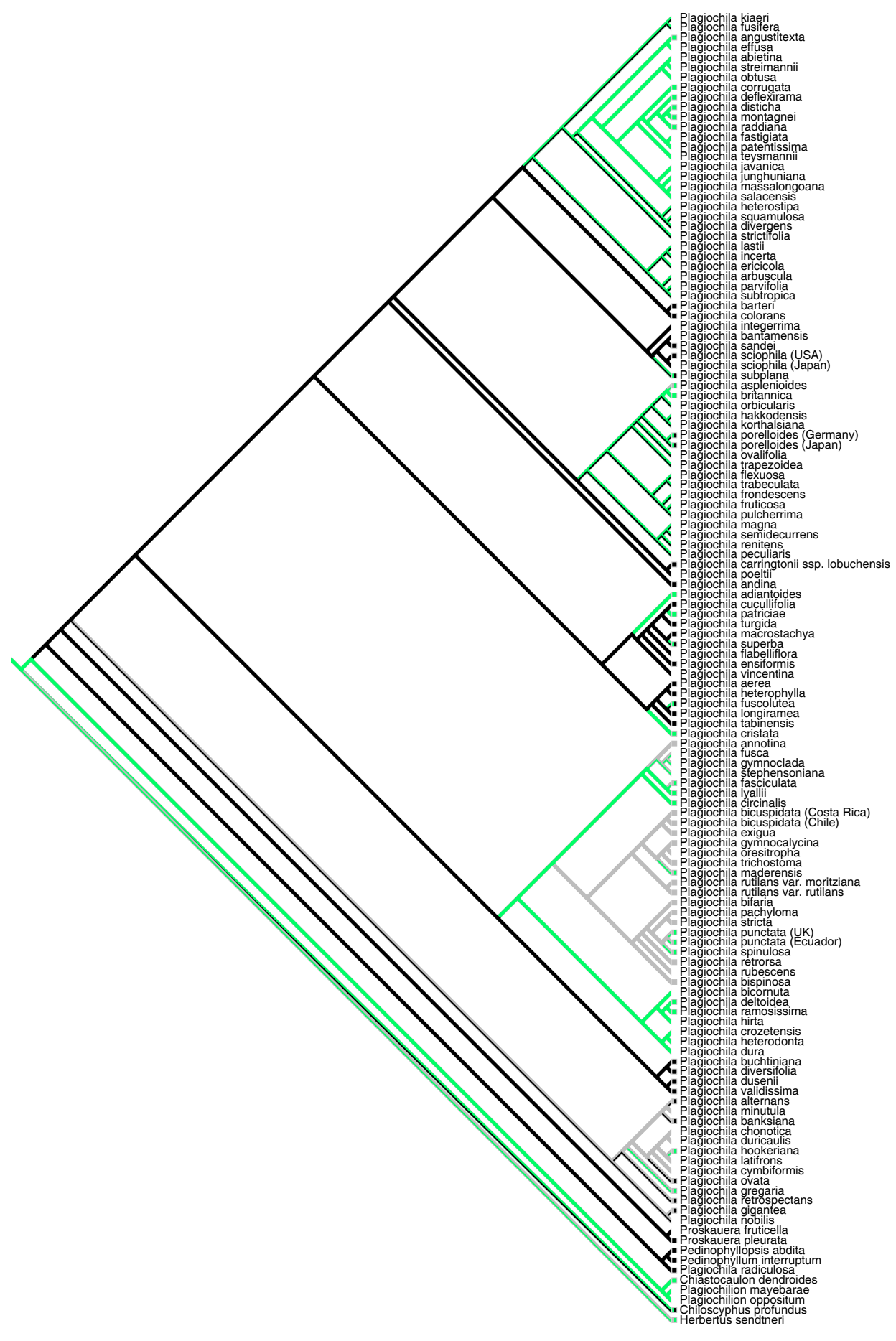

Parsimony reconstruction of the ancestral states of the trait "structure of oil bodies" in the family Plagiochilaceae, with the states: homogenous (grey), coarsely segmented (green), fine papillose (black). Steps: 30. Uncertain or polymorphic states are multicoloured. 


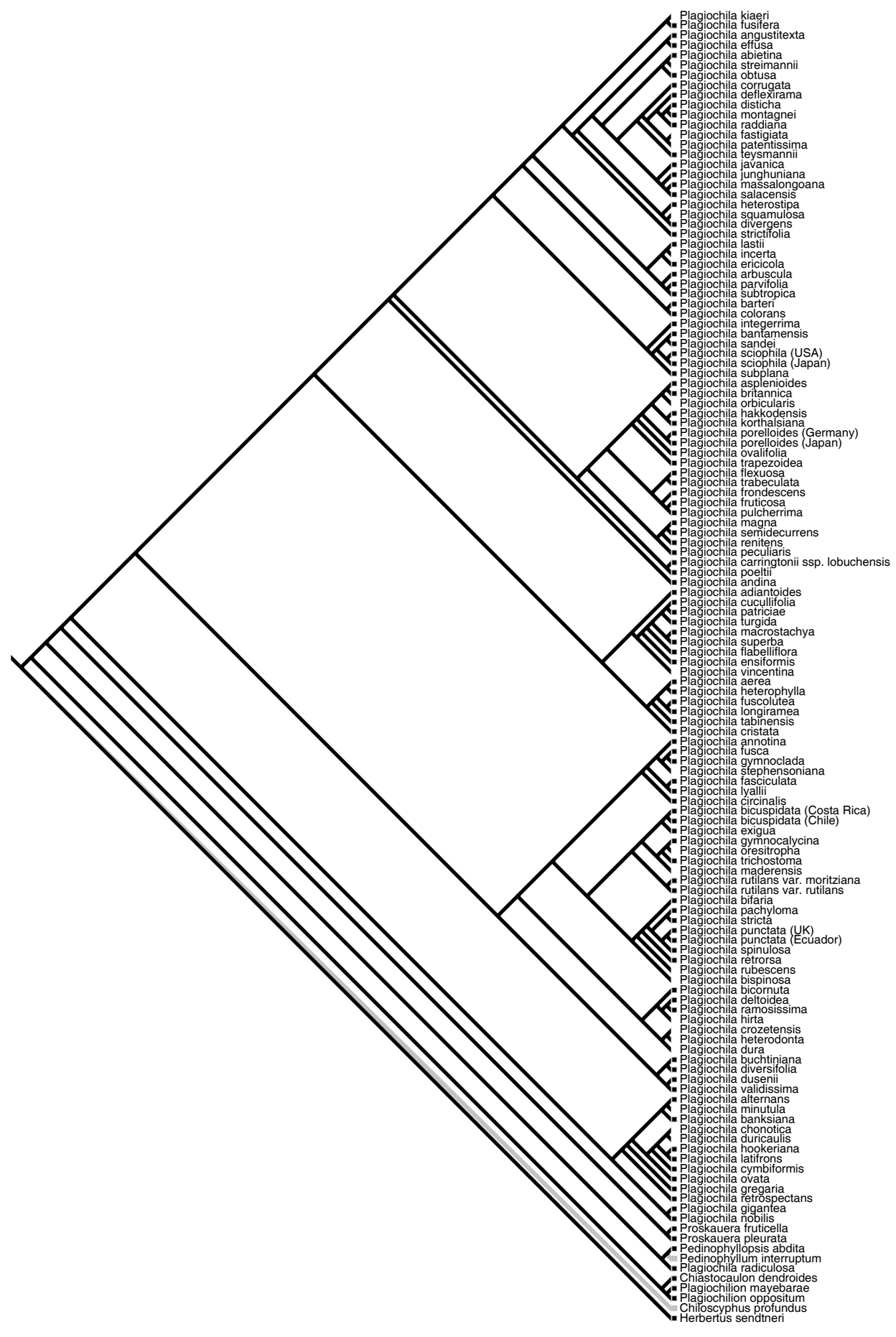

Parsimony reconstruction of the ancestral states of the trait "sexual condition" in the family Plagiochilaceae, with the states: monoecious (grey), dioecious (black). Steps: 2. Uncertain or polymorphic states are multicoloured. 


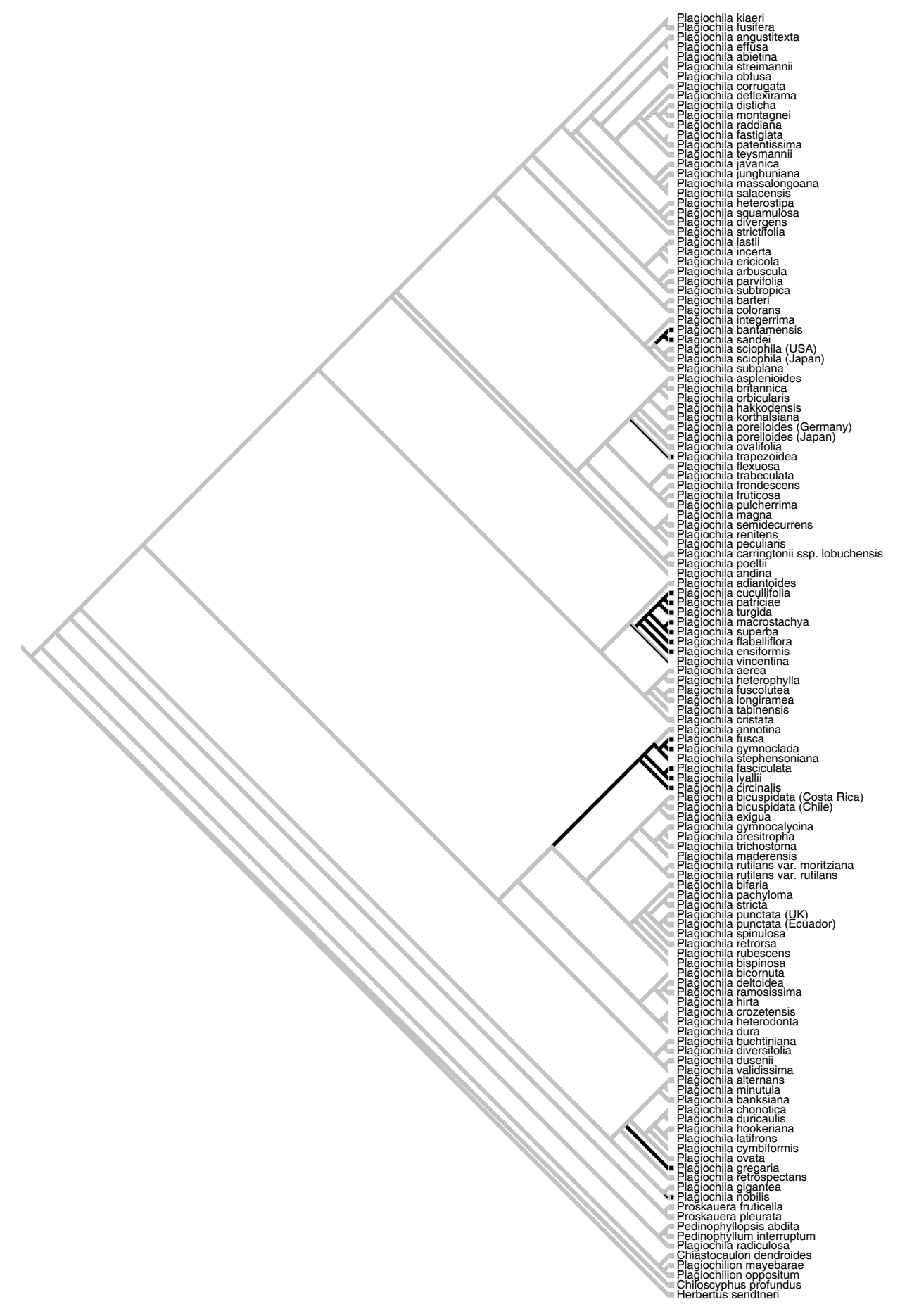

Parsimony reconstruction of the ancestral states of the trait "androecia" in the family Plagiochilaceae, with the states: simple (grey), fan shaped (or at least gregarious) (black). Steps: 7. Uncertain or polymorphic states are multicoloured. 


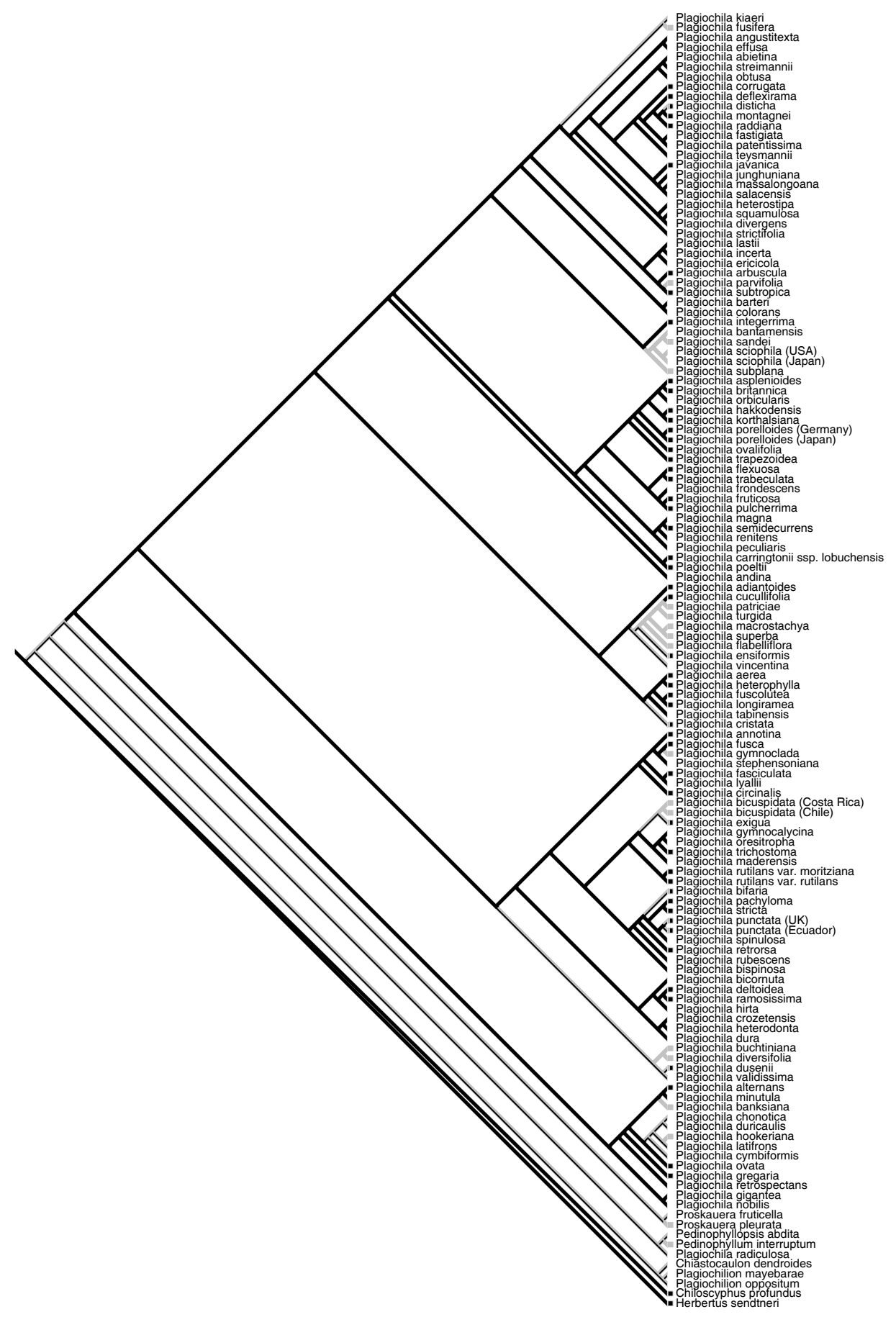

Parsimony reconstruction of the ancestral states of the trait "opposite male bracts in dorsal view" in the family Plagiochilaceae, with the states: not overlapping (grey), overlapping (black). Steps: 20. Uncertain or polymorphic states are multicoloured. 


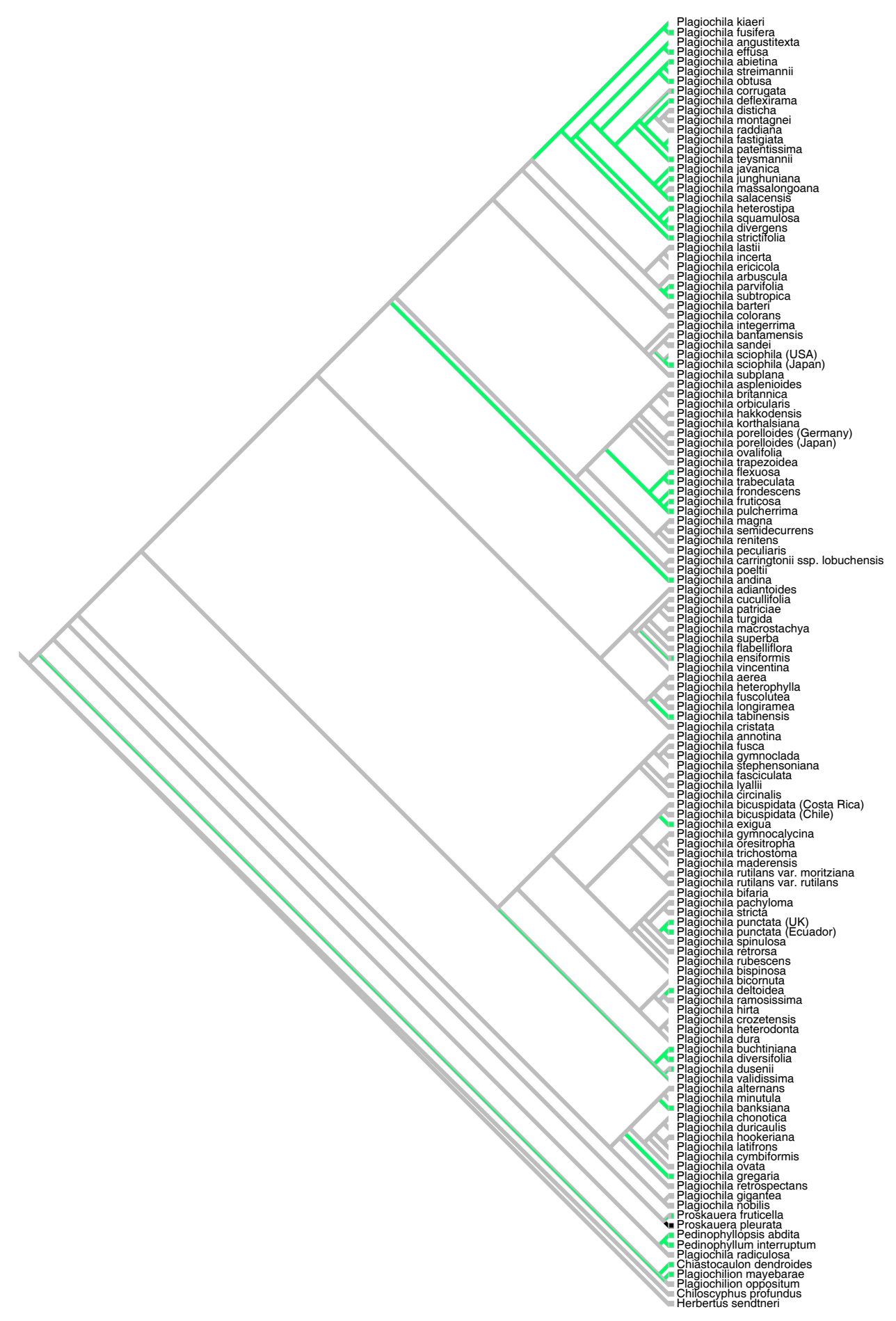

Parsimony reconstruction of the ancestral states of the trait "perianth shape" in the family Plagiochilaceae, with the states: cylindrical (grey), campanulate (blue), subrotundate (black). Steps: 22. Uncertain or polymorphic states are multicoloured. 


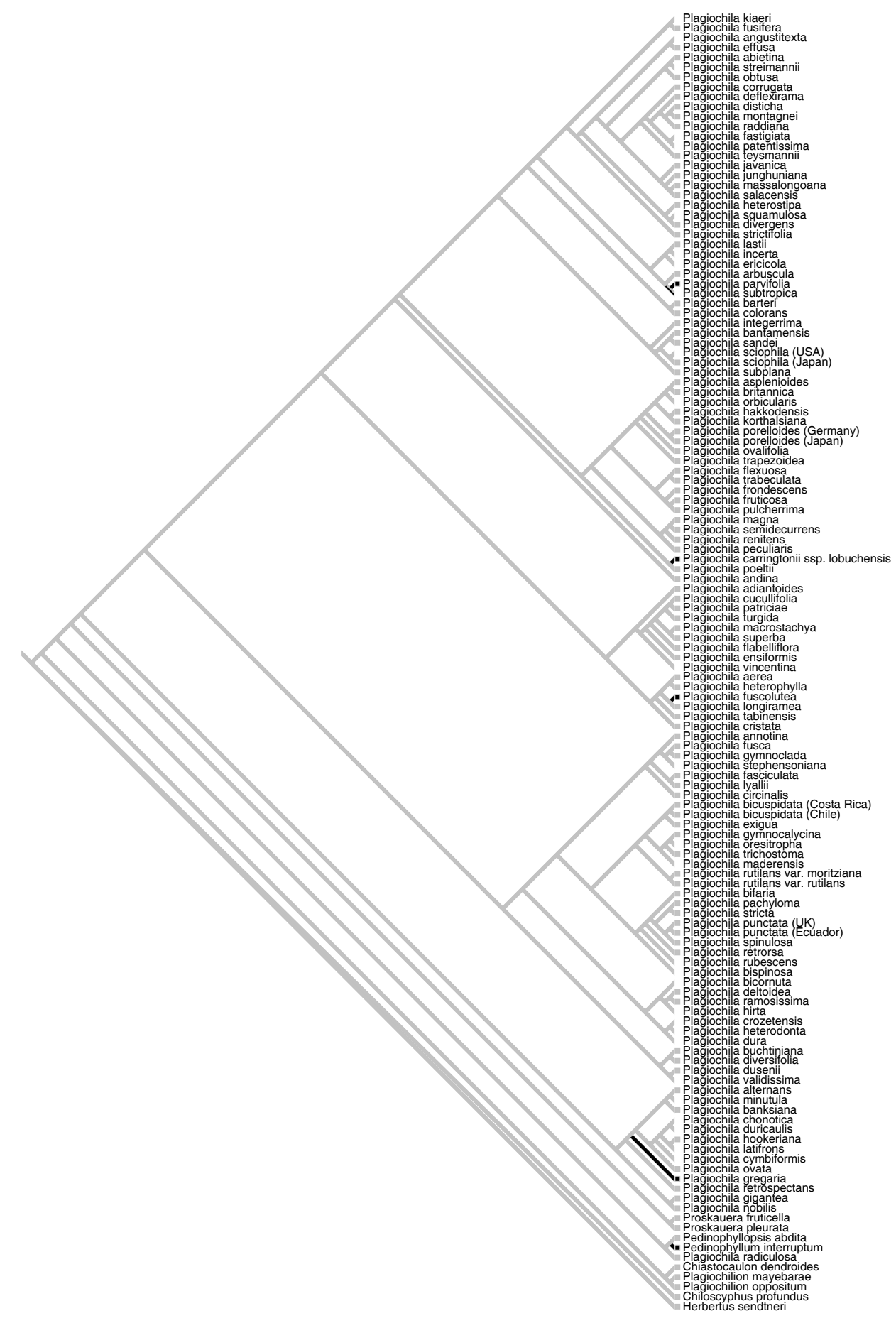

Parsimony reconstruction of the ancestral states of the trait "perianth mouth" in the family Plagiochilaceae, with the states: always toothed (grey), sometimes entire (black). Steps: 5. Uncertain or polymorphic states are multicoloured. 


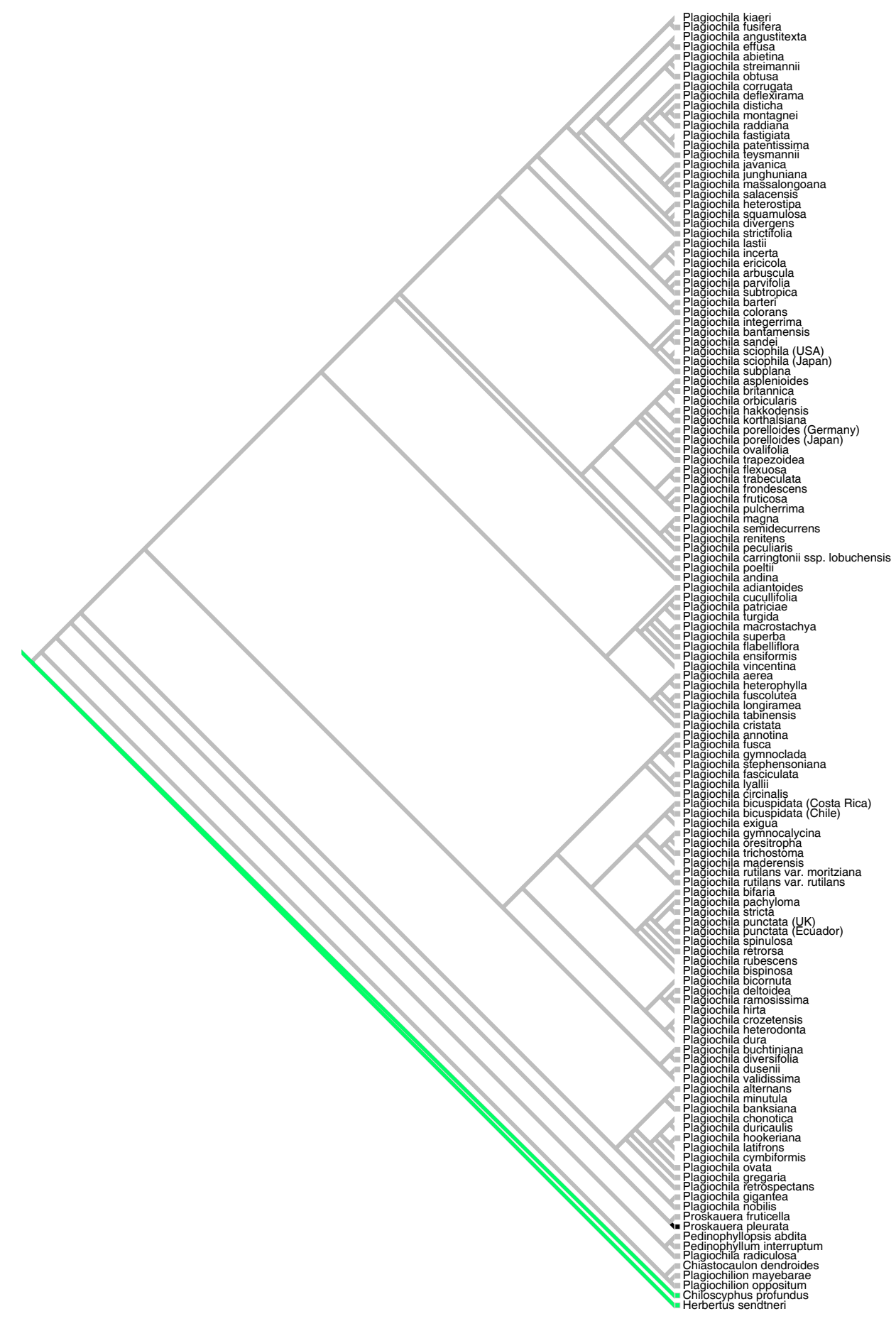

Parsimony reconstruction of the ancestral states of the trait "perianth with" in the family Plagiochilaceae, with the states: two keels (grey), three keels (green), more than three keels (black). Steps: 2. Uncertain or polymorphic states are multicoloured. 


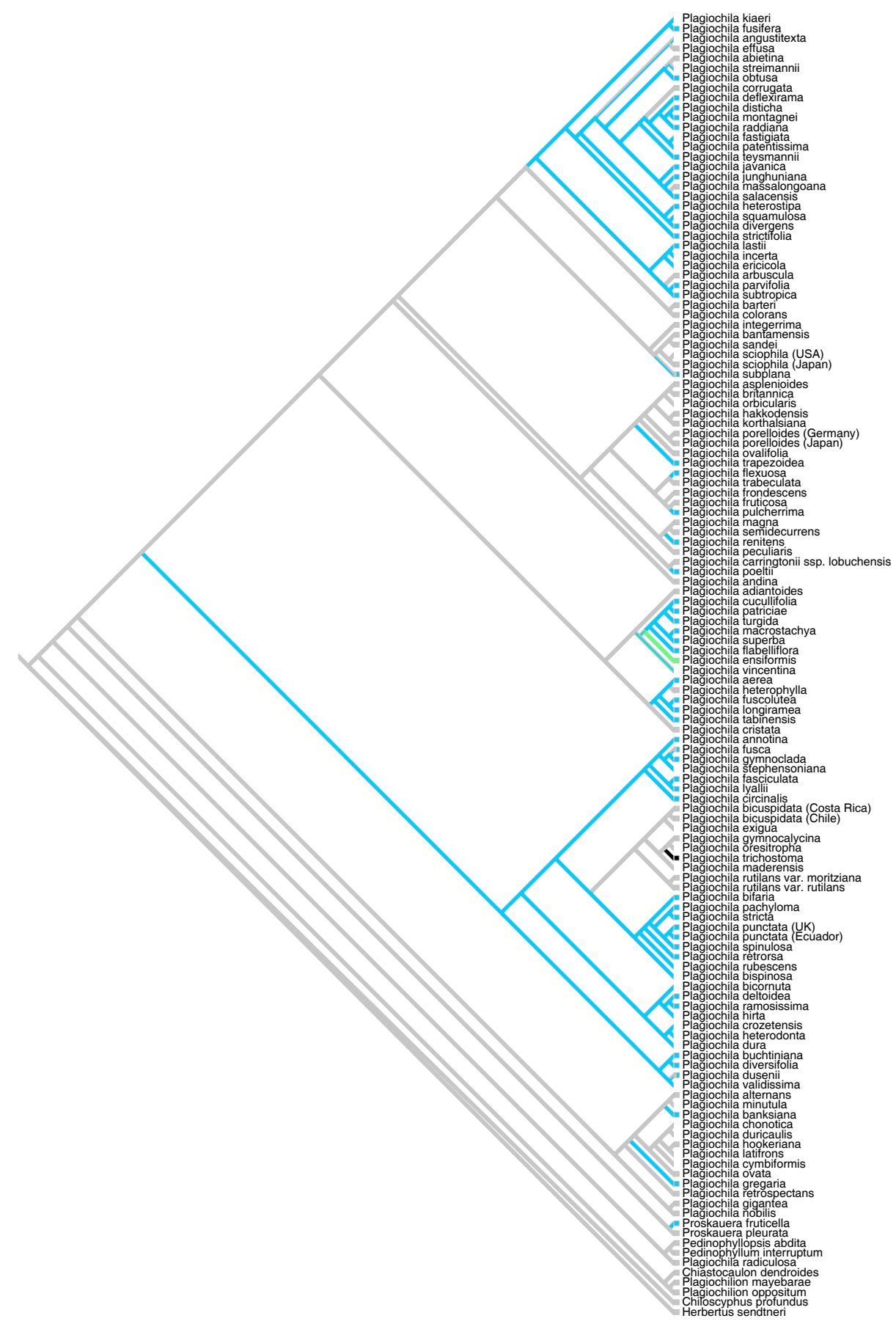

Parsimony reconstruction of the ancestral states of the trait "dorsal keel of perianth" in the family Plagiochilaceae, with the states: without wing (grey), with one wing (green), with $1-2$ wings (blue), with ridge and low wing (black). Steps: 24. Uncertain or polymorphic states are multicoloured. 


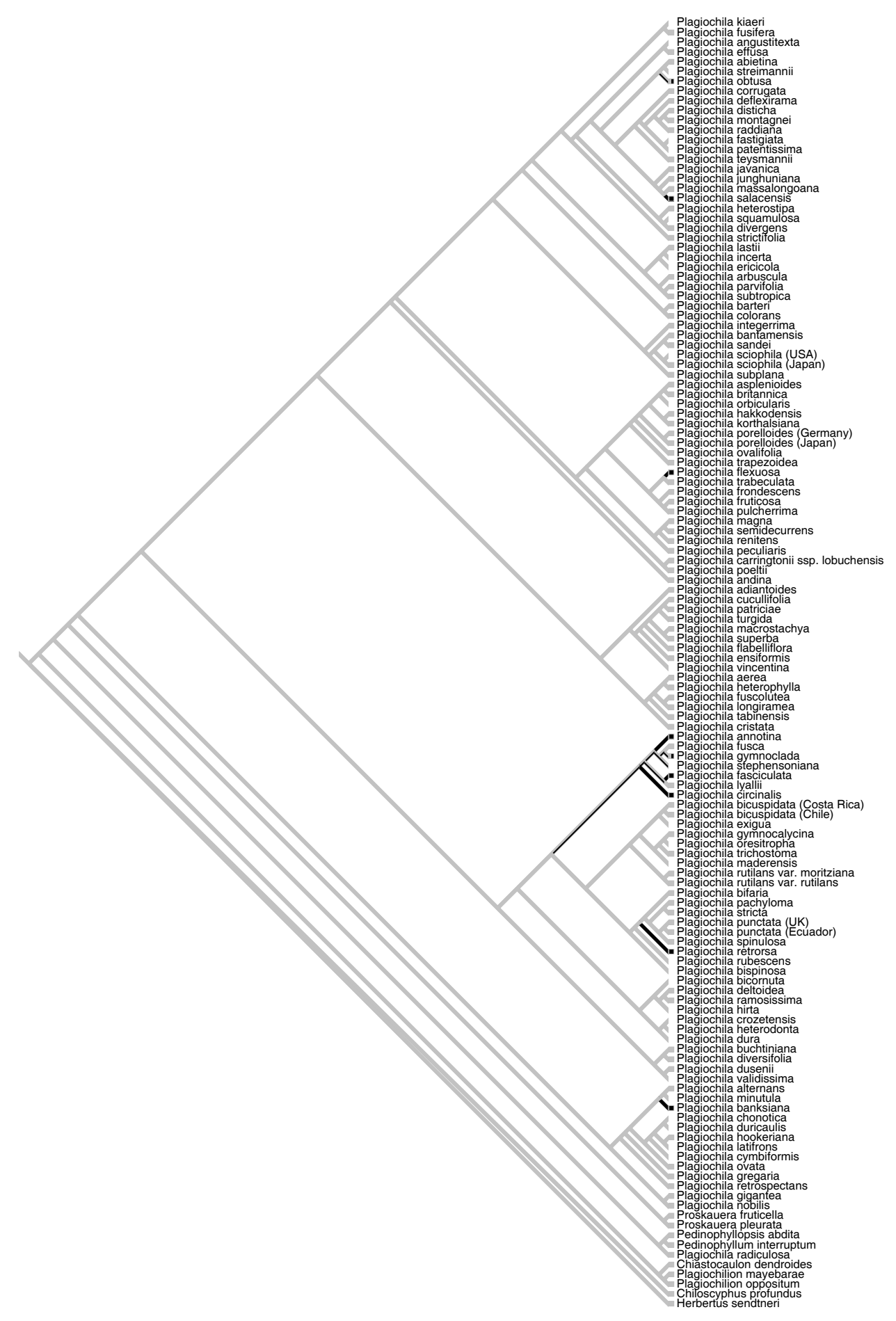

Parsimony reconstruction of the ancestral states of the trait "ventral keel of perianth" in the family Plagiochilaceae, with the states: without wing (grey), with one wing (blue), with $1-2$ wings (black). Steps: 9. Uncertain or polymorphic states are multicoloured. 


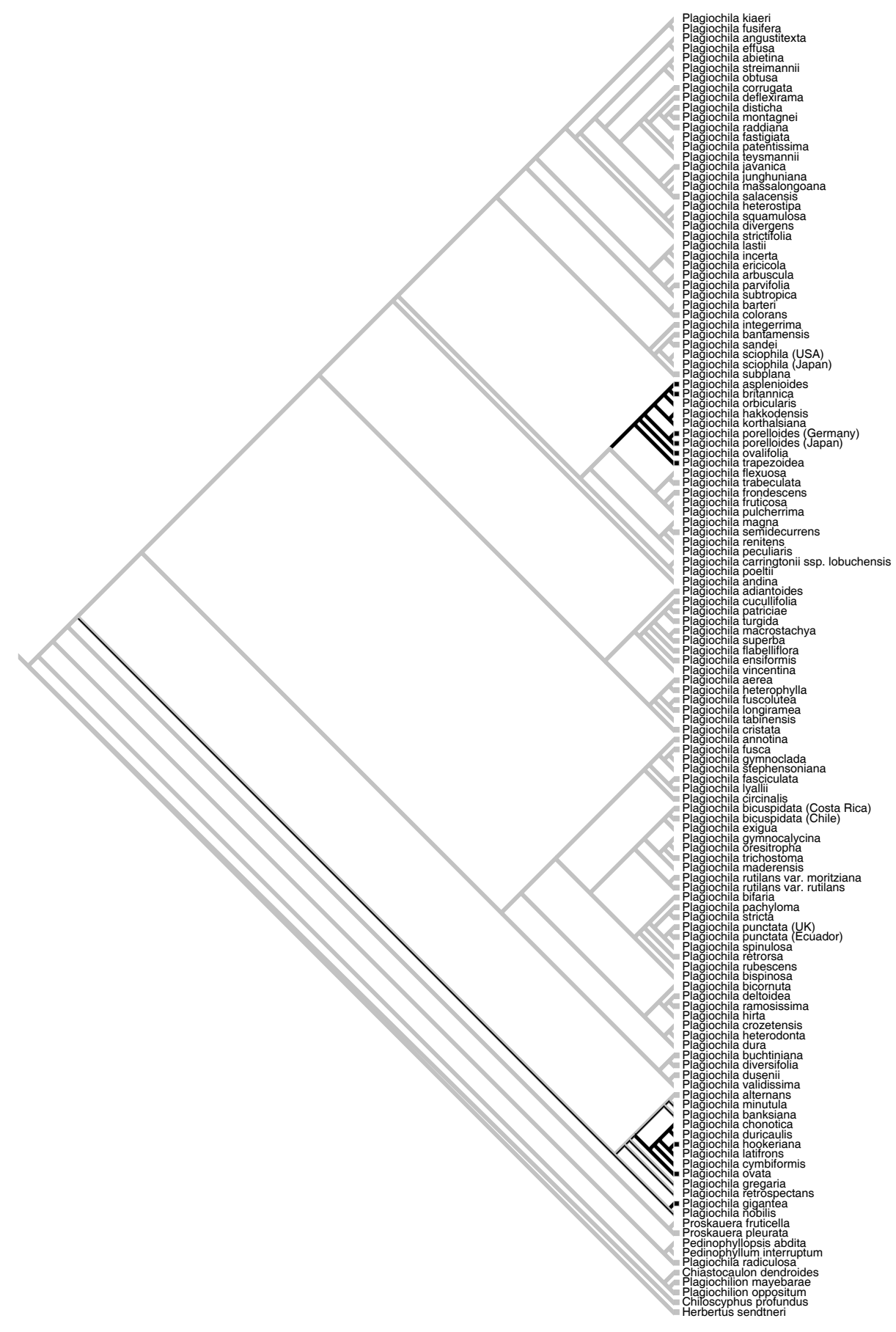

Parsimony reconstruction of the ancestral states of the trait "seta" in the family Plagiochilaceae, with the states: short (less than $12 \mathrm{~mm}$ longer than perianth) (grey), long (more than $12 \mathrm{~mm}$ longer than perianth) (black). Steps: 3. Uncertain or polymorphic states are multicoloured. 


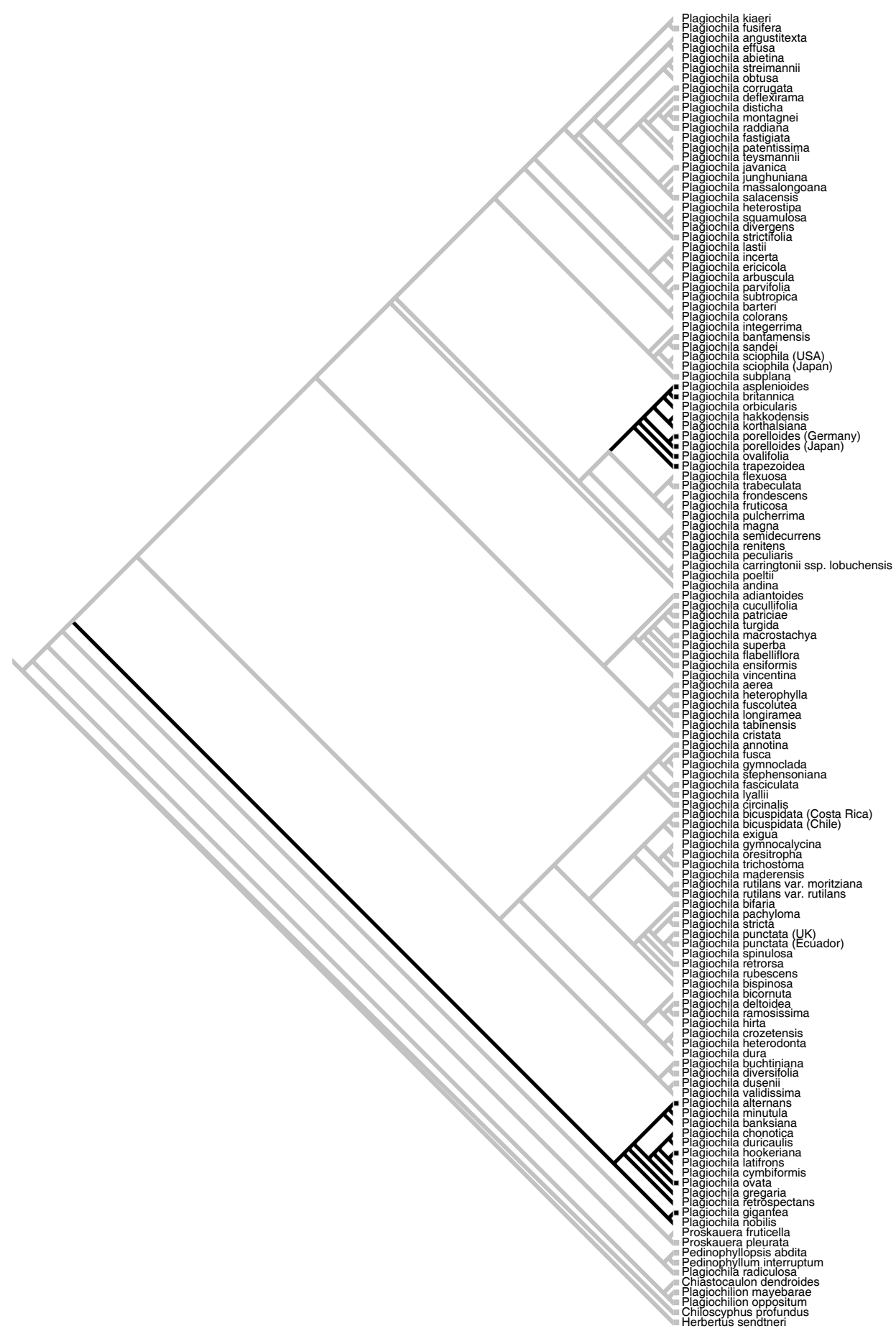

Parsimony reconstruction of the ancestral states of the trait "capsule shape" in the family Plagiochilaceae, with the states: +/- globose (grey), cylindrical (black). Steps: 2. Uncertain or polymorphic states are multicoloured. 


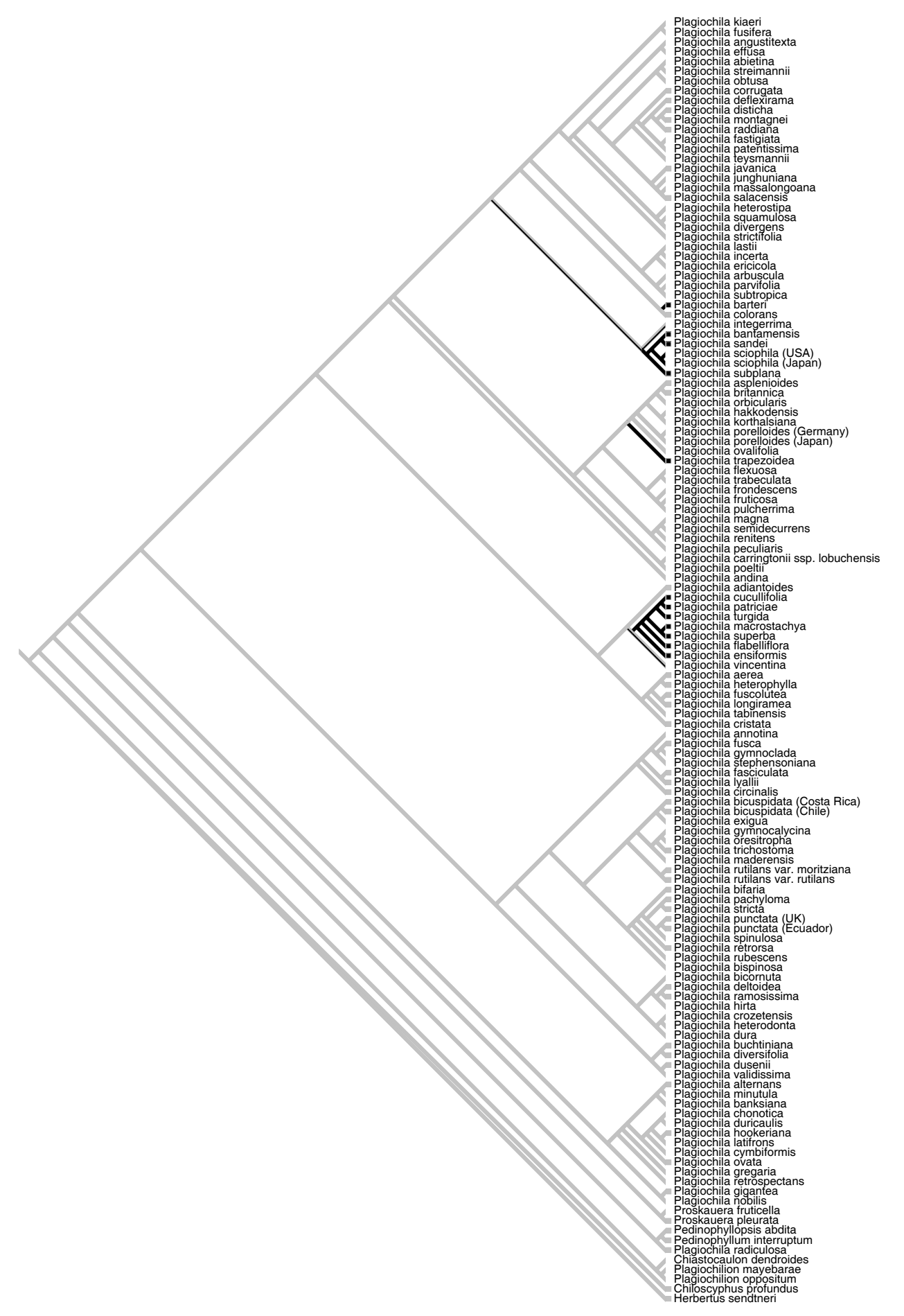

Parsimony reconstruction of the ancestral states of the trait "epidermal layer of capsule wall" in the family Plagiochilaceae, with the states: with thickenings (grey), without thickenings (black). Steps: 4. Uncertain or polymorphic states are multicoloured. 


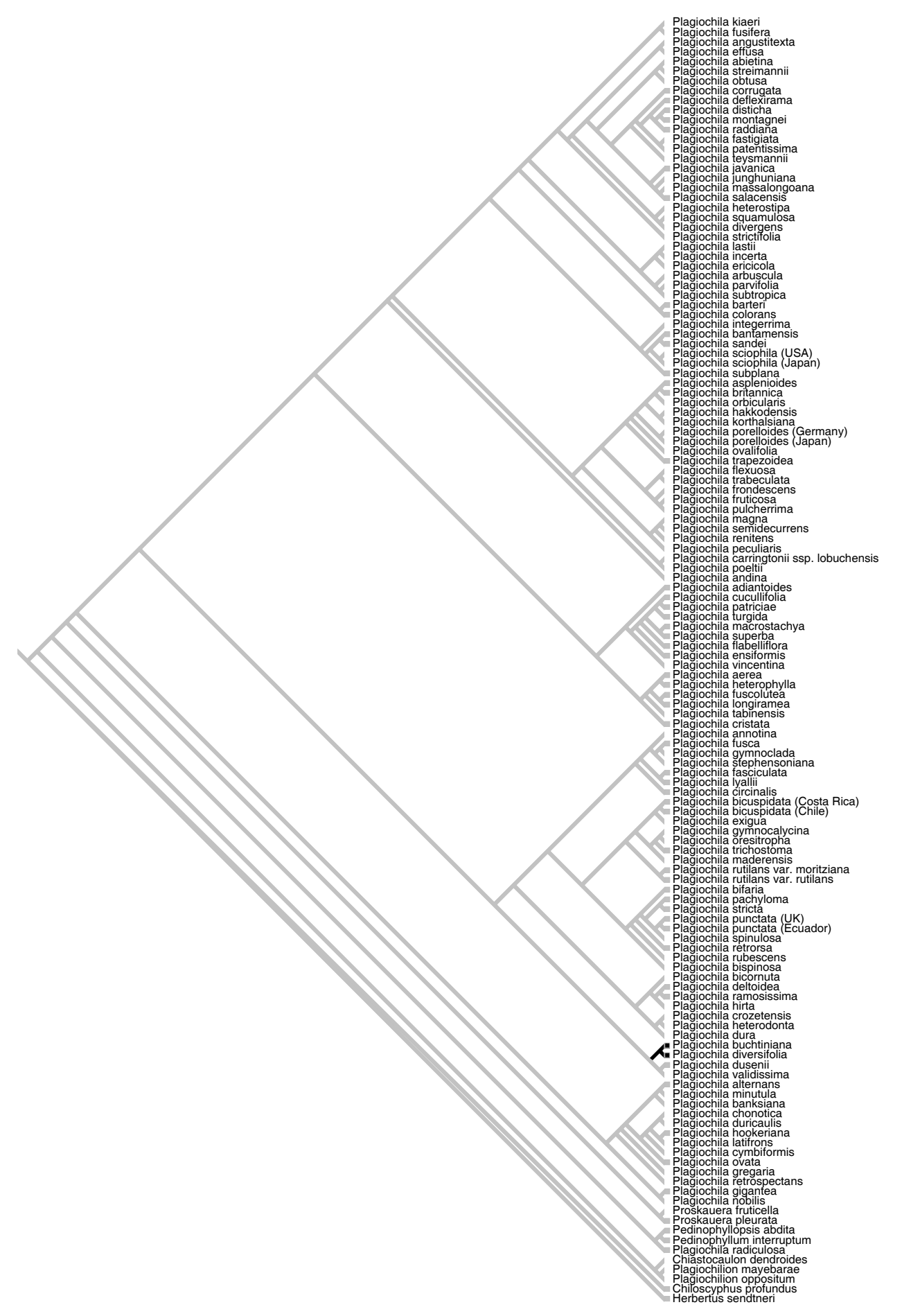

Parsimony reconstruction of the ancestral states of the trait "innermost layer of capsule wall" in the family Plagiochilaceae, with the states: with thickenings (grey), without thickenings (black). Steps: 1. Uncertain or polymorphic states are multicoloured. 


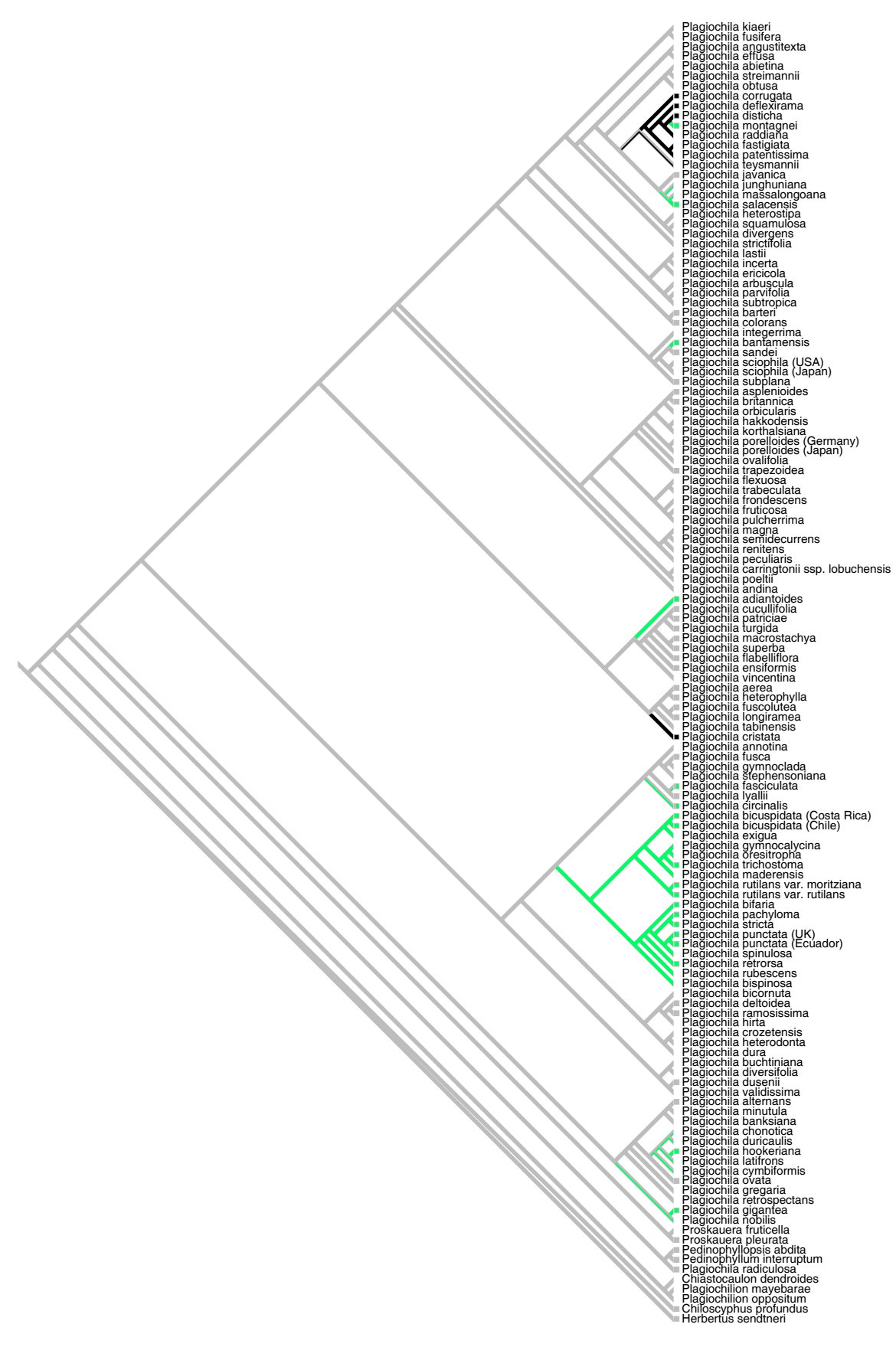

Parsimony reconstruction of the ancestral states of the trait "type of thickenings in innermost layer of capsule wall" in the family Plagiochilaceae, with the states: ladder like / fenestrate (grey), nodulose, discrete or confluent at base or (partly) coalescent (green), mixture of discrete and coalescent thickenings (black). Steps: 11. Uncertain or polymorphic states are multicoloured. 


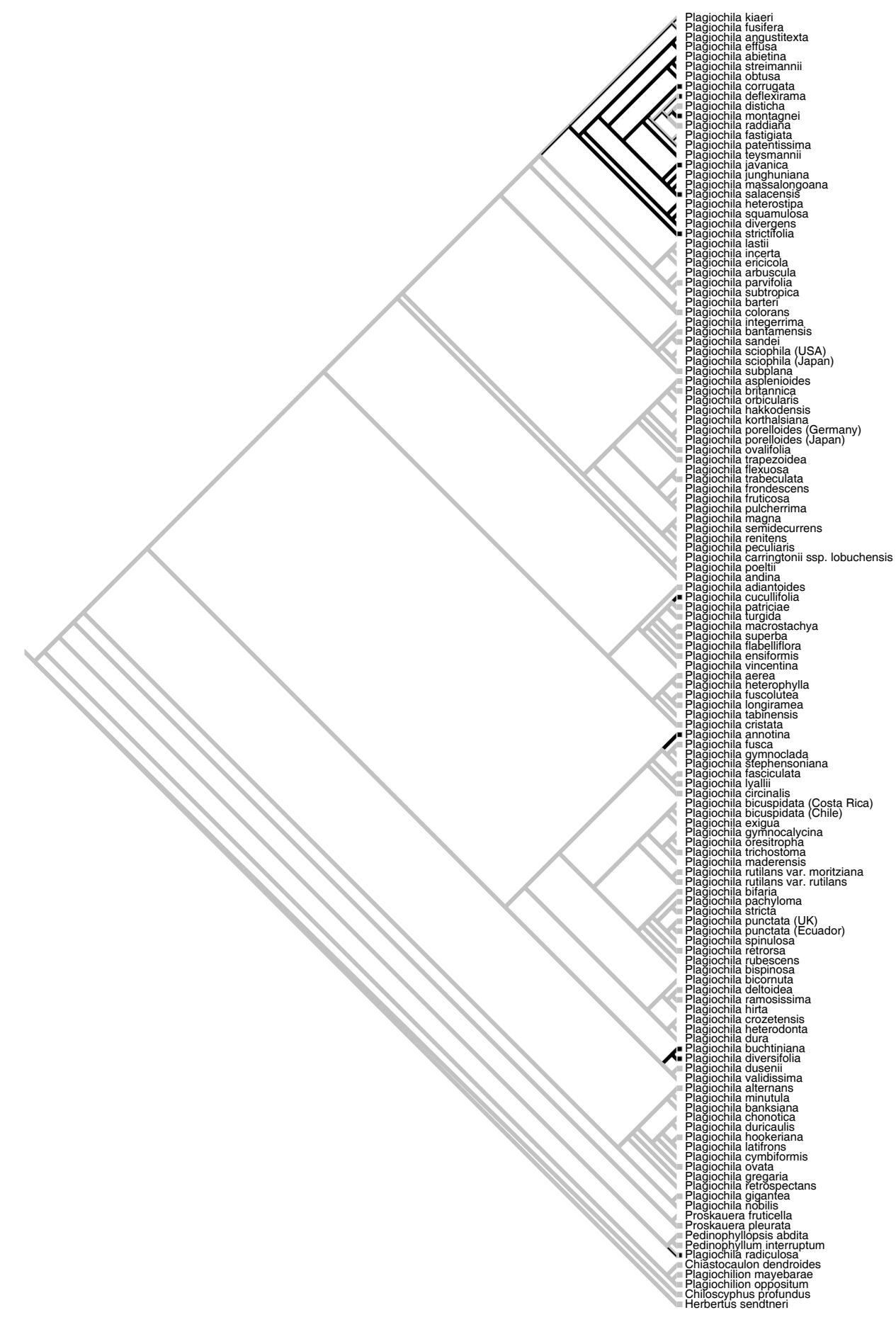

Parsimony reconstruction of the ancestral states of the trait "spores (at time of release)" in the family Plagiochilaceae, with the states: unicellular (grey), multicellular (black). Steps: 8. Uncertain or polymorphic states are multicoloured. 


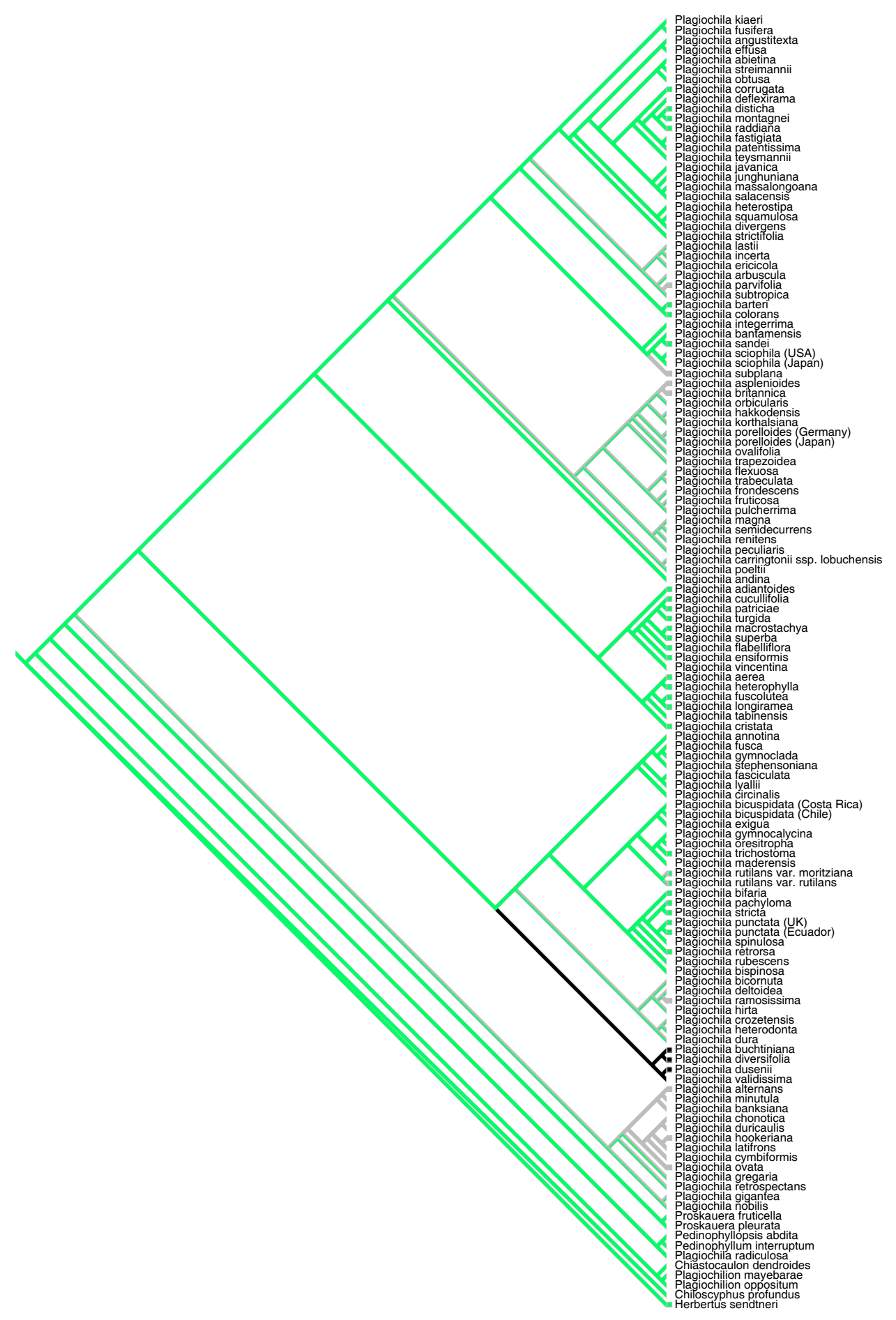

Parsimony reconstruction of the ancestral states of the trait "sporoderm structure" in the family Plagiochilaceae, with the states: verrucate (grey), baculate (green), echinate - baculate (black). Steps: 8. Uncertain or polymorphic states are multicoloured. 


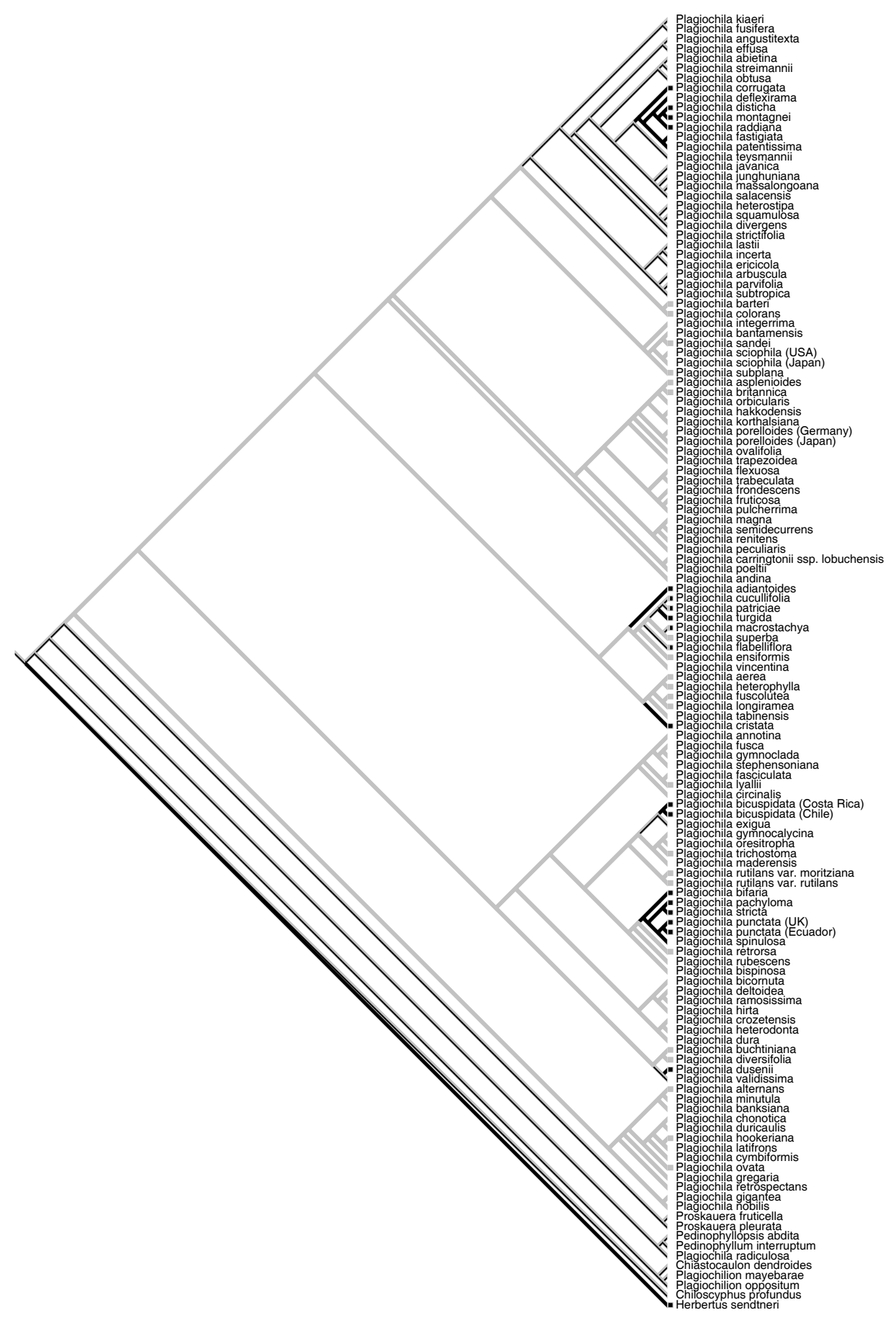

Parsimony reconstruction of the ancestral states of the trait "elater surface" in the family Plagiochilaceae, with the states: smooth (grey), rough (black). Steps: 12. Uncertain or polymorphic states are multicoloured. 


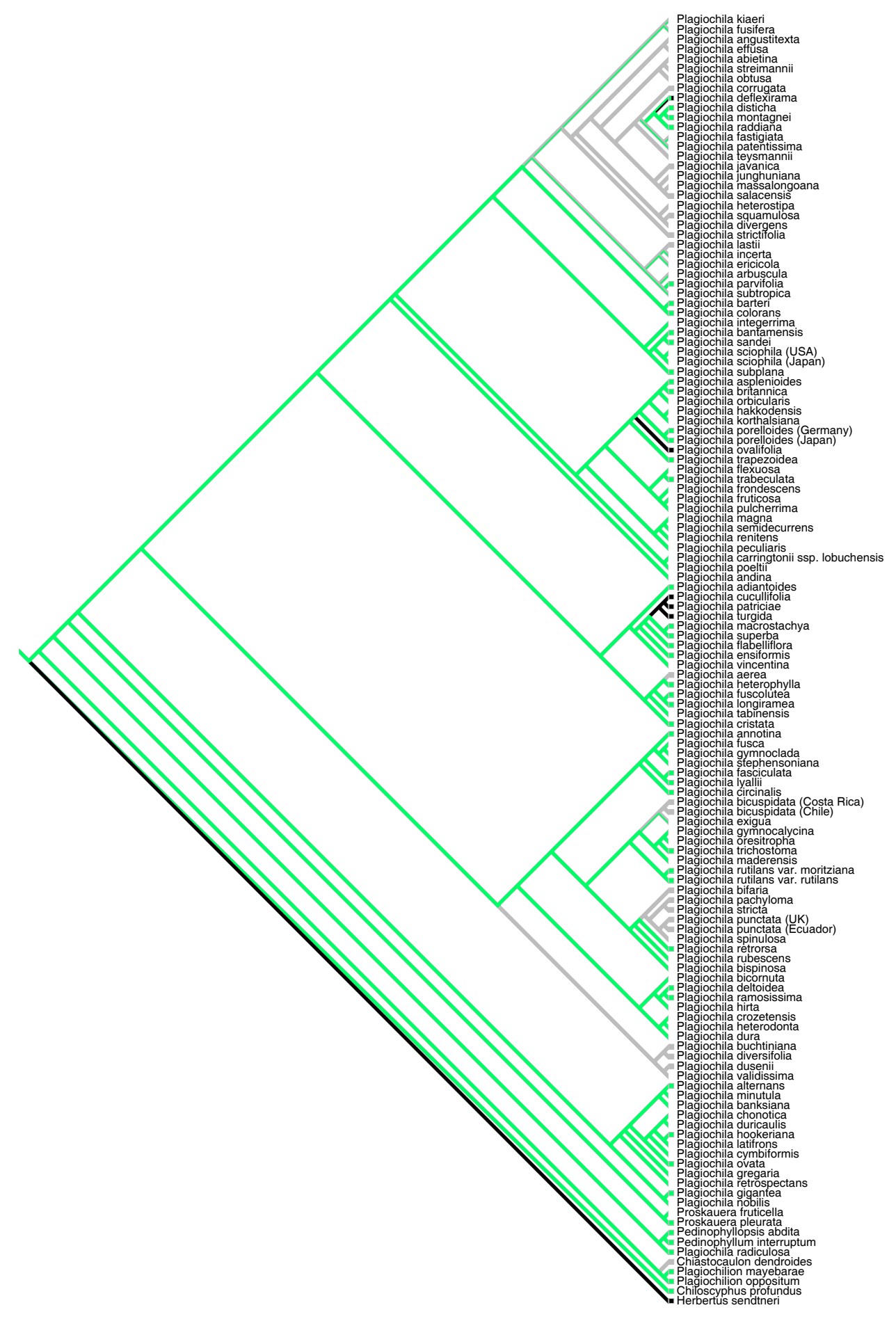

Parsimony reconstruction of the ancestral states of the trait "spirals per elater" in the family Plagiochilaceae, with the states: 1 - 2 (grey), 2 (green), more than 2 (black). Steps: 12. Uncertain or polymorphic states are multicoloured. 


\subsection{Step matrices}

Table 13 MacClade codes and description of distribution areas used in biogeographical analyses (Numbers refer to Fig. 3.5.3).

\begin{tabular}{|c|c|l|}
\hline $\begin{array}{c}\text { MacClade } \\
\text { code }\end{array}$ & No. & \multicolumn{1}{|c|}{ description } \\
\hline $\mathbf{0}$ & 1 & West Holarctic \\
\hline $\mathbf{1}$ & 10 & East Holarctic \\
\hline $\mathbf{2}$ & 2 & Alaska \\
\hline $\mathbf{3}$ & 3 & West U.S.A. \\
\hline $\mathbf{4}$ & 4 & East U.S.A. \\
\hline $\mathbf{5}$ & 5 & Central America \\
\hline $\mathbf{6}$ & 6 & West Indies \\
\hline $\mathbf{7}$ & 7 & North-West South America \\
\hline $\mathbf{8}$ & 8 & East South America \\
\hline $\mathbf{9}$ & 9 & Patagonia \\
\hline A & 16 & Antarctica \\
\hline B & 11 & Europe \\
\hline C & 12 & West Africa \\
\hline D & 13 & East Africa \\
\hline E & 15 & Cape Region \\
\hline F & 14 & Madagascar \\
\hline G & 17 & China \\
\hline H & 18 & Kamtschatka \\
\hline J & 21 & Japan \\
\hline K & 19 & India \\
\hline L & 20 & Indochina \\
\hline M & 22 & Malesia \\
\hline P & 23 & Papuasia \\
\hline Q & 24 & Polynesia \\
\hline R & 25 & Australia \\
\hline S & 26 & New Zealand \\
\hline & & \\
\hline
\end{tabular}




\section{Matrix I}

(cost for crossing of oceans $=2$ )

\begin{tabular}{llllllllllllllllllllllllll}
0 & 1 & 2 & 3 & 4 & 5 & 6 & 7 & 8 & 9 & $A$ & $B$ & $C$ & $D$ & $E$ & $F$ & $G$ & $H$ & J & $K$ & L & M & P & Q & R & S \\
\hline & 1 & 1 & 1 & 1 & 2 & 2 & 3 & 4 & 4 & 5 & 2 & 4 & 3 & 4 & 4 & 2 & 2 & 3 & 3 & 3 & 4 & 5 & 6 & 6 & 7
\end{tabular}

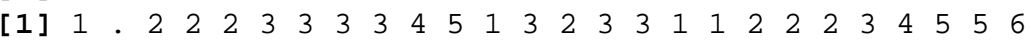

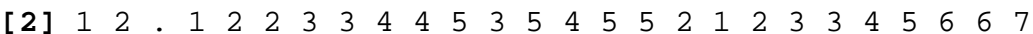

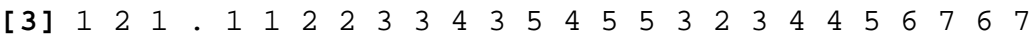

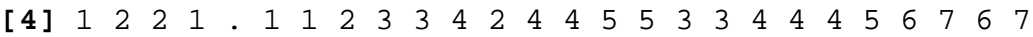

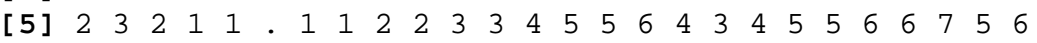

[6] $2 \begin{array}{llllllllllllllllllllllllll} & 3 & 3 & 2 & 1 & 1 & & 1 & 2 & 2 & 3 & 2 & 4 & 4 & 5 & 5 & 4 & 4 & 5 & 5 & 5 & 6 & 6 & 7 & 5 & 6\end{array}$

[7] $3 \begin{array}{llllllllllllllllllllllllll} & 3 & 3 & 2 & 2 & 1 & 1 & . & 1 & 1 & 2 & 2 & 3 & 4 & 4 & 5 & 4 & 4 & 5 & 5 & 5 & 6 & 5 & 6 & 4 & 5\end{array}$

[8] $4 \begin{array}{llllllllllllllllllllllllll}4 & 3 & 4 & 3 & 3 & 2 & 2 & 1 & . & 1 & 2 & 2 & 2 & 3 & 3 & 4 & 4 & 4 & 5 & 5 & 5 & 6 & 5 & 6 & 4 & 5\end{array}$

[9] $4 \begin{array}{llllllllllllllllllllllllll}4 & 4 & 4 & 3 & 3 & 2 & 2 & 1 & 1 & . & 1 & 3 & 3 & 4 & 3 & 4 & 5 & 5 & 6 & 6 & 6 & 5 & 4 & 5 & 3 & 4\end{array}$

[A] $5 \begin{array}{llllllllllllllllllllllllll}5 & 5 & 4 & 4 & 3 & 3 & 2 & 2 & 1 & . & 4 & 3 & 3 & 2 & 3 & 6 & 6 & 6 & 5 & 5 & 4 & 3 & 4 & 2 & 3\end{array}$

[B] $\begin{array}{llllllllllllllllllllllllll}2 & 1 & 3 & 3 & 2 & 3 & 2 & 2 & 2 & 3 & 4 & . & 2 & 3 & 3 & 4 & 2 & 2 & 3 & 3 & 3 & 4 & 5 & 6 & 6 & 7\end{array}$

[C] $4 \begin{array}{llllllllllllllllllllllllll} & 3 & 5 & 5 & 4 & 4 & 4 & 3 & 2 & 3 & 3 & 2 & \text {. } & 1 & 1 & 2 & 4 & 4 & 5 & 3 & 4 & 4 & 5 & 6 & 5 & 6\end{array}$

[D] $3 \begin{array}{llllllllllllllllllllllllll}3 & 2 & 4 & 4 & 4 & 5 & 4 & 4 & 3 & 4 & 3 & 3 & 1 & . & 1 & 1 & 3 & 3 & 4 & 2 & 3 & 3 & 4 & 5 & 5 & 6\end{array}$

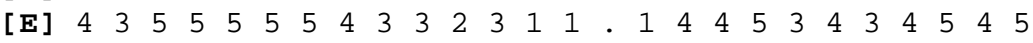

[F] $4 \begin{array}{llllllllllllllllllllllllll}4 & 3 & 5 & 5 & 5 & 6 & 5 & 5 & 4 & 4 & 3 & 4 & 2 & 1 & 1 & . & 3 & 4 & 4 & 2 & 3 & 2 & 3 & 4 & 4 & 5\end{array}$

[G] $2 \begin{array}{lllllllllllllllllllllllll} & 1 & 2 & 3 & 3 & 4 & 4 & 4 & 4 & 5 & 6 & 2 & 4 & 3 & 4 & 3 & & 1 & 1 & 1 & 1 & 2 & 3 & 4 & 4\end{array}$

[H] $2 \begin{array}{llllllllllllllllllllllllll} & 1 & 1 & 2 & 3 & 3 & 4 & 4 & 4 & 5 & 6 & 2 & 4 & 3 & 4 & 4 & 1 & 1 & 1 & 2 & 2 & 3 & 4 & 5 & 5 & 6\end{array}$

[J] $3 \begin{array}{llllllllllllllllllllllllll}3 & 2 & 2 & 3 & 4 & 4 & 5 & 5 & 5 & 6 & 6 & 3 & 5 & 4 & 5 & 4 & 1 & 1 & . & 2 & 1 & 2 & 3 & 4 & 4 & 5\end{array}$

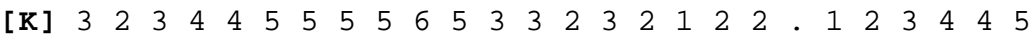

[L] $3 \begin{array}{llllllllllllllllllllllllll} & 2 & 3 & 4 & 4 & 5 & 5 & 5 & 5 & 6 & 5 & 3 & 4 & 3 & 4 & 3 & 1 & 2 & 1 & 1 & . & 1 & 2 & 3 & 3 & 4\end{array}$

[M] $4 \begin{array}{llllllllllllllllllllllllll} & 3 & 4 & 5 & 5 & 6 & 6 & 6 & 6 & 5 & 4 & 4 & 4 & 3 & 3 & 2 & 2 & 3 & 2 & 2 & 1 & & 1 & 2 & 2 & 3\end{array}$

[P] $5 \begin{array}{llllllllllllllllllllllllll}5 & 4 & 5 & 6 & 6 & 6 & 6 & 5 & 5 & 4 & 3 & 5 & 5 & 4 & 4 & 3 & 3 & 4 & 3 & 3 & 2 & 1 & & 1 & 1 & 2\end{array}$

[Q] $6 \begin{array}{llllllllllllllllllllllllll}6 & 5 & 6 & 7 & 7 & 7 & 7 & 6 & 6 & 5 & 4 & 6 & 6 & 5 & 5 & 4 & 4 & 5 & 4 & 4 & 3 & 2 & 1 & 2 & 2\end{array}$

[R] $6 \begin{array}{llllllllllllllllllllllllll}6 & 5 & 6 & 6 & 6 & 5 & 5 & 4 & 4 & 3 & 2 & 6 & 5 & 5 & 4 & 4 & 4 & 5 & 4 & 4 & 3 & 2 & 1 & 2 & & 1\end{array}$

[S] $7 \begin{array}{llllllllllllllllllllllllll} & 6 & 7 & 7 & 7 & 6 & 6 & 5 & 5 & 4 & 3 & 7 & 6 & 6 & 5 & 5 & 5 & 6 & 5 & 5 & 4 & 3 & 2 & 2 & 1 .\end{array}$

\section{Matrix II}

(cost for crossing of oceans $=3$ )

$\begin{array}{llllllllllllllllllllllllll}0 & 1 & 2 & 3 & 4 & 5 & 6 & 7 & 8 & 9 & A & B & C & D & E & F & G & H & J & K & L & M & P & Q & R & S\end{array}$

[0] \begin{tabular}{llllllllllllllllllllllllll}
\hline & 1 & 1 & 1 & 1 & 2 & 2 & 3 & 4 & 4 & 5 & 2 & 4 & 3 & 4 & 4 & 2 & 2 & 3 & 3 & 3 & 4 & 5 & 6 & 6 & 7
\end{tabular}

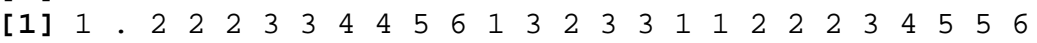

[2] $1 \begin{array}{llllllllllllllllllllllllll}1 & 2 & . & 1 & 2 & 2 & 3 & 3 & 4 & 4 & 5 & 3 & 5 & 4 & 5 & 5 & 2 & 1 & 2 & 3 & 3 & 4 & 5 & 6 & 6 & 7\end{array}$

[3] $1 \begin{array}{llllllllllllllllllllllllll} & 2 & 1 & 1 & 1 & 1 & 2 & 2 & 3 & 3 & 4 & 3 & 5 & 4 & 5 & 5 & 3 & 2 & 3 & 4 & 4 & 5 & 6 & 7 & 7 & 8\end{array}$

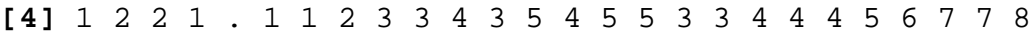

[5] $2 \begin{array}{llllllllllllllllllllllllll} & 3 & 2 & 1 & 1 & & 1 & 1 & 2 & 2 & 3 & 4 & 5 & 5 & 6 & 6 & 4 & 3 & 4 & 5 & 5 & 6 & 7 & 8 & 6 & 7\end{array}$

[6] $2 \begin{array}{llllllllllllllllllllllllll} & 3 & 3 & 2 & 1 & 1 & & 1 & 2 & 2 & 3 & 3 & 5 & 5 & 6 & 6 & 4 & 4 & 5 & 5 & 5 & 6 & 7 & 8 & 6 & 7\end{array}$

[7] $3 \begin{array}{llllllllllllllllllllllllll} & 4 & 3 & 2 & 2 & 1 & 1 & 0 & 1 & 1 & 2 & 3 & 4 & 5 & 5 & 6 & 5 & 4 & 5 & 6 & 6 & 7 & 6 & 7 & 5 & 6\end{array}$

[8] $4 \begin{array}{llllllllllllllllllllllllll}4 & 4 & 4 & 3 & 3 & 2 & 2 & 1 & . & 1 & 2 & 3 & 3 & 4 & 4 & 5 & 5 & 5 & 6 & 6 & 6 & 7 & 6 & 7 & 5 & 6\end{array}$

[9] $4 \begin{array}{llllllllllllllllllllllllll}4 & 4 & 3 & 3 & 2 & 2 & 1 & 1 & & 1 & 4 & 4 & 5 & 4 & 5 & 6 & 5 & 6 & 7 & 7 & 6 & 5 & 6 & 4 & 5\end{array}$

[A] $5 \begin{array}{llllllllllllllllllllllllll}5 & 6 & 5 & 4 & 4 & 3 & 3 & 2 & 2 & 1 & . & 5 & 4 & 4 & 3 & 4 & 7 & 6 & 7 & 7 & 6 & 5 & 4 & 5 & 3 & 4\end{array}$

[B] $\begin{array}{llllllllllllllllllllllllll}2 & 1 & 3 & 3 & 3 & 4 & 3 & 3 & 3 & 4 & 5 & . & 2 & 3 & 3 & 4 & 2 & 2 & 3 & 3 & 3 & 4 & 5 & 6 & 6 & 7\end{array}$

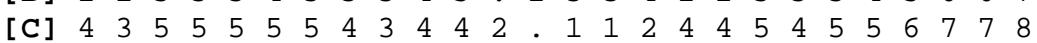

[D] $3 \begin{array}{llllllllllllllllllllllllll}3 & 2 & 4 & 4 & 4 & 5 & 5 & 5 & 4 & 5 & 4 & 3 & 1 & . & 1 & 1 & 3 & 3 & 4 & 3 & 4 & 4 & 5 & 6 & 6 & 7\end{array}$

[E] $4 \begin{array}{llllllllllllllllllllllllll} & 3 & 5 & 5 & 5 & 6 & 6 & 5 & 4 & 4 & 3 & 3 & 1 & 1 & 0 & 1 & 4 & 4 & 5 & 4 & 5 & 4 & 5 & 6 & 6 & 7\end{array}$

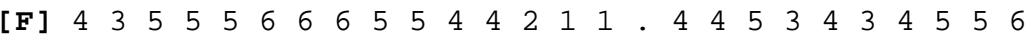

[G] $2 \begin{array}{llllllllllllllllllllllllll} & 1 & 2 & 3 & 3 & 4 & 4 & 5 & 5 & 6 & 7 & 2 & 4 & 3 & 4 & 4 & & 1 & 1 & 1 & 1 & 2 & 3 & 4 & 4 & 5\end{array}$

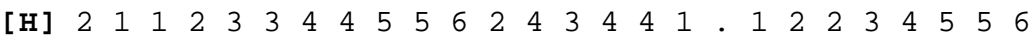

[J] $3 \begin{array}{llllllllllllllllllllllllll} & 2 & 2 & 3 & 4 & 4 & 5 & 5 & 6 & 6 & 7 & 3 & 5 & 4 & 5 & 5 & 1 & 1 & . & 2 & 1 & 2 & 3 & 4 & 4 & 5\end{array}$

[K] $3 \begin{array}{llllllllllllllllllllllllll} & 2 & 3 & 4 & 4 & 5 & 5 & 6 & 6 & 7 & 7 & 3 & 4 & 3 & 4 & 3 & 1 & 2 & 2 & . & 1 & 2 & 3 & 4 & 4 & 5\end{array}$

[L] $3 \begin{array}{llllllllllllllllllllllllll} & 2 & 3 & 4 & 4 & 5 & 5 & 6 & 6 & 7 & 6 & 3 & 5 & 4 & 5 & 4 & 1 & 2 & 1 & 1 & & 1 & 2 & 3 & 3 & 4\end{array}$

[M] $4 \begin{array}{llllllllllllllllllllllllll}4 & 3 & 4 & 5 & 5 & 6 & 6 & 7 & 7 & 6 & 5 & 4 & 5 & 4 & 4 & 3 & 2 & 3 & 2 & 2 & 1 & . & 1 & 2 & 2 & 3\end{array}$

[P] $5 \begin{array}{llllllllllllllllllllllllll}5 & 4 & 5 & 6 & 6 & 7 & 7 & 6 & 6 & 5 & 4 & 5 & 6 & 5 & 5 & 4 & 3 & 4 & 3 & 3 & 2 & 1 & . & 1 & 1 & 2\end{array}$

[Q] $6 \begin{array}{llllllllllllllllllllllllll}6 & 5 & 6 & 7 & 7 & 8 & 8 & 7 & 7 & 6 & 5 & 6 & 7 & 6 & 6 & 5 & 4 & 5 & 4 & 4 & 3 & 2 & 1 & . & 2 & 3\end{array}$

[R] $6 \begin{array}{llllllllllllllllllllllllll}6 & 5 & 6 & 7 & 7 & 6 & 6 & 5 & 5 & 4 & 3 & 6 & 7 & 6 & 6 & 5 & 4 & 5 & 4 & 4 & 3 & 2 & 1 & 2 & 1\end{array}$

[S] $7 \begin{array}{llllllllllllllllllllllllll}7 & 6 & 7 & 8 & 8 & 7 & 7 & 6 & 6 & 5 & 4 & 7 & 8 & 7 & 7 & 6 & 5 & 6 & 5 & 5 & 4 & 3 & 2 & 3 & 1 \text {. }\end{array}$ 


\section{Matrix III}

(cost for crossing of oceans $=4$ )

\begin{tabular}{llllllllllllllllllllllllll}
0 & 1 & 2 & 3 & 4 & 5 & 6 & 7 & 8 & 9 & A & B & C & D & $E$ & F & G & H & J & K & L & M & P & Q & R & S \\
\hline & 1 & 1 & 1 & 1 & 2 & 2 & 3 & 4 & 4 & 5 & 2 & 4 & 3 & 4 & 4 & 2 & 2 & 3 & 3 & 3 & 4 & 5 & 6 & 6 & 7
\end{tabular}

[1] $\left[\begin{array}{llllllllllllllllllllllllllllll} & 1 & 1 & 1 & 1 & 1 & 2 & 2 & 3 & 3 & 4 & 5 & 5 & 6 & 1 & 3 & 2 & 3 & 3 & 1 & 1 & 2 & 2 & 2 & 3 & 4 & 5 & 5 & 6\end{array}\right.$

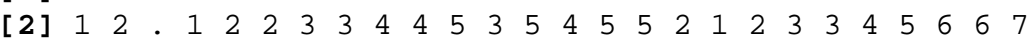

[3] $1 \begin{array}{llllllllllllllllllllllllll} & 2 & 1 & 1 & 1 & 1 & 2 & 2 & 3 & 3 & 4 & 3 & 5 & 4 & 5 & 5 & 3 & 2 & 3 & 4 & 4 & 5 & 6 & 7 & 7 & 8\end{array}$

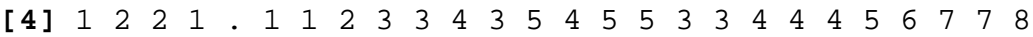

[5] $2 \begin{array}{llllllllllllllllllllllllll} & 3 & 2 & 1 & 1 & & 1 & 1 & 2 & 2 & 3 & 4 & 6 & 5 & 6 & 6 & 4 & 3 & 4 & 5 & 5 & 6 & 7 & 8 & 7 & 8\end{array}$

[6] $2 \begin{array}{llllllllllllllllllllllllll} & 3 & 3 & 2 & 1 & 1 & & 1 & 2 & 2 & 3 & 4 & 6 & 5 & 6 & 6 & 4 & 4 & 5 & 5 & 5 & 6 & 7 & 8 & 7 & 8\end{array}$

[7] $3 \begin{array}{llllllllllllllllllllllllll} & 4 & 3 & 2 & 2 & 1 & 1 & . & 1 & 1 & 2 & 4 & 5 & 6 & 6 & 7 & 5 & 4 & 5 & 6 & 6 & 7 & 7 & 8 & 6 & 7\end{array}$

[8] $4 \begin{array}{lllllllllllllllllllllllll}5 & 4 & 3 & 3 & 2 & 2 & 1 & 1 & 1 & 2 & 4 & 4 & 5 & 5 & 6 & 6 & 5 & 6 & 7 & 7 & 8 & 7 & 8 & 6 & 7\end{array}$

[9] $4 \begin{array}{llllllllllllllllllllllllll}4 & 5 & 4 & 3 & 3 & 2 & 2 & 1 & 1 & . & 1 & 5 & 5 & 6 & 5 & 6 & 6 & 5 & 6 & 7 & 7 & 7 & 6 & 7 & 5 & 6\end{array}$

[A] $5 \begin{array}{llllllllllllllllllllllllll} & 6 & 5 & 4 & 4 & 3 & 3 & 2 & 2 & 1 & . & 6 & 5 & 5 & 4 & 5 & 7 & 6 & 7 & 8 & 7 & 6 & 5 & 6 & 4 & 5\end{array}$

[B] $2 \begin{array}{llllllllllllllllllllllllll}2 & 1 & 3 & 3 & 3 & 4 & 4 & 4 & 4 & 5 & 6 & . & 2 & 3 & 3 & 4 & 2 & 2 & 3 & 3 & 3 & 4 & 5 & 6 & 6 & 7\end{array}$

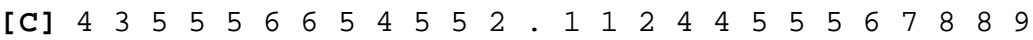

[D] $3 \begin{array}{llllllllllllllllllllllllll}3 & 2 & 4 & 4 & 4 & 5 & 5 & 6 & 5 & 6 & 5 & 3 & 1 & . & 1 & 1 & 3 & 3 & 4 & 4 & 4 & 5 & 6 & 7 & 7 & 8\end{array}$

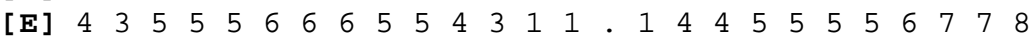

[F] $4 \begin{array}{llllllllllllllllllllllllll}4 & 3 & 5 & 5 & 5 & 6 & 6 & 7 & 6 & 6 & 5 & 4 & 2 & 1 & 1 & . & 4 & 4 & 5 & 4 & 5 & 4 & 5 & 6 & 6 & 7\end{array}$

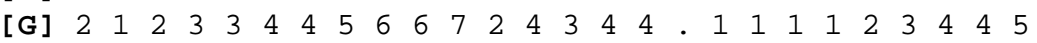

[H] $2 \begin{array}{llllllllllllllllllllllllll} & 1 & 1 & 2 & 3 & 3 & 4 & 4 & 5 & 5 & 6 & 2 & 4 & 3 & 4 & 4 & 1 & 1 & 1 & 2 & 2 & 3 & 4 & 5 & 5 & 6\end{array}$

[J] $3 \begin{array}{llllllllllllllllllllllllll} & 2 & 2 & 3 & 4 & 4 & 5 & 5 & 6 & 6 & 7 & 3 & 5 & 4 & 5 & 5 & 1 & 1 & . & 2 & 1 & 2 & 3 & 4 & 4 & 5\end{array}$

[K] $3 \begin{array}{llllllllllllllllllllllllll} & 2 & 3 & 4 & 4 & 5 & 5 & 6 & 7 & 7 & 8 & 3 & 5 & 4 & 5 & 4 & 1 & 2 & 2 & . & 1 & 2 & 3 & 4 & 4 & 5\end{array}$

[L] $3 \begin{array}{llllllllllllllllllllllllll}3 & 2 & 3 & 4 & 4 & 5 & 5 & 6 & 7 & 7 & 7 & 3 & 5 & 4 & 5 & 5 & 1 & 2 & 1 & 1 & . & 1 & 2 & 3 & 3 & 4\end{array}$

[M] $4 \begin{array}{llllllllllllllllllllllllll}4 & 3 & 4 & 5 & 5 & 6 & 6 & 7 & 8 & 7 & 6 & 4 & 6 & 5 & 5 & 4 & 2 & 3 & 2 & 2 & 1 & & 1 & 2 & 2 & 3\end{array}$

[P] $5 \begin{array}{llllllllllllllllllllllllll}5 & 4 & 5 & 6 & 6 & 7 & 7 & 7 & 7 & 6 & 5 & 5 & 7 & 6 & 6 & 5 & 3 & 4 & 3 & 3 & 2 & 1 & & 1 & 1 & 2\end{array}$

[Q] $6 \begin{array}{llllllllllllllllllllllllll}6 & 5 & 6 & 7 & 7 & 8 & 8 & 8 & 8 & 7 & 6 & 6 & 8 & 7 & 7 & 6 & 4 & 5 & 4 & 4 & 3 & 2 & 1 & 2 & 2\end{array}$

[R] $6 \begin{array}{llllllllllllllllllllllllll}6 & 5 & 6 & 7 & 7 & 7 & 7 & 6 & 6 & 5 & 4 & 6 & 8 & 7 & 7 & 6 & 4 & 5 & 4 & 4 & 3 & 2 & 1 & 2 & & 1\end{array}$

[S] $\begin{array}{lllllllllllllllllllllllllll}7 & 6 & 7 & 8 & 8 & 8 & 8 & 7 & 7 & 6 & 5 & 7 & 9 & 8 & 8 & 7 & 5 & 6 & 5 & 5 & 4 & 3 & 2 & 3 & 1 \text {. }\end{array}$

\section{$\underline{\text { Matrix IV }}$}

(cost for crossing of oceans $=2[\mathrm{~W} \rightarrow \mathrm{E}], 3[\mathrm{E} \rightarrow \mathrm{W}]$, or $2[\mathrm{~N} \leftarrow \rightarrow \mathrm{S}]$ )

\begin{tabular}{llllllllllllllllllllllllll}
0 & 1 & 2 & 3 & 4 & 5 & 6 & 7 & 8 & 9 & A & $B$ & $C$ & $D$ & $E$ & $F$ & $G$ & $H$ & $J$ & $K$ & $L$ & $M$ & $P$ & $Q$ & $R$ & $S$ \\
\hline
\end{tabular}

[0] $\begin{array}{llllllllllllllllllllllllll} & 1 & 1 & 1 & 1 & 2 & 2 & 3 & 4 & 4 & 5 & 2 & 4 & 3 & 4 & 4 & 2 & 2 & 3 & 3 & 3 & 4 & 5 & 6 & 6 & 7\end{array}$

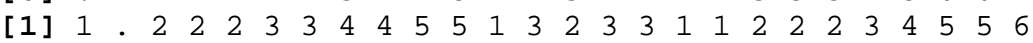

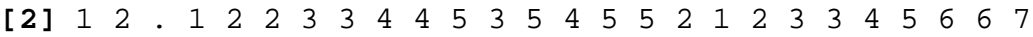

[3] $1 \begin{array}{lllllllllllllllllllllllllll} & 2 & 1 & 1 & 1 & 1 & 2 & 2 & 3 & 3 & 4 & 3 & 5 & 4 & 5 & 5 & 3 & 2 & 3 & 4 & 4 & 5 & 6 & 7 & 6 & 7\end{array}$

[4] $1 \begin{array}{llllllllllllllllllllllllll} & 2 & 2 & 1 & . & 1 & 1 & 2 & 3 & 3 & 4 & 2 & 4 & 4 & 5 & 5 & 3 & 3 & 4 & 4 & 4 & 5 & 6 & 7 & 6 & 7\end{array}$

[5] $2 \begin{array}{llllllllllllllllllllllllll} & 3 & 2 & 1 & 1 & & 1 & 1 & 2 & 2 & 3 & 3 & 4 & 5 & 5 & 6 & 4 & 3 & 4 & 5 & 5 & 6 & 6 & 7 & 5 & 6\end{array}$

[6] $2 \begin{array}{llllllllllllllllllllllllll}2 & 3 & 3 & 2 & 1 & 1 & . & 1 & 2 & 2 & 3 & 2 & 4 & 5 & 5 & 6 & 4 & 4 & 5 & 5 & 5 & 6 & 6 & 7 & 5 & 6\end{array}$

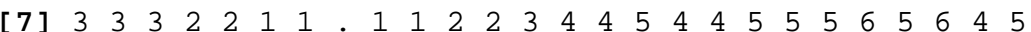

[8] $4 \begin{array}{llllllllllllllllllllllllll}4 & 3 & 4 & 3 & 3 & 2 & 2 & 1 & . & 1 & 2 & 2 & 2 & 3 & 3 & 4 & 4 & 4 & 5 & 5 & 5 & 6 & 5 & 6 & 4 & 5\end{array}$

[9] $4 \begin{array}{llllllllllllllllllllllllll}4 & 4 & 4 & 3 & 3 & 2 & 2 & 1 & 1 & & 1 & 3 & 3 & 4 & 3 & 4 & 5 & 5 & 6 & 6 & 6 & 5 & 4 & 5 & 3 & 4\end{array}$

[A] $5 \begin{array}{llllllllllllllllllllllllll}5 & 5 & 5 & 4 & 4 & 3 & 3 & 2 & 2 & 1 & . & 4 & 3 & 3 & 2 & 3 & 6 & 6 & 6 & 5 & 5 & 4 & 3 & 4 & 2 & 3\end{array}$

[B] $\begin{array}{llllllllllllllllllllllllll}2 & 1 & 3 & 3 & 3 & 4 & 3 & 3 & 3 & 4 & 5 & . & 2 & 3 & 3 & 4 & 2 & 2 & 3 & 3 & 3 & 4 & 5 & 6 & 6 & 7\end{array}$

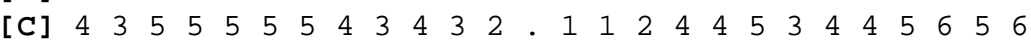

[D] $3 \begin{array}{llllllllllllllllllllllllll}3 & 2 & 4 & 4 & 4 & 5 & 5 & 5 & 4 & 4 & 3 & 3 & 1 & . & 1 & 1 & 3 & 3 & 4 & 2 & 3 & 3 & 4 & 5 & 5 & 6\end{array}$

[E] $4 \begin{array}{llllllllllllllllllllllllll}4 & 5 & 5 & 5 & 5 & 5 & 4 & 4 & 3 & 2 & 3 & 1 & 1 & & 1 & 4 & 4 & 5 & 3 & 4 & 3 & 4 & 5 & 4 & 5\end{array}$

[F] $4 \begin{array}{lllllllllllllllllllllllll}4 & 3 & 5 & 5 & 5 & 6 & 6 & 5 & 5 & 4 & 3 & 4 & 2 & 1 & 1 & . & 3 & 4 & 4 & 2 & 3 & 2 & 3 & 4 & 4\end{array}$

[G] $2 \begin{array}{llllllllllllllllllllllllll}2 & 1 & 2 & 3 & 3 & 4 & 4 & 5 & 5 & 6 & 6 & 2 & 4 & 3 & 4 & 4 & & 1 & 1 & 1 & 1 & 2 & 3 & 4 & 4 & 5\end{array}$

[H] $2 \begin{array}{llllllllllllllllllllllllll} & 1 & 1 & 2 & 3 & 3 & 4 & 4 & 5 & 5 & 6 & 2 & 4 & 3 & 4 & 4 & 1 & 1 & 1 & 2 & 2 & 3 & 4 & 5 & 5 & 6\end{array}$

[J] $3 \begin{array}{llllllllllllllllllllllllll}3 & 2 & 2 & 3 & 4 & 4 & 5 & 5 & 6 & 6 & 7 & 3 & 5 & 4 & 5 & 5 & 1 & 1 & 0 & 2 & 1 & 2 & 3 & 4 & 4 & 5\end{array}$

[K] $3 \begin{array}{llllllllllllllllllllllllll} & 2 & 3 & 4 & 4 & 5 & 5 & 6 & 6 & 7 & 6 & 3 & 4 & 3 & 4 & 3 & 1 & 2 & 2 & \text {. } & 1 & 2 & 3 & 4 & 4 & 5\end{array}$

[L] $3 \begin{array}{llllllllllllllllllllllllll}3 & 2 & 3 & 4 & 4 & 5 & 5 & 6 & 6 & 7 & 6 & 3 & 5 & 4 & 5 & 4 & 1 & 2 & 1 & 1 & & 1 & 2 & 3 & 3 & 4\end{array}$

[M] $4 \begin{array}{llllllllllllllllllllllllll}4 & 4 & 5 & 5 & 6 & 6 & 7 & 7 & 6 & 5 & 4 & 5 & 4 & 4 & 3 & 2 & 3 & 2 & 2 & 1 & 1 & 1 & 2 & 2 & 3\end{array}$

[P] $5 \begin{array}{llllllllllllllllllllllllll}5 & 4 & 5 & 6 & 6 & 7 & 7 & 6 & 6 & 5 & 4 & 5 & 6 & 5 & 5 & 4 & 3 & 4 & 3 & 3 & 2 & 1 & . & 1 & 1 & 2\end{array}$

[Q] $6 \begin{array}{llllllllllllllllllllllllll}6 & 5 & 6 & 7 & 7 & 8 & 8 & 7 & 7 & 6 & 5 & 6 & 7 & 6 & 6 & 5 & 4 & 5 & 4 & 4 & 3 & 2 & 1 & 2 & 2\end{array}$

[R] $6 \begin{array}{llllllllllllllllllllllllll}6 & 5 & 6 & 7 & 7 & 6 & 6 & 5 & 5 & 4 & 3 & 6 & 6 & 6 & 5 & 5 & 4 & 5 & 4 & 4 & 3 & 2 & 1 & 2 & \text {. } 1\end{array}$

[S] $\begin{array}{lllllllllllllllllllllllllll}7 & 6 & 7 & 8 & 8 & 7 & 7 & 6 & 6 & 5 & 4 & 7 & 7 & 7 & 6 & 6 & 5 & 6 & 5 & 5 & 4 & 3 & 2 & 2 & 1\end{array}$. 


\section{$\underline{\text { Matrix V }}$}

(cost for crossing of oceans $=3[\mathrm{~W} \rightarrow \mathrm{E}], 2[\mathrm{E} \rightarrow \mathrm{W}]$, or $2[\mathrm{~N} \leftarrow \rightarrow \mathrm{S}]$ )

\begin{tabular}{llllllllllllllllllllllllll}
0 & 1 & 2 & 3 & 4 & 5 & 6 & 7 & 8 & 9 & A & B & C & D & $E$ & F & G & H & J & K & L & M & P & Q & R & S \\
\hline & 1 & 1 & 1 & 1 & 2 & 2 & 3 & 4 & 4 & 5 & 2 & 4 & 3 & 4 & 4 & 2 & 2 & 3 & 3 & 3 & 4 & 5 & 6 & 6 & 7
\end{tabular}

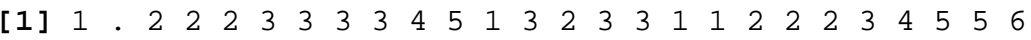

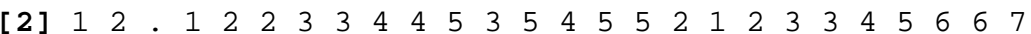

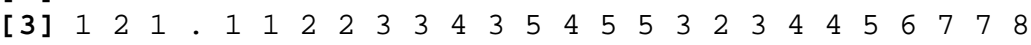

[4] $1 \begin{array}{llllllllllllllllllllllllll}1 & 2 & 2 & 1 & & 1 & 1 & 2 & 3 & 3 & 4 & 3 & 5 & 4 & 5 & 5 & 3 & 3 & 4 & 4 & 4 & 5 & 6 & 7 & 7 & 8\end{array}$

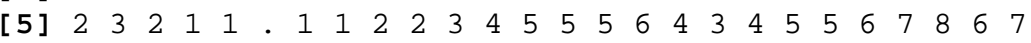

[6] $2 \begin{array}{llllllllllllllllllllllllll} & 3 & 3 & 2 & 1 & 1 & & 1 & 2 & 2 & 3 & 3 & 5 & 5 & 5 & 6 & 4 & 4 & 5 & 5 & 5 & 6 & 7 & 8 & 6 & 7\end{array}$

[7] $3 \begin{array}{llllllllllllllllllllllllll} & 4 & 3 & 2 & 2 & 1 & 1 & . & 1 & 1 & 2 & 3 & 4 & 5 & 4 & 5 & 5 & 4 & 5 & 6 & 6 & 7 & 6 & 7 & 5 & 6\end{array}$

[8] $4 \begin{array}{llllllllllllllllllllllllll}4 & 4 & 4 & 3 & 3 & 2 & 2 & 1 & 1 & 1 & 2 & 3 & 3 & 4 & 4 & 5 & 5 & 5 & 6 & 6 & 6 & 7 & 6 & 7 & 5 & 6\end{array}$

[9] $4 \begin{array}{llllllllllllllllllllllllll}5 & 4 & 3 & 3 & 2 & 2 & 1 & 1 & . & 1 & 4 & 4 & 4 & 3 & 4 & 6 & 5 & 6 & 7 & 7 & 6 & 5 & 6 & 4 & 5\end{array}$

[A] $5 \begin{array}{llllllllllllllllllllllllll}5 & 5 & 4 & 4 & 3 & 3 & 2 & 2 & 1 & . & 5 & 3 & 3 & 2 & 3 & 6 & 6 & 7 & 6 & 6 & 5 & 4 & 5 & 3 & 4\end{array}$

[B] $\begin{array}{llllllllllllllllllllllllll}2 & 1 & 3 & 3 & 2 & 3 & 2 & 2 & 2 & 3 & 4 & . & 2 & 3 & 3 & 4 & 2 & 2 & 3 & 3 & 3 & 4 & 5 & 6 & 6 & 7\end{array}$

[C] $4 \begin{array}{lllllllllllllllllllllllll}4 & 5 & 5 & 4 & 4 & 4 & 3 & 2 & 3 & 3 & 2 & \text {. } & 1 & 1 & 2 & 4 & 4 & 5 & 4 & 5 & 5 & 6 & 7 & 6 & 7\end{array}$

[D] $3 \begin{array}{llllllllllllllllllllllllll}3 & 2 & 4 & 4 & 4 & 5 & 5 & 4 & 3 & 4 & 3 & 3 & 1 & . & 1 & 1 & 3 & 3 & 4 & 3 & 4 & 4 & 5 & 6 & 6 & 7\end{array}$

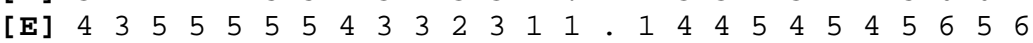

[F] $4 \begin{array}{llllllllllllllllllllllllll}4 & 3 & 5 & 5 & 5 & 6 & 6 & 5 & 4 & 4 & 3 & 4 & 2 & 1 & 1 & . & 4 & 4 & 5 & 3 & 4 & 3 & 4 & 5 & 5 & 6\end{array}$

[G] $2 \begin{array}{lllllllllllllllllllllllllll}2 & 1 & 2 & 3 & 3 & 4 & 4 & 4 & 4 & 5 & 6 & 2 & 4 & 3 & 4 & 3 & \text {. } & 1 & 1 & 1 & 1 & 2 & 3 & 4 & 4 & 5\end{array}$

[H] $2 \begin{array}{llllllllllllllllllllllllll} & 1 & 1 & 2 & 3 & 3 & 4 & 4 & 4 & 5 & 6 & 2 & 4 & 3 & 4 & 4 & 1 & 1 & 1 & 2 & 2 & 3 & 4 & 5 & 5 & 6\end{array}$

[J] $3 \begin{array}{llllllllllllllllllllllllll}3 & 2 & 2 & 3 & 4 & 4 & 5 & 5 & 5 & 6 & 6 & 3 & 5 & 4 & 5 & 4 & 1 & 1 & 0 & 2 & 1 & 2 & 3 & 4 & 4 & 5\end{array}$

[K] $3 \begin{array}{llllllllllllllllllllllllll} & 2 & 3 & 4 & 4 & 5 & 5 & 5 & 5 & 6 & 5 & 3 & 3 & 2 & 3 & 2 & 1 & 2 & 2 & \text {. } & 1 & 2 & 3 & 4 & 4 & 5\end{array}$

[L] $3 \begin{array}{llllllllllllllllllllllllll} & 2 & 3 & 4 & 4 & 5 & 5 & 5 & 5 & 6 & 5 & 3 & 4 & 3 & 4 & 3 & 1 & 2 & 1 & 1 & . & 1 & 2 & 3 & 3 & 4\end{array}$

[M] $4 \begin{array}{lllllllllllllllllllllllll}4 & 4 & 5 & 5 & 6 & 6 & 6 & 6 & 5 & 4 & 4 & 4 & 3 & 3 & 2 & 2 & 3 & 2 & 2 & 1 & & 1 & 2 & 2 & 3\end{array}$

[P] $5 \begin{array}{llllllllllllllllllllllllll}5 & 4 & 5 & 6 & 6 & 6 & 6 & 5 & 5 & 4 & 3 & 5 & 5 & 4 & 4 & 3 & 3 & 4 & 3 & 3 & 2 & 1 & & 1 & 1 & 2\end{array}$

[Q] $6 \begin{array}{lllllllllllllllllllllllll}6 & 5 & 6 & 7 & 7 & 7 & 7 & 6 & 6 & 5 & 4 & 6 & 6 & 5 & 5 & 4 & 4 & 5 & 4 & 4 & 3 & 2 & 1 & 2 & 2\end{array}$

[R] $6 \begin{array}{llllllllllllllllllllllllll}6 & 5 & 6 & 6 & 6 & 5 & 5 & 4 & 4 & 3 & 2 & 6 & 5 & 5 & 4 & 4 & 4 & 5 & 4 & 4 & 3 & 2 & 1 & 2 & 1\end{array}$

[S] $7 \begin{array}{lllllllllllllllllllllllll} & 6 & 7 & 7 & 7 & 6 & 6 & 5 & 5 & 4 & 3 & 7 & 6 & 6 & 5 & 5 & 5 & 6 & 5 & 5 & 4 & 3 & 2 & 2 & 1\end{array}$. 


\subsection{Vouchers}

Table 14 Analysed species of Plagiochilaceae. Vouchers, distributions, and preliminary accession numbers. Two accession numbers for one gene refer to either the 5' or 3' part of the gene. Vouchers are housed at GOET if not indicated otherwise.

\begin{tabular}{|c|c|c|c|c|c|c|}
\hline \multirow{2}{*}{ Species } & \multirow{2}{*}{ Country } & \multirow{2}{*}{ Distribution } & \multirow{2}{*}{ Voucher } & \multicolumn{3}{|c|}{ Accession numbers: } \\
\hline & & & & $r b c \mathrm{~L}$ & rps4 & ITS \\
\hline Chiastocaulon dendroides (Nees) Carl & Japan & $\begin{array}{l}\text { Southeast Asia (China, Japan, Indonesia, Philippines, } \\
\text { Papua New Guinea, New Hebrides, Malaysia) }\end{array}$ & Kurita 84, 2000, (HIRO) & AY699991 & AY438212 & AY438232 \\
\hline \begin{tabular}{|l} 
Chiloscyphus profundus (Nees) J.J.Engel \& \\
R.M.Schust (former Lophocolea heterophylla)
\end{tabular} & Germany & Holarctis & Heinrichs \& Groth, 2003 & DQ194107 & DQ193972 & AJ422240 \\
\hline $\begin{array}{l}\begin{array}{l}\text { Herbertus sendtneri (Nees) A.Evans (former } H . \\
\text { subdentatus) }\end{array} \\
\end{array}$ & Bolivia & South America, Europe & Groth s.n. & AY699993 & AY438203 & AJ413177 \\
\hline Pedinophyllopsis abdita (Sull.) R.M.Schust. \& Inoue & Chile & \multirow{2}{*}{$\begin{array}{l}\text { South America (Argentina, Chile), Subantarctic Islands } \\
\text { (Kerguelen) }\end{array}$} & Hyvoenen 5839, 1992 & & & DQ194038 \\
\hline Pedinophyllopsis abdita (Sull.) R.M.Schust. \& Inoue & Argentina & & Hyvoenen 2556, 1986 & $2<$ & DQ193985 & $\sum \leq$ \\
\hline Pedinophyllum interruptum (Nees) Kaal. & Germany & \multirow{2}{*}{$\begin{array}{l}\text { Europe, North America (Appalachian Mountains, } \\
\text { Canada) }\end{array}$} & Drehwald s.n. & $\begin{array}{l}\text { DQ194085 } \\
\text { DQ194071 } \\
\end{array}$ & & \\
\hline Pedinophyllum interruptum (Nees) Kaal. & Great Britain & & Rycroft 01003 & $3<$ & AY438216 & AY438234 \\
\hline Plagiochila (cf.) bispinosa Lindenb. & Chile & South America (Patagonia) & Rycroft, 020720-2 & DQ194118 & DQ193976 & DQ194031 \\
\hline Plagiochila (cf.) fusca Sande Lac. & Indonesia & Southeast Asia (Java, Indonesia, Philippines) & Gradstein 10259,2003 & DQ194143 & DQ193992 & DQ194041 \\
\hline Plagiochila (cf.) gymnoclada Sande Lac. & Indonesia & $\begin{array}{l}\text { Southeast Asia (Indonesia, Philippines, Solomon Islands, } \\
\text { China, Malaysia, New Caledonia, Sri Lanka) }\end{array}$ & Gradstein 10317, 2004 & DQ194148 & DQ193995 & DQ194044 \\
\hline Plagiochila (cf.) hirta Taylor & Argentina & $\begin{array}{l}\text { South America (Argentina and Chile south of } 44^{\circ} 19^{\prime} \mathrm{S}, \\
\text { Falkland Islands) }\end{array}$ & Long 31680, 2003 & DQ194152 & DQ193996 & DQ194046 \\
\hline Plagiochila (cf.) hookeriana Lindenb. & Argentina & South America (Chile and Argentina south of $40^{\circ} \mathrm{S}$ ) & Holz 108 & DQ194153 & DQ193997 & DQ194047 \\
\hline Plagiochila (cf.) latifrons Gottsche \& Hampe & Chile & $\begin{array}{l}\text { South America (Chile [Tierra del Fuego, Southern } \\
\text { Patagonian Channels]) }\end{array}$ & Rycroft 020720-24 & DQ194157 & DQ194002 & DQ194050 \\
\hline $\begin{array}{l}\text { Plagiochila (cf.) minutula (Hook. \& Taylor) Gottsche, } \\
\text { Lindenb. \& Nees }\end{array}$ & $\begin{array}{l}\text { Prince Edward Isl. } \\
\text { (South Africa) }\end{array}$ & $\begin{array}{l}\text { Subantarctic Islands (Prince Edward Islands, Amsterdam } \\
\text { Islands, Kerguelen, Crozet Islands) }\end{array}$ & Ochyra 434/01, 2001 & & DQ194007 & DQ194054 \\
\hline Plagiochila abietina (Nees) Nees \& Mont. & $\begin{array}{l}\text { Papua New } \\
\text { Guinea }\end{array}$ & $\begin{array}{l}\text { Southeast Asia (Papua New Guinea, New Caledonia, } \\
\text { Java, Australia [Cape York Peninsula]) }\end{array}$ & Norris 63841, 1981 & $\begin{array}{l}\text { DQ194082 } \\
\text { DQ194068 }\end{array}$ & DQ193973 & \\
\hline Plagiochila adiantoides (Sw.) Lindenb. & Costa Rica & $\begin{array}{l}\text { Central and South America (from Mexico and the West } \\
\text { Indies to north Argentina) }\end{array}$ & Heinrichs et al. 4314, 1999 & DQ194108 & AY438204 & AJ422027 \\
\hline Plagiochila aerea Taylor & Ecuador & Central and South America (from Mexico to Bolivia) & Heinrichs et al. 4321, 1999 & DQ194109 & AY438205 & AJ422028 \\
\hline Plagiochila alternans Lindenb. \& Gottsche & Bolivia & $\begin{array}{l}\text { Central and South America (from Mexico and the West } \\
\text { Indies to Bolivia) }\end{array}$ & Heinrichs et al. 4178 & AY699995 & AY547691 & AY550130 \\
\hline Plagiochila andina Steph. & Bolivia & South America (Bolivia) & Heinrichs \& Müller 4046, 1997 & DQ194111 & DQ193974 & DQ194028 \\
\hline Plagiochila angustitexta Steph. & Malawi & Africa (Tanzania, Malawi) & Hodgetts M3024 & DQ194096 & $\sum$ & AJ866738 \\
\hline Plagiochila annotina Lindenb. & New Zealand & Australia and South Pacific (New Zealand, Tasmania) & Engel 21735, 1995 & $\begin{array}{l}\text { DQ194083 } \\
\text { DQ194069 }\end{array}$ & & 29 \\
\hline
\end{tabular}




\begin{tabular}{|c|c|c|c|c|c|c|}
\hline \multirow{2}{*}{ Species } & \multirow{2}{*}{ Country } & \multirow{2}{*}{ Distribution } & \multirow{2}{*}{ Voucher } & \multicolumn{3}{|c|}{ Accession numbers: } \\
\hline & & & & $r b c \mathrm{~L}$ & rps4 & ITS \\
\hline Plagiochila arbuscula (Brid.) Lindenb. & Japan & $\begin{array}{l}\text { Southeast Asia (Japan, Malaysia, Indonesia, Thailand, } \\
\text { Taiwan, Samoa Islands, China, Fiji Islands, New } \\
\text { Caledonia, Papua New Guinea, Philippines, Solomon } \\
\text { Islands), Australia and South Pacific (Australia } \\
\text { [Queensland], Tahiti, Micronesia [Ponape Islands]) }\end{array}$ & Yamaguchi 18287, 1999, (HIRO) & DQ194112 & AY547692 & AY550131 \\
\hline Plagiochila asplenioides (L.) Dumort. & Germany & East Asia, Holarctis & Heinrichs \& Groth, 2001 & AY699996 & AY547693 & AJ414629 \\
\hline Plagiochila banksiana Gottsche & New Zealand & Australia and South Pacific (New Zealand) & Frey \& Pfeiffer 98-T121, 1998 & DQ194114 & AY547694 & AY550132 \\
\hline \multirow[b]{2}{*}{$\begin{array}{l}\text { Plagiochila bantamensis (Reinw., Blume \& Nees) } \\
\text { Mont. }\end{array}$} & \multirow[b]{2}{*}{ Japan } & \multirow{2}{*}{$\begin{array}{l}\text { Southeast Asia (Japan, Indonesia, Malaysia, Cambodia, } \\
\text { Philippines, India [Nicobar Islands], China, Fiji Islands, } \\
\text { Papua New Guinea, Samoa Islands, Singapore, Sri Lanka, } \\
\text { Vietnam) }\end{array}$} & \multirow[b]{2}{*}{ Yamaguchi 16890, 1998, (HIRO) } & DQ194084 & \multirow[b]{2}{*}{ AY547695 } & \multirow[b]{2}{*}{ AY275160 } \\
\hline & & & & DQ194070 & & \\
\hline Plagiochila barteri Mitt. & Malawi & $\begin{array}{l}\text { Africa (Sierra Leone, Cameroons, Sao Thomé \& Principe, } \\
\text { Kenya, Congo, Tanzania, Madagascar, Malawi) }\end{array}$ & O'Shea M7062a & & AJ866764 & AJ866749 \\
\hline Plagiochila bicornuta Steph. & Malaysia & Southeast Asia (Malaysia) & Schäfer-Verwimp 18716, 1997 & DQ194115 & DQ193975 & DQ194030 \\
\hline Plagiochila bicuspidata Gottsche & Costa Rica & \multirow{2}{*}{$\begin{array}{l}\text { Central and South America (Chile, Costa Rica, Mexico, } \\
\text { Venezuela) }\end{array}$} & Holz CR-787 (A), 1999 & DQ194116 & AY547696 & AY550133 \\
\hline Plagiochila bicuspidata Gottsche (former P. rufescens) & Chile & & Drehwald 3201, 1997 & DQ194188 & DQ194019 & AY390532 \\
\hline Plagiochila bifaria (Sw.) Lindenb. & Spain & $\begin{array}{l}\text { Central and South America (from Mexico to Bolivia \& } \\
\text { SE Brazil), Atlantic Europe, Macaronesia }\end{array}$ & Drehwald 3922 & DQ194117 & AY438206 & AJ413173 \\
\hline Plagiochila britannica Paton & Great Britain & Atlantic Europe (Great Britain, British Islands) & Rycroft 00015,2000 & DQ194119 & AY438207 & AY275162 \\
\hline Plagiochila buchtiniana Steph. & Bolivia & South America (Bolivia, Peru) & Groth s.n., 2000 & DQ194120 & AY438208 & AJ413306 \\
\hline Plagiochila carringtonii ssp lobuchensis Grolle & Buthan & $\begin{array}{l}\text { East Asia (Bhutan, China [Yunnan], India [Sikkim], } \\
\text { Nepal) }\end{array}$ & Long 288857 & DQ194121 & AY438209 & AJ414631 \\
\hline \multirow{2}{*}{ Plagiochila chonotica Taylor } & \multirow{2}{*}{ Chile } & \multirow{2}{*}{ South America (Chile [Chonos Archipelago]) } & Drehwald \& Mues 3319, 1997 & DQ194122 & $2<$ & $2<$ \\
\hline & & & Holz \& Franzaring CH-00-108 & 3 & AY547697 & AY550134 \\
\hline Plagiochila circinalis (Lehm. \& Lindenb.) Lindenb. & New Zealand & Southeast Asia (New Zealand) & Pfeiffer 98-T166, 1998 & $2 \leq$ & DQ193977 & DQ194032 \\
\hline Plagiochila colorans Steph. & Ruanda & Africa (Uganda, Kenya, Congo, Tanzania, Rwanda) & Buchbender \& Fischer 1115 & DQ194123 & AJ866765 & AJ866751 \\
\hline Plagiochila corrugata (Nees) Nees \& Mont. & Brazil & South America (Brazil, Bolivia, Paraguay) & da Costa \& Gradstein 3731,2000 & DQ194124 & DQ193978 & AJ744789 \\
\hline Plagiochila cristata (Sw.) Lindenb. & Ecuador & $\begin{array}{l}\text { Central and South America (from Costa Rica and the } \\
\text { West Indies to Bolivia, SE-Brazil) }\end{array}$ & Holz 424 E/5-01, 2001 & DQ194125 & AY438210 & AJ422015 \\
\hline Plagiochila crozetensis Kaal. & $\begin{array}{l}\text { Marion Island } \\
\text { (South Africa) }\end{array}$ & $\begin{array}{l}\text { Subantarctic Islands (Prince Edward Islands, Crozet } \\
\text { Islands) }\end{array}$ & Gremmen 94-007, 1994 & & DQ193979 & DQ194033 \\
\hline Plagiochila cucullifolia J.B.Jack \& Steph. & Ecuador & $\begin{array}{l}\text { Central and South America (Ecuador, Costa Rica, } \\
\text { Panama, Colombia) }\end{array}$ & Holz 558 E/5-01, 2001 & DQ194126 & AY438211 & AJ422012 \\
\hline Plagiochila cymbiformis Inoue & Chile & South America (Chile [Magellanes]) & Goffinet, s.n. & DQ194127 & DQ193980 & DQ194034 \\
\hline Plagiochila deflexirama Taylor & Costa Rica & Central and South America (Costa Rica, Bolivia, Peru) & Heinrichs 11, 1999 & DQ194128 & AY547698 & AY550135 \\
\hline Plagiochila deltoidea Lindenb. & New Zealand & Southeast Asia (New Zealand, Tasmania) & Frey 98-T116, 1998 & DQ194129 & AY547699 & AY550136 \\
\hline Plagiochila disticha (Lehm. \& Lindenb.) Lindenb. & Ecuador & South America, Lowland and lower montane rainforest & Holz 436 E/5-01, 2001 & DQ194130 & AY438214 & AJ422014 \\
\hline Plagiochila divergens Steph. & Kenya & Africa (Ruanda, Congo, Uganda, Tanzania, Kenya) & Solga s.n. & DQ194102 & DQ193981 & DQ194027 \\
\hline Plagiochila diversifolia Lindenb. \& Gottsche & Ecuador & $\begin{array}{l}\text { South America (Ecuador, Brazil [Minas Gerais, Rio de } \\
\text { Janeiro], Bolivia, Argentina [Jujuy]) }\end{array}$ & Holz 017 E/5-01, 2001 & DQ194131 & AY438215 & AJ413308 \\
\hline Plagiochila dura De Not. & Chile & $\begin{array}{l}\text { South America (Chile [Tierra del Fuego, Patagonian } \\
\text { Channels and Valdivian region south of } 39^{\circ} 38^{\prime} \mathrm{S} \text { ]) }\end{array}$ & Drehwald 3190, 1997 & DQ194133 & AY547700 & AY550137 \\
\hline
\end{tabular}




\begin{tabular}{|c|c|c|c|c|c|c|}
\hline \multirow{2}{*}{ Species } & \multirow{2}{*}{ Country } & \multirow{2}{*}{ Distribution } & \multirow{2}{*}{ Voucher } & \multicolumn{3}{|c|}{ Accession numbers: } \\
\hline & & & & $r b c \mathrm{~L}$ & rps4 & ITS \\
\hline $\begin{array}{l}\text { Plagiochila duricaulis (Hook. \& Taylor) Gottsche, } \\
\text { Lindenb. \& Nees }\end{array}$ & Chile & $\begin{array}{l}\text { South America (Chile [Tierra del Fuego and Patagonian } \\
\left.\text { Channels south of } 46^{\circ} 50^{\prime} \mathrm{S}\right] \text { ) }\end{array}$ & Rycroft, 020721-9 & DQ194134 & DQ193983 & DQ194036 \\
\hline Plagiochila dusenii Steph. & Argentina & $\begin{array}{l}\text { South America (Argentina [Rio Negro], Strait of } \\
\text { Magellan, Patagonia) }\end{array}$ & Holz 146 & DQ194135 & DQ193984 & DQ194037 \\
\hline Plagiochila effusa Steph. & Malawi & Africa (Sierra Leone, Uganda, Tanzania, Angola, Malawi) & Longton M8417a & DQ194103 & 3 & AJ866743 \\
\hline Plagiochila ensiformis Taylor & Ecuador & South America (Ecuador, Colombia) & $\begin{array}{l}\text { Sauer \& Gradstein MS-E 115, BEGP 149, } \\
2001\end{array}$ & & AY547701 & AY275163 \\
\hline \multirow{2}{*}{ Plagiochila ericicola Steph } & \multirow{2}{*}{ Tansania } & \multirow{2}{*}{ Africa (Congo, Uganda, Tanzania) } & \multirow{2}{*}{ Pócs et al. 87172/S } & DQ194081 & \multirow{2}{*}{ DQ193986 } & \multirow{2}{*}{ AJ866748 } \\
\hline & & & & DQ194067 & & \\
\hline Plagiochila exigua (Taylor) Taylor & Tenerife & $\begin{array}{l}\text { North America (USA [Virginia, North Carolina]), } \\
\text { Europe (Tenerife, Ireland), South America (Brazil, } \\
\text { Chile), Africa (Réunion, Sri Lanka, Kenya, South Africa, } \\
\text { Lesotho), Southeast Asia (Bhutan, China, Japan, Nepal, } \\
\text { New Caledonia, Papua New Guinea) }\end{array}$ & Drehwald 5 & DQ194137 & AY547702 & AF539461 \\
\hline Plagiochila fasciculate Lindenb. & Australia & $\begin{array}{l}\text { Australia and South Pacific (Australia, New Zealand, } \\
\text { Tasmania) }\end{array}$ & Renker A18.2 & DQ194138 & DQ193988 & DQ194040 \\
\hline Plagiochila fastigiata Lindenb. \& Gottsche & Mexico & Central America (Mexico, Honduras, Panama) & Gradstein 8274, BEGP 195, 1992 & DQ194139 & DQ193989 & AJ744790 \\
\hline Plagiochila flabelliflora Steph. & Brazil & South America (SE Brazil) & Schäfer-Verwimp \& Verwimp 10669, 1988 & 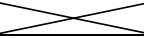 & DQ193990 & AF539462 \\
\hline Plagiochila flexuosa Mitt. & Japan & Southeast Asia (Japan, Bhutan, China, Nepal, Thailand) & Kurita 147, 2000, (HIRO) & DQ194140 & AY547703 & AY550138 \\
\hline Plagiochila frondescens (Nees) Lindenb. & Bali & $\begin{array}{l}\text { Southeast Asia (Indonesia, Philippines, Sri Lanka, India } \\
\text { [Maduras]) }\end{array}$ & Schäfer-Verwimp 20704, 1999 & DQ194141 & AY438219 & AY438237 \\
\hline \multirow{2}{*}{$\begin{array}{l}\text { Plagiochila fruticella (Hook. \& Taylor) Gottsche, } \\
\text { Lindenb. \& Nees }\end{array}$} & \multirow[b]{2}{*}{ New Zealand } & \multirow{2}{*}{$\begin{array}{l}\text { Australia and South Pacific (New Zealand) Southeast } \\
\text { Asia (Japan, Bhutan, China, Taiwan, India [Assam, } \\
\text { Sikkim, West Bengal], Nepal, Philippines, Thailand) }\end{array}$} & \multirow[b]{2}{*}{ Engel 20426, 1995} & DQ194087 & \multirow[b]{2}{*}{ DQ193991 } & \multirow[b]{2}{*}{ DQ194051 } \\
\hline & & & & DQ194073 & & \\
\hline Plagiochila fuscolutea Taylor & Costa Rica & Central and South America (Costa Rica to Bolivia) & Heinrichs et al. 4400 & DQ194144 & AY547704 & AJ416086 \\
\hline Plagiochila fusifera Taylor & Seychelles & $\begin{array}{l}\text { Africa (French Guinea, Nigeria, Somaliland, Uganda, } \\
\text { Congo, Malawi, Seychelles, Rwanda) }\end{array}$ & Pócs 9342/B & DQ194145 & AJ866760 & AJ866746 \\
\hline Plagiochila gigantea Lindenb. & New Zealand & Australia and South Pacific (New Zealand) & 17 Herangi 30 & DQ194146 & DQ193993 & DQ194042 \\
\hline \multirow{2}{*}{$\begin{array}{l}\text { Plagiochila gregaria (Hook. \& Taylor) Gottsche, } \\
\text { Lindenb. \& Nees }\end{array}$} & \multirow{2}{*}{ New Zealand } & \multirow{2}{*}{ Australia and South Pacific (New Zealand) } & \multirow{2}{*}{ Engel 22153, 1995} & DQ194086 & \multirow{2}{*}{ DQ193994 } & \multirow{2}{*}{ DQ194043 } \\
\hline & & & & DQ194072 & & \\
\hline Plagiochila gymnocalycina (Lehm. \& Lindenb.) Mont. & Bolivia & $\begin{array}{l}\text { Central and South America (Bolivia, Jamaica, } \\
\text { Colombia, Brazil) }\end{array}$ & Drehwald 4729, 2001 & DQ194147 & AY438218 & AY390531 \\
\hline Plagiochila hakkodensis Steph. & Japan & East Asia (Japan, China) & Yamaguchi 12271, 1995, (HIRO) & DQ194149 & AY547705 & AY275164 \\
\hline $\begin{array}{l}\text { Plagiochila heterodonta (Hook. \& Taylor) Gottsche, } \\
\text { Lindenb. \& Nees }\end{array}$ & $\begin{array}{l}\text { Marion Island } \\
\text { (South Africa) }\end{array}$ & $\begin{array}{l}\text { Subantarctic Islands (St. Paul Islands, Amsterdam } \\
\text { Islands, Kerguelen, Prince Edward Islands, Chile [Juan } \\
\text { Fernandez]) }\end{array}$ & Ochyra 1317/03, 2003 & DQ194150 & & DQ194045 \\
\hline Plagiochila heterophylla Lindenb. var. heterophylla & United Kingdom & $\begin{array}{l}\text { Central and South America (Costa Rica to Ecuador), } \\
\text { Atlantic Europe (United Kingdom, NW-France) }\end{array}$ & Rycroft 97006, B.E.G.P. 80 & DQ194151 & AY547706 & AY275165 \\
\hline Plagiochila heterostipa Steph. & Malawi & Africa (Congo, Ruanda, South Africa, Malawi) & O'Shea M7070a & DQ194080 & AJ866757 & AJ866735 \\
\hline Plagiochila incerta Gottsche & Madagascar & Africa (Madagascar) & Pócs 9447/L & $\begin{array}{l}\text { DQ194066 } \\
\text { DQ194101 }\end{array}$ & AJ866761 & AJ866737 \\
\hline
\end{tabular}




\begin{tabular}{|c|c|c|c|c|c|c|}
\hline \multirow{2}{*}{ Species } & \multirow{2}{*}{ Country } & \multirow{2}{*}{ Distribution } & \multirow{2}{*}{ Voucher } & \multicolumn{3}{|c|}{ Accession numbers: } \\
\hline & & & & $r b c \mathrm{~L}$ & rps4 & ITS \\
\hline Plagiochila integerrima Steph. & Malawi & $\begin{array}{l}\text { Africa (Nigeria, Fernando Po, Sao Thomé and Principe, } \\
\text { Cameroons, Congo, Uganda, Kenya, Tanzania, Mauritius, } \\
\text { Madagascar, Malawi, Kenya) }\end{array}$ & O'Shea M7552a & DQ194095 & AY547707 & AY275166 \\
\hline Plagiochila javanica (Sw.) Nees \& Mont. & Indonesia & Southeast Asia (Indonesia, Philippines) & Gradstein 10209, 2003 & DQ194154 & DQ193998 & AJ744791 \\
\hline Plagiochila junghuniana Sande Lac. & Malaysia & $\begin{array}{l}\text { Southeast Asia (Malaysia, Philippines, China [Fujian, } \\
\text { Hainan], Taiwan, Indonesia, New Caledonia, Papua New } \\
\text { Guinea) }\end{array}$ & Schäfer-Verwimp 18544, 1997 & DQ194155 & DQ193999 & DQ194048 \\
\hline Plagiochila kiaeri Gottsche & Madagascar & Africa (Madagascar, Uganda) & Pócs 9477/A6 & DQ194094 & 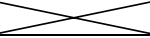 & DQ194025 \\
\hline Plagiochila korthalsiana Molk. & Indonesia & Southeast Asia (Java, Philippines) & Gradstein 10258,2003 & DQ194156 & DQ194000 & DQ194049 \\
\hline Plagiochila lastii Mitt. & Comores & $\begin{array}{l}\text { Africa (Uganda, Congo, Rwanda, Kenya, Tanzania, } \\
\text { Malawi, South Africa, Comores) }\end{array}$ & Pócs et al. 9273/U & DQ194097 & AY547708 & AY550139 \\
\hline Plagiochila longiramea Steph. & Bolivia & South America (Bolivia) & Heinrichs et al. 4071, 1997 & DQ194089 & AY547709 & AF539463 \\
\hline \multirow{2}{*}{ Plagiochila lyallii Mitt. } & \multirow{2}{*}{ New Zealand } & \multirow{2}{*}{ Australia and South Pacific (New Zealand) } & \multirow{2}{*}{ Engel 22357, 1997} & DQ194090 & \multirow{2}{*}{ DQ194004 } & \\
\hline & & & & DQ194076 & & \\
\hline Plagiochila macrostachya Lindenb. & Ecuador & $\begin{array}{l}\text { Central and South America (Mexico to Bolivia, } \\
\text { Southeast Brazil, West Indies) }\end{array}$ & Holz 080 E/5-01, 2001 & DQ194160 & AY547710 & 2016 \\
\hline Plagiochila maderensis Gottsche & Portugal & Europe (Madeira) & Rycroft, 99030, 1999 & DQ194161 & DQ194005 & AY462143 \\
\hline Plagiochila magna Inoue & Japan & Southeast Asia (Japan, Taiwan) & Kurita 258, 2000, (HIRO) & DQ194162 & AY438221 & AY275167 \\
\hline Plagiochila massalongoana Schiffn. & Indonesia & $\begin{array}{l}\text { Southeast Asia (Indonesia, Philippines, Malaysia, India } \\
\text { [Nicobar Islands], China [Fujian, Hainan], Taiwan, New } \\
\text { Caledonia, Papua New Guinea) }\end{array}$ & Gradstein 10315, 2004 & DQ194163 & DQ194006 & \\
\hline Plagiochila montagnei Nees & Bolivia & $\begin{array}{l}\text { North America (USA [Florida]), Central and South } \\
\text { America (Bolivia, Mexico, Costa Rica, Cuba, Haiti, } \\
\text { Jamaica, Panama, Guadeloupe, Trinidad and Tobago, } \\
\text { Colombia, Venezuela, Guyana, Surinam, French Guiana, } \\
\text { Brazil [Para, Rio de Janeiro, Sao Paulo]) }\end{array}$ & Groth s.n., 2000 & DQ194164 & DQ194008 & AJ744793 \\
\hline Plagiochila nobilis Gottsche & Indonesia & $\begin{array}{l}\text { Southeast Asia (Indonesia, Philippines, Papua New } \\
\text { Guinea) }\end{array}$ & Gradstein s.n., 2003 & DQ194166 & DQ194010 & DQ194055 \\
\hline \multirow{2}{*}{ Plagiochila obtusa Lindenb. } & \multirow{2}{*}{ Indonesia } & \multirow{2}{*}{$\begin{array}{l}\text { Southeast Asia (China [Hainan], Indonesia, Papua New } \\
\text { Guinea) }\end{array}$} & \multirow{2}{*}{ Schäfer-Verwimp 16980, 1995} & DQ194091 & \multirow{2}{*}{ DQ194011 } & \multirow{2}{*}{ DQ194056 } \\
\hline & & & & DQ194077 & & \\
\hline Plagiochila orbicularis (S.Hatt) S.Hatt. & Japan & East Asia (Japan) & Kurita 132, 2000, (HIRO) & DQ194167 & AY438222 & AY275168 \\
\hline Plagiochila oresitropha Spruce & Ecuador & South America (Ecuador, Peru [Cuzco]) & Holz 422 E/5-01, 2001 & DQ194168 & DQ194012 & 3 \\
\hline Plagiochila ovalifolia Mitt. & Japan & \multirow{2}{*}{$\begin{array}{l}\text { Southeast Asia (Japan, China, Taiwan, Korea, } \\
\text { Philippines) }\end{array}$} & Ohnishi 5723, 2002, (HIRO) & $\infty$ & AY547711 & AY275169 \\
\hline Plagiochila ovalifolia Mitt. & Japan & & Ohnishi 5684, 2002, (HIRO) & DQ194169 & $2<$ & $\Longrightarrow$ \\
\hline Plagiochila ovata Lindenb. \& Gottsche & Costa Rica & $\begin{array}{l}\text { Central and South America (Costa Rica, Mexico, } \\
\text { Columbia, Venezuela, Ecuador, Peru, Bolivia) }\end{array}$ & Heinrichs et al. 4158 & AY699997 & AY547712 & AJ422017 \\
\hline Plagiochila pachyloma Taylor & Ecuador & $\begin{array}{l}\text { South America (Ecuador, Peru [Cuzco], Venezuela, } \\
\text { Colombia) }\end{array}$ & Anton ECU4, 1997 & DQ194171 & DQ194013 & DQ194057 \\
\hline
\end{tabular}




\begin{tabular}{|c|c|c|c|c|c|c|}
\hline \multirow{2}{*}{ Species } & \multirow{2}{*}{ Country } & \multirow{2}{*}{ Distribution } & \multirow{2}{*}{ Voucher } & \multicolumn{3}{|c|}{ Accession numbers: } \\
\hline & & & & $r b c \mathrm{~L}$ & rps4 & ITS \\
\hline Plagiochila parvifolia Lindenb. & Thailand & \begin{tabular}{|l|} 
North America (USA [District of Columbia, North \\
Carolina, South Carolina]), Southeast Asia (Thailand, \\
Burma, Indonesia, Sri Lanka, Philippines, Bangladesh, \\
Bhutan, China, Taiwan, India [Himalaya, Assam, Sikkim], \\
Japan, Korea, Burma, Nepal, Papua New Guinea, \\
Vietnam)
\end{tabular} & Schäfer-Verwimp 23824, 2004 & DQ194172 & DQ194014 & DQ194058 \\
\hline Plagiochila patentissima Steph. & Brazil & South America (Brazil) & Gradstein 3703,2000 & DQ194173 & AY547713 & AY550140 \\
\hline Plagiochila patriciae J.Heinrichs \& H.Anton & Costa Rica & Central and South America (Costa Rica, Colombia) & Holz CR 00-0176, 2000 & DQ194174 & AY547714 & AY275170 \\
\hline Plagiochila peculiaris Schiffn. & Bhutan & $\begin{array}{l}\text { Southeast Asia (Bhutan, Indonesia, Thailand, China, } \\
\text { India [Assam], Nepal, Vietnam) }\end{array}$ & Long 28832, 1999 & DQ194176 & AY547716 & AY550141 \\
\hline Plagiochila poeltii Inoue \& Grolle & India & $\begin{array}{l}\text { East Asia (India [Sikkim], China [Sichuan, Xizang], } \\
\text { Nepal) }\end{array}$ & Long 22802, 1992 & DQ194177 & AY547717 & AY550142 \\
\hline Plagiochila porelloides (Torr.) Lindenb. & Germany & Europe (Germany), East Asia (Japan, China, Korea), & Heinrichs \& Groth 4340, 2001 & AY699998 & AY547718 & AJ414633 \\
\hline $\begin{array}{l}\text { Plagiochila porelloides (Torr.) Lindenb. (former } P \text {. } \\
\text { satoi) }\end{array}$ & Japan & $\begin{array}{l}\text { North Africa, North America (Canada [Queen Charlotte } \\
\text { Island]) }\end{array}$ & Ohnishi 5720, 2002, (HIRO) & DQ194192 & AY547723 & AY550144 \\
\hline Plagiochila pulcherrima Horik. & Japan & $\begin{array}{l}\text { Southeast Asia (Japan, China, Taiwan, Thailand, } \\
\text { Vietnam) }\end{array}$ & Ohnishi 5771, 1999, (HIRO) & DQ194179 & AY438223 & AY438239 \\
\hline Plagiochila punctata (Taylor) Taylor & United Kingdom & Atlantic Europe (United Kingdom, Norway, Ireland), & Rycroft 01013 & DQ194180 & AY547719 & AJ413174 \\
\hline $\begin{array}{l}\begin{array}{l}\text { Plagiochila punctata (Taylor) Taylor (former } P . \\
\text { patzschkei) }\end{array} \\
\end{array}$ & Ecuador & $\begin{array}{l}\text { Central and South America (Ecuador, Costa Rica, } \\
\text { Dominican Republic, Venezuela, Bolivia), Africa } \\
\text { (Comores, Madagascar, Tanzania, Uganda, Zaire) }\end{array}$ & Holz 389 E/5-01, 2001 & DQ194175 & AY547715 & AJ422018 \\
\hline Plagiochila raddiana Lindenb. & Ecuador & $\begin{array}{l}\text { North America (USA [Florida, North Carolina, } \\
\text { Tennessee, South Carolina, Georgia, Alabama, } \\
\text { Mississippi, Louisiana]), Central and South America } \\
\text { (Ecuador, Mexico, Guatemala, Nicaragua, Cuba, Lesser } \\
\text { Antilles, Colombia, Venezuela, Brazil, Bolivia) }\end{array}$ & Holz 045 E/5-01, 2001 & DQ194181 & AY438225 & AJ422020 \\
\hline Plagiochila radiculosa Mitt. & New Zealand & Australia and South Pacific (New Zealand) & Engel 23337, 1997 & DQ194182 & DQ194017 & DQ194059 \\
\hline Plagiochila ramosissima (Hook.) Lindenb. & New Zealand & Australia and South Pacific (New Zealand) & Engel et al. 25155,2003 & DQ194183 & DQ194018 & DQ194060 \\
\hline Plagiochila renitens (Nees) Lindenb. & Malaysia & \begin{tabular}{|l|}
$\begin{array}{l}\text { Southeast Asia (Malaysia, Indonesia, Philippines, Papua } \\
\text { New Guinea) }\end{array}$ \\
\end{tabular} & Schäfer-Verwimp, 18736/A, 1997 & DQ194184 & AY569440 & AY569441 \\
\hline Plagiochila retrorsa Gottsche & Costa Rica & $\begin{array}{l}\text { North America (Appalachian Mountains to Central } \\
\text { America), Central America (Costa Rica, Mexico) }\end{array}$ & Heinrichs et al. 4154 & DQ194185 & AY547720 & AJ422021 \\
\hline Plagiochila retrospectans (Nees) Lindenb. & New Zealand & Australia and South Pacific (New Zealand, Tasmania) & Frey \& Pfeiffer 98-T88, 1998 & DQ194186 & AY547721 & AY550143 \\
\hline Plagiochila rubescens (Lehm. \& Lindenb.) Lindenb. & Chile & South America (Chile) & Rycroft, 020723-6 & DQ194187 & AJ866767 & AJ781752 \\
\hline $\begin{array}{l}\text { Plagiochila rutilans var. moritziana Gottsche \& } \\
\text { Lindenb. }\end{array}$ & Ecuador & $\begin{array}{l}\text { Central and South America (northern and central Andes } \\
\text { to northern Argentina, Greater and Lesser Antilles, SE } \\
\text { Brazil) }\end{array}$ & Holz 408 E/5-01, 2001 & DQ194165 & DQ194009 & AJ416080 \\
\hline Plagiochila rutilans var. rutilans Lindenb. & Bolivia & $\begin{array}{l}\text { Central and South America (northern and central Andes } \\
\text { to northern Argentina, Greater and Lesser Antilles, SE } \\
\text { Brazil) }\end{array}$ & Groth 101,2000 & DQ194189 & AY438226 & AJ416081 \\
\hline Plagiochila salacensis Gottsche & Indonesia & $\begin{array}{l}\text { Southeast Asia (Indonesia, Thailand, China [Guangxi, } \\
\text { Yunnan], India [Himalaya], Philippines) }\end{array}$ & Gradstein 10312, 2004 & DQ194190 & DQ194020 & DQ194061 \\
\hline Plagiochila sandei Dozy & Indonesia & Southeast Asia (Indonesia, Philippines) & Gradstein 9970 & DQ194191 & AY438228 & AJ414634 \\
\hline
\end{tabular}




\begin{tabular}{|c|c|c|c|c|c|c|}
\hline \multirow{2}{*}{ Species } & \multirow{2}{*}{ Country } & \multirow{2}{*}{ Distribution } & \multirow{2}{*}{ Voucher } & \multicolumn{3}{|c|}{ Accession numbers: } \\
\hline & & & & $r b c L$ & rps4 & ITS \\
\hline Plagiochila sciophila Nees & Japan & $\begin{array}{l}\text { Southeast Asia (Japan, Nepal, Indonesia, Philippines, } \\
\text { Thailand, Vietnam, Bhutan, China, Taiwan, India [Jammu } \\
\text { and Kashmir], Malaysia, Samoa) }\end{array}$ & Ohnishi 5400, 2002, (HIRO) & DQ194193 & AY547724 & AY275171 \\
\hline $\begin{array}{l}\text { Plagiochila sciophila Nees (former P. euryphyllon ssp. } \\
\text { echinata) (Syn. fide So, 2001) }\end{array}$ & USA & $\begin{array}{l}\text { North America (USA[North Carolina, South Carolina, } \\
\text { Tennessee]) }\end{array}$ & Smith \& Davison s.n., 1991 & DQ194136 & DQ193987 & DQ194039 \\
\hline $\begin{array}{l}\text { Plagiochila semidecurrens (Lehm. \& Lindenb.) } \\
\text { Lindenb. }\end{array}$ & Nepal & $\begin{array}{l}\text { North America (from Alaska south the Rocky } \\
\text { Mountains), Southeast Asia (Nepal, Philippines, Bhutan, } \\
\text { China, India [Sikkim], Indonesia, Japan, Nepal, Papua } \\
\text { New Guinea) }\end{array}$ & Long 21348, 1991 & DQ194194 & AY438227 & AY275172 \\
\hline Plagiochila spinulosa (Dicks.) Dumort. & Belgium & $\begin{array}{l}\text { Atlantic Europe (Belgium), North America (USA } \\
\text { [Florida, New York, Pennsylvania]) }\end{array}$ & Dauphin et al. 3811, 1996 & DQ194195 & AY547725 & AY275173 \\
\hline Plagiochila squamulosa Mitt. & Kenya & $\begin{array}{l}\text { Africa (Eritrea, Ethiopia, Somaliland, Cameroon, Uganda, } \\
\text { Congo, Rwanda, Tanzania, Malawi) }\end{array}$ & Chuah 0310/AB & DQ194098 & AJ866758 & AJ744796 \\
\hline Plagiochila stephensoniana Mitt. & New Zealand & Australia and South Pacific (New Zealand) & Schäfer-Verwimp 14091, 1991 & DQ194196 & DQ194021 & DQ194062 \\
\hline Plagiochila streimannii Inoue & Indonesia & Southeast Asia (Indonesia) & Gradstein 10309, 2004 & DQ194197 & AJ866763 & AJ866744 \\
\hline Plagiochila stricta Lindenb. & Costa Rica & $\begin{array}{l}\text { Central and South America (Costa Rica, Madagascar, } \\
\text { Ecuador, Bolivia, Dominican Republic, West Indies, } \\
\text { Jamaica, Guadeloupe, SE Brazil), Africa (Madagascar), } \\
\text { Europe (Portugal [Madeira], Spain [Tenerife]) }\end{array}$ & Heinrichs et al. 4401 & DQ194198 & AY438229 & AJ416646 \\
\hline Plagiochila strictifolia Steph. & Malawi & $\begin{array}{l}\text { Africa (Sierra Leone, Togo, Ivory Coast, Nigeria, } \\
\text { Cameroon, Sao Tomé and Principe, Uganda, Congo, } \\
\text { Angola, Tanzania, Malawi) }\end{array}$ & Hodgetts M2490a & DQ194099 & AJ866759 & AJ866734 \\
\hline Plagiochila subplana Lindenb. & French Guiana & $\begin{array}{l}\text { Central and South America (French Guiana, Trinidad } \\
\text { and Tobago, Mexico, Guyana, Jamaica, Ecuador, } \\
\text { Martinique, Haiti, Cuba, Dominican Republic) }\end{array}$ & Holz FG 32 & DQ194199 & AY438224 & AY275174 \\
\hline Plagiochila subtropica Steph. & Nepal & $\begin{array}{l}\text { East Asia (Nepal, Bhutan, China [Yunnan], India [Assam, } \\
\text { Bengal]) }\end{array}$ & Long 17359, 1989 & DQ194200 & AY547726 & AY550145 \\
\hline Plagiochila superba (Nees) Mont. \& Nees & Costa Rica & $\begin{array}{l}\text { Central and South America (Mexico to Bolivia, SE- } \\
\text { Brazil, West Indies) }\end{array}$ & Heinrichs et al. 4175, 1999 & DQ194201 & AY438230 & AJ416084 \\
\hline Plagiochila tabinensis Steph. & Costa Rica & -Central and South America (Costa Rica to Bolivia) & Heinrichs et al. 4156 & $2<$ & AY438231 & AJ422026 \\
\hline Plagiochila tabinensis Steph. & Ecuador & 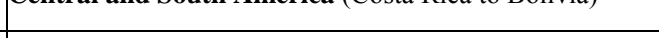 & Holz 073 E/5-01, 2001 & DQ194202 & 3 & 3 \\
\hline Plagiochila teysmannii Sande Lac. & Indonesia & Southeast Asia (Indonesia, Cambodia, Philippines) & Gradstein 10308, 2004 & DQ194203 & AJ866762 & AJ866745 \\
\hline Plagiochila trabeculata Steph. & Japan & $\begin{array}{l}\text { Southeast Asia (Japan, China, Indonesia, Nepal, } \\
\text { Philippines, Thailand) }\end{array}$ & Kurita 257, 2000, (HIRO) & DQ194204 & AY547727 & AY550146 \\
\hline Plagiochila trapezoidea Lindenb. & $\begin{array}{l}\text { Papua New } \\
\text { Guinea }\end{array}$ & Southeast Asia (Papua New Guinea, Java, Indonesia) & Norris 64932, 1981 & $\begin{array}{l}\text { DQ194093 } \\
\text { DQ194079 }\end{array}$ & DQ194022 & DQ194063 \\
\hline Plagiochila trichostoma Gottsche & Ecuador & $\begin{array}{l}\text { Central and South America (Ecuador Costa Rica, } \\
\text { Colombia, Peru) }\end{array}$ & Holz 429 E/5-01, 2001 & DQ194205 & AY547728 & AJ416082 \\
\hline Plagiochila turgida Herzog & Ecuador & Central and South America (Central America to Peru) & Holz 070 E/5-01, 2001 & DQ194206 & AY547729 & AJ422024 \\
\hline Plagiochila validissima Steph. & Bolivia & South America (Bolivia) & Heinrichs et al. 4058, 1997 & DQ194207 & DQ194023 & DQ194064 \\
\hline Plagiochila vincentina Lindenb. & Costa Rica & $\begin{array}{l}\text { Central and South America (Costa Rica to Bolivia, } \\
\text { Brazil, West Indies) }\end{array}$ & Heinrichs et al. 4331, 1999 & DQ194208 & DQ194024 & AY275175 \\
\hline Plagiochilion mayebarae S.Hatt & Japan & East Asia (Japan, Taiwan, China, India [Sikkim]) & Onishi 5588, 2002, (HIRO) & AY699999 & AY438220 & AY438238 \\
\hline
\end{tabular}




\begin{tabular}{|c|c|c|c|c|c|c|}
\hline \multirow{2}{*}{ Species } & \multirow{2}{*}{ Country } & \multirow{2}{*}{ Distribution } & \multirow{2}{*}{ Voucher } & \multicolumn{3}{|c|}{ Accession numbers: } \\
\hline & & & & $r b c \mathrm{~L}$ & rps4 & ITS \\
\hline $\begin{array}{l}\text { Plagiochilion oppositum (Reinw., Blume \& Nees) } \\
\text { S.Hatt }\end{array}$ & Indonesia & $\begin{array}{l}\text { Southeast Asia (Indonesia, New Hebrides, Philippines, } \\
\text { Taiwan, Vietnam, Burma, Sri Lanka, Samoa) }\end{array}$ & Schäfer-Verwimp 20935, 1999 & AY700000 & DQ194001 & DQ194053 \\
\hline \multirow{3}{*}{$\begin{array}{l}\text { Proskauera pleurata (Hook. \& Taylor) Gottsche, } \\
\text { Lindenb. \& Nees }\end{array}$} & \multirow{3}{*}{ New Zealand } & \multirow{3}{*}{ Australia and South Pacific (New Zealand) } & \multirow{2}{*}{ Schäfer-Verwimp 14071, 1991} & DQ194088 & & \\
\hline & & & & DQ194074 & & \\
\hline & & & Schäfer-Verwimp 13777, 1991 & $2<$ & DQ194015 & DQ194052 \\
\hline Proskauera fruticosa Mitt. & Japan & \multirow{2}{*}{$\begin{array}{l}\text { Asia (Bhutan, China, India, Japan, Nepal, Philippines, } \\
\text { Thailand) }\end{array}$} & Deguchi, s.n., 1997, (HIRO) & DQ194142 & $\sum$ & $\sum$ \\
\hline Proskauera fruticosa Mitt. & India & & Long 23002 & 3 & AY438217 & AY438235 \\
\hline
\end{tabular}


Table 15 Accessions used to evaluate the stability of Plagiochilaceae in molecular analyses.

\begin{tabular}{|c|c|c|c|}
\hline Species & rps4 & Species & $r b c L$ \\
\hline Adelanthus lindenbergianus & AY608042 & Adelanthus lindenbergianus & AY462285 \\
\hline Balantiopsis cancellata & AY462340 & Balantiopsis cancellata & AY462286 \\
\hline Bazzania spec. & AY608048 & Bazzania tricrenata & AY699990 \\
\hline Blepharostoma trichophyllum & AY608050 & Blepharostoma trichophyllum & AY462289 \\
\hline Calypogeia muelleriana & AY608052 & Calypogeia muelleriana & U87065 \\
\hline Cephalozia catenulata & AY608053 & Cephalozia bicuspidata & AY462291 \\
\hline Gottschea nuda & AY462351 & Gottschea nuda & AY462297 \\
\hline Heteroscyphus argutus & AY462355 & Heteroscyphus coalitus & AY149844 \\
\hline Isotachis armata & AY462358 & Isotachis lyallii & AY608032 \\
\hline Jamesoniella autumnalis & AJ251066 & Jamesoniella autumnalis & AY462303 \\
\hline Jungermannia leiantha & AY507451 & Jungermannia leiantha & AY149838 \\
\hline Lepicolea scolopendra & AY462365 & Lepicolea scolopendra & AY462308 \\
\hline Lepidozia reptans & AY608083 & Lepidozia reptans & U87075 \\
\hline Lophozia ventricosa & AY462369 & Lophozia ventricosa & AY699994 \\
\hline Marsupidium latifolium & AY608088 & Marsupidium latifolium & AY608034 \\
\hline Nardia assamica & AY462374 & Nardia assamica & AY462316 \\
\hline Pedinophyllum truncatum & AY462382 & Pedinophyllum truncatum & AY149855 \\
\hline Scapania nemorea & AY608108 & Porella cordeana & AY302457 \\
\hline Schistochila lehmannia & AY608109 & Porella japonica & AY302459 \\
\hline Triandrophyllum subtrifidum & AY608117 & Porella platyphylla & AY302458 \\
\hline Trichocolea tomentosa & AY608118 & Scapania undulata & AY149840 \\
\hline \multirow[t]{4}{*}{ Tritomaria quinquedentata } & AY608119 & Schistochila appendiculata & AY507424 \\
\hline & & Triandrophyllum subtrifidum & AY462331 \\
\hline & & Trichocolea tomentella & AY462332 \\
\hline & & Tritomaria quinquedentata & AY700003 \\
\hline
\end{tabular}




\section{Lebenslauf}

$\underline{\text { Persönliche Daten }}$
Name:
Henk Groth
Geboren am:
09.11.1974
Geboren in:
Elmshorn, Deutschland
Staatsangehörigkeit: deutsch
Familienstand:
Adresse:
Telefon:
verheiratet (Milena Groth-Malonek), keine Kinder
Karl-Grüneklee-Str. 1, 37077 Göttingen, Germany
0049-(0)176-23565675

$\underline{\text { Wissenschaftlicher Bildungsgang }}$

Bis 1994

1994

$1995-2002$

$2002-2005$

Vorträge

2002

2002

2003

Tagungen

2001

2002
Abitur, Detlefsenschule, Glückstadt

Teilnahme an der V. Internationalen Biologie Olympiade (Varna, Bulgarien)

Studium Biologie-Diplom an der Georg-August-Universität Göttingen (Hauptfach: Botanik, Nebenfächer: Mikrobiologie, Informatik)

Abschlußarbeit: „Untersuchungen zur Sippenstruktur und Verwandtschaft in Plagiochila Sektion Bidentes Carl" (Note: 1,0)

Promotion, Georg-August-Universität Göttingen

Titel: „Molecular Phylogeny and morphological reconstructions of Plagiochilaceae (Jungermanniopsida), with hypotheses on biogeography and divergence times “

Henk Groth: „Untersuchungen zur Sippenstruktur und Verwandtschaft in Plagiochila Sektion Bidentes Carl" Hauskolloqium des Botanischen Instituts Göttingen

Jochen Heinrichs \& Henk Groth: "Systematics of Plagiochila. A molecular, morphological and phytochemical approach", Tagungsbeitrag Botanikertagung 2002, Freiburg i. Br.

Jochen Heinrichs, Henk Groth, Melanie Lindner: „Molecular Phylogeny and Biogeography of the Plagiochilaceae”, Tagungsbeitrag Botany 2003, St. Louis, MO, USA

Teilnahme und Posterbeitrag zum 15. Internationalen Symposium "Biodiversity and Evolutionary Biology", Bochum

"Botanikertagung 2002", Freiburg i. Br. 

Biology“, Frankfurt (Main)

Posterbeitrag: Henk Groth, Melanie Lindner, Jochen Heinrichs: „Biogeography of Plagiochila (Hepaticae): natural species groups span several floristic kingdoms“"

2004 "Bryophylogeny 2004", the 2nd International Symposium on the Molecular Systematics of Bryophytes, Göttingen

7. Jahrestagung der GfBS, Stuttgart

Teilnahme an den Workshops: „Baumkonstruktion” (Leitung: Dr. H. Schmidt) und „Supertrees” (Leitung: Dr. O. Bininda - Emonds)

$\underline{\text { wissenschaftliche Tätigkeiten }}$

1998 - 2002 studentische Hilfskraft im A.-v.-Haller Institut für Pflanzenwissenschaften Göttingen:

WS 1998/99 Assistenz im Botanisch-Apparativen Grundpraktikum (Leitung: Dr. U. Hofmann)

SS $1999 \quad$ Kursleitung Botanische Bestimmungsübungen

WS 1999/00 Assistenz im Botanisch-Apparativen Grundpraktikum (Leitung: Dr. H. Depta)

11.2002 - 12. 2002 wissenschaftliche Hilfskraft, Prof. Mues, Universität Saarbrücken

01.2003 - 10. 2005 wissenschaftliche Mitarbeiterstelle Bat IIa/2, finanziert durch DFG-Projekt Nr. He 3584/1

SS $2004 \quad$ Blockpraktikum Systematik III

(Einführung in die Laborarbeit, Laborteil)

$\underline{\text { weitere Tätigkeiten }}$

SS 2000-2004 Administration der Computeranlage der Abteilung „Systematische Botanik“ im Albrecht von Haller Institut für Pflanzenwissenschaften, Georg-August-Universität Göttingen 


\section{$\underline{\text { Wissenschaftliche Veröffentlichungen }}$}

$\underline{2001}$

Heinrichs, J. \& Groth, H.: Tolpis staticifolia (All.) Schultz-Bip. (Asteraceae) adventiv bei Hardegsen / Südniedersachen. Flor. Rundbr. 34: 75-77.

Heinrichs, J., Groth, H., Gradstein, S. R., Rycroft, D. S., Cole, W. J. \& Anton, H.: Plagiochila rutilans (Hepaticae): a poorly known species from tropical America. Bryologist 104: 350-361.

$\underline{2002}$

Groth, H., Helms, G. \& Heinrichs, J.: The systematic status of Plagiochila sects. Bidentes Carl and Caducilobae Inoue (Hepaticae) inferred from nrDNA ITS sequences. Taxon 51: 675-684.

Heinrichs, J., Groth, H., Holz, I., Rycroft, D. S., Renker, C. \& Pröschold, T.: The systematic position of Plagiochila moritziana, P. trichostoma and P. deflexa, based on ITS sequences of nuclear ribosomal DNA, morphology and lipophylic secondary metabolites. Bryologist 105:189-203.

Heinrichs, J., Pröschold, T., Renker, C., Groth, H. \& Rycroft, D. S.: Plagiochila virginica A.Evans rather than P. dubia Lindenb. \& Gottsche occurs in Macaronesia; placement in sect. Contiguae Carl is supported by ITS sequences of nuclear ribosomal DNA. Plant Syst. Evol. 230: 221-230.

Heinrichs, J., Rycroft, D. S., Groth, H. \& Cole, W. J.: Morphological and Phytochemical Studies of Plagiochila papillifolia Steph., a Neotropical liverwort new to Europe. J. Bryol. 24:119-126.

Renker, C., Heinrichs, J., Pröschold, T., Groth, H. \& Holz, I.: ITS sequences of nuclear ribosomal DNA support the generic placement and the disjunct range of Plagiochila (Adelanthus) carringtonii. Cryptogamie, Bryol. 23:23-29.

Rycroft, D. S., Cole, W. J. , Heinrichs, J., Groth, H., Renker, C. \& Pröschold, T.: Phytochemical, morphological and molecular ecidence for the occurrence of the Neotropical liverwort Plagiochila stricta in the Canary Islands, new to Macaronesia. Bryologist 105:363-372.

$\underline{2003}$

Groth, H. \& Heinrichs, J.: Reinstatement of Chiastocaulon Carl (Plagiochilaceae), based on evidence from nuclear ribosomal ITS and chloroplast gene rps4 sequences. Pl. Biol. 5: 615-622.

Groth, H., Lindner, M., Wilson, R., Hartmann, F.A., Schmull, M., Gradstein, S.R. \& Heinrichs, J.: Biogeography of Plagiochila (Hepaticae): natural species groups span several floristic kingdoms. J. Biogeogr. 30: 965-978. 
Heinrichs, J., Gradstein, S.R., Groth H. \& Lindner, M.: Plagiochila cucullifolia var. anomala var. nov. from Ecuador, with notes on discordant molecular and morphological variation in Plagiochila. Plant Syst. Evol. 242: 205-216.

Heinrichs, J., Wilson, R. \& Groth, H.: A new locality of Plagiochila dimorpha var. ecuadorica (Plagiochilaceae). Cryptogamie, Bryol. 24: 155-158.

$\underline{2004}$

Feldberg, K., Groth H., Wilson, R., Schäfer-Verwimp, A. \& Heinrichs, J.: Cryptic speciation in Herbertus (Herbertaceae, Jungermanniopsida): Range and morphology of Herbertus sendtneri inferred from nrITS sequences. Plant Syst. \& Evol. 249: 247-261.

Groth, H., Hartmann, F. A., Wilson R. \& Heinrichs, J.: nrITS sequences and morphology indicate a synonymy of the Patagonian Plagiochila rufescens Steph. and the Central American Plagiochila bicuspidata Gottsche. Cryptogamie, Bryol. 25: 19-28.

Groth, H., Lindner, M. \& Heinrichs, J.: Phylogeny and biogeography of Plagiochila (Plagiochilaceae) based on nuclear and chloroplast DNA sequences. Monogr. Syst. Bot. Missouri Bot Gard. 98: 365-387.

Heinrichs, J., Groth, H., Lindner, M., Feldberg K. \& Rycroft D. S.: Molecular, morphological and phytochemical evidence for a broad species concept of Plagiochila bifaria (Sw.) Lindenb. (Hepaticae). Bryologist 107: 28-40.

Heinrichs, J., Groth, H., Lindner, M., Renker, C., Pócs, T. \& Pröschold, T.: Intercontinental distribution of Plagiochila corrugata (Plagiochilaceae, Hepaticae) inferred from nrDNA ITS sequences and morphology. Bot. J. Linnean Soc. 146: 469-481.

Heinrichs, J., Groth, H. \& Sauer, M.: New synonyms in Plagiochila III. Cryptogamie, Bryol. 25: 35-37.

Heinrichs, J., Lindner, M. \& Groth, H.: Sectional classification of North American Plagiochila (Plagiochilaceae, Hepaticae). Bryologist 107: 489-496.

Rycroft, D. S., Groth, H. \& Heinrichs, J.: Reinstatement of Plagiochila maderensis (Jungermanniopsida: Plagiochilaceae) based on chemical evidence and nrDNA ITS sequences. J. Bryol. 26: 37-45.

Wilson, R., Gradstein, S. R., Heinrichs, J., Groth, H., Ilkiu Borges, A. L. \& Hartmann, F. A.: Phylogeny of Lejeuneaceae: A cladistic analysis of chloroplast gene $r b c \mathrm{~L}$ sequences and morphology with preliminary comments on the mitochondrial nad42 spacer region. Monogr. Syst. Bot. Misssouri Bot. Gard. 98: 189-202. 
Groth, H. \& Heinrichs, J.: Maximum likelihood analyses of chloroplast gene $r b c \mathrm{~L}$ sequences indicate relationships of Syzygiella (Jungermanniopsida) with Lophoziaceae rather than Plagiochilaceae. Cryptogamie, Bryol. 26: 49-57.

Heinrichs, J.,Lindner, M., Gradstein, S.R., Groth, H., Buchbender, V., Solga, A., Fischer, E.: Origin and subdivision of Plagiochila (Jungermanniidae: Plagiochilaceae) in tropical Africa based on evidence from nuclear and chloroplast DNA sequences and morphology. Taxon 54: 317-333.

Heinrichs, J., Lindner, M., Groth, H. \& Renker, C.: Distribution and synonymy of Plagiochila punctata (Taylor) Taylor, with hypotheses on the evolutionary history of Plagiochila sect. Arrectae (Plagiochilaceae, Hepaticae). Plant Syst. \& Evol. 250: 105-117.

Schmull, M., Heinrichs, J., Baier, R., Ullrich, D., Wagenitz, G., Groth, H., Hourticolon, S. \& Gradstein, S. R.: The type database at Göttingen (GOET) - a virtual herbarium online. Taxon 54: 251-254. 